\title{
SOROLOGIA DA INFECÇÃO CHAGÁSICA NO PROGRAMA DE CONTROLE DO ESTADO DE SÃO PAULO, BRASIL
}

\section{MARIA ESTHER DE CARVALHO}

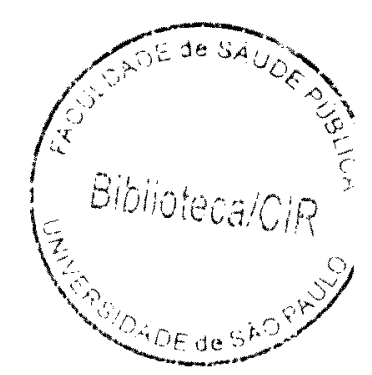

Tese apresentada ao Departamento de Epidemiologia da Faculdade de Saúde Pública da Universidade de São Paulo para obtenção do grau de Doutor.

Área de concentração:

Epidemiologia

ORIENTADOR: PROF. TITULAR

DR. JOSÉ MARIA SOARES BARATA

SÃo PAULO 
Autorizo, exclusivamente para fins acadêmicos e científicos, a reprodução total ou parcial desta tese, por processos fotocopiadores.

Assinatura:

São Paulo, 10 de novembro de 2000.

$40733 / 2001(d u c)$ 


\section{INDICE}

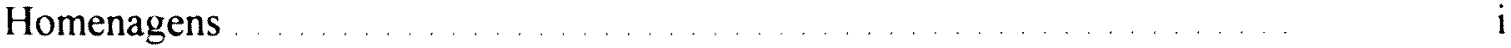

Dedicatorias . . . . . . . . . . . . . . . . . . . . . . . .

Agradecimentos . . . . . . . . . . . . . . . . . . .

Resumo . . . . . . . . . . . . . . . . . . . . . . . . . . .

Summary . . . . . . . . . . . . . . . . . . . . . . . . .

1 INTRODUÇ̃̃o $\ldots \ldots \ldots \ldots \ldots \ldots \ldots \ldots \ldots \ldots \ldots \ldots \ldots$

1.1 O diagnóstico laboratorial da infecção chagásica . . . . . . . . . . . 2

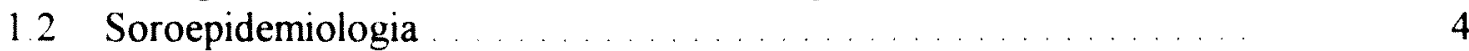

1.3 Inserção da sorologia nas atividades de controle da doença de

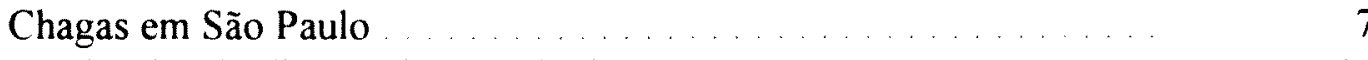

1.4 Tendências do diagnóstico sorológico ................. 16

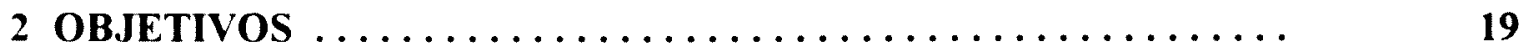

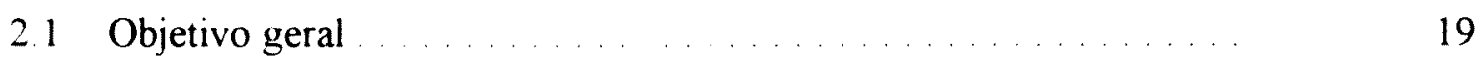

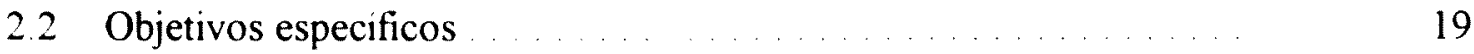

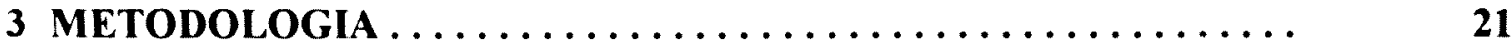

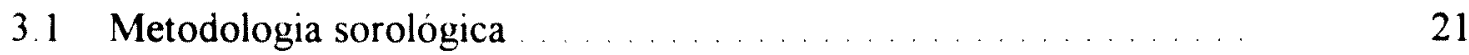

3.1 .1 Antigenos . . . . . . . . . . . . . . . . . . . . . . 21

3.1.2 Soros-controle ........................... 22

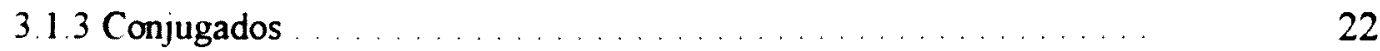

3.1 .4 Colheita de amostras de sangue . . . . . . . . . . . . . . . . . 22

3.1 .5 As diluições de corte . . . . . . . . . . . . . . . . . . . . . . . . . 22

3.2 Classificação epidemiológica de caso de infecção chagásica . . . . . 23

3.3 Fonte de dados . . . . . . . . . . . . . . . . . . . . . . . . 24

3.4 Populações de estudo e análise de dados de levantamentos

sorológicos realizados no Estado de São Paulo . . . . . . . . . . . . 31

3.4.1 População amostrada de escolares de 54 municipios de diferentes
Regionais do Estado de São Paulo durante o periodo de 1973 a 1983 .

3.4.2 População de 5 localidades rurais do município de Taquarituba no periodo de $1974-1976 \ldots \ldots \ldots \ldots \ldots \ldots \ldots \ldots \ldots \ldots \ldots \ldots$

3.4 .2 .1 Antecedentes . . . . . . . . . . . . . . . . . . . . 34

3.4.2.2 Estimativa da relação entre idade e sororreatividade para
infecção chagásica $\ldots \ldots \ldots \ldots \ldots \ldots \ldots \ldots \ldots \ldots \ldots \ldots \ldots$

3.4.3 População amostrada dos municípios das Microrregiões Campos de Itapetininga, 1976 - 1978 e Encosta Ocidental da Mantiqueira Paulista, 1980

3.4.4 População rural dos municipios: Cananéia, Iguape e Peruibe, 1980 1982 
3.4.5 População de Unidades Domiciliares inseridas no Programa de

Controle da doença de Chagas (PCDCh) entre 1984 e 1997

3.4.5.1 Generalidades do PCDCh . . . . . . . . . . . . . . . . . . 38

3.4.5.2 A racionalidade da sorologia no PCDCh . . . . . . . . . . 40

3.4.5.3 Normas do PCDCh à aplicação da sorologia ............. 40

3.4 .5 Área controle negativo ...................... 41

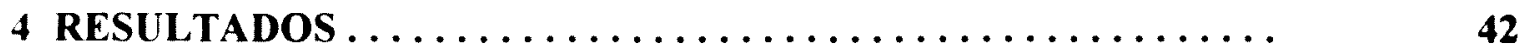

4.1 Do inquérito realizado entre escolares da $1^{\mathrm{a}}$ série do $1^{\circ}$ grau de escolas rurais em 54 municipios do Estado, entre 1973 e $1983 \ldots \ldots .42$

4.1 .1 Linha de base . . . . . . . . . . . . . . . . . . . . 42

4.1 .2 Inquérito escolar de 1973 a $1983 \ldots \ldots \ldots \ldots \ldots \ldots \ldots . \ldots \ldots$

4.2 Do inquérito realizado em Taquarituba, entre 1974 e $1976 \ldots \ldots \ldots$

Estımatıva da relação entre idade e sororreatividade para infecção

chagasica

60

43 Dos inqueritos nos municipios das Microrregiões Campos de Itapetininga, entre 1976 e 1978 e Encosta Ocidental da Mantiqueira

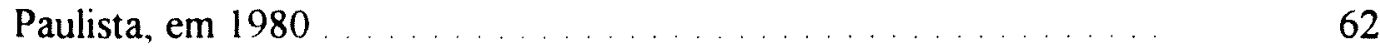

4.3.1 Municipios da Microrregião Campos de Itapetıninga . . . . . . . . . 62

4.3.2 Municipios da Encosta Ocidental da Mantiqueira Paulısta . . . . . . . 65

4.4 Do inquérito nos municipios Cananéia, Iguape e Peruibe, 1980 a

4.5 Do Programa de Controle da doença de Chagas entre 1984 e 1997. 79

4.5.I No Serviço Regional da SUCEN da Grande São Paulo (SR-1) . . . . . 79

4.5.2 No Serviço Regional da SUCEN de Taubaté (SR-3) . . . . . . . . . . 79

4.5.3 No Serviço Regional da SUCEN de São Vicente (SR-2) . . . . . . . . 81

4.5.4 No Serviço Regional da SUCEN de Sorocaba (SR-4) . . . . . . . . . . 90

4.5.5 No Serviço Regional da SUCEN de Campinas (SR-5) . . . . . . . . . 99

4.5.6 No Serviço Regional da SUCEN de Ribeirão Preto (SR-6) . . . . . . 108

4.5.7 No Serviço Regional da SUCEN de São José do Rio Preto (SR-8) . . $\quad 117$

4.5.8 No Serviço Regional da SUCEN de Araçatuba (SR-9). . . . . . . . . 128

4.5.9 No Serviço Regional da SUCEN de Presidente Prudente (SR-10). . . $\quad 134$

4.5.10 No Serviço Regional da SUCEN de Marilia (SR-11) ......... 140

5 DISCUSSÃo $\ldots \ldots \ldots \ldots \ldots \ldots \ldots \ldots \ldots \ldots \ldots \ldots \ldots \ldots \ldots \ldots$

6 CONCLUSÕES $\ldots \ldots \ldots \ldots \ldots \ldots \ldots \ldots \ldots \ldots \ldots \ldots \ldots \ldots \ldots \ldots$

7 REFERÊNCIAS $\ldots \ldots \ldots \ldots \ldots \ldots \ldots \ldots \ldots \ldots \ldots \ldots \ldots \ldots \ldots \ldots$ 


\section{ANEXOS}

Anexo I - Distribuição de frequências de localidades existentes e trabalhadas e de Unidades Domiciliares (UDs) trabalhadas e com reagentes sorológicos para infecção chagásica, nos municipios das Regiões de Governo no Serviço Regional da SUCEN de São Vicente (SR-2), 1984 a 1997

Anexo II - Distribuição de frequências de localidades existentes e trabalhadas e de Unidades Domiciliares (UDs) trabalhadas e com reagentes sorológicos para infeç̧ão chagásica, nos municípios das Regiões de Governo no Serviço Regional da SUCEN de Sorocaba (SR-4), 1984 a 1997

Anexo III- Distribuição de frequências de localidades existentes e trabalhadas e de Unidades Domiciliares trabalhadas e com reagentes sorologicos para infecção chagásica, nos municipios das Regiões de Governo no Serviço Regional da SUCEN de Campinas (SR-5), 1984 a 1997

Anexo IV - Distribuição de frequências de localidades existentes e trabalhadas e de Unidades Domiciliares trabalhadas e com reagentes sorológicos para infecção chagásica, nos municipios das Regiões de Govemo no Serviço Regional da SUCEN de Ribeirão Preto (SR-6), 1984 a 1997

Anexo V - Distribuição de frequências de localidades existentes e trabalhadas e de Unidades Domiciliares trabalhadas e com reagentes sorologicos para infecção chagásica, nos municipios das Regiōes de Governo no Serviço Regional da SUCEN de São José do Rio Preto (SR-8), 1984 a 1997

Anexo VI - Distribuição de frequências de localidades existentes e trabalhadas e de Unidades Domiciliares (UDs) trabalhadas e com reagentes sorológicos para infecção chagásica, nos municipios das Regiões de Governo no Serviço Regional da SUCEN de Araçatuba (SR-9), 1984 a 1997

Anexo VII - Distribuição de frequências de localidades existentes e trabalhadas e de Unidades Domiciliares (UDs) trabalhadas e com reagentes sorológicos para infecção chagásica, nos municípios das Regiões de Governo no Serviço Regional da SUCEN de Presidente Prudente (SR-10), 1984 a 1997

Anexo VIII - Distribuição de frequências de localidades existentes e trabalhadas e de Unidades Domiciliares (UDs) trabalhadas e com reagentes sorológicos para infecção chagásica, nos municípios das Regiões de Governo no Serviço Regional da SUCEN de Marilia (SR-11), 1984 a 1997 


\section{Homenagens}

Resgatar informações sobre sorologia de infecção chagásica no Estado de São Paulo significou para mim volver a memória ao final da década de 1960 quando, ainda estudante da Faculdade de Ciências Farmacêuticas da USP, conheci o "staff" do Serviço de Erradicação da Malária e Profilaxia da Doença de Chagas - SEMPDC.

Em 1969, Eduardo Olavo da Rocha e Silva, médico da Divisão de Combate a Vetores (nova denominação do SEMPDC, em 1970 transformada em Superintendência de Saneamento Ambiental - SUSAM, hoje Superintendência de Controle de Endemias SUCEN), recebeu a incumbência de seu diretor, Renato de Robert Corrêa, de buscar condições para a execução de exames sorológicos que permitissem avaliar os efeitos da campanha contra os vetores da doença de Chagas, medida tornada necessária pela redução das populações de triatomíneos nas casas. Desta procura resultou a celebração de um Convènio entre essa Unidade da Secretaria de Estado da Saúde e a Cadeira de Parasitologia da Faculdade de Medicina da Universidade de São Paulo (hoje Departamento de Parasitologia do Instituto de Ciências Biomédicas da USP). Com a cessão de um microscópio de fluorescência pela Organização Panamericana de Saúde, representada por Tito Lopes da Silva, dentro de poucos meses iniciaram-se os primeiros levantamentos sorológicos com a utilização da técnica de imunofluorescência indireta ${ }^{154}$, ${ }^{155}$, sob a responsabilidade do Prof. Associado Cláudio Santos Ferreira, então Instrutor de Ensino daquela Cadeira. O fornecimento de treinamento de pessoal e de suporte técnicocientífico propiciou a incorporação, em 1972, dessas atividades em instalações próprias da SUSAM, graças ao empenho do Superintendente, Flávio Dionísio da Costa, da Diretora Administrativa, Cyonea Villas Bôas Cione e do Diretor do Departamento de Combate a Vetores, Odilon Ferreira Guarita. A criação e o funcionamento do laboratório de sorologia para o diagnóstico da infecção chagásica na sede do Serviço permitiram a produção dos milhares de resultados que hoje, associados aos dados de triatomíneos vetores, denotam o sucesso do controle da transmissão vetorial no Estado 
Mas a figura com que eu mais associo a sorologia propriamente dita é, sem dúvida, a do médico

\section{Odilon Ferreira Guarita,}

responsável pelo desenvolvimento do inquérito sorológico mais expressivo realizado, o de prevalência em amostra de escolares de 9 a 14 anos em todos os municipios do Estado, entre 1968 e 1970, excetuando-se os da região da Grande São Paulo

Dr. Guarita acompanhou, ansiosamente e de perto, todas as fases da instalação do Laboratório de Sorologia e da execução dos testes iniciais do que viria a ser a continuação de seu trabalho de avaliação dos efeitos da campanha de combate ao vetor no Estado

$\mathrm{Na}$ organização do inquérito que se seguiria àquele, alguns profissionais foram exemplares em participação e empenho nas atividades de campo, tornando-as factiveis e gratificantes. Eu os homenageio nas pessoas do engenheiro

José Maluf, in memoriam, do chefe de equipe de campo, hoje Diretor Administrativo,

\section{Benedicto da Silva,}

e da educadora

\section{Maria Elena da Silva,}

importante elo entre o Serviço e o professorado da zona rural, com o qual pudemos lograr atingir nossos objetivos maiores. 


\section{Dedicatórias}

Aos meus avós maternos, Conceta De Marinis (la maestrina) e Francesco Lamparelli (mestre Ciccilo), que chegaram ao Brasil nos idos de 1902, vindos de sua "bella Italia", para integrar a força de trabalho deste Estado de São Paulo e "fazer a América", na esperança de "lavoro e fortuna". Recusando oferta de permanecer na Capital, na ilusão de atingir melhores oportunidades no interior, dirigiram-se inicialmente ao Vale do Paraiba, às fazendas de café, quando ocorria a substituição da mão-de-obra escrava pela de imigrantes europeus, principalmente italianos. Não se adaptaram, entretanto, ao plantio dessa cultura, tampouco a tocar equinos para o escoamento da produção cafeeira, restando-lhes investir nas habilidades que já desenvolviam em sua terra natal, ligadas à confecção de utensílios de cerâmica. Ao acompanhar o contigente que se dirigia para o oeste, evidentemente sem o saberem, tangenciaram a área geográfica onde grassava a doença de Chagas, nas regiões de Campinas e de Ribeirão Preto e, nos últimos anos de suas vidas, na região Sorocabana $\mathrm{O}$ acaso os fez permanecer nas zonas urbanas de municipios que estavam por instalar redes de esgoto e, portanto, que mostravam-se promissores quanto à capacidade de absorver os produtos de sua arte ${ }^{110}$. Infelizmente, esta não foi a sorte de muitos de seus compatriotas, desconhecedores da existência da doença de Chagas naquelas regiões. 
Ao querido Cláudio, que dispõe de uma generosidade inesgotável quando se trata de compartilhar todas as minhas dificuldades e limitações. Con amore.

Ao Marcelo, Fábio e Renato, na certeza de que, lendo este trabalho, compreenderão as razões de minhas ausências em alguns momentos de suas vidas.

Ao Rubens Antônio da Silva que, com sua dedicação entusiasmada ao Programa de Controle da Doença de Chagas do Estado de São Paulo, contribuiu decisivamente na análise crítica de nossa atuação nesse Programa, além da participação na coletânea de informações que compuseram diversos bancos de dados

A Wandercy Santos Rosa, amiga dedicada e incansável funcionária que foi do Serviço Regional da SUCEN de Ribeirão Preto, in memoriam e com saudades 


\section{Agradecimentos}

Ao meu orientador, Prof. Dr. José Maria Soares Barata, que se manteve incansavelmente disponivel para as criticas e sugestões de cursos, estágio, estudos e bibliografia pertinentes à tese, apoiando-me ainda na participação de eventos de natureza cientifica no exterior

A Superintendência de Controle de Endemias, que autorizou a realização do curso de Pósgraduação junto ao Departamento de Epidemiologia da Faculdade de Saúde Pública da USP

À CAPES, pela concessão de uma bolsa de estudos por um ano.

A Prof Dr ${ }^{\mathrm{a}}$ Maria do Rosário Dias de Oliveira Latorre, pelo estágio fornecido na área de Estatistica e, principalmente, pelo brilhantismo didático com que conduziu o curso de "Modelos de regressão aplicados à epidemiologia"

Aos professores de curso de pós-graduação na USP: Maria Heloisa Trebilcock Affonso, Lucille Maria Floeter-Winter, Lygia Busch Iversson, Eduardo Massad, Eliseu Alves Waldman e Sabina D. Gotlieb, que imprimiram suas orientações ao meu aperfeiçoamento acadêmico

Aos Professores componentes da banca examinadora, a quem dedico profunda admiração e respeito, Dra. Lygia B. Iversson, Dr. Emey F. Plessman Camargo, Dr. João Carlos Pinto Dias e Dr. Ennio Luz, pela contribuição em suas sugestões e críticas pertinentes ao trabalho

Ao Pesquisador Científico da SUCEN, Horacio Manuel Santana Teles que, com paciência e bom humor, procedeu as revisões minuciosas e criteriosas de diversas versões do manuscrito.

Aos estagiários que passaram pelo Laboratório, e que tiveram importante participação em diversas fases dos diferentes levantamentos sorológicos realizados na SUCEN; outrossim desenvolveram importantes trabalhos em seus diferentes setores de atividades, em especial Alair Perini Fucks (in memoriam), do Setor de Xenodiagnóstico do Instituto 'Dante Pazzanese de Cardiologia”, Iara Lúcia Laporta Ferreira, do Instituto Butantan, Maria 
Márcia Imenez Ishida, do Departamento de Parasitologia da Universidade Federal de Santa Catarina, Sônia Maria Francisco, Historiadora e Farmacêutica-Bioquímica, Dalva Marli Valério Wanderley, do Departamento de Combate a Vetores da SUCEN, Ricardo Mário de Carvalho Ciaravolo, do Serviço Regional da SUCEN de São Vicente, Maria Ângela Silveira Massucato e as estagiárias do Programa de Aperfeiçoamento da FUNDAP, Regina Tomoko Shirasuna (neé Ninomia), Andréa Moreira da Cunha e Fabiana Zacharias.

A Hilda Maria Solis Acosta, da Universidad Mayor de San Marco, Lima, Peru, na vigência de seu estágio no Laboratório, quando realizava seu Mestrado e, posteriormente, seu Doutorado, junto ao Departamento de Análises Clinicas da Faculdade de Ciências Farmacêuticas da USP, pelo proficuo intercàmbio técnico-cientifico, além da amizade Igualmente a Hugo Albarracin Veizaga, da Secretaria da Saúde de Cochabamba, Bolivia, ex-aluno de pós-graduação do Departamento de Epidemiologia da Faculdade de Saúde Pública da USP

Aos funcionários da SUCEN, Benedita Aparecida Magalhães da Silva, Guiomar Fonseca Matos, Kleber José Whitaker, Maria Eduarda Pereira Farinha, Viviane Emi Nakano e às ex-funcionárias Marcia Regina Delgado e Regina Yoshika Yazawa, todos exemplos de dedicação ao trabalho realizado, pela amizade e pelo apoio técnico em diversas fases do trabalho.

A Pesquisadora Cientifica do Laboratório de Protozooses por Flagelados, da SUCEN de Mogi-Guaçu, Vera Lúcia Cortiço Corrêa Rodrigues, aos Diretores de Serviços Regionais da SUCEN e funcionários responsáveis pelo Programa de Controle da Doença de Chagas em São Vicente, Ricardo Mário de Carvalho Ciaravolo e Maria de Fátima Domingos, em Sorocaba, Sueli Yasumaro, Antonio Henrique Alves Gomes e Marlene Silva Rafael, em Ribeirão Preto, Maurício Vladimir Botti e Maria Ivone de Almeida, em São José do Rio Preto, Sirle Abdo Salloum Scandar e Marcelo Papa e em Araçatuba, Clóvis Pauliquévis Jr e Lilian Aparecida Colebrusco Rodas, pelas facilidades na obtenção de dados disponíveis em arquivos 
A Técnica da Coleção de Culturas do IAL/S.Paulo, Sra. Filomena Magaldi Jordão, pela cessão de amostras de cultivos de Trypanosoma cruzi e aos Pesquisadores Científicos do Instituto "Dante Pazzanese" de Cardiologia da Secretaria de Estado da Saúde de São Paulo, Vera Lúcia Pereira Chiaccola e Antônio Marcos de Aparecida Levy, pela cessão de amostras de soros-controle positivos para infecção chagásica.

Ás funcionárias da Faculdade de Saúde Pública da USP, Angela Maria Pereira Silva Lima, Márcia Aparecida Garcia da Silva, Maria Aparecida Mendes e Renilda Maria de Figueiredo, pela atenção com que sempre me atenderam nas questões formais, no transcorrer de todo o curso de pós-graduação. 
CARVAlHO ME de. Sorologia de infecção chagásica no Programa de Controle do Estado de São Paulo, Brasil. São Paulo, 2000. [Tese de Doutoramento - Faculdade de Saúde Pública da USP]

\section{RESUMO}

Objetivo Resgatar dados primários de sorologia de infecção chagásica no Programa de Controle do Estado de São Paulo (PCDCh), entre 1972 e 1997, visando a avaliar padrões de distribuição espacial e etária da infecção em diversas populações submetidas a diferentes situações de risco e apontar rumos para prosseguir nessa investigação. Metodologia. Análise soroepidemiológica de resultados de reações de imunofluorescência indireta obtidas em inquéritos populacionais, entre escolares e moradores de Unidades Domiciliares com presença de vetores infectados por Trypanosoma cruzi ou tendo ingesta reagente para sangue humano. Análise de fichas de investigação de casos sororreagentes Análise de probitos, para estimar associação entre idade e resposta sorológica em população sedentária, sujeita a transmissão vetorial Resultados. Observou-se associação positiva entre idade e soropositividade em área com persistência de vetor intradomiciliar Inquérito escolar indicou tendência a queda da positividade entre 1973 e 1983, principalmente na Região de Sorocaba, último reduto de Triatoma infestans no Estado. Perfis de títulos caracterizaram áreas de baixa endemicidade: dentre as Regiões de Campinas e de Sorocaba, a interrupção da transmissão foi mais precoce na de Campinas, com diferença de 15 anos. Casos importados e de transmissão oral produziram padrão de transmissão baixo porém constante na área "indene". No Planalto predominaram autoctonia e infecções pregressas. Não houve associação entre presença de triatomineos infectados e moradores sororreagentes entre 1984 e 1997. Conclusões. Reduzidos os focos domiciliares de vetores, a sorologia tende a fornecer baixos valores preditivos Sugere-se re-direcionamento do seu uso, em situações de risco potencial: filhos de mães sororreagentes, detectadas no PCDCh, grupos alóctones provenientes de áreas endêmicas de doença de Chagas e áreas de manutenção de ciclo silvestre da transmissão.

Descritores: Infecção chagásica. Soroepidemiologia. Programa de Controle. Vigilância epidemiológica 
CARVALHO ME de. Sorologia de infecção chagásica no Programa de Controle do Estado de São Paulo, Brasil. São Paulo, 2000. [Seroepidemiology of Chagas disease in the Chagas Disease Control Program of the São Paulo State, Brazil.] São Paulo (BR); 2000. [Tese de doutorado - Faculdade de Saúde Pública - USP].

\section{SUMMARY}

Objective. To retrieve first-hand data concerning Chagas disease serology related to the Chagas Disease Control Program (PCDCh) from 1972 to 1997, to evaluate spatial and age group distribution of infected populations under different risk situations and to indicate how to proceed with this investigation. Methods. Seroepidemiological analysis of the results of indirect immunofluorescence tests applied to the surveillance of school-children and residents of domicilliary units infested with vectors parasitized by Trypanosoma cruzi or human blood having been identified in their ingesta. Probit analysis was used to investigate association of age with serological response in a sedentary population under persistent risk. Results. A positive association of age with serological response was found. A survey involving school-children showed a tendency towards a decrease in positivity between 1973 and 1983, chiefly in the Sorocaba Region, the last stronghold of Triatoma infestans in São Paulo. Titer patterns typical of low endemicity regions were found. Comparing the Campinas and Sorocaba regions, transmission was interrupted in Campinas 15 years previously. Cases of imported and orally transmited infections produced a pattern of low but constant transmission in "transmission-free" areas. In the plateau areas most cases were autochtonous or acquired long ago. No association was found of the presence of infected vectors with seropositive residents during 1984-1997. Conclusions. As a consequence of reduced domiciliary vector foci, low predictive values of serological tests are expected. From now on the use of serology is indicated to assess congenital cases connected to seropositive women; allochthonous populations from endemic regions and those from regions where sylvatic transmission of $T$. cruzi occurs

Descriptors: Chagas disease. Seroepidemiology. Control Program. Epidemiological surveillance. 


\section{INTRODUÇÃO}

O primeiro caso humano de doença de Chagas no Estado de São Paulo, mais precisamente no municipio de Ribeirão Preto, foi observado por BAYMA ${ }^{20}$, em 1914 que, decorridos quase dois meses da inoculação em cobaios de amostras de sangue de diversos pacientes, encontrou, no sangue do animal que recebeu uma das amostras, "tripanozomas", identificados, após coloração pelo método de Giemsa, como sendo da espécie Trypanosoma (Schizotrypamum) cruzi Chagas, 1909. Seria um caso crônico, na opinião de FREITAS $^{87}$ (1950), pois não havia menção de exame a fresco de sangue, notoriamente pouco sensível nesta fase da doença ${ }^{88}{ }^{169}$, devido a características do desenvolvimento do parasita em vertebrados ${ }^{200}$. Novo caso da doença no Estado de São Paulo, desta vez do municipio de Brotas, então região de Marilia, foi descrito por CARINI e MACIEL ${ }^{34}$, ainda em 1914

Segundo idéia corrente, a doença de Chagas foi relegada a plano secundário, no meio cientifico, até o início da década de $1940^{25.146}$, tendo voltado a despertar interesse desde então ${ }^{158}$ O relato de apenas cerca de 40 casos descritos durante o intervalo entre 1909 e 1945, segundo FREITAS ${ }^{86}$ (1947), indica a escassa atenção dada a essa doença, a despeito de ROSENFELD e CARDOSO $^{162}$ (1941) terem assinalado o encontro de triatomineos infectados por T. cruzi em vastas áreas do território paulista.

No Brasil, o início das atividades de controle de Triatoma infestans (Klug, 1834), principal vetor da doença, deu-se em fins da década de 40, no Estado de Minas Gerais ${ }^{219}$. Este fato estimulou a aplicação de programa análogo no Estado de São Paulo ${ }^{25 .}$ 96. 193 Planos governamentais e privados de investimentos econômicos na lavoura de café, no Estado de São Paulo, explicam o ressurgimento do interesse nas questões relacionadas com a doença de Chagas ${ }^{25.158 .189 .190}$. Sentiu-se a necessidade de avaliar a extensão desse problema nas áreas incluídas na proposta de recuperação das "terras esgotadas", isto é, já intensivamente exploradas pela frente de desbravamento do interior (SILVA ${ }^{189} 1981$ ). Visava-se ao "retorno de capital para dentro dos limites do Estado", segundo BURALLI ${ }^{25}$ (1985). ROCHA E SILVA et al. ${ }^{158}$ (1979) consideram alguns trabalhos, como os de 
ROSENFELD e CARDOSO $^{162}$ (1941) e de FREITAS $^{87}$ (1950) como marcos da implantação do Serviço de Combate aos Vetores da doença de Chagas no Estado. Neles desenha-se a gravidade do quadro da distribuição da doença e, com especial destaque, a dos triatomineos vetores, razões suficientes para a implantação de medidas de controle.

No periodo correspondente ao "silêncio" em torno da doença, foi escassa a produção científica relacionada com o diagnóstico sorológico da fase crônica, como se deduz das citações de ROMAÑA e $\operatorname{DIAS}^{161}$ (1942) com relação à reação de fixação do complemento (RFC) e às discussões a respeito de antigenos e tentativas de seu aperfeiçoamento.

Evidentemente, o desempenho de uma técnica sorológica depende da qualidade do antígeno usado, quaisquer que sejam os agentes etiológicos investigados. Comenta FIFE $\mathrm{JR}{ }^{77}$ (1972) que todo o progresso do imunodiagnóstico assenta-se no desenvolvimento de antígenos $O$ caso particular da infeç̧ão chagásica não é exceção, buscam-se ainda hoje antigenos purificados, de alta especificidade, que forneçam resultados diagnósticos cada vez mais precisos $24,31.108 .118 .194,222$

\section{$1.1 O$ diagnóstico laboratorial da infecção chagásica}

Preconizava-se, na década de 40, para demonstração direta de $T$. cruzi no sangue periférico de pacientes com suspeita de doença de Chagas na fase aguda: exame a fresco de amostras de sangue, sem tratamento prévio ou após centrifugação e preparações (estiramentos ou gotas espessas) coradas por meio da técnica de Giemsa. Para o diagnóstico parasitológico da fase crônica as técnicas indiretas eram recomendadas: xenodiagnóstico, inoculação em animais de laboratório e cultura (FREITAS ${ }^{86}$ 1947).

Reconhecidos como altamente específicos, os métodos parasitológicos são pouco sensíveis, dai resultando frequentes falsos negativos. MUNIZ e FREITAS $^{133}$ (1944), FREITAS $^{86}$ (1947) e FREITAS e ALMEIDA ${ }^{88}$ (1949) salientam as limitações da parasitoscopia para a pesquisa de $T$. cruzi no sangue periférico e a conveniência do uso das "reações de imunidade", assim denominadas pelos autores. Despertou também 
interesse a detecção de alterações, produzidas pelo parasita, de proteinas plasmáticas análise da distribuição das proporções de frações protêicas, exemplificada pelos trabalhos de VERSIANI e CAVALCANTI ${ }^{208}$ (1943) e de MUNIZ e FREITAS $^{134}$ (1944), consideradas por FREITAS ${ }^{86}$ (1947) como tentativas frustradas de técnicas diagnósticas, por sua baixa especificidade. Por outro lado, admitida a permanência, tanto de $T$. cruzi, quanto dos anticorpos específicos correspondentes, por toda a vida do infectado, afigurava-se promissora sua detecção.

RAMOS et al. ${ }^{151}$ (1949) avaliaram os recursos diagnósticos, clínicos e laboratoriais, então disponiveis para investigar a doença de Chagas, por ocasião de estudo epidemiológico em área intensamente infestada por triatomíneos vetores, no municipio de Cajuru, distrito de Cássia dos Coqueiros (Região de Ribeirão Preto). De um conjunto de 500 observações, obtiveram $337(67,4 \%)$ positivas por meio da RFC. Um subconjunto de 132 casos com $103(78,0 \%)$ positivos sorológicos (RFC) revelou apenas $24(23,3 \%)$ positivos por xenodiagnóstico. Segundo os mesmos autores, gota espessa, hemocultura e inoculação em animais de laboratório são ainda menos sensiveis durante a fase crônica da doença

A reação de fixação do complemento, segundo GUERREIRO e MACHADO ${ }^{100}$ (1913), é ainda frequentemente citada, não obstante a eventual mudança na ordem dos nomes dos seus autores, fato atribuido a RAMOS et al. ${ }^{151}$ (1949), que a justificaram por terem usado antigeno diferente do originalmente descrito pelos autores. Essa técnica foi objeto de considerável refinamento, comprovável pela extensa lista de publicações, demonstrada pela revisão de literatura publicada por MAEKELT ${ }^{121}$ (1960). Pesquisadores do Brasil e da Argentina polarizaram as investigações, destacando-se, no Brasil, aqueles dos Estados de Minas Gerais, Rio de Janeiro e São Paulo. A resultante reação de fixação do complemento padronizada, foi publicada em 1976 por ALMEIDA e FIFE JR. ${ }^{3}$ sob o patrocinio da Organização Panamericana da Saúde (OPAS).

FREITAS e ALMEIDA ${ }^{88}$ (1949), cujo trabalho merece destaque do ponto de vista técnico, recomendam executar a RFC com leitura fotométrica de $50 \%$ de hemólise, do que resulta considerável incremento da precisão de resultados de reações quantitativas, 
uma vez que a curva de hemólise (em termos de absorbância) se aproxima de uma reta nessa região e o coeficiente angular (correlação entre fixação do complemento e hemólise) tende a ser máximo. Por outro lado, à medida que as leituras de hemólise tendem para $0 \%$ ou $100 \%$, o coeficiente angular tende para zero, disto resultando leituras imprecisas. No mesmo trabalho os autores relatam a obtenção de um antigeno mais estável do que o anteriormente usado

\subsection{Soroepidemiologia}

A viabilidade da soroepidemiologia é consequência do refinamento das técnicas sorológicas, usadas de inicio para diagnóstico individual, principalmente de viroses, arboviroses em particular ${ }^{139}$ Tendo como objetivos principais os da vigilância, possibilita determinar o status imunológico de populações e prevalências idade-específicas de eventos, comparar dados de diferentes populações, efetuar estudos longitudinais e monitorar programas de vacinação e de controle. Os resultados das provas sorológicas podem ser correlacionados com características de populações sob estudo quanto a diferenças de hereditariedade, localização geográfica ou mesmo, de modus vivendi ${ }^{141}$ O termo soroepidemiologia foi aplicado pela primeira vez em 1950, por PAUL e RIORDAN $^{140}$, em trabalho sobre poliomielite entre esquimós.

A disponibilidade de um elenco crescente de provas sorológicas com características de sensibilidade e especificidade adequadas aos propósitos visados $\left(\right.$ KAGAN $\left.^{106} 1973\right)$ permitiu sua aplicação à epidemiologia de protozooses ou helmintoses. No final da década de 50 e no início da de 60 foi particularmente acelerada a evolução das reações de imunofluorescência indireta (RIFI) e de hemaglutinação indireta (HAI), amplamente usadas em estudos soroepidemiológicos de protozooses (CARVALHO ${ }^{35}$ 1985).

Tradicionalmente, o diagnóstico das protozooses dependia da identificação morfológica de seus agentes por meio de exame, ao microscópio de luz, de material biológico proveniente do hospedeiro ou, quando exequível, após inoculação em animais ou cultura (demonstração indireta). No caso particular da doença de Chagas, o encontro 
de parasitas no sangue, relativamente fácil durante a fase aguda, tornava-se extremamente dificil nas fases subsequentes, mesmo quando usados os recursos de inoculação em animais ou cultura. As decisões quanto à etiologia das entidades em estudo deviam ser tomadas à base de dados clínicos e epidemiológicos. Datam do início do século vinte os primeiros experimentos com reações de fixação do complemento para a deteç̧ão de anticorpos associados a $T$. cruzi (KAGAN ${ }^{106}$ 1973). Seu campo de aplicação foi-se ampliando de modo a ocupar destacada posição na pesquisa clínico-epidemiológica.

As reações de imunofluorescência resultaram dos trabalhos de COONS et al. ${ }^{49}$ (1941), que usaram a técnica direta, que consistia em corar, usando globulinas especificas previamente marcadas por fluoresceina, antígenos pneumocócicos em amostras de tecidos. Esse método de identificação de antigenos despertou interesse imediato, desencadeando uma sequencia de pesquisas dirigidas à sua aplicação a outros agentes. FIFE JR. e MUSCHEL $^{78}$ (1959) adaptam essa técnica ao diagnóstico da infecção chagásica e comparam seus resultados com os da reação de fixação do complemento

É particularmente interessante do ponto de vista epidemiológico observar, usando técnicas como a citada, projetadas para uso em grande escala, o comportamento sorológico de populações humanas submetidas ao risco de transmissão da infecção chagásica. Anticorpos específicos anti-T. cruzi, da classe das imuneglobulinas, são dependentes da infecção e permanecem na circulação por toda a vida dos infectados não submetidos a tratamento específico (ROTTENBERG et al. ${ }^{163}$ 1991). As estimativas de prevalência associadas à sua detecção incluem, portanto, os casos crônicos, dificilmente identificáveis por meio das técnicas parasitológicas tradicionais

Perfis sorológicos passiveis de comparação com padrões de endemicidade préexistentes, associados a regiões holo, meso ou hipoendêmicas, podem delinear-se a partir de distribuições de frequências de títulos sorológicos determinados em inquéritos transversais $\left(\mathrm{KAGAN}^{106} 1973\right)$. Variações individuais dos títulos são dependentes da fase da doença ${ }^{35,63}$. LUQUETTI e RASSI ${ }^{118}$ (1998) também destacam a importância de determinar os títulos ao avaliar pacientes submetidos a tratamentos específicos. 
Verificar as proporções de soropositividade por faixa etária e sexo contribui para a análise de características da transmissão, associadas ou não a medidas de controle de vetores. Crianças nascidas após a implantação de tais medidas representam indicadores de sua eficácia ${ }^{2}$ 9. 46. 64. 105.158 . Inquéritos abrangentes permitem detectar variações do comportamento sorológico ao longo de diversas faixas etárias 42. 43. 54. 56. 165. 196. 207. Mediante o conhecimento prévio da situação epidemiológica, avaliam-se os riscos potenciais de transmissão em grupos especificos ${ }^{8.143 .206}$

GOLDSMITH et al. ${ }^{94}$ (1985) utilizam a sorologia para investigar o possivel impacto da redução de ações de controle de anofelinos vetores da malária, por meio de aspersão de DDT, sobre a transmissão da infecção chagásica em Cerro del Aire, Estado de Oaxaca, México. Sabe-se que o DDT, embora não indicado para o controle de triatomíneos, não é totalmente inócuo para estes insetos. Incluíram-se neste estudo crianças de menos de 7 anos, sendo os casos positivos (33 casos) submetidos a xenodiagnóstico e hemocultura. Isolaram-se parasitas em $45 \%$ deles

SEGURA et al. ${ }^{188}$ (1985) compararam, na Argentina, dados obtidos em distintas ocasiões, após campanhas contra vetores ou medidas de controle de transfusões sanguíneas; observaram declínio de proporções de soropositivos dentre jovens de 18 anos de idade, alistados no serviço militar daquele pais. Nesta linha de pesquisa, dirigida a determinados segmentos de idade, há o trabalho realizado em Cuba em 1989, com população de estudantes nicaraguenses, em que $8,5 \%$ se revelaram soropositivos para infecção chagásica. Este fato confirma a existência de interesse na preservação da saúde e no acompanhamento clínico-cardiológico deste segmento da população estudantil ${ }^{13 !}$.

HOFF et al. ${ }^{105}$ (1985) destacam a relevância do uso da sorologia em todas da fases de uma campanha contra a doença de Chagas: preparatória, ataque e consolidação. Dados sorológicos obtidos em estudos transversais, realizados em algumas áreas do Estado de São Paulo, em que há informações sobre naturalidade e tempo de permanência dos habitantes em locais bem definidos, são úteis para estimar tempos de permanência no foco suficientes para produzir a passagem, de certa proporção dos habitantes do estado soronegativo para o soropositivo (CARVALHO et al. ${ }^{40}$ 2000; FERREIRA et al. ${ }^{76}$ 1994). 


\subsection{Inserção da sorologia nas atividades de controle da doença de Chagas em} São Paulo

Durante a década de 50 foi considerável a produção de informações sobre a distribuição da doença de Chagas, decorrentes de levantamentos conduzidos sob a égide do Serviço de Profilaxia da Malária 5, 48. 89. 103. 126. 138. 171. 192. 193. 202. 203, que detinha a responsabilidade das ações de combate à endemia chagásica em $1951^{160}$, período classificado por ROCHA E SILVA et al. ${ }^{158}$ (1979) de "anterior a realização da campanha de erradicação da malária (CEM)", marcado por atividades de controle nem abrangentes nem continuas. Nesses trabalhos, os informes relativos à extensão da infecção humana decorrem do uso da reação de fixação do complemento. Durante o periodo compreendido entre 1951 e 1958, dentre 15271 amostras examinadas, 1422 $(9,31 \%)$ resultaram positivas ${ }^{50.56}$ Entretanto, o Programa de Controle não preconizava a sorologia como atividade rotineira, como o foi a busca de triatomineos, resultando daí informaçōes fragmentárias $\left(\right.$ SILVA $^{189} 1981$ )

Mesmo estando então disponivel técnica sorológica apoiada em bases confiáveis, como dito por FREITAS ${ }^{86}$ (1947), o Serviço de Controle da Doença de Chagas seguia realizando exames diretos de gotas espessas de sangue periférico, método de escolha para o diagnóstico de malária Estava em vigor a Campanha de Erradicação da Malária (CEM) no Estado, cujos técnicos estavam também treinados para pesquisar, em suas atividades rotineiras, formas de tripanossomas no sangue. Para o controle da doença de Chagas o Programa inseria-se na "fase mais ativa da (EM; de 1959 a 1967', na qual se incluía a fase de ataque denominada "arrastão". Esta consistiu na aplicação de hexacloreto de benzeno (BHC) em toda a área infestada, nas habitações rurais e seus anexos ${ }^{158}$, sobretudo entre os anos de 1965 e $1967^{25.123}$. Em Washington, DC, EUA, durante uma reunião de expertos em doença de Chagas, da Organização Panamericana da Saúde, CORRÊA ${ }^{50}$ (1969) apresentou dados sobre a deteç̧ão de casos de tripanosomiase americana no Estado de São Paulo por meio do exame de gotas espessas de sangue: dentre 183897 amostras examinadas em 1968, 3 haviam resultado positivas $(0,002 \%)$ e, até maio de 1969 , apenas 1 amostra havia resultado positiva dentre 81484 examinadas $(0,001 \%)$. Na 
publicação de CORRÈA et al. ${ }^{52}$ (1970) são detalhados os resultados de exames de gotas espessas de sangue, realizados pelo Serviço de Erradicação da Malária e Profilaxia da Doença de Chagas (SEMPDC) do Estado de São Paulo, hoje Superintendência de Controle de Endemias (SUCEN): durante o período compreendido entre 2 de fevereiro de 1960 e 30 de junho de 1970, de 2646079 amostras examinadas, 17 resultaram positivas para T. cruzi $(0,001 \%)$

A utilização da RFC foi decorrência de reunião de Grupo de Estudos em Sorologia da Doença de Chagas, havida em San Juan, Porto Rico, em 1966, para estabelecer as bases da padronização dessa reação, considerada então a mais aperfeiçoada quanto às características de sensibilidade, especificidade e padronização vigentes na época. Ficou claro, entretanto, que outras técnicas também mereciam ser investigadas ${ }^{136}$ A partir do segundo semestre de 1968, dez anos decorridos dos levantamentos sorológicos anteriores, abrangente inquérito foi delineado pelo SEMPDC, com amostragem desenhada pelo Departamento de Epidemiologia da Faculdade de Saúde Pública da USP, para aplicação em todos os municipios do Estado, à exceção daqueles agregados na Região da Grande São Paulo. Encontrava-se o Programa de Controle da Doença de Chagas em sua fase de "expurgo seletivo (1968-1972)"25, 160 e foram incluídos nesse inquérito os escolares das redes de ensino público urbano e rural, com idades entre 9 e 14 anos. Sendo necessário obter valores de prevalência da infecção chagásica no Estado (CORRÊA ${ }^{30}$ 1969; GUARITA et al. ${ }^{96}$ 1978), esse estudo buscou elaborar um quadro da infecção humana por $T$. cruzi, tendo como indicadores pessoas nascidas após serem iniciadas as atividades de controle do vetor, o que abrangeu crianças nascidas entre 1954 e 1961, portanto na fase inicial "anterior a realização da campanha de erradicação da malária (CEM)" e no início da "fase mais ativa da (EM; de 1959 a 1967"158. Seguia-se o modelo preconizado para o Estado de Minas Gerais, pelo então Instituto Nacional de Endemias Rurais INERu, o que lhe permitiria obter, em todo o Brasil, dados comparáveis (GUARITA et al. $\left.{ }^{96} 1978\right)$.

A aplicação da reações de imunofluorescência ao diagnóstico da infecção chagásica, descrita por FIFE JR. e MUSCHEL ${ }^{78}$ (1959), inevitavelmente estimulou pesquisas tendentes a refiná-las. Era o início da implantação de uma técnica que logo viria 
a ser largamente utilizada. Estudos de comparação entre resultados de técnicas de fixação do complemento e de imunofluorescência indireta (ALVAREZ et al. ${ }^{4}$ 1968; ARAUJO e BATISTA $^{11}$ 1969; CAMARGO ${ }^{27}$ 1966), trouxeram o suporte cientifico fundamental para a sua adoção pelos programas de controle e vigilância.

Nessa época também surgia a técnica de hemaglutinação indireta, descrita por CERISOLA et al. ${ }^{44}$ (1962), na Argentina. Mostrando resultados comparáveis aos da fixação de complemento e de imunofluorescência (CERISOLA et al. ${ }^{45}$ 1970), ainda hoje ocupa lugar de destaque entre as técnicas disponiveis. De execução facilitada pela disponibilidade de "kits" comerciais (FUCKS et al. ${ }^{90} 1980$ ), entretanto, tem custo elevado, fator limitante para seu amplo emprego (ANDRADE ${ }^{8}$ 1994)

Os primeiros resultados de inquéritos obtidos com a RIFI, pela Diretoria de Combate a Vetores (antigo SEMPDC), foram apresentados em 1970. MALUF et al. ${ }^{123}$ (1970) não encontraram sororreatividade em amostra de 242 crianças de Bariri, entre 1 e 4 anos de idade, concluindo ter sido interrompida a transmissão natural da doença de Chagas naquele municipio. ROCHA E SILVA et al. ${ }^{155}$ (1970) demonstraram a facilidade de obtenção de amostras de sangue de polpa digital, absorvidas em papel-filtro, em área piloto de vigilância epidemiológica no Estado, compreendida por municípios da Região de Bauru: Balbinos, Guarantã, Pirajui, Pongai, Presidente Alves e Urú, em amostra de 2215 crianças de 1 a 8 anos de idade. Removem-se, desse modo, consideráveis obstáculos de ordem prática, especialmente quando se trabalha com pessoas dessa faixa etária, sem risco de perda de qualidade da avaliação epidemiológica. Obtiveram-se aí 5 amostras sororreagentes $(0,22 \%)$, todas procedentes do município Pongai, localidade Bairro do Fundão. A investigação de 4 desses casos revelou familiares positivos sorológicos em 3 deles e mãe positiva em dois deles (mãe ausente nos outros dois), o que sugere a possibilidade de existência de transmissão congênita ao se constatar ausência de infestação nas casas da localidade ${ }^{154}$.

A conveniência do uso de papel-filtro como suporte de amostras de sangue foi reconhecida a partir do trabalho de $\operatorname{WOLFF}^{218}$ (1958), segundo o qual a preservação dos anticorpos porventura nelas existentes é garantida, sendo adequado a "todos os tipos de 
provas sorológicas", MAEKELT e COLMENARES DE ALAYON ${ }^{122}$ (1960) executam RFC para o diagnóstico da doença de Chagas utilizando amostras de sangue colhido em papel-filtro. ANDERSON et al. ${ }^{7}$ (1961), aplicam-no ao diagnóstico de esquistossomose, obtendo resultados comparáveis aos esperados com uso de soros; salientam as vantagens desse suporte quanto à colheita, transporte e conservação de amostras. Esta técnica de colheita de sangue aplicada à RIFI para o diagnóstico da infecção chagásica foi inicialmente discutida por SADUN et al. ${ }^{164}$ (1963) e, no Brasil, por SOUZA e CAMARGO $^{197}$ (1966). HOFF é al. ${ }^{105}$ (1985) já haviam observado, em 1974, concordância bruta de $94,3 \%$ (positividade e negatividade) entre resultados de uma técnica (RFC), em que utilizaram soros e outra (RIFI) em que utilizaram eluatos de sangue total, ambas aplicadas a pessoas residentes em Castro Alves, BA. Deve-se ressaltar que a RFC era a técnica-padrão indicada formalmente, naquela época, para sorologia de infecção chagásica (MOTT et al. ${ }^{132}$ 1976).

Um aspecto importante do processo de padronização que interessou estudar foi a avaliação da quantidade de sangue contida em manchas aproximadamente circulares, de acordo com a prática corrente, adotada por SOUZA e CAMARGO ${ }^{197}$ (1966). Deve-se lembrar que as diluições dos eluatos dependem de estimativas de volume de sangue contido na porção de papel usada (FERREIRA et al. ${ }^{72} 1970$; FERREIRA e CARVALHO $^{75}$ 1982). Ulteriormente, a colheita passou a ser feita em fitas de papel-filtro, tomando as manchas a forma retangular: simplificou-se notavelmente o cálculo de sua área superficial (FERREIRA et al. ${ }^{73}$ 1971) e, consequentemente, o do volume de sangue contido, expresso em $\mu \mathrm{l}$ por $\mathrm{cm}^{2}$ de papel. Esse cálculo é válido para um mesmo lote de papel e deve ser refeito sempre quando outro for usado.

É evidente a importância epidemiológica da identificação de casos agudos, particularmente quando se trata de avaliar a eficácia de medidas de controle de vetores Tradicionalmente, o diagnóstico de casos agudos, ou incidentes, dependia exclusivamente de exames clínicos auxiliados por pesquisa de parasitas no sangue (utilizando métodos diretos ou indiretos). As reações sorológicas indicavam-se para esclarecer a etiologia de processos de evolução lenta, frequentemente assintomáticos. Entretanto, análises de frações de imunoglobulinas apontaram para a possibilidade de distinção entre casos 
crônicos e agudos por meio de pesquisa de imunoglobulinas $M(\operatorname{IgM})$, produzidas no inicio de processos infecciosos, indicativas, portanto, de fase aguda (CAMARGO e AMATO NETO ${ }^{30}$ 1974; PRIMAVERA et al. ${ }^{147}$ 1990; VATTUONE et al. ${ }^{204}$ 1973) Convem salientar que esses autores trabalharam com pacientes presumidos como infectados (fase aguda ou crônica) e não infectados. A avaliação dos resultados em situações de campo nunca foi efetivamente realizada, segundo HOFF et al ${ }^{105}$ (1985), talvez porque, nas áreas em que o trabalho foi realizado, as condições já eram pouco favoráveis à transmissão, possivelmente após a fase de ataque. Neste caso, seria suficiente analisar os resultados sorológicos das crianças nascidas após o início das campanhas de controle. $O$ fato é que a observação de $\operatorname{lgM}$ especifico para $T$. cruzi não foi prática adotada em inquéritos populacionais, pelo Serviço de Controle, no Estado de São Paulo. Um obstáculo a mais para a sua adoção é representada pelo fato de não se dispor, com a regularidade necessária, de soros comprovadamente IgM-reagentes para controlar os resultados das reações.

Ainda hoje há na literatura relatos sobre as dificuldades encontradas na deteç̧ão destes anticorpos, geralmente associados a titulos muito baixos (FIGUEIREDO-SILVA et $a^{79}{ }^{79}$ 1991, REICHE e JANKEVICIUS ${ }^{152}$ 1997), por vezes abaixo do limiar de detecção por meio de técnicas correntes, embora tenha sido comprovada sua presença em eluatos de sangue total absorvido em papel-filtro, mesmo após 2,5 meses de armazenamento (GUIMARÃES et al. ${ }^{102} 1978$ ).

Durante o ano de 1972 realizam-se inquéritos em vários municípios do Estado, à base da reação de imunofluorescência indireta, a fim de verificar: operacionalidade da técnica sorológica, padronização de reagentes, consistência de resultados e estimativa da grandeza da amostra a ser adotada para a avaliação da infecção chagásica em indicador criança nascida após 1967 , isto é, após o término da fase "arrastão" de combate aos triatomíneos vetores ${ }^{160}$.

Na fase da campanha denominada de "Prioridades"25, 158. 160, entre 1973 e 1982, em que os municipios eram trabalhados segundo periodicidades anuais (Prioridade 1), bienais (Prioridade 2) ou trienais (Prioridade 3), de acordo com a presença ou ausência de 
seu principal vetor, $T$. infestans, foi então aplicado o inquérito soroepidemiológico em escolares da primeira série do primeiro grau da rede oficial de ensino da zona rural Restrições orçamentárias tornaram impossivel estender o trabalho a todos os municípios do Estado, como anteriormente realizado por GUARITA et al ${ }^{96}$ (1978). Excluído o Serviço Regional da Grande São Paulo (SR 1), selecionaram-se, de cada um dos 9 restantes Serviços Regionais da SUCEN: SR 2- São Vicente, SR 3- Taubaté, SR 4 Sorocaba, SR 5- Campinas, SR 6- Ribeirão Preto, SR 8- São José do Rio Preto, SR 9 Araçatuba, SR 10- Presidente Prudente e SR 11- Marilia (Figura 1) apenas os 6 municipios em que era maior a prevalência da doença de Chagas. Nos 54 municípios realizaram-se, sistematicamente, os inquéritos escolares durante 11 anos ${ }^{97-99}$, até que, em fins de 1983, uma Comissão Interna de Técnicos da SUCEN decidiu encerrar essa atividade, alegando o fato de não ter sido detectado nenhum caso da infecção naquele ano $^{174}$

O período iniciado em 1984 representou uma nova fase (consolidação vigilância entomológica ${ }^{160}$ ) das atividades da SUCEN, no controle dos vetores da doença de Chagas: os exames sorológicos passaram a ser utilizados em áreas ainda mais restritas, à base de informações fornecidas por notificantes de triatomíneos ou como decorrência de pesquisa de rotina programada, de acordo com prioridades impostas por diferentes graus de infestação das casas por vetores da doença de Chagas. Eram então colhidas amostras de sangue de moradores dessas Unidades Domiciliares (UDs) quando satisfeitas as condições: $1^{a}$ ) os triatomineos deveriam pertencer à espécie $T$. infestans ou, $2^{a}$ ) se pertencentes a outras espécies vetoras, estar positivos para $T$. cruzi ou ter sugado sangue humano $^{25}$. A partir de 1994 houve nova mudança de critérios para o uso da sorologia associada à doença de Chagas: necessidade de demonstrar a existência de triatomíneos no intradomicilio infectados por $T$. cruzi. Esta orientação é ainda hoje vigente segundo o Programa de Controle da Doença de Chagas*.

\footnotetext{
- Secretaria de Estado da Saúde de São Paulo. Superintendência de Controle de Endemias (SUCEN). Oficio Circular SUP N ${ }^{\circ}$ 79/93 de 13-12-93. São Paulo: SUCEN; 1993.
} 


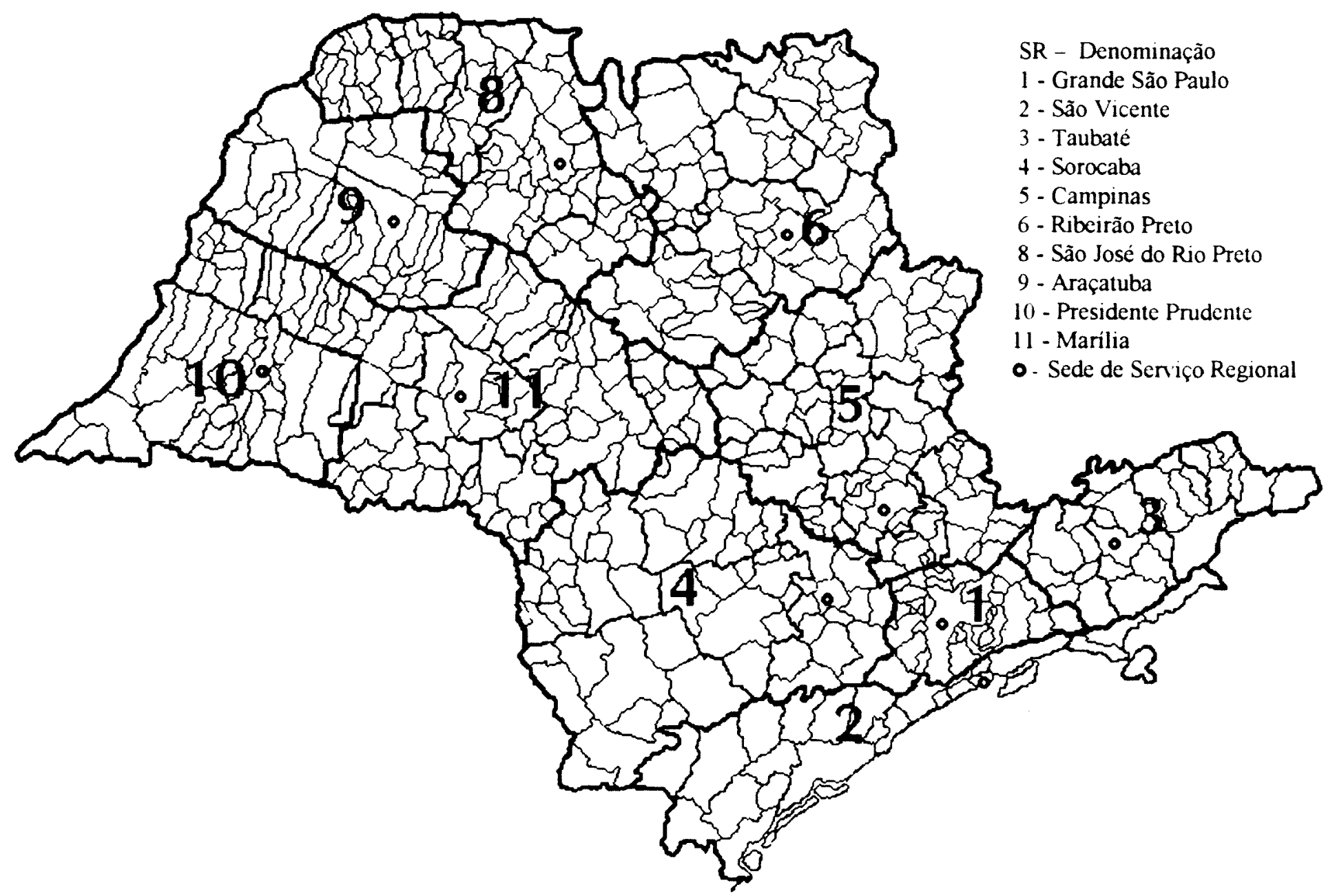

FONTE: SUCEN

Figura 1 - Mapa do Estado de São Paulo com as divisões por Serviços Regionais (SRs) da SUCEN. 
Em fins da década de 70, já se supunha como um evento raro, no Estado de São Paulo, a transmissão da doença de Chagas por vetor (ROCHA E SILVA et al. ${ }^{158}$ 1979) Nesse trabalho, a assertiva de a transmissão tender a ser interrompida tinha como base resultados parciais dos inquéritos sorológicos em escolares, aí incluidos os da primeira serie do primeiro grau, realizados entre 1973 e 1983 em zona rural ${ }^{97-99}$. A publicação de ROCHA e SILVA et al. op.cit. menciona, portanto, os primeiros resultados desse inquérito, destacando a queda de positividade sorológica e tomando como ponto de referência o inquérito realizado entre 1968 e 1970 por GUARITA et al. ${ }^{96}$ (1978), na Região de Sorocaba. Nessa região encontravam-se, no passado, as maiores proporções de domicilios colonizados por $T$. infestans no Estado. Os autores citam ainda os trabalhos realizados ai entre 1976 e 1980, por GOLDBAUM et al. ${ }^{93}$ (1979) e LITVOC et al. ${ }^{114}$ (1979), em colaboração com o Laboratório de Sorologia da SUCEN Esses estudos revelaram baixas proporções de prevalência sorológica nos grupos etários mais jovens. Os mesmos dados apresentados por SOUZA et al. ${ }^{198}$ (1984) servem para acentuar as inferências anteriores sobre a interrupção da transmissão vetorial da doença de Chagas no Estado de São Paulo

Conquanto as informações a respeito da infecção chagásica, por meio de sorologia, continuassem restritas aos trabalhos de GUARITA et al. ${ }^{96}$ (1978) e de ROCHA E SILVA et al. ${ }^{158}$ (1979), ou reduzidas a resumos ${ }^{36,37,39,41-43,54,93,97-99,114,128,155,211}$, que limitam a apresentação de pormenores epidemiologicamente relevantes, disponiveis apenas nas versões completas, logo inacessiveis a consultas ulteriores, também em âmbito internacional, a OPAS admitiu a interrupção da transmissão domiciliar da doença de Chagas em vastas áreas do Estado de São Paulo ${ }^{137}$

É interessante notar que, por ocasião da realização do Inquérito Nacional sobre a prevalência da infecção chagásica no Brasil, de 1975 a 1980, o Estado de São Paulo foi dele excluido, por terem sido considerados já satisfatórios os dados de frequências de soropositividade disponiveis (CAMARGO et al. ${ }^{33}$ 1984). Entretanto, como atesta o trabalho recente de FEITOSA e KRIEGER ${ }^{71}$ (1991) sobre estimativas de prevalência e análises de tendências de comportamento da infecção chagásica no Brasil, são ainda efetivamente escassos os dados disponíveis sobre a situação de São Paulo quanto à 
soropositividade para doença de Chagas. Esses autores ainda reportam informações, dentro do periodo de 1949 a 1976, algumas delas referentes a proporções de prevalência da infecção em bancos de sangue.

Os dados resgatados, até agora de dificil acesso, serão disponibilizados para ulteriores elaborações, como modelagem matemática, exemplificada em trabalhos de RABINOVICH et al. ${ }^{150}$ (1990), em área endêmica da Argentina e de VELASCOHERNANDEZ $^{206}$ (1991), sobre modelo teórico da dinâmica de transmissão, ou ainda estudos aplicados a estimativas de incidência a partir de dados de prevalência, como citado por HAYES e SCHOFIELD ${ }^{104}$ (1990). Mesmo prescindindo de recursos matemáticos não triviais, tratamentos simples por meio de estatística descritiva permitirão deles extrair informações relevantes de caráter epidemiológico. Por outro lado, seria razão suficiente para o resgate desses dados, a necessária atualização de informações soroepidemiológicas relativas à infecção chagásica em numerosos municípios do Estado de São Paulo, a respeito dos quais os relatos publicados remontam à década de 50

O Estado de São Paulo, tendo conseguido o status de pioneiro, no Brasil, por controlar a transmissão vetorial da doença de Chagas, não poderia deixar de ter registro do extenso trabalho de controle do vetor, particularmente o representado pelas atividades resultantes dos numerosos inquéritos sorológicos efetuados desde a década de 70. Após compilados e analisados, dados até então jacentes nos arquivos do Serviço de Combate ao Vetor, sobre a campanha de que resultou a interrupção da transmissão natural da doença de Chagas no Estado de São Paulo, tornar-se-ão acessíveis pela primeira vez aos pesquisadores em geral, servindo de exemplo oferecido aos demais Estados da Federação ou mesmo a paises vizinhos que não tenham ainda logrado resultados desejáveis no combate à infecção chagásica e a seus vetores ${ }^{2,13,130,145,196}$ 


\subsection{Tendências do diagnóstico sorológico}

Dados comparativos reportados por CAMARGO ${ }^{29}$ (1976) já apontavam para a possibilidade de adoção, além das técnicas de sorodiagnósticas correntes, de outras introduzidas após a década de 70, como as da imunoperoxidase, hemaglutinação, aglutinação de tripanossomas, aglutinação de látex sensibilizado e floculação de fragmentos de tripanossomas. Recomendavam, como critério de escolha para uso em inquéritos populacionais, a observação de sensibilidade e especificidade em pequenas quantidades de sangue obtido por punção digital e, por exemplo, absorvido em papelfiltro. Já para aplicação em diagnóstico individual e mesmo para exclusão de doadores de sangue, indicavam a utilização de um conjunto de técnicas que assegurem máxima sensibilidade

No final da década de 70 e início da de 80 , a técnica de imunoensaio enzimático (enzyme-linked immunosorbent assay - ELISA), passou a ser aplicada à infeç̧ão chagásica. Permite leitura instrumental dos resultados, pormenor de grande importância prática em epidemiologia, de que resultam eliminação do componente subjetivo e economia de tempo, assegurando a consistência de características de sensibilidade e especificidade dos melhores testes

Documento elaborado por GUIMARÃES ${ }^{101}$ (1984), sob o patrocínio da OPAS, fornece as especificações de reagentes utilizados em sorologia de infecção chagásica, em que se incluem técnicas vigentes, já bem estabelecidas, como as da imunofluorescência, hemaglutinação, fixação de complemento, floculação em lâminas de microscopia, aglutinação direta e ELISA. ZICKER et al. ${ }^{220}$ (1990), em trabalho recente, comparam as técnicas RIFI, IHA e ELISA, com a utilização de soros e eluatos de sangue de trabalhadores não qualificados, em Goiânia, GO. Apontam ELISA para fins epidemiológicos, tendo em vista a possibilidade de uso de eluatos de sangue, preservando sensibilidade, rendimento e baixo custo, além de leitura por meio de colorímetro fotoelétrico 
Estuda-se atualmente a deteç̧ão de frações outras das imunoglobulinas da classe das IgG, segundo SPINELLA et al. ${ }^{199}$ (1992). Esses autores observam a predominância de IgG2a, cerca de duas semanas após infecção experimental de camundongos por $T$. cruzi, persistente na fase crônica da infeç̧ão. Para a identificação dessas sub-classes de imunoglobulinas utiliza-se a técnica ELISA com antigenos devidamente purificados Detecção de anticorpos que reconhecem frações especificas de superficie de epimastigotas de $T$. cruzi, de determinados pesos moleculares, 72- e 90-kDa (KIRCHHOFF et al. ${ }^{108}$ 1987) também constitui promissor campo de possibilidades no diagnóstico laboratorial da infecção chagásica, principalmente por distingui-la de leishmanioses, evitando reações cruzadas (falso-positivas), comuns quando usadas técnicas sorológicas tradicionais (SCHATTSCHNEIDER et al. ${ }^{168}$ 1992)

A década de 90 assistiu a importantes progressos na investigação de genomas de muitos organismos, ai incluidos os protozoários, dentre os quais $T$. cruzi. Esses estudos, resultantes de projetos transnacionais de colaboração, abrem campos inimaginavelmente vastos de pesquisa, cujas consequências permeiam áreas relacionadas com a prevenção e eventual cura da doença de Chagas (DEGRAVE $t$ t al. ${ }^{60}$ 1997). Hoje, são objeto de estudos acadêmicos e práticos as técnicas baseadas na detecção de antígenos de parasitas por meio de recursos de biologia molecular, mais especificamente análises de kDNA (BRENER ${ }^{23} 1982$, WINCKER et al. ${ }^{216}$ 1994), nas quais é utilizada a reação em cadeia promovida por polimerase (polymerase chain reaction, PCR), como recomendado pela Organização Mundial da Saúde $\left(\right.$ WHO $\left.^{219} 1991\right)$. Essa técnica possibilita a amplificação de sequências nucleotidicas de DNA em quantidades diminutas, de outro modo não detectáveis, com elevadas sensibilidade e especificidade (ZINGALES ${ }^{221} 1993$ ).

Entretanto, apesar de muito apregoado, o uso de PCR no diagnóstico da infecção chagásica é encarado com cautela. Às dificuldades de padronização soma-se a facilidade de contaminação por amostras positivas e consequente ônus em termos de tempo e material necessário para descontaminação ${ }^{135}$. É ainda uma ferramenta reservada ao esclarecimento de casos não resolvidos por meio das técnicas convencionais ${ }^{166}$. 
É observável também a tendência à identificação, nos hospedeiros, de antigenos excretados por parasitas. Também neste caso se aplica ELISA (BRENIÉRE et al. ${ }^{24}$ 1997)

Segundo SEGURA* (1997) há, disponíveis no mercado, cerca de 30 "kits" para o diagnóstico sorológico da infeç̧ão chagásica com base em ELISA, em que se utilizam antigenos recombinantes. LUQUETTI"* (1999) observa que, dentre os diversos "kits" existentes no mercado, há aqueles que definitivamente não produzem bons resultados, alertando os pesquisadores para a necessidade de manterem rigoroso controle de qualidade dos testes

Em 1999, RABELLO et al. ${ }^{149}$ publicaram a descrição de uma nova técnica imunensaio em particula de gel (PaGIA) - com a utilização de peptídeos sintéticos representantes de sequências de $T$. cruzi em sua forma tripomastigota. Obtiveram resultados comparáveis aos das técnicas de imunofluorescência, hemaglutinação e ELISA e apresentaram, como vantagens, simplicidade de execução e demanda de apenas 20 minutos para executá-la. Obviamente, sempre que se adota uma nova técnica, é necessária a padronização e a verificação de replicabilidade. Ao que parece, o emprego de antígenos recombinantes em sendo mais acessiveis, serão uma ferramenta importante ao controle e vigilância de endemias, como a doença de Chagas.

\footnotetext{
- Elza Segura. conferência "Diagnóstico laboratorial" em "Simposio de enfermedad de Chagas" realizada durante XIII Congresso da Federação Latino Americana de Parasitologia em Havana. Cuba. novembro de 1997.

** Alejandro O. Luquetti. comunicação oral realizada na Sessão "Biología Molecular II - Trypanosoma spp", durante o XIV Congresso da Federação Latino Americana de Parasitologia, em Acapulco, México, 15 de outubro de 1999.
} 


\section{OBJETIVOS}

\subsection{Objetivo Geral}

Este trabalho tem como objetivo resgatar e analisar dados primários de sorologia da infecção chagásica de populações humanas do Estado de São Paulo, produzidos no Laboratório de Soroepidemiologia da Superintendência de Controle de Endemias SUCEN, desde sua implantação em 1972, até o ano de 1997, consolidando o máximo de informações existentes sobre a situação epidemiológica da doença nesse periodo

\subsection{Objetivos Específicos}

2.2.1 Analisar a evolução da prevalência de infecção chagásica recente em áreas submetidas a controle de vetores, em população de escolares da $1^{\mathrm{a}}$ série do $1^{\circ}$ grau de escolas rurais de 54 municipios do Estado de São Paulo, entre 1973 e 1983

2.2.2 Analisar dados sorológicos colhidos entre 1974 e 1976, referentes à população residente na zona rural do município de Taquarituba, área submetida a ações de controle de vetores e com persistência de $T$. infestans intradomiciliar, estimando a relação entre idade e sororreatividade para infecção chagásica no segmento da população com idades entre 6 e 30 anos

2.2.3 Comparar valores de soroprevalência da infecção chagásica, por grupo etário, obtidos entre 1976 e 1980, em áreas nas quais se admite a interrupção da transmissão vetorial em ocasiões diferentes, como os municípios das Microrregiões Campos de Itapetininga e da Encosta Ocidental da Mantiqueira Paulista 
2.2.4 Delinear perfis sorológicos e comparar as distribuições de títulos sorológicos para infecção chagásica das populações de áreas consideradas indenes (municipios do Vale do Ribeira: Cananéia e Iguape, e da Baixada Santista, Peruibe; dados de 1980 a 1982) e de áreas de transmissão vetorial sob controle no Estado de São Paulo (municípios das Microrregiões Campos de Itapetininga e Encosta Ocidental da Mantiqueira Paulista; dados entre 1976 e 1980)

2.2.5 Analisar pormenorizada e criticamente os resultados de aplicação de provas sorológicas, no período compreendido entre 1984 e 1997, referentes a habitantes de Unidades Domiciliares do Estado de São Paulo em que se encontraram triatomíneos infectados por T. cruzi ou com reação para hábito alimentar positiva para sangue humano ou ainda presença de $T$. infestans, como determina o Programa de Controle da Doença de Chagas (PCDCh). 


\section{METODOLOGIA}

\subsection{Metodologia sorológica}

A técnica sorológica utilizada, a reação de imunofluorescência indireta (RIFI), é executada em duas fases: na primeira o antígeno reage com anticorpos eventualmente presentes no soro a ser examinado; na segunda são evidenciados, por meio de fluorescência, os anticorpos existentes, mediante o uso de conjugado, composto de antiimunoglobulinas marcadas com isotiocianato de fluoresceina. Utilizou-se antígeno constituido por formas de cultivo de $T$. cruzi fixadas em lâminas de microscopia (CAMARGO ${ }^{27}$ 1966) com 20 áreas demarcadas, permitindo a execução de igual número de reações em cada ${ }^{38.74}$ Ulteriormente passaram a encontrar-se no mercado lâminas com $o$ antigeno previamente fixado. O material examinado era constituido por eluatos de sangue total, colhido em papel-filtro $O$ processo de eluição, simplificado por FERREIRA e CARVALHO ${ }^{74}$ (1973), passou a ser feito em "godets" de porcelana, com tampa, e não em tubos de ensaio. A quantidade de sangue contida em área superficial unitária de papelfiltro foi calculada de acordo com as recomendações de FERREIRA e CARVALHO ${ }^{75}$ (1982). Tendo em vista a marutenção da qualidade, essa operação sempre foi repetida quando do emprego de novos lotes de papel.

\subsubsection{Antígenos}

Culturas de T. cruzi (cepa "Y") foram inicialmente cedidas pelo Instituto Adolfo Lutz de São Paulo. Depois passaram a ser compradas, sob forma liofilizada, na unidade de vendas de reagentes desse Instituto. Após desativada essa área, as opções passaram a ser: amostras de culturas de T. cruzi do Laboratório de Protozoologia da SUCEN de MogiGuaçu, que utilizava a "cepa do Acre" (BARATA et al. ${ }^{14} 1988$ ) e antígenos comerciais, principalmente "Biolab" (Rio de Janeiro) e "Salck" (São Paulo). O preparo de lâminasantígeno, a partir de culturas de $T$. cruzi, seguiu técnica descrita por CAMARGO ${ }^{27}$ (1966) 


\subsubsection{Soros-controle}

Os soros-controle positivos e negativos foram fornecidos pelo Setor de Xenodiagnóstico do Instituto "Dante Pazzanese" de Cardiologia, da Secretaria de Estado da Saúde. No inicio da implantação do Laboratório de Sorologia na SUSAM, estes eram fornecidos por pessoal do Laboratório de produção de cultivos de $T$. cruzi do Instituto Adolfo Lutz de São Paulo

\subsubsection{Conjugados}

Sempre adquiridos no comércio, de preferência de fonte caprina, anti-IgG humana, marcas "BBL" e "Hyland" (norte-americanos), "Behring" (alemão ocidental), "Pasteur" (francès), "Biolab" (nacional. Rio de Janeiro), "Salck" (nacional, São Paulo). Importante salientar que sempre foram titulados em termos de maxima reatividade $\left(\mathrm{CAMARGO}^{28}\right.$, 1973 e conforme indicado em suas bulas), contra-coloração com Azul de Evans a $1: 10000$

\subsubsection{Colheita de amostras de sangue}

Os inquéritos soroepidemiológicos realizaram-se com sangue colhido de polpa digital em papel-filtro de diferentes procedências. Inicialmente usou-se o papel "Klabin 80", substituido por "Whatman" $\mathrm{n}^{\circ} 1$, equivalente em gramatura. A partir da década de 1980 adotou-se o papel "Whatman" $n^{\circ} 3$, que apresenta o dobro de absorção de sangue que o de $\mathrm{n}^{\circ} 1$. As quantidades de sangue absorvidas por $\mathrm{cm}^{2}$ de papel variam de lote para lote, sendo que os mais delgados contêm, por $\mathrm{cm}^{2}$ de papel, o equivalente a $6,9-7,2 \mu \mathrm{l}$ de soro; os de maior gramatura, de 14,9 a $15,4 \mu$ de soro

\subsubsection{As diluições de corte}

Nos primeiros trabalhos foi selecionada a diluição de corte $1: 40$, de acordo com o preconizado por CAMARGO e AMATO NETO $^{30}$ (1974). Em seguida, adotaram-se diluições segundo sequência logarítmica de base 2 , sendo $1: 32$ a diluição correspondente Com o objetivo de aumentar a sensibilidade das reações, mesmo em detrimento de perda 
de especificidade ${ }^{0.3}$, deliberou-se usar a diluição de corte 1:16, sugerida por SADUN et $a l{ }^{164}$ (1963). Entretanto, passaram-se a realizar habitualmente reações quantitativas, a fim de possibilitar a caracterização dos resultados dentro de seu espectro de distribuição e determinar a média geométrica dos títulos.

\subsection{Classificação epidemiológica de caso de infecção chagásica}

Merece destaque a classificação epidemiológica de casos de infecção chagásica adotada pela SUCEN e utilizada nos bancos de dados. É considerado AUTÓCTONE o de pessoa que a adquiriu em área de transmissão vetorial no Estado de São Paulo Dependendo de informações sobre ausência de deslocamentos, o caso pode ser admitido como AUTÓCTONE DO MUNICÍPIO ou DA REGIÃO em que foi detectado. A aquisição da infeç̧ão em área endèmica fora do Estado de São Paulo, caracteriza caso IMPORTADO Pairando dúvida quanto à sua procedência, isto é, observando-se tempos de residência compativeis com transmissão vetorial tanto no Estado de São Paulo como em outros de área endêmica para doença de Chagas, tem-se caso INDETERMINADO Considera-se o caso de transmissão por transfusão sangüínea ou mesmo por práticas de risco que possibilitem o contato de sangue ou de outro material contaminado por $T$. cruzi, como INDUZIDO e o de idade inferior a do período de ocorrência de transmissão vetorial na área, na ausência de indícios de outras formas de transmissão, com presença de mãe portadora de infecção chagásica, como CONGÊNITO. Quando vários mecanismos de transmissão são arrolados, o caso é classificado como INCONCLUSIVO

Formas de transmissão, embora não levem à classificação epidemiológica, denotam apenas a importância da via de aquisição, como a oral, por práticas de manipulação de risco e/ou ingestão de carcaças e de carnes de caça cruas ou mal cozidas, quanto à orientação de medidas que podem ser adotadas para seu controle. 


\subsection{Fonte de dados}

Dados primários de sorologia foram gerados no Laboratório de Soroepidemiologia da SUCEN, desde sua origem, em 1972. Para comparações, dados anteriores a esse ano foram colhidos na literatura. O Quadro 3.3 resume a fonte de dados de acordo com o grupo populacional envolvido.

Quadro 3.3 - Informações sobre as fontes de dados referentes à sorologia para infecção chagásica no Programa de Controle do Estado de São Paulo, entre 1973 e 1997.

\begin{tabular}{|c|c|}
\hline $\begin{array}{l}\text { População estudada e } \\
\text { Periodo de observação }\end{array}$ & Fontes de dados e Localização de arquivos \\
\hline $\begin{array}{l}\text { População amostrada de } \\
\text { escolares de } 1^{a} \text { série do } 1^{\circ} \\
\text { grau de escolas da zona } \\
\text { rural de } 54 \text { municipios do } \\
\text { Estado (Fig. 2). } \\
\text { (1973 a 1983) }\end{array}$ & $\begin{array}{l}\text { - Boletins SUCEN } 246 \text { - "Doença de Chagas - Resumo mensal } \\
\text { das amostras de sangue" e resumos anuais do Lab. de Soroepi- } \\
\text { demiologia, com resultados de reações de imunofluorescência } \\
\text { indireta-RIFI- examinadas, negativas, reagentes e duvidosas, } \\
\text { por Serviço Regional (SR) da SUCEN e por Municipio, entre } \\
\text { os anos de } 1973 \text { e } 1983 \text {. } \\
\text { - Boletins SUCEN-248 e SUCEN-248A, de identificação de } \\
\text { amostras colhidas, por Serviço Regional, Municipio e Ano. } \\
\text { Arquivo do Lab. Soroepidemiologia. } \\
\text { - Boletins SUCEN/ Depto. de Combate a Vetores (DCV) / } \\
\text { Divisão de Orientação Técnica (DOT)- Seção de Epidemiolo- } \\
\text { gia (DOT-1) "Inquérito de escolares: investigação de caso de } \\
\text { infecção chagásica". Arquivo do Lab. de Soroepidemiologia. }\end{array}$ \\
\hline $\begin{array}{l}\text { População residente em } 5 \\
\text { Localidades (Bairros) do } \\
\text { municipio de Taquarituba } \\
\text { (Figs } 3 \text { e } 4 \text { ) } \\
\text { (1974 a 1976) }\end{array}$ & $\begin{array}{l}\text { - Boletins de identificação de amostras colhidas (nome, idade, } \\
\text { sexo, endereço, tempo de moradia na casa, naturalidade) e } \\
\text { resultado de RIFI em } 1974 \text { e em 1976. Arquivo do Lab. de } \\
\text { Soroepidemiologia. }\end{array}$ \\
\hline $\begin{array}{l}\text { População amostrada dos } \\
\text { municipios das Micror- } \\
\text { regiões Homogêneas } \\
\text { Campos de Itapetininga } \\
\text { (1976 a 1978) e Encosta } \\
\text { Ocidental da Mantiqueira } \\
\text { Paulista (1980) (Fig. 4). }\end{array}$ & $\begin{array}{l}\text { - Boletins de identificação de amostras colhidas (nome, idade, } \\
\text { sexo, endereço, tipo de moradia, tempo de moradia na casa, } \\
\text { presença de "barbeiros" na casa e resultado de RIFI) por } \\
\text { Municipio e por Localidade. Arquivo do Lab. de Soroepide- } \\
\text { miologia. }\end{array}$ \\
\hline
\end{tabular}




\begin{tabular}{|c|c|}
\hline $\begin{array}{l}\text { Populações residentes } \\
\text { dos municipios de } \\
\text { Cananéia, Iguape e } \\
\text { Peruibe (Fig. 4) } \\
\text { (1980 a 1982) }\end{array}$ & $\begin{array}{l}\text { - Boletins de identificação de amostras colhidas, por Municipio } \\
\text { e por Localidade. Arquivo do Lab. de Soroepidemiologia. } \\
\text { - Fichas de investigação epidemiológica de caso de infecção } \\
\text { chagásica, contendo informações sobre identificação, história } \\
\text { do caso (antecedentes, hábitos e movimentação do caso), } \\
\text { história da casa, apreciação do caso em relação à casa e à } \\
\text { Localidade onde o mesmo foi descoberto e classificação do } \\
\text { caso. Arquivo do Lab. de Soroepidemiologia. }\end{array}$ \\
\hline $\begin{array}{l}\text { População moradora em } \\
\text { Unidades Domiciliares } \\
\text { inseridas no Programa de } \\
\text { Controle da Doença de } \\
\text { Chagas - PCDCh. } \\
\text { (1984 a 1997) }\end{array}$ & $\begin{array}{l}\text { - Boletins de identificação de amostras colhidas, por SR, } \\
\text { Municipio, Localidade e Ano. Arquivo do Lab. de Soroepide- } \\
\text { miologia. } \\
\text { - Lista de códigos de Localidades e de Municipios do Estado. } \\
\text { Arquivo da DOT/SUCEN. } \\
\text { - Boletins ME } 503 \text { "Hábito alimentar"e ME 502A "Unidade } \\
\text { Domiciliar Positiva" contendo informações sobre triatomineos } \\
\text { capturados: espécie, fase evolutiva, infecção por T. cruzi, local } \\
\text { de captura e resultado de exame de identificação de hábito } \\
\text { alimentar, complementados por Boletins ME 504 "Exame } \\
\text { sorologico (RIFI)". Arquivo Morto do DCV e de SRs da } \\
\text { SUCEN. } \\
\text { - Formulários SUCEN-294: "Boletim de Captura de Triatomi- } \\
\text { neos" e SUCEN-290: "Boletim Diário de Pesquisa e Rociado", } \\
\text { contendo resumo de atividades das operações de pesquisa de } \\
\text { exemplares de triatomineos realizadas pelo desinsetizador, por } \\
\text { Municipio, Localidade e Unidade Domiciliar. Arquivos mortos } \\
\text { do DCV e dos SRs da SUCEN. } \\
\text { - Livros de registro de notificações de triatomineos do Serviço } \\
\text { Regional da SUCEN de São Vicente, de } 1984 \text { a 1997. } \\
\text { - Livros de registro de hábito alimentar ("Precipitina") de } \\
\text { triatomineos, entre } 1984 \text { e 1986, por Serviço Regional da } \\
\text { SUCEN. Arquivo do Lab. de Parasitoses por Flagelados } \\
\text { ("DOT-3") de Mogi-Guaçu. } \\
\text { - Planejamentos e Relatórios de Avaliação dos Serviços Regio- } \\
\text { nais da SUCEN, de } 1983 \text { a 1997. Arquivos do DCV. } \\
\text { - Fichas de investigação epidemiologica de casos reagentes } \\
\text { sorológicos dos Serviços Regionais da SUCEN. Arquivos do } \\
\text { Lab. de Soroepidemiologia, da DOT e dos respectivos SRs. }\end{array}$ \\
\hline
\end{tabular}




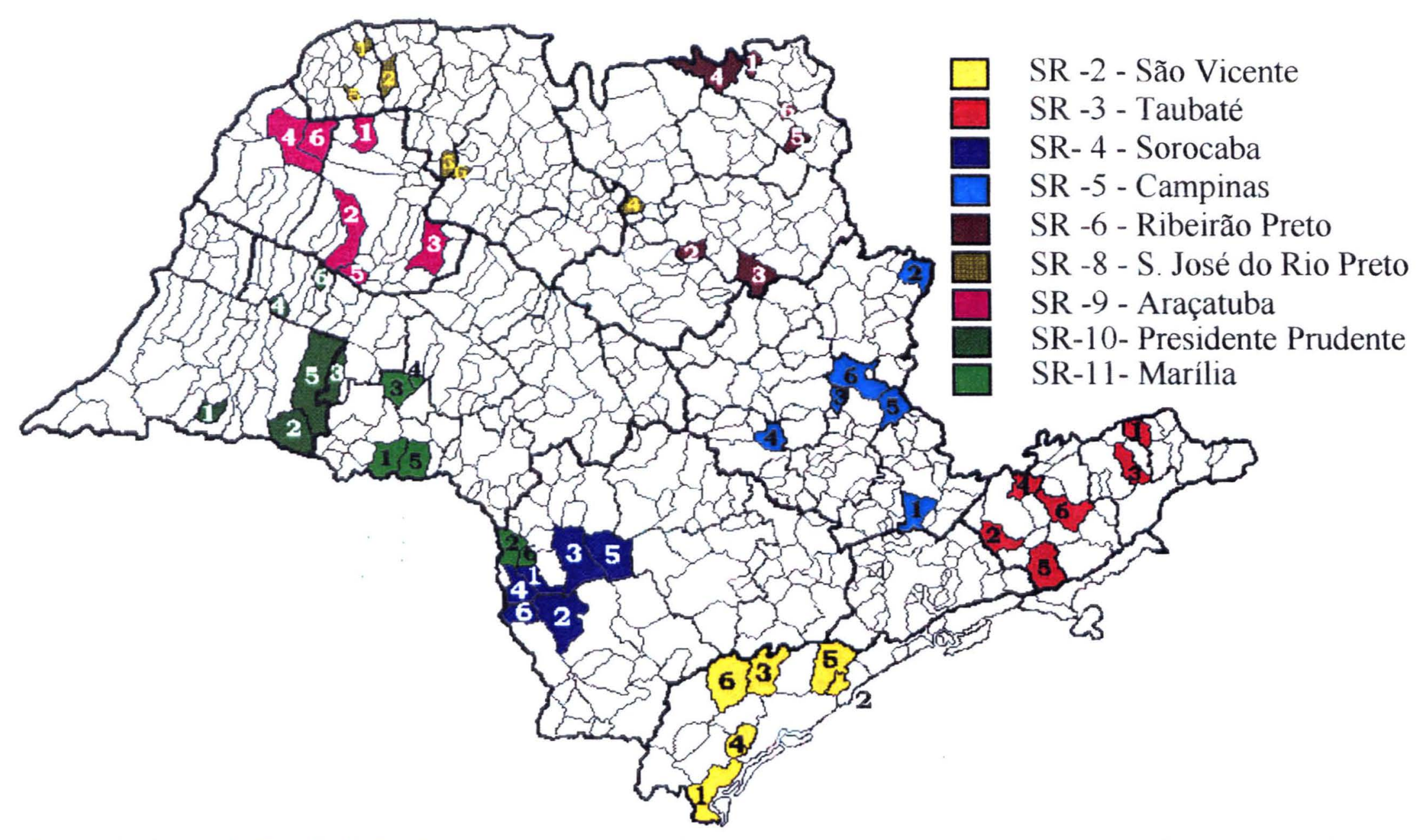

Figura 2 - Mapa do Estado de São Paulo com a indicação dos 54 municípios trabalhados em sorologia de escolares da $1^{\mathrm{a}}$ série do $1^{\circ}$ grau, de zona rural, nos diferentes Serviços Regionais (SRs) da SUCEN, entre 1973 e 1983. (Legendas dos municípios na página seguinte) 
Legenda da Figura 2 - Lista dos municipios trabalhados em sorologia de escolares da $1^{\mathrm{a}}$ série do $1^{\circ}$ grau, de zona rural, nos diferentes Serviços Regionais (SRs) da SUCEN, entre 1973 e 1983.

\section{SR 2 - SÃO VICENTE}

1- Cananéia

2- Itariri

3- Juquiá

4- Pariquera-Açu

5- Pedro de Toledo

6- Sete Barras
SR 3 - TAUBATÉ

1 - Cruzeiro

2- Jacareí

3- Lorena

4- Monteiro Lobato

5- Paraibuna

6- Taubaté
SR 4 - SOROCABA

1- Cel. Macedo

2- Itaberá

3- Itaí

4- Itaporanga

5- Paranapanema

6- Riversul
SR 5 - CAMPINAS

1. Atibaia

2. Caconde

3. Conchal

4. Iracemápolis

5. Itapira

6. Mogi-Guą̧u
SR 6 - RIB. PRETO

1. Aramina

2. Guariba

3. Luiz Antônio

4. Miguelópolis

5. Restinga

6. Ribeirão Corrente
SR 8 - S. J. RIO PRETO

1. Dolcinópolis

2. Estrela D'Oeste

3. Macaubal

4. Paraiso

5. São Francisco

6. União Paulista

\section{SR 9 - ARAÇATUBA}

1. Auriflama

2. Guararapes

3. Penápolis

4. Pereira Barreto

5. Piacatu

6. Sud-Menucci
SR 10 - PRES. PRUDENTE SR 11 - MARÍLIA
1. Estrela do Norte
2. Iepè
3. João Ramalho
4. Mariápolis
5. Rancharia
6. Salmorão

1. Cândido Mota

2. Fartura

3. Lutécia

4. Oscar Bressane

5. Palmital

6. Taguaí 


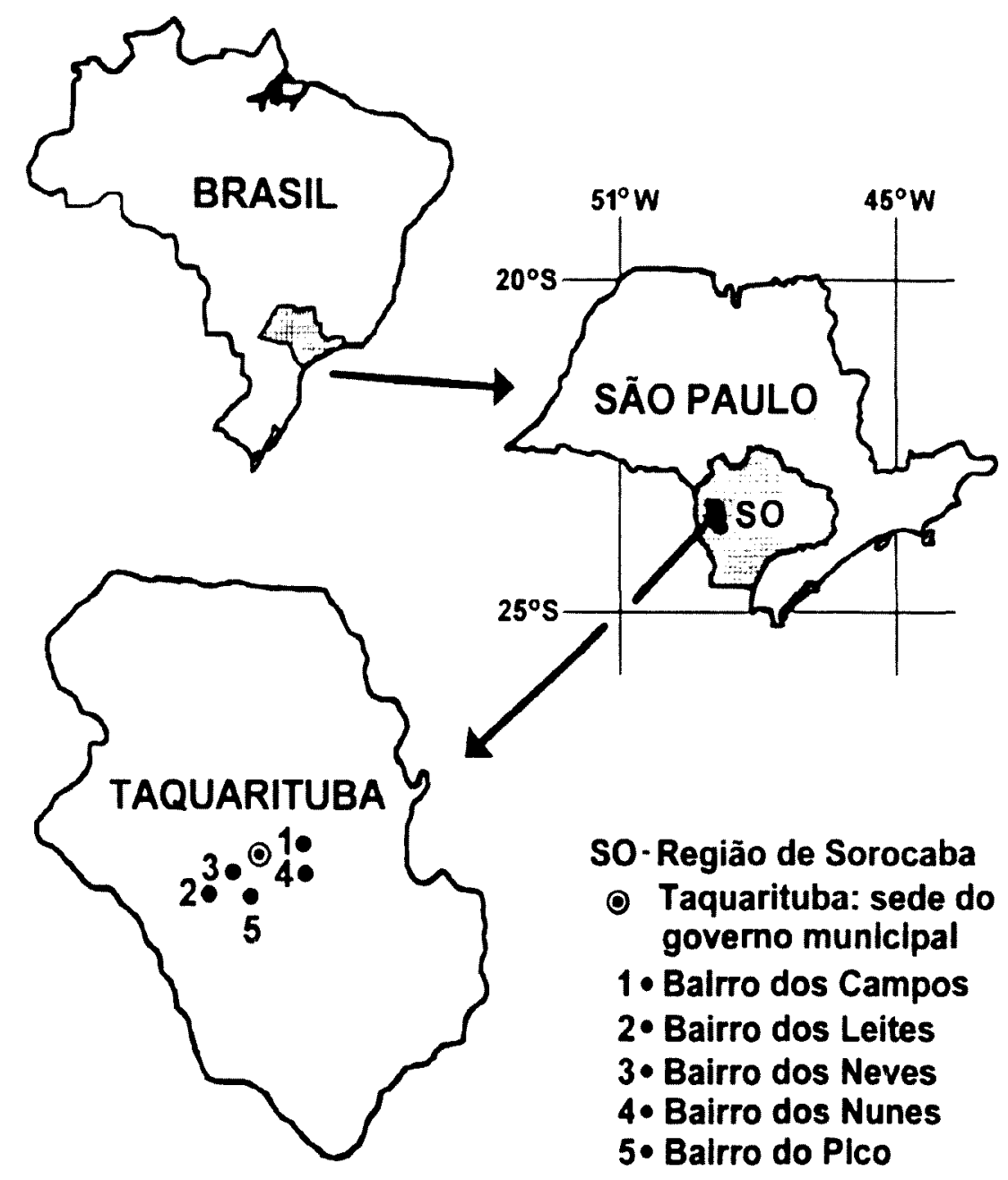

Figura 3. Localização dos Bairros trabalhados em sorologia de infecção chagásica no município de Taquarituba, Estado de São Paulo, 1974 a 1976. 


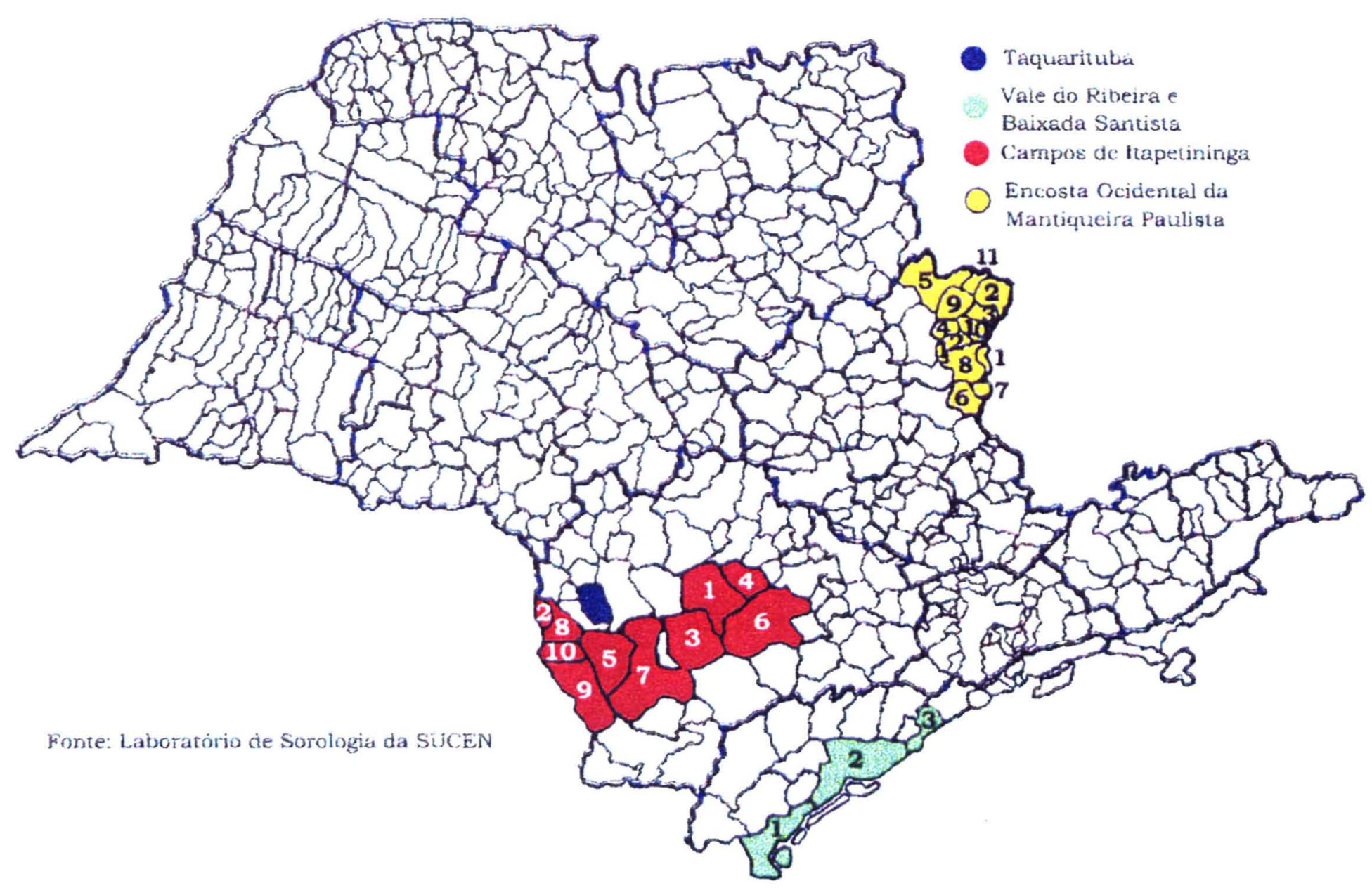

Figura 4 - Mapa do Estado de São Paulo com indicação de municipios trabalhados: Taquarituba; do Vale do Ribeira, da Baixada Santista, das Microrregiões Campos de Itapetininga e Encosta Ocidental da Mantiqueira Paulista, entre 1974 e 1982. (Legenda dos municípios na página seguinte) 
Legenda da Figura 4 - Lista dos municipios trabalhados em sorologia: Taquarituba, Vale do Ribeira, Baixada Santista e das Microrregiões Homogèneas Campos de Itapetininga e Encosta Ocidental da Mantiqueira Paulista

VALE DO RIBEIRA

1 - Cananéia

2 - Iguape

BAIXADA SANTISTA

3 - Peruibe

MICRORREGIÃO CAMPOS DE ITAPETININGA

1 - Angatuba

2 - Barão de Antonina

3 - Buri

4 - Guareí

5 - Itaberá

6 - Itapetininga

7 - Itapeva

8 - Itaporanga

9 - Itararé

10 - Riversul

MICRORREGIĀo ENCOSTA OCIDENTAL DA MANTIQUEIRA PAULISTA

1 - Águas da Prata

2-Caconde

3 - Divinolândia

4 - Itobí

5 - Mococa

6 - Espírito Santo do Pinhal

7 - Santo Antônio do Jardim

8 - São João da Boa Vista

9 - São José do Rio Pardo

10- São Sebastião da Grama

11- Tapiratiba

12- Vargem Grande do Sul 


\subsection{Populações de estudo e análise de dados de levantamentos sorológicos realizados no Estado de São Paulo}

Por abranger trabalhos de diferentes periodos de execução, a metodologia também foi diferente, à medida que os procedimentos técnicos foram sendo aperfeiçoados e modificados com o tempo. Assim, optou-se por apresentar, em cada grupo populacional perquirido, a declaração dos pormenores metodológicos envolvidos. Foram criados bancos de dados em programa FoxPro ${ }^{T M}$ para Windows ${ }^{T M}$, para processar informações sobre as populações incluidas nas fases do trabalho relacionadas no Quadro 3.4. Análises de frequências foram obtidas em Programa Epi-Info ${ }^{59}$

Quadro 3.4 - Informações sobre as populações incluidas nos estudos sorológicos.

\begin{tabular}{|l|l|l|}
\hline População estudada & $\begin{array}{l}\text { Período de } \\
\text { observação }\end{array}$ & Bancos de dados - Variáveis observadas \\
\hline $\begin{array}{l}\text { População amostrada de } \\
\text { escolares de } 1^{2} \text { série do } 1^{\circ} \\
\text { grau de escolas da zona } \\
\text { rural de 54 municipios do } \\
\text { Estado (Fig. 2) }\end{array}$ & 1973 a 1983 & $\begin{array}{l}\text { Banco 1. Serviço Regional, Municipio, Ano, } \\
\text { Número de amostras examinadas, Número de } \\
\text { amostras reagentes, Número de amostras } \\
\text { duvidosas. } \\
\text { Banco 2. Serviço Regional, Município, Ano, } \\
\text { Idade e Sexo. } \\
\text { Banco 3. Serviço Regional, Ano, Idade, Sexo, } \\
\text { Ano de nascimento, Número de amostras } \\
\text { examinadas, Número de amostras reagentes no } \\
\text { total, na familia e nos vizinhos, Classificação } \\
\text { epidemiológica de caso reagente sorológico, } \\
\text { Unidade Federativa dos casos e Grau de } \\
\text { parentesco com o caso. }\end{array}$ \\
\hline $\begin{array}{l}\text { População residente nas } \\
\text { Localidades (Bairros): } \\
\text { dos Campos, dos Leites, } \\
\text { dos Neves, dos Nunes e } \\
\text { do Pico, no municipio de } \\
\text { Taquarituba (Figs. 3 e 4) }\end{array}$ & 1974 a 1976 & $\begin{array}{l}\text { Banco 4. Localidade, Numero da casa, Nome, } \\
\text { Idade, Sexo, Tempo de moradia na casa, } \\
\text { Naturalidade, Resultado de RIFI em 1974 e } \\
\text { Resultado de RIFI em 1976. }\end{array}$ \\
\begin{tabular}{l} 
(2 784 amostras) \\
\hline
\end{tabular} & & \\
\hline
\end{tabular}




\begin{tabular}{|c|c|c|}
\hline $\begin{array}{l}\text { População amostrada dos } \\
\text { municipios da } \\
\text { Microrregião Homogènea } \\
\text { Campos de Itapetininga } \\
\text { (Fig. 4) } \\
\text { (15 } 117 \text { amostras) }\end{array}$ & 1976 a 1978 & $\begin{array}{l}\text { Banco 5. Município, Localidade, Nome, Idade, } \\
\text { Sexo, Número da casa, Tipo de moradia, Tempo } \\
\text { de moradia na casa, Presença de "barbeiros" na } \\
\text { casa, Resultado de RIFI expresso em título. }\end{array}$ \\
\hline $\begin{array}{l}\text { População amostrada dos } \\
\text { municípios da } \\
\text { Microrregião Homogènea } \\
\text { Encosta Ocidental da } \\
\text { Mantiqueira Paulista (Fig. } \\
\text { 4) } \\
\text { (16 351 amostras) }\end{array}$ & 1980 & $\begin{array}{l}\text { Banco 6. Municipio, Localidade, Nome, Idade, } \\
\text { Sexo, Número da casa, Tipo de moradia, Tempo } \\
\text { de moradia na casa, Presença de "barbeiros" na } \\
\text { casa, Resultado de RIFI expresso em titulo. }\end{array}$ \\
\hline $\begin{array}{l}\text { Populações residentes de } \\
\text { Cananéia, Iguape e } \\
\text { Peruibe (Fig. 4) } \\
\text { (17 } 075 \text { amostras) }\end{array}$ & 1980 a 1982 & $\begin{array}{l}\text { Bancos } 7 \text { a 9, referentes a cada município, } \\
\text { digitados separadamente. Localidade, Número da } \\
\text { casa, Idade, Sexo, Resultado de RIFI expresso em } \\
\text { título, Tempo de moradia na área } \\
\text { Variáveis observadas em fichas de investigação } \\
\text { epidemiológica de caso reagente sorológico de } \\
\text { idades inferiores a } 15 \text { anos: Idade, Sexo, } \\
\text { Naturalidade, Classificação epidemiológica de } \\
\text { caso de infecção chagásica, Observações } \\
\text { sorológicas relativas a familiares próximos. }\end{array}$ \\
\hline $\begin{array}{l}\text { População moradora em } \\
\text { Unidades Domiciliares } \\
\text { inseridas no Programa de } \\
\text { Controle da Doença de } \\
\text { Chagas (PCDCh) } \\
\text { ( } 17286 \text { amostras) }\end{array}$ & 1984 a 1997 & $\begin{array}{l}\text { Bancos } 10 \text { a } 23 \text {, referentes a cada ano trabalhado, } \\
\text { digitados separadamente. Serviço Regional, } \\
\text { Municipio, Localidade, Número da casa, Idade, } \\
\text { Sexo, Resultado de RIFI expresso em título, Tipo } \\
\text { de atendimento e informações sobre os } \\
\text { triatomineos capturados: Espécie, Fase evolutiva, } \\
\text { Infecção por } T \text {. cruzi, Local de captura, } \\
\text { Resultado de exame de identificação de hábito } \\
\text { alimentar (se Humano ou de outra fonte). } \\
\text { Variáveis adicionais observadas em fichas de } \\
\text { investigação epidemiológica de caso reagente } \\
\text { sorologico: Naturalidade, Tempo de residência na } \\
\text { área. }\end{array}$ \\
\hline
\end{tabular}




\subsubsection{População amostrada de escolares de 54 municípios de diferentes Regiões do Estado de São Paulo, 1973 a 1983.}

O levantamento sorológico para infecção chagásica entre alunos da primeira série do primeiro grau, matriculados em escolas de zonas rurais de municipios selecionados dos Serviços Regionais da SUCEN (Figura 2) foi desenvolvido no periodo de 1973 a 1983. Deste trabalho foram excluidas a Região da Grande São Paulo e, até 1981, também a Região de Taubaté, que foi criada como Serviço Regional da SUCEN apenas nessa data. Limitações de ordem operacional e de recursos orçamentários impuseram a utilização de inquéritos de prevalência em escala bem mais reduzida do que a considerada necessária para dar continuidade à investigação iniciada entre escolares em $1968^{96}$. A seleção dos municipios incluidos foi baseada naqueles que, dentre os de maiores proporções de soroprevalência também compartilhassem proximidade geográfica. Em cada Serviço Regional foram selecionados 6 municípios, com base em inquérito sorológico realizado de 1968 a 1970, abrangendo crianças de 9 a 14 anos, em todo o Estado, excetuando-se os da Grande São Paulo (GUARITA et al. ${ }^{96} 1978$ ).

Ao todo foram trabalhados 48 municipios até 1981 e, com a inclusão do Serviço regional da SUCEN de Taubaté, o número de municípios passou a 54 (relacionados na legenda da Figura 2). Desta Regional, os municípios do Litoral Norte pertenciam à de São Vicente e os do Vale do Paraiba, ao Nivel Central da SUCEN. Por meio de amostragem estratificada por conglomerado, tendo como variável o número de escolas rurais do primeiro grau existentes nos municípios selecionados, obteve-se a média de 3000 alunos por ano, distribuidos entre as escolas sorteadas.

Foi aplicada análise de regressão ${ }^{58}$ para a observação de tendência anual de prevalência da infecção chagásica, em indicador criança nascida após campanha de combate a vetores. Com a finalidade de caracterizar a população dos escolares quanto ao sexo e à média de idade utilizou-se uma amostra de 10\% de cada Serviço Regional.

Neste trabalho entre escolares da primeira série do primeiro grau, de escolas das zonas rurais dos municipios selecionados, foi adotada diluição de corte de 1:32. A reação era realizada apenas de forma qualitativa. Sendo a leitura visual e sujeita a erros de 
interpretação subjetiva, ainda que se adotasse critério de intensidade de fluorescência para a decisão do resultado, alguns padrões de fluorescência eram, obviamente, fracos em relação ao observado no controle reagente. Por esse motivo, alguns resultados foram fornecidos como duvidosos $(0,19 \%$ dos casos). Estes podem ser atribuidos a falsos reagentes ou limiares de reatividade (LUQUETTI et al. ${ }^{119} 1999$ ) ou a niveis iniciais de anticorpos em um curso normal de infecção, cujos aumentos podem ser acompanhados em amostras obtidas em periodos subsequentes (FORATTINI et al. ${ }^{85} 1981$ ). Nos resultados analisados especificamente nesse estudo, consideram-se apenas os que foram reagentes à diluição de corte. Assim, deixaram de ser considerados no cálculo de percentuais de reatividade, os seguintes números de amostras, por Serviço Regional:

SR-2 - São Vicente: 5 amostras; SR-4 - Sorocaba: 26 amostras; SR-5 - Campinas: 6 amostras; SR-6 - Ribeirão Preto: 13 amostras; SR-9 - Araçatuba: 1 amostra; SR-10 Presidente Prudente: 7 amostras e SR-11 - Marilia: 5 amostras

Para efeito de investigações epidemiológicas, entretanto, os casos foram averiguados, na medida do possivel

\subsubsection{População de 5 localidades rurais do município Taquarituba, 1974-1976.}

\subsubsection{Antecedentes}

Trabalho de epidemiologia de infecção chagásica, realizado entre 1974 e 1976, abrangeu aproximadamente 1900 amostras de moradores de 5 localidades: Bairro dos Campos, Bairro dos Neves, Bairro dos Nunes, Bairro dos Leites e Bairro do Pico (Figura 3), representativas das 22 de zona rural existentes no município de Taquarituba. A população total do município era, na ocasião do estudo, de 13964 habitantes, dos quais 7606 de zona rural ${ }^{91}$. Os critérios para a seleção dessas localidades foram condições epidemiológicas semelhantes de transmissão da doença de Chagas e proximidade geográfica, que facilitava os trabalhos de supervisão de campo (MELLO et al. ${ }^{128}$ 1977). Taquarituba situa-se na Região de Sorocaba, Região de Governo Avaré (Figuras 3 e 4), onde predominava $T$. infestans. Nesta região, durante o inquérito sorológico realizado em população de escolares com idades entre 9 e 14 anos entre 1968 e 1970, revelaram-se 
positivas 87 amostras dentre 820 colhidas $(10,6 \%)$. Neste mesmo inquérito, o municipio apresentou uma positividade de $11,6 \%$ (GUARITA et al. ${ }^{96} 1978$ ).

Esse trabalho buscou observar a ocorrência de infecção chagásica em área de persistência de infestação domiciliar por $T$. infestans. A soropositividade encontrada foi de aproximadamente $14 \%$ no conjunto de todas as idades (CARVALHO et al. ${ }^{37}$ 1977) Investigações realizadas em cerca de $70 \%$ dos casos demonstraram $50 \%$ de autoctonia. Nenhum caso autóctone de menos de 7 anos foi observado (MELLO et al. ${ }^{128} 1977$ )

\subsubsection{Estimativa da relação entre idade e sororreatividade para infecção chagásica}

Utilizando-se metodologia descritiva de estudo transversal (FORATTINI ${ }^{81}$ 1992), os resultados sorológicos foram associados às variáveis localidade, idade, sexo, tempo de moradia na casa e naturalidade Diferenças entre proporções de soropositivos por localidade, idade e sexo foram analisadas estatisticamente (DAWSON-SAUNDERS \& TRAPP $^{58}$ 1994). Por tratar-se de população exposta, durante um certo período, ao risco de transmissão vetorial (admitido como invariante), formulou-se hipótese segundo a qual o tempo de exposição equivaleu a dose e a transição de um habitante de soronegativo para soropositivo a resposta (antes de evidenciar-se a eficácia das medidas de controle de populações de vetores). Portanto há apenas dois tipos possíveis de respostas: falso e verdadeiro, o que sugere a avaliação da relação dose-resposta por meio de análise de probitos (FINNEY ${ }^{80} 1980$ ), utilizada correntemente em ensaios biológicos, com fármacos em geral. Para o cálculo de probitos selecionaram-se dados de um grupo de pessoas no qual a soropositividade aumentou com a idade, correspondendo aos nascidos entre $1944 \mathrm{e}$ 1969 (idades entre 6 e 30 anos). Aplicou-se a equação $y=5+1 / \sigma(x-\mu)$, sendo $x$ e $y$ respectivamente os valores de dose (médias de idade) transformadas em logaritmos e proporções esperadas de respostas (soropositivos) transformadas em probitos. Médias e desvio-padrão das doses foram representadas, respectivamente, por $\mu$ e $\sigma$ (CARVALHO et al. $\left.{ }^{40} 2000\right)$ 


\subsubsection{População amostrada dos municípios das Microrregiões Campos de} Itapetininga, 1976-1978 e Encosta Ocidental da Mantiqueira Paulista, 1980.

As microrregiões homogêneas Campos de Itapetininga e Encosta Ocidental da Mantiqueira Paulista são áreas de colonização pretérita por T. infestans (SILVA ${ }^{189} 1981$ ), hoje dominadas por Panstrongylus megistus (Burmeister, 1835). Municipios que as compõem: da Microrregião Campos de Itapetininga, Angatuba, Barão de Antonina, Buri, Guarei, Itaberá, Itapetininga, Itapeva, Itaporanga, Itararé e Ribeirão Vermelho do Sul, atual Riversul e, da Microrregião Encosta Ocidental da Mantiqueira Paulista, Águas da Prata, Caconde, Divinolândia, Itobi, Mococa, Espírito Santo do Pinhal, Santo Antônio do Jardim. São João da Boa Vista, São José do Rio Pardo, São Sebastião da Grama, Tapiratiba e Vargem Grande do Sul (Figura 4)

As populações das localidades selecionadas nessas duas microrregiões foram submetidas à investigação sorológica para infecção chagásica, como parte de um projeto denominado "Quadro epidemiológico da doença de Chagas, estrutura agrária e programa de controle de vetores em São Paulo", integrado entre SUCEN e Departamento de Medicina Preventiva da Faculdade de Medicina da USP, parcialmente financiado pelo Conselho Nacional de Pesquisa (CNPq). Três aspectos foram abordados nesse Projeto: prevalência da infecção chagásica; relações entre a doença de Chagas e modificações de estrutura agrária e avaliação do Programa de Controle em uma perspectiva histórica. Entre 1976 e 1978 foram trabalhadas cerca de 15000 amostras na microrregião Campos de Itapetininga, selecionadas a partir de população de 113265 habitantes dos 10 municípios e de 322 localidades que a compunham (LITVOC et al. ${ }^{115}$ 1979, MALUF et al. ${ }^{124}$ 1979). $\mathrm{Na}$ área da Encosta Ocidental da Mantiqueira Paulista foram processadas cerca de 16000 amostras procedentes de 12 municípios e 142 localidades, em 1980 (CARVALHO et al. ${ }^{36}$ 1980). Foram observadas baixas prevalências em grupos de idade inferiores a $10 \operatorname{anos}^{25}$

Para verificar-se a curva de endemicidade característica de cada microrregião, perfis sorológicos foram associados à distribuição de títulos das reações $\left(\mathrm{KAGAN}^{106}\right.$ 
1973). Testes de diferenças de proporções ${ }^{58}{ }^{195}$ foram aplicados a comparação de prevalèncias por grupos etários especificos.

\subsubsection{População rural dos municipios: Cananéia, Iguape e Peruíbe, 1980-1982.}

Entre 1980 e 1982 realizaram-se inquéritos sorológicos transversais para infeç̧ões chagásica e malárica em populações dos municipios de Peruibe, da Baixada Santista e Cananeia e Iguape, do Vale do Ribeira (Figura 4), pertencentes, por sua vez, ao Serviço Regional da SUCEN de São Vicente, abrangendo cerca de 20000 amostras. Áreas tradicionalmente conhecidas como de transmissão de malária em baixos niveis ${ }^{34}$ são tambem consideradas indenes para doença de Chagas $^{211}$ As espécies de vetores registradas são Triatoma tibiamaculata Pinto, 1926, P. megistus e Rhodmius domesticus Neiva e Pinto, 1923 (FORATTINI et al. ${ }^{84}$ 1980). O perfil sorológico correspondente à população desta área constituiu importante ponto de comparação com as demais áreas do Estado de São Paulo, como controle negativo.

\subsubsection{População de Unidades Domiciliares inseridas no Programa de Controle da Doença de Chagas (PCDCh) entre 1984 e 1997.}

Cerca de 17000 registros foram tabulados por Serviço Regional (SR) da SUCEN: Grande São Paulo (SR-1), São Vicente (SR-2), Taubaté (SR-3), Sorocaba (SR-4), Campinas (SR-5), Ribeirão Preto (SR-6), São José do Rio Preto (SR-8), Araçatuba (SR9), Presidente Prudente (SR-10) e Marilia (SR-11), que inclui a região de Bauru, antigo SR-7

Caracteristicas associadas ao vetor e presença de sororreagente na casa foram avaliadas por teste de associação "odds ratio" com $95 \%$ de confiança ${ }^{58}$. Diferenças entre proporções de sororreatividade entre sexos e entre regiões foram calculadas por meio de testes de aderência a $95 \%$ de confiança (teste " $G$ ") ${ }^{195}$. Na comparação de resultados entre as Regionais, considerou-se a representada por São Vicente, que adotou estratégia de uso da sorologia diversa da preconizada no Programa em 1984, como "área controle negativo". 


\subsubsection{Generalidades do PCDCh}

Em 1984 encontrava-se o Programa de Controle da Doença de Chagas (PCDCh) no Estado de São Paulo na fase de vigilância entomológica, com o trabalho voltado para atividades de rotina de busca de triatomineos vetores em todas as casas e seus anexos, na zona rural e na periferia dos municípios infestados, seguida de tratamento químico daquelas que se mostravam positivas. Os municipios eram classificados em termos de prioridades (I, II e III), de acordo com as seguintes condições: I - presença de $T$. infestans em quaisquer niveis; II - presença de outras espécies consideradas secundárias, principalmente Triatoma sordida (Stäl, 1859) e P. megistus e III - ausência de triatomineos vetores ou sua presença eventual. Eram trabalhados com distintas periodicidades: anuais (Prioridade I), bienais (Prioridade II) e trienais (Prioridade III) ${ }^{158 .}$ 198. Encontravam-se 4 municípios em PI, 190 em PII e 285 em PIII ${ }^{198}$, totalizando 479 de 572 existentes no Estado ${ }^{92}$, excluidos apenas os pertencentes às regiões da Grande São Paulo, de Taubaté e os da maior parte de São Vicente. Nestes, a pesquisa de triatomíneos dava-se por meio de notificação de "barbeiros", realizada pelos próprios moradores. É importante salientar que esta atividade era preconizada para todo o Estado ${ }^{158 .}{ }^{198}$. Postos de Identificação de Focos de Triatomineos (PIFTs), instalados em Escolas e Unidades de Saúde de diversos municipios, integrados com as atividades da SUCEN, contribuiam decisivamente para o desencadeamento da pesquisa do vetor ${ }^{25.154 .191 .211}$.

Observado em pesquisas de rotina que a distribuição de triatomíneos vetores nos municípios não era homogênea, mas restrita a focos dentro de suas localidades ${ }^{25}$, estudouse, durante o ano de 1984, em uma área do Estado compreendida pelo Serviço Regional de Araçatuba, a passagem da Unidade de Trabalho para Localidade, utilizando-se os critérios de prioridades adotados nos municípios ${ }^{174}$. No ano seguinte, tendo essa nova metodologia sido considerada adequada ao propósito de racionalização de recursos e de rendimento técnico-operacional apropriado, a orientação foi adotada em todo o Estado. Quanto à Prioridade III o intervalo entre pesquisas de rotina passou de 3 para 4 anos (ROCHA E SILVA et al. ${ }^{160}$ 1998). Em decorrência disto, 100\% das localidades em PI, $50 \%$ em PII e $25 \%$ em PIII foram trabalhadas rotineiramente todos os anos, procurandose obedecer a cronogramas delineados em função das épocas do ano mais favoráveis à 
dispersão dos triatomíneos, de março a julho para $T$. sordida e de outubro a dezembro para $P$. megistus (BURALLI ${ }^{25} 1985$ ). O periodo 1985-1988 fecha um ciclo de quatro anos em que, teoricamente, todas as localidades em PIII foram investigadas, possibilitando nova análise de dados relativos às capturas de triatomineos, como frequência, local de encontro, tipo de atendimento oferecido à população, dentre outros

Todavia constatou-se que em apenas um Serviço Regional, o de Sorocaba, o trabalho fora realizado a contento nesse quadriênio. Nos demais, houve um deslocamento substancial de recursos técnico-operacionais do PCDCh para o controle de vetores da dengue e da febre amarela, Aedes aegypti Linnaeus, 1762 e Aedes albopictus Skuse, 1894, em propagação acelerada a partir de meados da década de 80 , em diversas áreas do Estado. Em alguns anos, nas áreas de Ribeirão Preto, Araçatuba e Marilia, observou-se o comprometimento total de recursos nessas atividades. Nas demais, para evitar-se a paralisação do Programa, foram priorizados atendimentos de notificações ou então transferências de programações para anos subsequentes ${ }^{175-184}$

A partir de 1990. com a constatação da inexistência de focos de T. infestans, novos critérios para as prioridades de atendimento às localidades foram adotados, considerando-se as infestações intradomiciliares e peridomiciliares, isto é, as razões entre total de intradomicilios ou peridomicilios positivos e total de intradomicilios ou peridomicilios pesquisados

Prioridade I - localidades com infestações intradomiciliar $\geq 5 \%$ e peridomiciliar $\geq 10 \%$; Prioridade II - localidades com infestações intradomiciliar $<5 \%$ e peridomiciliar $<10 \% \mathrm{e}$ Prioridade III - localidades com infestações intradomiciliar e peridomiciliar = zero

A rotina de pesquisa das casas e seus anexos de toda a localidade e o estímulo e atendimento de notificação foram preconizados para as localidades em Prioridades I e II, com a diferença de que, na segunda, são amostradas aquelas que deveriam ser submetidas à pesquisa. No cálculo do tamanho da amostra foi considerada uma infestação média no intradomicilio igual a 1\%, baseada em achados do período 1984-1988 no Serviço Regional de Sorocaba ${ }^{185}$. Em relação à periodicidade de trabalho, passa a ser bienal nas Prioridades I e II. Nas localidades em Prioridade III foi abolida a pesquisa de rotina e incentivada a 
notificação de triatomíneos e seu pronto atendimento, como formas de detectar focos iniciais de vetores nos domicílios ${ }^{191}$, metodologia já indicada para áreas sob vigilância epidemiológica desde fins da década de $1960^{153-155.158}$.

Considerou-se desde então "Unidade de Trabalho" a casa com seus anexos ou peridomicílio, daqui em diante denominada Unidade Domiciliar (UD) e "Unidade de Avaliação", a Localidade. Portanto, os resultados obtidos em sorologia no PCDCh sempre dizem respeito à UD, não traduzem, portanto, a situação de Localidade, tampouco de Município. Serão por vezes agrupados nos municipios e nas Regiões, para que se tenha a idéia de situação geográfica

\subsubsection{A racionalidade da sorologia no PCDCh}

Considerando-se o risco representado pela descoberta de focos de triatomíneos nos domicilios durante atividades de pesquisa rotineira ou de atendimento a notificações, o Programa previu a identificação de hábitos alimentares dos vetores e exames para sorodiagnóstico de infecção chagásica em moradores das UDs em questão. A constatação da ausência de infectados nascidos depois da época considerada como limite para aquisição da doença de Chagas autóctone, reforçaria a idéia de ter sido interrompida a transmissão vetorial no Estado de São Paulo, confirmando a hipótese, aventada para a fixação desse período, como sendo aquele compreendido entre fins da década de 1960 e início da década de $1970^{25}$

\subsubsection{Normas do PCDCh à aplicação da sorologia}

A colheita de sangue dos moradores para exames sorológicos foi condicionada às características do vetor capturado

- ser da espécie $T$. infestans, independentemente de estar ou não infectado por $T$. cruzi ou ter sugado sangue humano;

- ser de outras espécies vetoras e estar infectado por T. cruzi, além de ter sido encontrado no intradomicilio; 
- ser de outras espécies vetoras e ter ingerido sangue humano, além de ter sido encontrado tanto no intra como no peridomicilio

Portanto, a indicação da sorologia para o diagnóstico da infecção chagásica dependia do conhecimento dos resultados de exames dos triatomineos vetores, exceção feita à região de São Vicente, onde se colhia o sangue dos moradores durante atividade de atendimento às notificações, conduta justificada por questões de racionalização de recursos operacionais

A partir de 1994 a indicação dos exames sorológicos ficou restrita apenas aos moradores das UDs em que estivessem infectados os triatomineos encontrados no intradomicilio. Portanto, não mais seria necessário esperar por resultados de exames de hábito alimentar dos insetos para justificá-la. Este procedimento ainda é vigente até o momento

\subsubsection{4 Área controle negativo}

Administrativamente associada ao Serviço Regional da SUCEN de São Vicente, a região do Litoral Sul Paulista, formada por municipios da Baixada Santista e do Vale do Ribeira, distingue-se quanto a diversos aspectos. Na primeira, as cidades são de médio a grande portes, a zona urbana apresenta-se com desenvolvimento típico de balneários litorâneos, com inúmeros prédios de apartamentos próprios para ocupação em temporadas de veraneio, feriados e fins-de-semana. As zonas rurais são inexpressivas, exceto em Peruibe e Itanhaém, que ainda mantêm pequeno número delas. No Vale do Ribeira, os centros urbanos são de menor porte e cerca de $50 \%$ da população reside em zona rural ${ }^{92}$ Nesta, as moradias mantêm proximidade com as matas, propiciando à população local contatos esporádicos com triatomíneos vetores invasivos. Por este motivo, a prática da notificação, com sua rede de PIFTs implantada nesta Regional desde início da década de 80 (DELLATORRE et al. ${ }^{62}$ 1983) tem sido a tônica do Programa de Controle da Doença de Chagas 


\section{RESULTADOS}

\subsection{Do inquérito realizado entre escolares da $1^{*}$ série do $1^{\circ}$ grau de escolas rurais em 54 municípios do Estado, entre 1973 e 1983}

\subsubsection{Linha de base}

Os 6 municipios de cada Serviço Regional selecionados para o inquérito sorológico de escolares estão listados na Tabela 4.1.1. Na mesma também são apresentadas a cobertura e a positividade, pela reação de fixação de complemento, do trabalho de GUARITA et al. ${ }^{96} 1978$, linha de base para o referido inquérito.

Tabela 4.1.1 - Prevalências para infecção chagásica, de acordo com a cobertura obtida, em alguns municípios do Estado de São Paulo, por Serviço Regional da SUCEN, 1968-1970*.

\begin{tabular}{|c|c|c|c|c|}
\hline Município & $\begin{array}{r}\text { Cobertura } \\
(\% \text { amostras })\end{array}$ & $\begin{array}{l}\mathrm{N}^{\circ} \text { amostras } \\
\text { examinadas }\end{array}$ & $\begin{array}{r}\mathrm{N}^{\circ} \text { amostras } \\
\text { reagentes }\end{array}$ & $\begin{array}{r}\% \text { amostras } \\
\text { reagentes }\end{array}$ \\
\hline \multicolumn{5}{|c|}{ Serviço Regional de São Vicente - SR-2 } \\
\hline Cananéia & 80,20 & 77 & 1 & 1,30 \\
\hline Itariri & 63,33 & 57 & 0 & 0,00 \\
\hline Juquiá & 69,62 & 109 & 1 & 0,92 \\
\hline Pariquera-Açu & 71,74 & 63 & 1 & 1,59 \\
\hline Pedro de Toledo & 53,85 & 48 & 1 & 2,08 \\
\hline Sete Barras & 61,86 & 66 & 1 & 1,51 \\
\hline Sub-Total do SR-2 & 67,08 & 424 & 5 & 1,18 \\
\hline \multicolumn{5}{|c|}{ Serviço Regional de Taubaté - SR-3 } \\
\hline Cruzeiro & 68,52 & 333 & 1 & 0,30 \\
\hline Jacareí & 82,33 & 535 & 7 & 1,31 \\
\hline Lorena & 57,20 & 302 & 2 & 0,66 \\
\hline Monteiro Lobato & 93,24 & 69 & 1 & 1,45 \\
\hline Paraibuna & 78,88 & 175 & 2 & 1,14 \\
\hline Taubaté & 54,34 & 551 & 3 & 0,54 \\
\hline Sub-Total do SR-3 & 66,13 & 1965 & 16 & 0,81 \\
\hline \multicolumn{5}{|c|}{ Serviço Regional de Sorocaba - SR-4 } \\
\hline Coronel Macedo & 100,00 & 49 & 14 & 28,57 \\
\hline Itaberá & 94,24 & 128 & 30 & 23,44 \\
\hline Itaí & 98,16 & 106 & 20 & 18,87 \\
\hline Itaporanga & 96,55 & 138 & 40 & 28,98 \\
\hline Paranapanema & 96,00 & 94 & 32 & 34,04 \\
\hline
\end{tabular}




\begin{tabular}{|c|c|c|c|c|}
\hline Municipio & $\begin{array}{r}\text { Cobertura } \\
(\% \text { amostras })\end{array}$ & $\begin{array}{l}N^{\circ} \text { amostras } \\
\text { examinadas }\end{array}$ & $\begin{array}{r}\mathrm{N}^{\circ} \text { amostras } \\
\text { reagentes }\end{array}$ & $\begin{array}{r}\% \text { amostras } \\
\text { reagentes }\end{array}$ \\
\hline Riversul & 100,00 & 84 & 17 & 20,24 \\
\hline Sub-Total do SR-4 & 96,99 & 599 & 153 & 25,54 \\
\hline \multicolumn{5}{|c|}{ Serviço Regional de Campinas - SR-5 } \\
\hline Atibaia & 60.95 & 217 & 1 & 0,46 \\
\hline Caconde & 64,25 & 115 & 0 & 0,00 \\
\hline Conchal & 64,10 & 50 & 1 & 2,00 \\
\hline Iracemápolis & 96,87 & 31 & 1 & 3,23 \\
\hline Itapira & 84,59 & 236 & 1 & 0,42 \\
\hline Mogi Guaçu & 88,68 & 235 & 2 & 0,85 \\
\hline Sub-Total do SR-5 & 74,35 & 884 & 6 & 0,68 \\
\hline \multicolumn{5}{|c|}{ Serviço Regional de Ribeirão Preto - SR-6 } \\
\hline Aramina & 36,36 & 16 & 1 & 6,25 \\
\hline Guariba & 35,71 & 30 & 2 & 6,67 \\
\hline Luiz Antônio & 52,78 & 18 & 1 & 5,55 \\
\hline Miguelópolis & 47,18 & 67 & 5 & 7,46 \\
\hline Restinga & 25,00 & 5 & 1 & 20,00 \\
\hline Ribeirão Corrente & 38,09 & 8 & 1 & 12,50 \\
\hline Sub-Total do SR-6 & 41,79 & 144 & 11 & 7,64 \\
\hline \multicolumn{5}{|c|}{ Serviço Regional de São José do Rio Preto - SR-8 } \\
\hline Dolcinópolis & 34,78 & 7 & 1 & 14,29 \\
\hline Estrela d'Oeste & 82,99 & 100 & 12 & 12,00 \\
\hline Macaubal & 29,27 & 24 & 3 & 12,50 \\
\hline Paraiso & 55,26 & 19 & 2 & 10,53 \\
\hline São Francisco & 55,81 & 24 & 4 & 16,67 \\
\hline União Paulista & 60,00 & 9 & 1 & 11,11 \\
\hline Sub-Total do SR-8 & 59,77 & 183 & 23 & 12,57 \\
\hline \multicolumn{5}{|c|}{ Serviço Regional de Araçatuba - SR-9 } \\
\hline Auriflama & 54,83 & 188 & 4 & 2,13 \\
\hline Guararapes & 48,94 & 289 & 2 & 0,69 \\
\hline Penápolis & 50,76 & 365 & 2 & 0,55 \\
\hline Pereira Barreto & 33,93 & 234 & 1 & 0,43 \\
\hline Piacatu & 54,44 & 97 & 1 & 1,03 \\
\hline Sud Menucci & 55,84 & 146 & 1 & 0,68 \\
\hline Sub-Total do SR-9 & 47,08 & 1319 & 11 & 0,83 \\
\hline \multicolumn{5}{|c|}{ Serviço Regional de Presidente Prudente - SR-10 } \\
\hline Estrela do Norte & 78,05 & 28 & 2 & 7,14 \\
\hline lepê & 97,69 & 167 & 16 & 9,58 \\
\hline João Ramalho & 95,65 & 44 & 7 & 15,91 \\
\hline Mariápolis & 72,73 & 60 & 5 & 8,33 \\
\hline Rancharia & 92,18 & 224 & 14 & 6,25 \\
\hline Salmorão & 45,68 & 37 & 2 & 5,40 \\
\hline Sub-Total do SR-10 & 84,22 & 560 & 46 & 8,21 \\
\hline
\end{tabular}




\begin{tabular}{lcccr}
\hline Municipio & $\begin{array}{c}\text { Cobertura } \\
(\% \text { amostras })\end{array}$ & $\begin{array}{c}N^{\circ} \text { amostras } \\
\text { examinadas }\end{array}$ & $\begin{array}{r}\mathrm{N}^{\circ} \text { amostras } \\
\text { reagentes }\end{array}$ & $\begin{array}{r}\% \text { amostras } \\
\text { reagentes }\end{array}$ \\
\hline Cândido Mota & Serviço Regional de Marilia - SR-11 & 1 & \\
Fartura & 68,39 & 121 & 2 & 0,83 \\
Lutécia & 48,36 & 56 & 2 & 3,57 \\
Oscar Bressane & 48,94 & 23 & 1 & 8,70 \\
Palmital & 44,19 & 19 & 9 & 5,26 \\
Taguaí & 63,37 & 118 & 2 & 7,62 \\
\hline Sub-Total do SR-11 & 47,06 & 24 & 17 & 8,33 \\
\hline
\end{tabular}

* Fonte: GUARITA et al. ${ }^{96} 1978$.

Nos municípios de Itariri, SR-2 e Caconde, SR-5, os percentuais de positividade tinham sido iguais a zero. Em Caconde, a seleção deveu-se ao fato de na Regional não haver 6 municípios com reagentes sorológicos registrados no trabalho de GUARITA et al. ${ }^{96}$ (1978); foi escolhido por antecedentes de presença de triatomineos vetores e casos humanos da infecção chagásica ${ }^{48.87}$.

\subsubsection{Inquérito escolar de 1973 a 1983}

Os alunos matriculados na primeira série do primeiro grau das escolas selecionadas de zona rural, no período 1973-1983, possuiam idades entre 6 e 17 anos, com média e mediana iguais a 8,0 anos e $75 \%$ deles com até 9,0 anos. O sexo feminino foi representado por $44,8 \%$ do examinado e o masculino, $55,2 \%$

$\mathrm{Na}$ Tabela 4.1.2.1 seguem total de amostras obtidas, de reagentes e percentuais de sororreatividade para infecção chagásica em cada um dos 6 municipios selecionados dos Serviços Regionais da SUCEN. Também assinalam-se as Prioridades com as quais os mesmos eram classificados para efeito de trabalhos de controle de vetores. Essa classificação inexistia nas Regionais de São Vicente e Taubaté, consideradas áreas indenes para doença de Chagas. 
Tabela 4.1.2.1 - Sorologia de infecção chagásica em escolares da $1^{a}$ série do $1^{\circ}$ grau de escolas rurais de 54 municípios do Estado de São Paulo, 1973-1983

\begin{tabular}{|c|c|c|c|c|c|c|c|c|c|c|c|}
\hline Ano & 1973 & 1974 & 1975 & 1976 & 1977 & 1978 & 1979 & 1980 & 1981 & 1982 & 1983 \\
\hline \multicolumn{12}{|c|}{ Cananéia } \\
\hline $\mathrm{N}^{\circ}$ & 57 & 38 & 0 & 90 & 83 & 106 & 122 & 103 & 151 & 156 & 142 \\
\hline $\mathrm{R}$ & 0 & 0 & & 0 & 0 & 0 & 0 & 1 & 0 & 0 & 0 \\
\hline$\% \mathrm{R}$ & 0,0 & 0,0 & & 0,0 & 0,0 & 0,0 & 0,0 & 1,0 & 0,0 & 0,0 & 0,0 \\
\hline \multicolumn{12}{|c|}{ Itariri } \\
\hline $\mathrm{N}^{\circ}$ & 115 & 111 & 117 & 90 & 91 & 135 & 137 & 112 & 121 & 155 & 113 \\
\hline $\mathrm{R}$ & 1 & 2 & 1 & 0 & 1 & 0 & 3 & 0 & 0 & 0 & 0 \\
\hline$\% R$ & 0,9 & 1,8 & 0,9 & 0,0 & 1,1 & 0,0 & 2,2 & 0,0 & 0,0 & 0,0 & 0,0 \\
\hline \multicolumn{12}{|c|}{ Juquiá } \\
\hline $\mathrm{N}^{\circ}$ & 107 & 46 & 43 & 66 & 80 & 84 & 78 & 74 & 49 & 66 & 66 \\
\hline $\mathrm{R}$ & 0 & 0 & 3 & 3 & 0 & 0 & 0 & 0 & 1 & 0 & 0 \\
\hline$\% \mathrm{R}$ & 0.0 & 0,0 & 7,0 & 4,5 & 0,0 & 0,0 & 0,0 & 0,0 & 2,0 & 0,0 & 0,0 \\
\hline \multicolumn{12}{|c|}{ Pariquera-Açu } \\
\hline $\mathrm{N}^{\circ}$ & 91 & 37 & 0 & 50 & 79 & 67 & 96 & 85 & 85 & 105 & 127 \\
\hline $\mathrm{R}$ & 0 & 0 & & 0 & 0 & 0 & 0 & 0 & 0 & 0 & 0 \\
\hline$\% \mathrm{R}$ & 0,0 & 0,0 & & 0,0 & 0,0 & 0,0 & 0,0 & 0,0 & 0,0 & 0,0 & 0,0 \\
\hline \multicolumn{12}{|c|}{ Pedro de Toledo } \\
\hline $\mathrm{N}^{\circ}$ & 52 & 99 & 131 & 102 & 128 & 131 & 161 & 134 & 144 & 131 & 151 \\
\hline $\mathrm{R}$ & 0 & 0 & 0 & 0 & 1 & 0 & 0 & 0 & 0 & 1 & 0 \\
\hline$\% \mathrm{R}$ & 0,0 & 0,0 & 0,0 & 0,0 & 0,8 & 0,0 & 0,0 & 0,0 & 0.0 & 0,8 & 0,0 \\
\hline \multicolumn{12}{|c|}{ Sete Barras } \\
\hline $\mathrm{N}^{\circ}$ & 86 & 80 & 0 & 74 & 60 & 97 & 95 & 74 & 80 & 117 & 86 \\
\hline $\mathbf{R}$ & 0 & 0 & & 2 & 0 & 0 & 0 & 0 & 1 & 0 & 0 \\
\hline$\% \mathrm{R}$ & 0,0 & 0,0 & & 2,7 & 0,0 & 0,0 & 0,0 & 0,0 & 1,2 & 0,0 & 0,0 \\
\hline \multicolumn{12}{|c|}{ TOTAL SR-2 - SÃO VICENTE } \\
\hline $\mathrm{N}^{\circ}$ & 508 & 411 & 291 & 472 & 527 & 620 & 689 & 582 & 630 & 730 & 685 \\
\hline $\mathbf{R}$ & 1 & 2 & 4 & 5 & 2 & 0 & 3 & 1 & 2 & 1 & 0 \\
\hline$\% \mathrm{R}$ & 0.2 & 0,5 & 1.4 & 1,1 & 0,4 & 0,0 & 0,4 & 0,2 & 0,3 & 0,1 & 0,0 \\
\hline \multicolumn{12}{|c|}{ Cruzeiro } \\
\hline $\mathrm{N}^{0}$ & & & & & & & & & & 43 & 54 \\
\hline $\mathrm{R}$ & & & & & & & & & & 0 & 0 \\
\hline$\% \mathrm{R}$ & & & & & & & & & & 0,0 & 0,0 \\
\hline \multicolumn{12}{|c|}{ Jacarei } \\
\hline $\mathrm{N}^{0}$ & & & & & & & & & & 61 & 56 \\
\hline $\mathbf{R}$ & & & & & & & & & & 0 & 0 \\
\hline$\% \mathrm{R}$ & & & & & & & & & & 0,0 & 0,0 \\
\hline
\end{tabular}




\begin{tabular}{|c|c|c|c|c|c|c|c|c|c|c|c|}
\hline Ano & 1973 & 1974 & 1975 & 1976 & 1977 & 1978 & 1979 & 1980 & 1981 & 1982 & 1983 \\
\hline \multicolumn{12}{|c|}{ Lorena } \\
\hline $\mathrm{N}^{\circ}$ & & & & & & & & & & 29 & 36 \\
\hline $\mathrm{R}$ & & & & & & & & & & 0 & 0 \\
\hline$\% \mathrm{R}$ & & & & & & & & & & 0,0 & 0,0 \\
\hline \multicolumn{12}{|c|}{ Monteiro Lobato } \\
\hline $\mathrm{N}^{\circ}$ & & & & & & & & & & 47 & 44 \\
\hline $\mathrm{R}$ & & & & & & & & & & 0 & 0 \\
\hline$\% \mathrm{R}$ & & & & & & & & & & 0,0 & 0,0 \\
\hline \multicolumn{12}{|c|}{ Paraibuna } \\
\hline $\mathrm{N}^{\circ}$ & & & & & & & & & & 77 & 63 \\
\hline $\mathrm{R}$ & & & & & & & & & & 0 & 0 \\
\hline$\% \mathrm{R}$ & & & & & & & & & & 0,0 & 0,0 \\
\hline \multicolumn{12}{|c|}{ Taubaté } \\
\hline $\mathrm{N}^{\circ}$ & & & & & & & & & & 104 & 77 \\
\hline $\mathrm{R}$ & & & & & & & & & & 0 & 0 \\
\hline$\% \mathrm{R}$ & & & & & & & & & & 0,0 & 0,0 \\
\hline \multicolumn{12}{|c|}{ TOTAL SR-3 - TAUBATE } \\
\hline $\mathrm{N}^{\circ}$ & & & & & & & & & & 361 & 330 \\
\hline $\mathrm{R}$ & & & & & & & & & & 0 & 0 \\
\hline$\% \mathrm{R}$ & & & & & & & & & & 0,0 & 0,0 \\
\hline \multicolumn{12}{|c|}{ Coronel Macedo } \\
\hline $\mathrm{N}^{\circ}$ & 56 & 48 & +40 & 30 & 32 & $=\$ 1$ & 47 & 30 & $+4 i$ & 22 & 25 \\
\hline $\mathbf{R}$ & 15 & 5 & 0 & 2 & 1 & 0 & 0 & 0 & 0 & 0 & 0 \\
\hline$\% \mathrm{R}$ & 26,8 & 10,4 & 0,0 & 6,7 & 3,1 & 0,0 & 0,0 & 0,0 & 0,0 & 0,0 & 0,0 \\
\hline \multicolumn{12}{|c|}{ Itaberá } \\
\hline $\mathrm{N}^{\circ}$ & - 59 & 70 & 41 & 60 & 83 & 54 & -73 & 51 & 74 & 38 & 65 \\
\hline $\mathrm{R}$ & 7 & 3 & 2 & 1 & 0 & 1 & 1 & 0 & 1 & 0 & 0 \\
\hline$\% \mathrm{R}$ & 11,9 & 4,3 & 4,9 & 1,7 & 0,0 & 1,9 & 1,4 & 0,0 & 1,3 & 0,0 & 0,0 \\
\hline \multicolumn{12}{|c|}{ Itaí } \\
\hline $\mathrm{N}^{\circ}$ & 112 & 46 & 99 & 47 & 76 & 89 & 89 & 74 & 52 & 49 & 78 \\
\hline $\mathrm{R}$ & 4 & 0 & 0 & 0 & 2 & 0 & 2 & 0 & 1 & 0 & 0 \\
\hline$\% \mathrm{R}$ & 3,6 & 0,0 & 0,0 & 0,0 & 2,6 & 0,0 & 2,2 & 0,0 & 1,9 & 0,0 & 0,0 \\
\hline \multicolumn{12}{|c|}{ Itaporanga } \\
\hline $\mathrm{N}^{\circ}$ & 107 & B1: & 106 & 139 & WS & 126 & 166 & 166 & 136 & (118 & 126 \\
\hline $\mathrm{R}$ & 15 & 11 & 1 & 0 & 1 & 2 & 5 & 0 & 0 & 1 & 0 \\
\hline$\% \mathrm{R}$ & 14,0 & 8,4 & 0,9 & 0,0 & 0,7 & 1,6 & 3,0 & 0,0 & 0,0 & 0,9 & 0,0 \\
\hline \multicolumn{12}{|c|}{ Paranapanema } \\
\hline $\mathrm{N}^{\circ}$ & 84 & 76 & 90 & 80 & 82 & 93 & 184 & 61 & 55 & 48 & 34 \\
\hline $\mathrm{R}$ & 7 & 2 & 3 & 6 & 2 & 2 & 0 & 0 & 0 & 0 & 0 \\
\hline$\% \mathrm{R}$ & 8,3 & 2,6 & 3,3 & 7,5 & 2,4 & 2,1 & 0,0 & 0,0 & 0,0 & 0,0 & 0,0 \\
\hline
\end{tabular}




\begin{tabular}{|c|c|c|c|c|c|c|c|c|c|c|c|}
\hline Ano & 1973 & 1974 & 1975 & 1976 & 1977 & 1978 & 1979 & 1980 & 1981 & 1982 & 1983 \\
\hline \multicolumn{12}{|c|}{ Riversul } \\
\hline $\mathrm{N}^{\circ}$ & $\begin{array}{r}86 \\
4\end{array}$ & 87 & 60 & 121 & 122 & 70 & 130 & 89 & 115 & 92 & 109 \\
\hline $\mathrm{R}$ & 3 & 7 & 0 & 4 & 1 & 0 & 0 & 1 & 0 & 0 & 0 \\
\hline$\% \mathrm{R}$ & 3,5 & 8,0 & 0,0 & 3,3 & 0,8 & 0,0 & 0,0 & 1,1 & 0,0 & 0,0 & 0,0 \\
\hline \multicolumn{12}{|c|}{ TOTAL SR-4 - SOROCABA } \\
\hline $\mathrm{N}^{\circ}$ & 504 & 458 & 427 & 477 & 530 & 483 & 689 & 471 & 473 & 383 & 457 \\
\hline $\mathbf{R}$ & 51 & 2 & 6 & 13 & 7 & 5 & 8 & 1 & 2 & 1 & 0 \\
\hline$\% \mathrm{R}$ & 10,1 & 6,1 & 1,4 & 2,7 & 1,3 & 1,0 & 1,2 & 0,2 & 0,4 & 0,3 & 0,0 \\
\hline \multicolumn{12}{|c|}{ Atibaia } \\
\hline $\mathrm{N}^{\circ}$ & 93 & 117 & 112 & 105 & 108 & 100 & 83. & 71 & 77 & 102 & 115 \\
\hline R & 1 & 4 & 2 & 1 & 0 & 0 & 0 & 0 & 0 & 0 & 0 \\
\hline$\% \mathrm{R}$ & 1,1 & 3,4 & 1,8 & 0,9 & 0,0 & 0,0 & 0,0 & 0,0 & 0,0 & 0,0 & 0,0 \\
\hline \multicolumn{12}{|c|}{ Caconde } \\
\hline $\mathrm{N}^{\circ}$ & 11 & 1 & 13 & 14. & 1 & 10 & 12 & 14 & 12 & 10 & 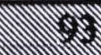 \\
\hline $\mathrm{R}$ & 2 & 1 & 0 & 0 & 0 & 0 & 0 & 0 & 0 & 0 & 0 \\
\hline$\% \mathrm{R}$ & 1,9 & 1,2 & 0,0 & 0,0 & 0,0 & 0,0 & 0,0 & 0,0 & 0,0 & 0,0 & 0,0 \\
\hline \multicolumn{12}{|c|}{ Conchal } \\
\hline $\mathrm{N}^{\circ}$ & $\begin{array}{l}62 \\
-12\end{array}$ & 49 & 67 & 64 & 68 & 59 & -4 & 38 & 33 & 43 & 57 \\
\hline R & 1 & 0 & 0 & 0 & 0 & 0 & 0 & 0 & 0 & 0 & 0 \\
\hline$\% \mathrm{R}$ & 1,6 & 0,0 & 0,0 & 0,0 & 0,0 & 0,0 & 0,0 & 0,0 & 0,0 & 0,0 & 0,0 \\
\hline \multicolumn{12}{|c|}{ Iracemápolis } \\
\hline $\mathrm{N}^{\circ}$ & 26 & 53 & 43 & 5 & 25 & 26 & 30 & 4 & 27 & 43 & 41 \\
\hline $\mathbf{R}$ & 0 & 0 & 0 & 0 & 0 & 0 & 0 & 0 & 0 & 0 & 0 \\
\hline$\% \mathrm{R}$ & 0,0 & 0,0 & 0,0 & 0,0 & 0,0 & 0,0 & 0,0 & 0,0 & 0,0 & 0,0 & 0,0 \\
\hline \multicolumn{12}{|c|}{ Itapira } \\
\hline$N^{\circ}$ & 18 & 12 & 11 & 18 & 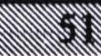 & 1 & 28. & 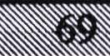 & 12 & 1 & 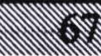 \\
\hline $\mathrm{R}$ & 0 & 0 & 0 & 0 & 0 & 0 & 0 & 0 & 0 & 0 & 0 \\
\hline$\% \mathrm{R}$ & 0,0 & 0,0 & 0,0 & 0,0 & 0,0 & 0,0 & 0,0 & 0,0 & 0,0 & 0,0 & 0,0 \\
\hline \multicolumn{12}{|c|}{ Mogi Guaçu } \\
\hline $\mathrm{N}^{\mathrm{o}}$ & 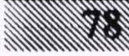 & itiv & \% & 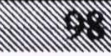 & m & 11. & 11 & 11 & 11 & ‥ & II \\
\hline $\mathbf{R}$ & 0 & 0 & 0 & 0 & 0 & 0 & 0 & 0 & 0 & 0 & 0 \\
\hline$\% \mathrm{R}$ & 0,0 & 0,0 & 0,0 & 0,0 & 0,0 & 0,0 & 0,0 & 0,0 & 0,0 & 0,0 & 0,0 \\
\hline \multicolumn{12}{|c|}{ TOTAL SR-5 - CAMPINAS } \\
\hline $\mathrm{N}^{\circ}$ & 416 & 461 & 456 & 462 & 445 & 471 & 470 & 438 & 449 & 468 & 507 \\
\hline $\mathrm{R}$ & 4 & 5 & 2 & 1 & 0 & 0 & 0 & 0 & 0 & 0 & 0 \\
\hline$\% \mathrm{R}$ & 1 & 1,1 & 0,4 & 0,2 & 0,0 & 0,0 & 0,0 & 0,0 & 0,0 & 0,0 & 0,0 \\
\hline \multicolumn{12}{|c|}{ Aramina } \\
\hline $\mathrm{N}^{\circ}$ & 39 & 49 & 39 & 29 & 37 & 28 & 15 & 16 & 20 & 23 & 33 \\
\hline $\mathbf{R}$ & 1 & 0 & 0 & 0 & 0 & 0 & 0 & 0 & 0 & 0 & 0 \\
\hline$\% \mathrm{R}$ & 2,6 & 0,0 & 0,0 & 0,0 & 0,0 & 0,0 & 0,0 & 0,0 & 0,0 & 0,0 & 0,0 \\
\hline
\end{tabular}




\begin{tabular}{llllllllllll}
\hline Ano & 1973 & 1974 & 1975 & 1976 & 1977 & 1978 & 1979 & 1980 & 1981 & 1982 & 1983 \\
\hline
\end{tabular}

Guariba

\begin{tabular}{llllllllllll}
\hline $\mathrm{N}^{\circ}$ & 56 & 34 & 45 & 48 & 53 & 55 & 54 & 50 & 53 & 46 & 34
\end{tabular}

$\begin{array}{llllllllllll}\mathrm{R} & 1 & 0 & 0 & 0 & 0 & 0 & 0 & 0 & 0 & 0 & 0\end{array}$

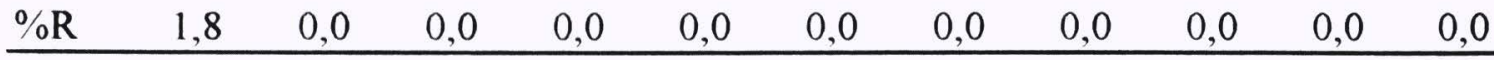

\begin{tabular}{llllllllllll}
\multicolumn{10}{c}{ Luiz Antônio } \\
\hline $\mathrm{N}^{\circ}$ & 35 & 53 & 48 & 63 & 53 & 50 & 60 & 64 & 61 & 44 & 53
\end{tabular}

$\begin{array}{lllllllllllr}\mathrm{R} & 0 & 0 & 0 & 0 & 0 & 0 & 0 & 0 & 0 & 0 & 0\end{array}$

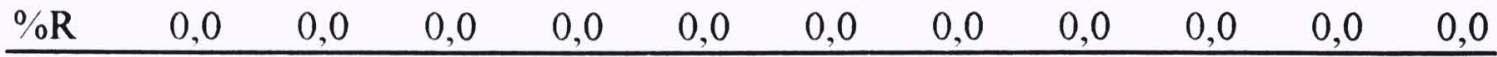
Miguelópolis

\begin{tabular}{llllllllllll}
\hline $\mathrm{N}^{\circ}$ & 36 & 30 & 33 & 33 & 35 & 41 & 22 & 26 & 36 & 52 & 36
\end{tabular}

$\begin{array}{lrrrrrrrrrrr}\mathrm{R} & 2 & 0 & 0 & 0 & 0 & 0 & 0 & 1 & 0 & 0 & 0\end{array}$

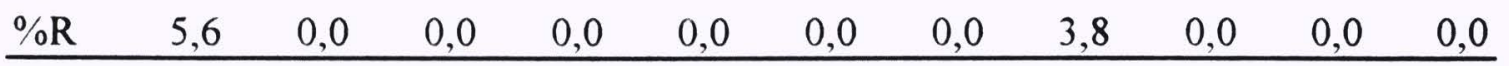

\begin{tabular}{lrrrrrrrrrrr}
\multicolumn{10}{c}{ Restinga } \\
\hline$N^{\circ}$ & 44 & 41 & 34 & 42 & 26 & 24 & 31 & 26 & 35 & 41 & 23
\end{tabular}

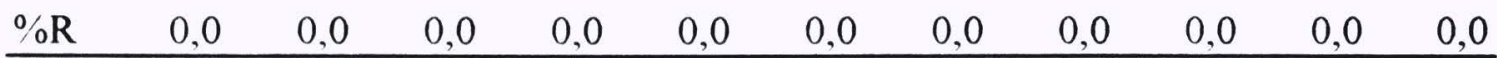

\begin{tabular}{llllllllllll}
\hline \multicolumn{11}{c}{ Ribeirão Corrente } \\
\hline $\mathrm{N}^{\circ}$ & 21 & 25 & 29 & 29 & 27 & 30 & 31 & 25 & 22 & 26 & 20
\end{tabular}

$\begin{array}{lrrrrrrrrrrr}\mathrm{R} & 0 & 0 & 0 & 0 & 0 & 0 & 0 & 0 & 0 & 0 & 0\end{array}$

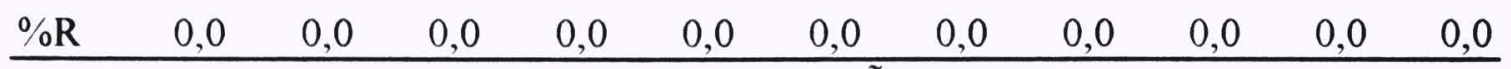

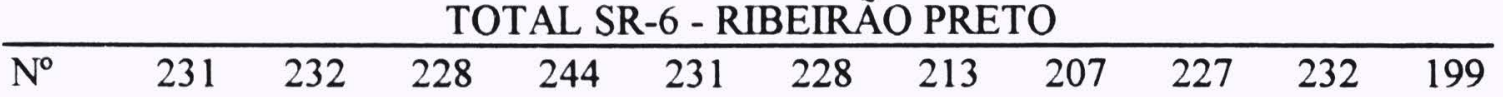

$\begin{array}{lrrrrrrrrrrr}\mathrm{R} & 4 & 0 & 0 & 0 & 0 & 0 & 0 & 1 & 0 & 0 & 0\end{array}$

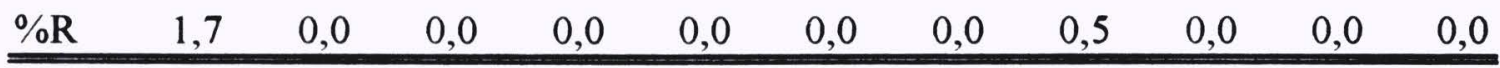

\section{Dolcinópolis}

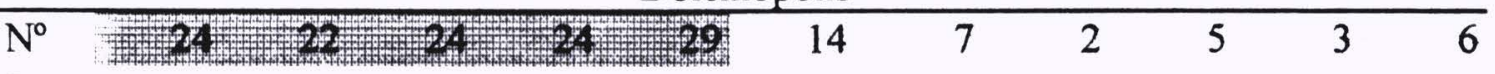

$\begin{array}{rrrrrrrrrrrr}\mathrm{R} & 1 & 0 & 0 & 0 & 0 & 0 & 1 & 0 & 0 & 0 & 0\end{array}$

\begin{tabular}{llllllllllll}
$\% \mathrm{R}$ & 4,2 & 0,0 & 0,0 & 0,0 & 0,0 & 0,0 & 14,3 & 0,0 & 0,0 & 0,0 & 0,0 \\
\hline
\end{tabular}

\section{Estrela D'Oeste}

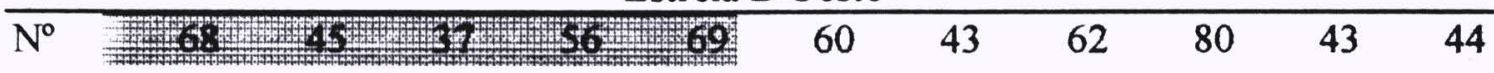

$\begin{array}{llllllllllll}\mathrm{R} & 2 & 0 & 0 & 0 & 0 & 1 & 0 & 0 & 0 & 0 & 0\end{array}$

\begin{tabular}{llllllllllll}
$\% \mathrm{R}$ & 2,9 & 0,0 & 0,0 & 0,0 & 0,0 & 1,7 & 0,0 & 0,0 & 0,0 & 0,0 & 0,0 \\
\hline
\end{tabular}

Macaubal

\begin{tabular}{|c|c|c|c|c|c|c|c|c|c|c|c|}
\hline $\mathrm{N}^{\circ}$ & 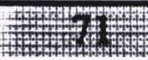 & 58 & 17 & 5 & 56 & 58 & 53 & 44 & 54 & 46 & 40 \\
\hline $\mathrm{R}$ & 0 & 0 & 0 & 0 & 0 & 0 & 0 & 0 & 0 & 0 & 0 \\
\hline$\% \mathrm{R}$ & 0,0 & 0,0 & 0,0 & 0,0 & 0,0 & 0,0 & 0,0 & 0,0 & 0,0 & 0,0 & 0,0 \\
\hline \multicolumn{12}{|c|}{ Paraíso } \\
\hline $\mathrm{N}^{\circ}$ & 19 & 36 & 21 & 20 & 27 & 22 & 25 & 21 & 36 & 20 & 13 \\
\hline R & 0 & 0 & 0 & 0 & 0 & 0 & 0 & 0 & 0 & 0 & 0 \\
\hline$\% \mathrm{R}$ & 0,0 & 0,0 & 0,0 & 0,0 & 0,0 & 0,0 & 0,0 & 0,0 & 0,0 & 0,0 & 0,0 \\
\hline
\end{tabular}




\begin{tabular}{llllllllllll}
\hline Ano & 1973 & 1974 & 1975 & 1976 & 1977 & 1978 & 1979 & 1980 & 1981 & 1982 & 1983 \\
\hline
\end{tabular}

São Francisco

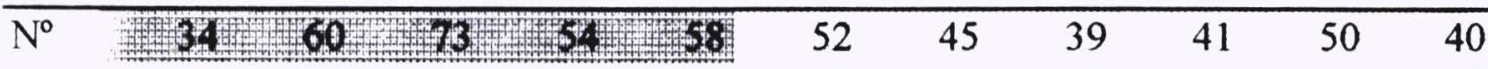

$\begin{array}{llllllllllll}\mathrm{R} & 2 & 0 & 0 & 0 & 0 & 0 & 0 & 0 & 0 & 0 & 0\end{array}$

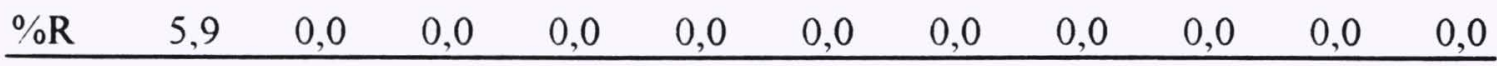
União Paulista

\begin{tabular}{llllllllll}
\hline $\mathrm{N}^{0}$ & 12 & 11 & 4
\end{tabular}

$\begin{array}{llllllllllll}\mathrm{R} & \mathrm{l} & 3 & 0 & 0 & 0 & 0 & 0 & 0 & 0 & 0 & 0\end{array}$

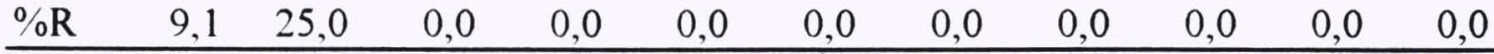
TOTAL SR-8 - SÃO JOSÉ DO RIO PRETO

\begin{tabular}{lrrrrrrrrrrr}
\hline $\mathrm{N}^{\circ}$ & 227 & 233 & 248 & 215 & 245 & 216 & 179 & 171 & 223 & 167 & 152 \\
$\mathrm{R}$ & 6 & 3 & 0 & 0 & 0 & 1 & 1 & 0 & 0 & 0 & 0 \\
$\% \mathrm{R}$ & 2,6 & 1,3 & 0,0 & 0,0 & 0,0 & 0,5 & 0,6 & 0,0 & 0,0 & 0,0 & 0,0 \\
\hline \hline
\end{tabular}

Auriflama

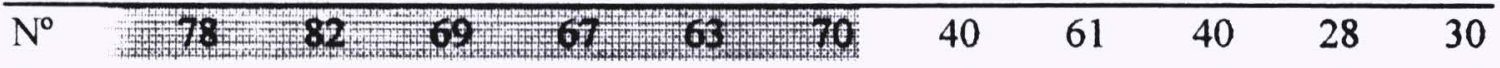

$\begin{array}{llllllllllll}\mathrm{R} & 1 & 1 & 0 & 0 & 0 & 0 & 0 & 0 & 0 & 0 & 0\end{array}$

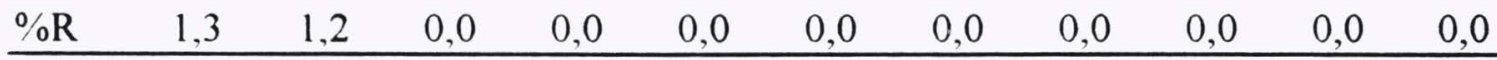
Guararapes

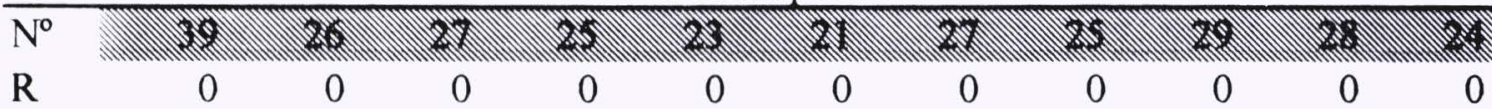

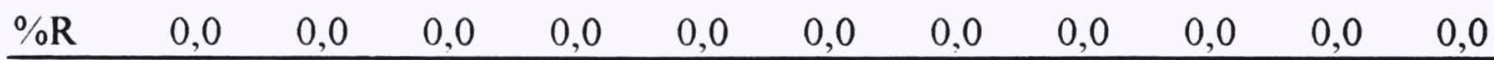

\begin{tabular}{llllllllllll}
\hline \multicolumn{10}{c}{ Penápolis } \\
\hline$N^{\circ}$ & 148 & 136 & 99 & 75 & 100 & 80 & 79 & 72 & 95 & 76 & 52
\end{tabular}

$\begin{array}{llllllllllll}\mathrm{R} & 0 & 0 & 0 & 0 & 0 & 0 & 0 & 1 & 1 & 1 & 0\end{array}$

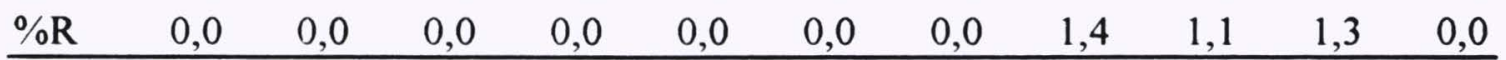

Pereira Barreto

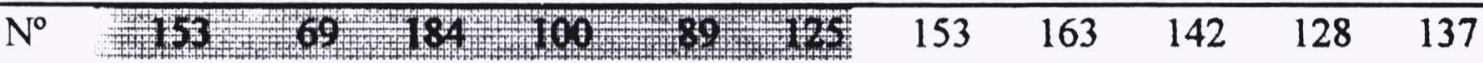

$\begin{array}{llllllllllll}\mathrm{R} & 1 & 1 & 0 & 1 & 0 & 1 & 0 & 0 & 2 & 0 & 0\end{array}$

\begin{tabular}{llllllllllll}
$\% \mathrm{R}$ & 0,6 & 1,4 & 0,0 & 1,0 & 0,0 & 0,8 & 0,0 & 0,0 & 1,4 & 0,0 & 0,0 \\
\hline
\end{tabular}
Piacatu

\begin{tabular}{llllllllllll}
\hline $\mathrm{N}^{\circ}$ & 33 & 41 & 37 & 26 & 58 & 40 & 49 & 36 & 24 & 24 & 33
\end{tabular}

$\begin{array}{rrrrrrrrrrrr}\mathrm{R} & 0 & 0 & 0 & 0 & 0 & 0 & 0 & 0 & 0 & 0 & 0\end{array}$

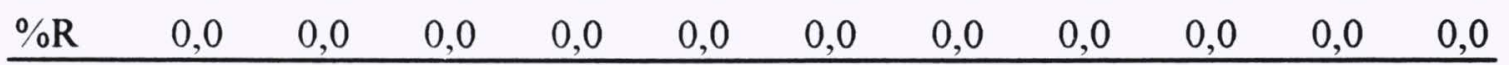

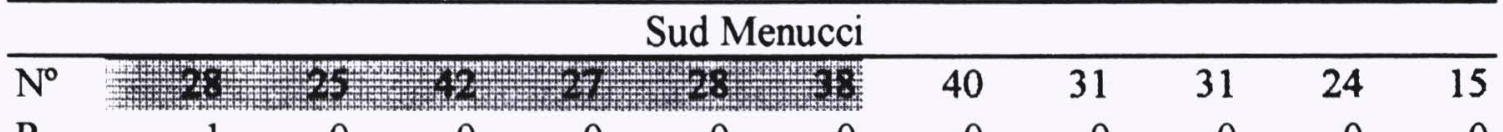

$\begin{array}{llllllllllll}\mathrm{R} & 1 & 0 & 0 & 0 & 0 & 0 & 0 & 0 & 0 & 0 & 0\end{array}$

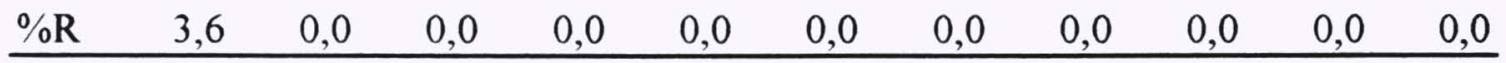
TOTAL SR-9 - ARAÇATUBA

\begin{tabular}{llllllllllll}
\hline $\mathrm{N}^{\circ}$ & 479 & 379 & 458 & 320 & 361 & 374 & 388 & 388 & 361 & 308 & 291
\end{tabular}

$\begin{array}{lrrrrrrrrrrr}\mathrm{R} & 3 & 2 & 0 & 1 & 0 & 1 & 0 & 1 & 3 & 1 & 0\end{array}$

\begin{tabular}{llllllllllll}
$\% \mathrm{R}$ & 0,6 & 0,5 & 0,0 & 0,3 & 0,0 & 0,3 & 0,0 & 0,3 & 0,8 & 0,3 & 0,0 \\
\hline
\end{tabular}




\begin{tabular}{|c|c|c|c|c|c|c|c|c|c|c|c|}
\hline Ano & 1973 & 1974 & 1975 & 1976 & 1977 & 1978 & 1979 & 1980 & 1981 & 1982 & 1983 \\
\hline \multicolumn{12}{|c|}{ Palmital } \\
\hline $\mathrm{N}^{\circ}$ & 116 & 97 & 111 & 89 & 8) & 37 & 81 & $=85$ & 90 & 93 & 66 \\
\hline $\mathrm{R}$ & 2 & 3 & 0 & 0 & 1 & 0 & 0 & 0 & 0 & 0 & 0 \\
\hline$\% \mathrm{R}$ & 1,7 & 3,1 & 0,0 & 0,0 & 1,2 & 0,0 & 0,0 & 0,0 & 0,0 & 0,0 & 0,0 \\
\hline \multicolumn{12}{|c|}{ Oscar Bressane } \\
\hline $\mathrm{N}^{\circ}$ & $\begin{array}{r}\quad 63 \\
\end{array}$ & 68 & 78 & 55 & men & mis & 16 & MN & 14 & 14 & in \\
\hline $\mathrm{R}$ & 2 & 1 & 0 & 0 & 0 & 0 & 0 & 0 & 0 & 0 & 0 \\
\hline$\% \mathrm{R}$ & 3,2 & 1,5 & 0,0 & 0,0 & 0,0 & 0,0 & 0,0 & 0,0 & 0,0 & 0,0 & 0,0 \\
\hline \multicolumn{12}{|c|}{ Taguaí } \\
\hline $\mathrm{N}^{\circ}$ & $\begin{array}{r}-44 \\
\end{array}$ & 41 & 49 & 35 & 43 & 42 & 33 & 37 & 29 & 20 & 28 \\
\hline $\mathrm{R}$ & 3 & 2 & 0 & 0 & 0 & 1 & 0 & 0 & 0 & 0 & 0 \\
\hline$\% \mathrm{R}$ & 6,8 & 4,9 & 0,0 & 0,0 & 0,0 & 2,4 & 0,0 & 0,0 & 0,0 & 0,0 & 0,0 \\
\hline \multicolumn{12}{|c|}{ TOTAL SR-11 - MARÍLIA } \\
\hline $\mathrm{N}^{\circ}$ & 422 & 432 & 433 & $37 !$ & 407 & 355 & 362 & 349 & 356 & 341 & 319 \\
\hline $\mathrm{R}$ & 12 & 11 & 1 & 0 & 1 & 1 & 0 & 0 & 0 & 0 & 0 \\
\hline$\% \mathrm{R}$ & 2,8 & 2.5 & 0.2 & 0,0 & 0,2 & 0,3 & 0,0 & 0,0 & 0,0 & 0,0 & 0,0 \\
\hline
\end{tabular}

$\mathrm{N}^{\circ}=\mathrm{n}^{\circ}$ de amostras examinadas; $\mathrm{R}=\mathrm{n}^{\circ}$ de amostras reagentes; $\% \mathrm{R}=$ percentagem de amostras reagentes.

\section{Prioridade $1 \quad$ Prioridade $2 \stackrel{m}{m}$ Prioridade 3}

Alguns municípios foram reclassificados no período, casos de Itaí, Atibaia, Conchal, Dolcinópolis, Estrela D’Oeste, Macaubal, São Francisco, União Paulista, Auriflama, Pereira Barreto, Sud Menucci, Cândido Mota, Fartura, Palmital e Taguai, de P1 para P2, enquanto Iepê passou de P1 para P3 e Rancharia passou de P1 para P2 e a seguir, para P3. 
Na Tabela 4.1.2.2 observa-se a distribuição de amostras examinadas, reagentes e duvidosas para infecção chagásica e, em gráfico, a curva de regressão para a distribuição da sororreatividade ao longo dos anos (Figura 4.1.2)

Tabela 4.1.2.2 - Distribuição de frequências de amostras reagentes e duvidosas em inquerito sorológico para infecção chagásica entre escolares da $1^{\mathrm{a}}$ série do $1^{\circ}$ grau de escolas de zona rural de 54 municípios do Estado de São Paulo, 1973-1983.

\begin{tabular}{|c|c|c|c|c|c|}
\hline \multirow[b]{2}{*}{ Ano } & \multicolumn{2}{|c|}{$\mathrm{N}^{\circ}$ de amostras } & \multirow{2}{*}{$\begin{array}{c}\% \\
\text { reagentes }\end{array}$} & \multirow{2}{*}{$\begin{array}{c}\mathrm{N}^{\circ} \text { de amostras } \\
\text { duvidosas }\end{array}$} & \multirow{2}{*}{$\begin{array}{c}\% \\
\text { duvidosas }\end{array}$} \\
\hline & examinadas & reagentes & & & \\
\hline 1973 & 3108 & 85 & 2,73 & 0 & 0,00 \\
\hline 1974 & 2998 & 55 & 1,83 & 38 & 1,27 \\
\hline 1975 & 2954 & 13 & 0,44 & 10 & 0,34 \\
\hline 1976 & 2867 & 21 & 0,73 & 6 & 0,21 \\
\hline 1977 & 3035 & 13 & 0,43 & 5 & 0,16 \\
\hline 1978 & 3089 & 8 & 0,26 & 1 & 0,03 \\
\hline 1979 & 3338 & 12 & 0,36 & 3 & 0,09 \\
\hline 1980 & 2964 & 5 & 0,17 & 0 & 0,00 \\
\hline 1981 & 3064 & 7 & 0,23 & 0 & 0,00 \\
\hline 1982 & 3270 & 3 & 0,09 & 0 & 0,00 \\
\hline 1983 & 3256 & 0 & 0,00 & 0 & 0,00 \\
\hline Total & 33943 & 222 & 0,65 & 63 & 0,19 \\
\hline
\end{tabular}


Soromeagentes \%

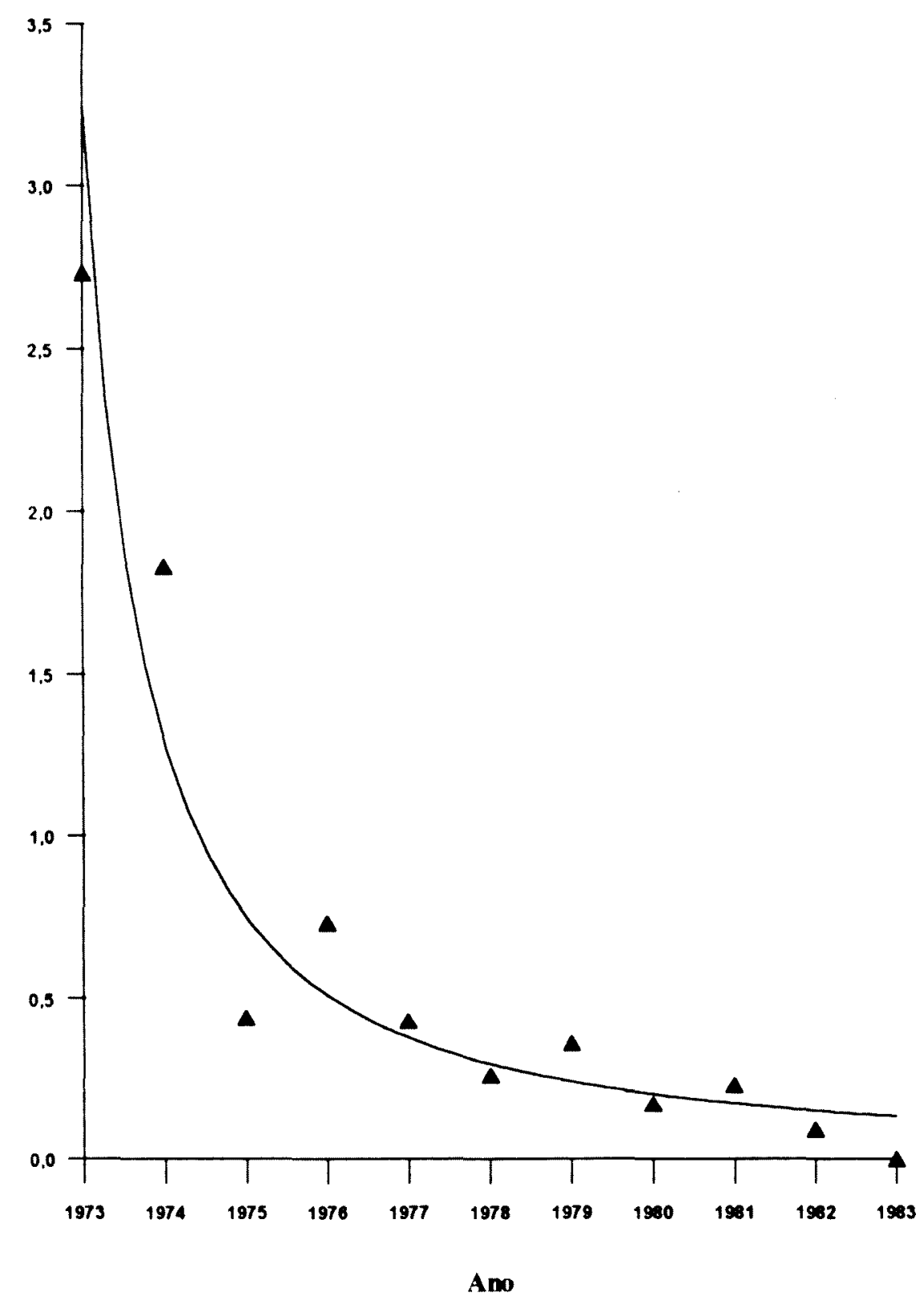

Figura 4.1.2 - Distribuição da sororreatividade para infecção chagásica entre escolares da $1^{\text {a }}$ série do $1^{\circ}$ grau de escolas da zona rural de 54 municipios do Estado de São Paulo (1973 - 1983). Curva de regressão

$a=1,181 ; b=-1,337 ; r=-0,797 ; r^{2}=0,636$ 
Os percentuais de sororreatividade, por Regional da SUCEN, foram condensados para o período 1973-1983 (Tabela 4.1.2.3)

Tabela 4.1.2.3 - Frequências percentuais de sororreatividade para infecção chagásica entre escolares da $1^{a}$ série do $1^{\circ}$ grau de escolas de zona rural de 54 municípios do Estado de São Paulo, segundo Serviço Regional da SUCEN, 1973-1983

\begin{tabular}{lllllllllll}
\hline Ano & \multicolumn{8}{c}{ Serviço Regional da SUCEN* } \\
& 2 & 3 & 4 & 5 & 6 & 8 & 9 & 10 & 11 \\
\hline 1973 & 0,20 & $\ldots$ & 10,12 & 0,96 & 1,73 & 2,64 & 0,63 & 1,25 & 2,84 \\
1974 & 0,49 & $\ldots$ & 6,11 & 1,08 & 0,00 & 1,29 & 0,53 & 1,02 & 2,55 \\
1975 & 1,37 & $\ldots$ & 1,41 & 0,22 & 0,00 & 0,00 & 0,00 & 0,24 & 0,23 \\
1976 & 1,06 & $\ldots$ & 2,73 & 0,22 & 0,00 & 0,00 & 0,31 & 0,33 & 0,00 \\
1977 & 0,38 & $\ldots$ & 1,32 & 0,22 & 0,00 & 0,00 & 0,00 & 0,69 & 0,25 \\
1978 & 0,00 & $\ldots$ & 1,03 & 0,00 & 0,00 & 0,46 & 0,27 & 0,00 & 0,28 \\
1979 & 0,43 & $\ldots$ & 1,16 & 0,00 & 0,00 & 0,56 & 0,00 & 0,00 & 0,00 \\
1980 & 0,17 & $\ldots$ & 0,21 & 0,00 & 0,48 & 0,00 & 0,26 & 0,28 & 0,00 \\
1981 & 0,32 & $\ldots$ & 0,42 & 0,00 & 0,00 & 0,00 & 0,83 & 0,00 & 0,00 \\
1982 & 0,14 & 0,00 & 0,26 & 0,00 & 0,00 & 0,00 & 0,32 & 0,00 & 0,00 \\
1983 & 0,00 & 0,00 & 0,00 & 0,00 & 0,00 & 0,00 & 0,00 & 0,00 & 0,00 \\
\hline \hline
\end{tabular}

${ }^{*} 2=$ S. Vicente; $3=$ =Taubaté; 4=Sorocaba; $5=$ Campinas; $6=$ Ribeirão Preto; 8=S. José do Rio Preto;9=Aracatuba; $10=$ Presidente Prudente: $11=$ Marilia.

Dentre os casos reagentes e duvidosos $(n=237)$, as idades variaram de 6 a 17 anos, com média e mediana iguais a 9,0 anos e $75 \%$ dos casos com até 10 anos. Não foi observada diferença de idades entre os sexos (Tabela 4.1.2.4). Em 48 casos (16,84\%) as informações não foram disponiveis 
Tabela 4.1.2.4 - Distribuição de frequências de idades de reagentes e de duvidosos sorológicos para infeç̧ão chagásica em escolares de $1^{\text {a }}$ série do $1^{\circ}$ grau de escolas da zona rural de 54 municipios do Estado de São Paulo, 1973-1983.

\begin{tabular}{ccccccc}
\hline $\begin{array}{c}\text { Idade } \\
\text { (anos) }\end{array}$ & \multicolumn{2}{c}{ Feminino } & \multicolumn{2}{c}{ Masculino } & \multicolumn{2}{c}{ Feminino+ Masculino } \\
\hline 6 & 3 & $\%$ & $\mathrm{~N}^{\circ}$ & $\%$ & $\mathrm{~N}^{\circ}$ & $\%$ \\
7 & 33 & 27,0 & 30 & 26,1 & 63 & 26,6 \\
8 & 20 & 16,4 & 23 & 20,0 & 43 & 18,1 \\
9 & 21 & 17,2 & 19 & 16,5 & 40 & 16,9 \\
10 & 22 & 18,0 & 15 & 13,0 & 37 & 15,6 \\
11 & 6 & 4,9 & 10 & 8,7 & 16 & 6,8 \\
12 & 10 & 8,2 & 4 & 3,5 & 14 & 5,9 \\
13 & 4 & 3,3 & 7 & 6,1 & 11 & 4,6 \\
14 & 1 & 0,8 & 1 & 0,9 & 2 & 0,8 \\
15 & 1 & 0,8 & 1 & 0,9 & 2 & 0,8 \\
16 & 1 & 0,8 & 0 & 0,0 & 1 & 0,4 \\
17 & 0 & 0,0 & 1 & 0,9 & 1 & 0,4 \\
\hline Total & 122 & 100,0 & 115 & 100,0 & 237 & 100,0 \\
\hline
\end{tabular}

Das 2207 amostras de sangue colhidas entre familiares e vizinhos próximos dos casos, $570(25,83 \%)$ resultaram reagentes para infecção chagásica, assim distribuidos: 455 $(79,83 \%)$ entre familiares e $115(20,17 \%)$ entre vizinhos. Em 21 casos de 85 em que havia relato de grau de parentesco, as mães foram sororreagentes; em 16 casos, mãe e pai; em 1 caso, mãe e avó. Dentre os 237 casos com resultados sorológicos reagentes ou duvidosos houve investigação preliminar em 170 deles $(71,73 \%)$. Foram classificados como: autóctones do município - 96 casos $(56,47 \%)$; autóctones da região - 22 casos $(12,94 \%)$; importados de outros Estados da Federação - 48 casos $(28,23 \%)$; induzidos - 2 casos $(1,18 \%)$ e inconclusivos -2 casos com possibilidades de terem sido induzido ou autóctone $\mathrm{e}$ induzido ou congênito $(1,18 \%)$ 
A classificação epidemiológica dos casos segundo ano de nascimento está apresentada na Tabela 4.1.2.5.

Tabela 4.1.2.5 - Classificação de casos de infecção chagásica segundo ano de nascimento, de escolares da $1^{\text {a }}$ série do $1^{\circ}$ grau de escolas rurais de 54 municípios do Estado de São Paulo, 1973-1983.

\begin{tabular}{|c|c|c|c|c|c|c|c|c|c|c|c|c|c|c|}
\hline \multirow{2}{*}{$\begin{array}{l}\text { Ano } \\
\text { nasc. }\end{array}$} & \multicolumn{2}{|c|}{ AUM } & \multicolumn{2}{|c|}{ AUR } & \multicolumn{2}{|c|}{ IMP } & \multicolumn{2}{|c|}{ IND } & \multicolumn{2}{|c|}{ INC } & \multicolumn{2}{|c|}{ IGN } & \multicolumn{2}{|c|}{ Total } \\
\hline & $\mathrm{N}^{\circ}$ & $\%$ & $N^{\circ}$ & $\%$ & $N^{o}$ & $\%$ & $N^{o}$ & $\%$ & $\mathrm{~N}^{0}$ & $\%$ & $\mathrm{~N}^{0}$ & $\%$ & $N^{0}$ & $\%$ \\
\hline 1958 & 0 & 0,0 & 0 & 0,0 & $\mathrm{I}$ & 2,1 & 0 & 0,0 & 0 & 0,0 & 0 & 0,0 & 1 & 0,4 \\
\hline 1959 & 1 & 1,0 & 0 & 0,0 & 1 & 2,1 & 0 & 0,0 & 0 & 0,0 & 0 & 0,0 & 2 & 0,8 \\
\hline 1960 & 0 & 0,0 & 0 & 0,0 & 4 & 8,3 & 0 & 0,0 & 0 & 0,0 & 0 & 0,0 & 4 & 1,7 \\
\hline 1961 & 5 & 5,2 & 0 & 0,0 & 1 & 2,1 & 0 & 0,0 & 0 & 0,0 & 0 & 0,0 & 6 & 2,5 \\
\hline 1962 & 2 & 2,1 & 0 & 0,0 & 0 & 0,0 & 0 & 0,0 & 0 & 0,0 & 0 & 0,0 & 2 & 0,8 \\
\hline 1963 & 4 & 4,2 & 3 & 13,6 & 4 & 8,3 & 0 & 0,0 & 0 & 0,0 & 5 & 7,5 & 16 & 6,8 \\
\hline 1964 & 10 & 10,4 & l & 4,5 & 11 & 23,0 & 0 & 0,0 & 0 & 0,0 & 8 & 11,9 & 30 & 12,7 \\
\hline 1965 & 15 & 15,6 & 4 & 18,3 & l & 2,1 & 0 & 0,0 & 0 & 0,0 & 14 & 20,9 & 34 & 14,4 \\
\hline 1966 & 21 & 22,0 & 3 & 13,6 & 3 & 6,2 & 0 & 0,0 & 0 & 0,0 & 16 & 23,9 & 43 & 18,2 \\
\hline 1967 & 17 & 17,7 & 6 & 27,3 & 6 & 12,5 & 0 & 0,0 & 0 & 0,0 & 19 & 28,3 & 48 & 20,3 \\
\hline 1968 & 6 & 6,2 & 2 & 9,1 & 4 & 8,3 & 0 & 0,0 & 0 & 0,0 & 4 & 6,0 & 16 & 6,7 \\
\hline 1969 & 4 & 4,2 & 2 & 9,1 & 3 & 6,2 & 0 & 0,0 & 1 & 50,0 & 0 & 0,0 & 10 & 4,2 \\
\hline 1970 & 3 & 3,1 & 1 & 4,5 & 4 & 8,3 & 1 & 50,0 & 0 & 0,0 & 0 & 0,0 & 9 & 3,8 \\
\hline 1971 & 3 & 3,1 & 0 & 0,0 & 1 & 2,1 & 0 & 0,0 & 0 & 0,0 & 1 & 1,5 & 5 & 2,1 \\
\hline 1972 & l & 1,0 & 0 & 0,0 & 2 & 4,2 & 0 & 0,0 & 0 & 0,0 & 0 & 0,0 & 3 & 1,3 \\
\hline 1973 & 2 & 2,1 & 0 & 0,0 & 0 & 0,0 & 1 & 50,0 & 1 & 50,0 & 0 & 0,0 & 4 & 1,7 \\
\hline 1974 & 2 & 2,1 & 0 & 0,0 & 0 & 0,0 & 0 & 0,0 & 0 & 0,0 & 0 & 0,0 & 2 & 0,8 \\
\hline 1975 & 0 & 0,0 & 0 & 0,0 & 2 & 4,2 & 0 & 0,0 & 0 & 0,0 & 0 & 0,0 & 2 & 0,8 \\
\hline Total & 96 & 100.0 & 22 & 100.0 & $\overline{48}$ & 100.0 & 2 & 100.0 & 2 & 100.0 & 67 & 100.0 & 237 & 100,0 \\
\hline
\end{tabular}

Quanto à naturalidade dos casos, os Estados Federativos distribuíram-se em:

$$
\begin{aligned}
& \text { SP - } 152 \text { casos }(74,51 \%) \\
& \text { MG }-25 \operatorname{casos}(12,26 \%) \\
& \text { PR }-10 \operatorname{casos}(4,90 \%) \\
& \text { BA - } 7 \text { casos }(3,43 \%) \\
& \text { AL }-6 \text { casos }(2,94 \%) \text { e } \\
& \text { MT }-4 \operatorname{casos}(1,96 \%)
\end{aligned}
$$


Observando-se a distribuição de casos segundo sua classificação e ano de nascimento, nos Serviços Regionais de São Vicente (SR-2), de Sorocaba (SR-4) e nos demais da SUCEN, verifica-se que, no SR-2 houve concentração de casos importados $(94,05 \%)$, no SR-4 predominaram os autóctones $(85,71 \%)$ e nos demais SRs $50,00 \%$ dos casos foram autóctones, $43,05 \%$ importados, $2,78 \%$ induzidos e 4,17\% foram inconclusivos (Tabela 4 126) Um dos casos autóctones da região de São Vicente (SR-2) foi descrito como forma de transmissão por manipulação de caça (FORATTINI et al. ${ }^{85} 1981$ )

Tabela 4.1.2.6 - Classıficação de casos de infecção chagásica segundo ano de nascimento, nos Serviços Regionais da SUCEN de São Vicente, Sorocaba e nos demais, de escolares da $1^{a}$ série do $1^{\circ}$ grau de escolas rurais de 54 municipios do Estado de São Paulo, 1973-1983.

\begin{tabular}{|c|c|c|c|c|c|c|c|c|}
\hline \multirow{2}{*}{$\begin{array}{l}\text { Ano } \\
\text { Nasc. }\end{array}$} & \multicolumn{2}{|c|}{$\mathrm{SR}-2$} & \multicolumn{2}{|c|}{$S R-4$} & \multicolumn{4}{|c|}{ Demais SRs } \\
\hline & AUT & IMP & AUT & IMP & AUT & IMP & IND & INC \\
\hline 1958 & 0 & 1 & 0 & 0 & 0 & 0 & 0 & 0 \\
\hline 1959 & 0 & 0 & 1 & 0 & 0 & 1 & 0 & 0 \\
\hline 1960 & 0 & 0 & 0 & 0 & 0 & 4 & 0 & 0 \\
\hline 1961 & 0 & 0 & 3 & 0 & 2 & 1 & 0 & 0 \\
\hline 1962 & 0 & 0 & 1 & 0 & 1 & 0 & 0 & 0 \\
\hline 1963 & 0 & 0 & 3 & 1 & 4 & 3 & 0 & 0 \\
\hline 1964 & 0 & 2 & 7 & 1 & 4 & 8 & 0 & 0 \\
\hline 1965 & 1 & 0 & 14 & 0 & 4 & 1 & 0 & 0 \\
\hline 1966 & 0 & 0 & 16 & 0 & 8 & 3 & 0 & 0 \\
\hline 1967 & 0 & 2 & 16 & 0 & 7 & 5 & 0 & 0 \\
\hline 1968 & 0 & 2 & 7 & 0 & 1 & 2 & 0 & 0 \\
\hline 1969 & 0 & 1 & 5 & 1 & 1 & 0 & 0 & 1 \\
\hline 1970 & 0 & 2 & 2 & 1 & 2 & 1 & 1 & 0 \\
\hline 1971 & 0 & 0 & 2 & 1 & 1 & 0 & 0 & 0 \\
\hline 1972 & 0 & 2 & 0 & 0 & 0 & 0 & 0 & 1 \\
\hline 1973 & 1 & 0 & 1 & 0 & 0 & 0 & 1 & 1 \\
\hline 1974 & 0 & 0 & 1 & 0 & 1 & 0 & 0 & 0 \\
\hline 1975 & 0 & 0 & 0 & 0 & 0 & 2 & 0 & $\underline{0}$ \\
\hline Total & 2 & 12 & 79 & 5 & 36 & 31 & 2 & 3 \\
\hline
\end{tabular}

$\mathrm{AUT}=$ autoctone; $\mathrm{IMP}=$ importado; $\mathrm{IND}=$ induzido; $\mathrm{INC}=$ inconclusivo 


\subsection{Do inquérito realizado em Taquarituba, entre 1974 e 1976}

A amostra da população selecionada incluiu $26,4 \%$ das casas e $30,7 \%$ dos habitantes da zona rural de Taquarituba, distribuidos entre as localidades: Bairro dos Campos, Bairro dos Neves, Bairro dos Nunes, Bairro dos Leites e Bairro do Pico.

Selecionaram-se para análise os resultados correspondentes a 2784 amostras de sangue, de um total de 2871 (87 duvidosos foram rejeitados). Por falta de informações suficientes, excluiram-se 739 amostras da análise de tempo de moradia na casa, ficando $n=$ 2079

A soroprevalência na população examinada foi de $13,6 \%$, sem diferença significativa entre as localidades ( $p=0,053)$, como se vê na Tabela 4.1, ainda que o Bairro dos Campos apresentasse proporção de soropositividade mais elevada do que as observadas nos outros

Tabela 4.2.1 - Sororreatividade para infecção chagásica de habitantes de Taquarituba, SP, Brasil, 1974 a 1976

\begin{tabular}{lccccc}
\hline Localidade & $\begin{array}{c}\text { Amostras } \\
\text { examinadas }\end{array}$ & \multicolumn{2}{c}{ Amostras positivas } & \multicolumn{2}{c}{ Amostras negativas } \\
& No & $\%$ & $\mathrm{~N}^{\circ}$ & $\%$ \\
\hline Campos & 731 & 123 & 16,8 & 608 & 83,2 \\
Neves & 473 & 55 & 11,6 & 418 & 88,4 \\
Nunes & 597 & 73 & 12,2 & 524 & 87,8 \\
Pico & 576 & 72 & 12,5 & 504 & 87,5 \\
Leites & 407 & 57 & 14,0 & 350 & 86,0 \\
\hline Total & 2784 & 380 & 13,6 & 2404 & 86,4 \\
\hline
\end{tabular}


A Tabela 4.2 .2 mostra a distribuição da soropositividade por local de nascimento Os nascidos em Taquarituba $(n=1752)$ contribuíram com $62,9 \%$ das amostras e $62,4 \%$ de todos os soropositivos (237/380). Esta proporção atingiu $85,5 \%$ quando foram incluídos os municípios vizinhos; 95,3\% quando incluídos todos os nascidos na Região de Sorocaba e $97,1 \%$ para os nascidos no Estado de São Paulo.

Tabela 4.2.2 - Sororreatividade para infecção chagásica, por local de nascimento, de habitantes de Taquarituba. SP, Brasil, 1974 a 1976.

\begin{tabular}{|c|c|c|c|c|c|c|}
\hline \multirow{2}{*}{ Local de nascimento } & \multicolumn{2}{|c|}{ Total } & \multicolumn{2}{|c|}{ Positivos } & \multicolumn{2}{|c|}{ Negativos } \\
\hline & $N^{0}$ & $\%$ & $N^{\circ}$ & $\%$ & $N^{0}$ & $\%$ \\
\hline Taquarituba & 1752 & 62,9 & 237 & 62,4 & 1515 & 63,0 \\
\hline Municipios vizinhos & 319 & 11.5 & 62 & 16,3 & 257 & 10,7 \\
\hline Sorocaba e vizinhanças & 466 & 16,7 & 67 & 17,6 & 399 & 16,6 \\
\hline Outras regiões de S. Paulo & 138 & 5,0 & 3 & 0,8 & 135 & 5,6 \\
\hline Outros estados & 106 & 3,8 & 11 & 2,9 & 95 & 4,0 \\
\hline Paises estrangeiros & 3 & 0,1 & 0 & 0,0 & 3 & 0,1 \\
\hline Total & 2784 & 100,0 & 380 & 100,0 & 2404 & 100,0 \\
\hline
\end{tabular}

A permanència na casa atual foi de 9,4 anos em média (mediana $=4,0$ anos). Um grupo de 870 pessoas $(41,8 \%$ da população estudada), com idades entre 0 e 82 anos, havia sempre morado na mesma casa. Dentro deste grupo, a duração média de residência era de 14,9 anos (mediana $=10,0$ anos). Encontrou-se pelo menos um ocupante soropositivo em 273 das 498 casas visitadas $(54,8 \%)$ e em 31 delas $(6,2 \%)$ foi observada soropositividade em mais da metade dos moradores.

A distribuição de soropositividade por grupo etário é mostrada na Tabela 4.2.3. A proporção de soropositivos aumentou com a idade até atingir $30,3 \%$ no grupo de $30-39$ anos (média $=24,2$ anos), caindo para $21,4 \%$, em média, nos grupos etários mais elevados (40 anos ou mais). 
Tabela 4.2.3 - Soropositividade para infecção chagásica, por grupo etário, de habitantes do Municipio de Taquarituba, SP, Brasil, 1974 a 1976

\begin{tabular}{ccccccc}
\hline $\begin{array}{c}\text { Grupo etário } \\
\text { (anos) }\end{array}$ & $\begin{array}{c}\text { Média de idade } \\
\text { (anos) }\end{array}$ & $\begin{array}{c}\text { Amostras } \\
\text { examinadas }\end{array}$ & $\mathrm{N}^{\text {O }}$ & $\%$ & $\mathrm{~N}^{\text {ositivas }}$ & $\%$ \\
\hline \hline $0-9$ & 4,1 & 856 & 9 & 1,1 & 847 & 99,0 \\
$10-14$ & 11,9 & 354 & 32 & 9,0 & 322 & 91,0 \\
$15-19$ & 17,0 & 342 & 45 & 13,2 & 279 & 81,6 \\
$20-29$ & 24,0 & 487 & 111 & 22,8 & 376 & 77,2 \\
$30-39$ & 37,2 & 264 & 80 & 30,3 & 184 & 69,7 \\
$40-49$ & 44,0 & 223 & 53 & 23,8 & 170 & 76,2 \\
$50-59$ & 54,0 & 133 & 21 & 15,8 & 112 & 84,2 \\
$60-69$ & 63,5 & 83 & 19 & 22,8 & 64 & 77,1 \\
$70-88$ & 75,0 & 42 & 10 & 23,8 & 32 & 76,2 \\
\hline \hline Total & 21,7 & 2784 & 380 & 13,7 & 2404 & 86,4 \\
\hline \hline
\end{tabular}

A proporção de soropositivos na amostra analisada foi de $13,6 \%$, sem diferença significativa entre sexos: $13,3 \%$ (177 casos/1 338 amostras) no sexo feminino e 14,0\% (203 casos/1 446 amostras) no masculino $(p=0,626)$.

\section{Estimativa da relação entre idade e sororreatividade para infecção chagásica}

Do cálculo da equação da reta (Figura 4.2), em que $x=$ média de idades dentro de cada grupo etário (transformada em logaritmos) e $y=$ percentagem de soropositivos (transformada em probitos) resultaram: $a=1,089 ; b=2,278 ; r^{2}=0,965 . \operatorname{IC}_{95 \%}(b)=$ $[2,040 ; 2,517]$. O tempo necessário para que $25 \%$ da população passasse de soronegativa para soropositiva, calculado por meio de probitos, foi de 26,00 anos: $\operatorname{IC}_{95 \%}(t)=[23,38$ anos, 30,00 anos]. Obtida por extrapolação, a idade em que teoricamente $50 \%$ da população passaria a soropositiva foi estimada em 50,70 anos: $\operatorname{IC}_{95 \%}(t)=[41,39 ; 68,78$ anos] 


\section{$\%$ Probitos}

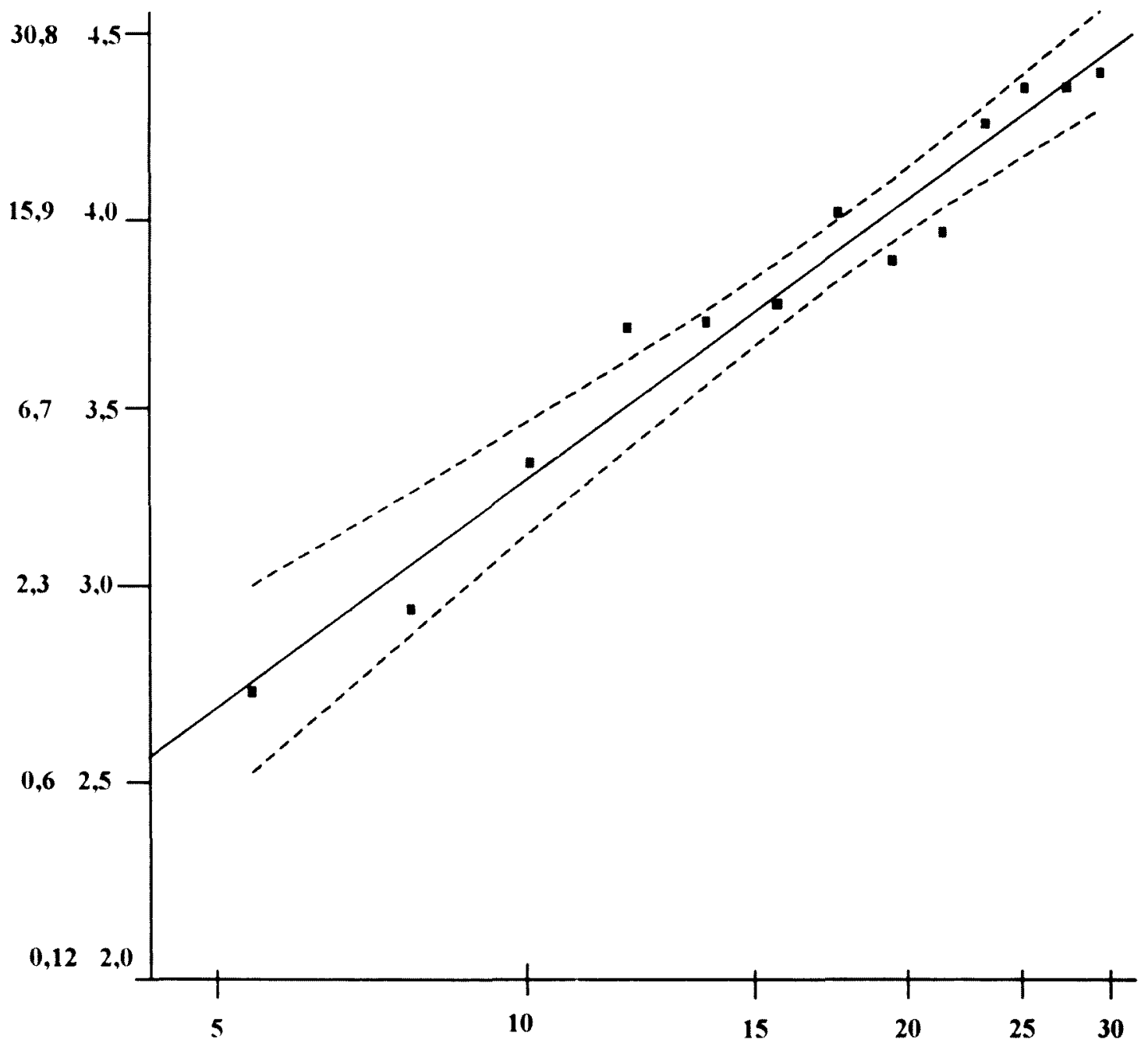

Idade (anos)

Figura 4.2 - Relação entre médias de idades (em anos) transformadas em logaritmos e probitos de soropositividade para infecção chagásica. Taquarituba, SP, 1974 - 1976. 


\subsection{Dos inquéritos nos municípios das Microrregiōes Campos de Itapetininga, entre 1976 e 1978 e Encosta Ocidental da Mantiqueira Paulista, em 1980}

\subsubsection{Municípios da Microrregião Campos de Itapetininga}

Os dez municipios dessa microrregião distribuem-se pelas Regiões de Governo de Avaré, municipios: Barão de Antonina e Itaporanga; Itapetininga, municípios: Angatuba, Guarei e Itapetininga e Itapeva, municipios: Buri, Itaberá, Itapeva, Itararé e Riversul, por sua vez inseridos no Serviço Regional da SUCEN de Sorocaba. Ocupam área de $9591 \mathrm{~km}^{2}(3,86 \% \text { do Estado })^{92}$.

A Tabela 4.3.1.1 apresenta o total de amostras examinadas e reagentes para infecção chagásica, bem como o número de localidades existentes e trabalhadas. Os percentuais de reatividade variaram de 2,89 a 19,22 , respectivamente, nos municípios Itarare e Itaporanga. A positividade na população em geral foi de 10,21\%

Tabela 4.3.1.1 - Sorologia para infecção chagásica na microrregião Campos de Itapetininga, Estado de São Paulo, 1976-1978

\begin{tabular}{lrrrrrrr}
\hline Municipio & $\begin{array}{r}\mathrm{N}^{\circ} \text { loc. } \\
\text { exist. }\end{array}$ & $\begin{array}{r}\mathrm{N}^{\circ} \text { loc. } \\
\text { trab. }\end{array}$ & $\begin{array}{r}\% \text { loc. } \\
\text { trab. }\end{array}$ & $\begin{array}{r}\mathrm{N}^{0} \text { am. } \\
\text { colhidas }\end{array}$ & $\begin{array}{r}\mathrm{N}^{\circ} \text { am. } \\
\text { reagentes }\end{array}$ & $\begin{array}{r}\% \text { am. } \\
\text { reagentes }\end{array}$ & $\begin{array}{r}\text { IC** dos } \\
\text { reag. (\%) }\end{array}$ \\
\hline Angatuba & 35 & 5 & 14,29 & 1215 & 116 & 9.55 & $8,02-11,33$ \\
Barão de Antonina & 9 & 1 & 11.11 & 158 & 26 & 16.46 & $11,48-23,02$ \\
Buri & 27 & 3 & 11.11 & 487 & 17 & 3.49 & $2,19-5,52$ \\
Guarei & 21 & 4 & 19,05 & 703 & 45 & 6,40 & $4,82-8,46$ \\
Itaberá & 39 & 10 & 25,64 & 3014 & 552 & 18.32 & $16,97-19,74$ \\
Itapetininga & 70 & 11 & 15,71 & 2513 & 114 & 4.54 & $3.79-5,42$ \\
Itapeva & 42 & 7 & 16,67 & 3230 & 291 & 9.01 & $8,07-10,05$ \\
Itaporanga & 24 & 4 & 16.67 & 1441 & 277 & 19.22 & $17,27-21,34$ \\
Itararé & 43 & 6 & 13,95 & 1557 & 45 & 2,89 & $2,17-3,85$ \\
Riversul & 23 & 4 & 17,39 & 799 & 60 & 7.51 & $5,88-9.55$ \\
\hline Total & 333 & 55 & 16.52 & 15117 & 1543 & 10.21 & $9.73-10.70$ \\
\hline
\end{tabular}

*Fonte: SUCEN/DCV/DOT-Listagem de localidades por municipios dos Serviços Reginnais.

**IC=Intervalo de Confiança (95\%).

Nas 55 localidades trabalhadas a reatividade variou de 0,22 a $33,15 \%$, sendo que o resultado foi nulo apenas em uma delas, ou 1,8\% dos casos (Tabela 4.3.1.2). 
Tabela 4.3.1.2 - Sorologia para infecção chagásica em localidades dos municípios da microrregião Campos de Itapetininga, Estado de São Paulo, 1976-1978

\begin{tabular}{|c|c|c|c|c|c|c|c|}
\hline Localidade & $\begin{array}{l}N^{\circ} \text { am } \\
\text { exam. }\end{array}$ & $\begin{array}{l}\text { No am. } \\
\text { reag. }\end{array}$ & $\begin{array}{r}\% \text { am. } \\
\text { reag. }\end{array}$ & Localidade & $\begin{array}{l}\mathrm{N}^{\circ} \text { am. } \\
\text { exam. }\end{array}$ & $\begin{array}{c}\mathrm{N}^{\circ} \text { am. } \\
\text { reag. }\end{array}$ & $\begin{array}{r}\% \text { am. } \\
\text { reag. }\end{array}$ \\
\hline \multicolumn{8}{|c|}{ Angatuba } \\
\hline $\mathrm{B}^{\circ}$ dos Buenos & 177 & 8 & 4.52 & $\mathrm{~B}^{\mathrm{c}}$ do Salto & 515 & 65 & 12,62 \\
\hline $\mathrm{B}^{\circ}$ dos Nunes & 123 & 7 & 5.69 & Faz. União & 127 & 11 & 8,66 \\
\hline $\mathrm{B}^{\circ}$ Ribeirão Grande & 273 & 25 & 9.16 & & & & \\
\hline \multicolumn{8}{|c|}{ Barão de Antonina } \\
\hline $\mathrm{B}^{\circ}$ Barragem & 158 & 26 & 16.46 & & & & \\
\hline \multicolumn{8}{|c|}{ Buri } \\
\hline $\mathrm{B}^{\circ}$ Enxovia & 136 & 4 & 2.94 & $\mathrm{~B}^{\circ}$ Vitorino Camilo & 241 & 12 & 4,98 \\
\hline $\mathrm{B}^{\circ}$ Fundão & 110 & 1 & 0.91 & & & & \\
\hline \multicolumn{8}{|c|}{ Guarei } \\
\hline $\mathrm{B}^{\circ}$ da Areia Branca & 286 & 25 & 8.74 & $\mathrm{~B}^{\circ}$ dos Lemes & 82 & 5 & 6,10 \\
\hline $\mathrm{B}^{\circ}$ da Capela Velha & 87 & 5 & 5.75 & $\mathrm{~B}^{\circ}$ do Rincão & 248 & 10 & 4,03 \\
\hline \multicolumn{8}{|c|}{ Itaberá } \\
\hline $\mathrm{B}^{\prime}$ Agua Amarela & 872 & 144 & 16.51 & $\mathrm{~B}^{\circ}$ Passa Três & 143 & 43 & 30.07 \\
\hline $\mathrm{B}^{\prime \prime}$ Est Eng Maia & 497 & 71 & 14.29 & $\mathrm{~B}^{\circ}$ Pirituba & 337 & 65 & 19,29 \\
\hline $\mathrm{B}^{\circ}$ Limeira & +13 & 75 & 18.16 & $\mathrm{~B}^{\circ}$ Ponte Alta & 69 & 8 & 11.59 \\
\hline $\mathrm{B}^{\prime \prime}$ Mangueiro Gde & 356 & 118 & 33.15 & $\mathrm{~B}^{\circ}$ Ribeirão Bonito & 53 & 7 & 13.21 \\
\hline $\mathrm{B}^{\circ}$ Mestre Pedro & 118 & 5 & +.24 & $\mathrm{~B}^{\circ}$ Sta Label & 156 & 16 & 10.26 \\
\hline \multicolumn{8}{|c|}{ ltapetininga } \\
\hline $\mathrm{B}^{\circ}$ Bernardi & 190 & 20 & 10.53 & Faz. Sta. Luzia & 40 & 1 & 2,50 \\
\hline $\mathrm{B}^{\circ}$ Campo Grande & 274 & 10 & 3,65 & Faz. São João & 99 & 9 & 9,09 \\
\hline $\mathrm{B}^{\circ}$ Capivari & 89 & 1 & 1.12 & $\mathrm{~B}^{\circ}$ dos Soares & 327 & 10 & 3,06 \\
\hline $\mathrm{B}^{\circ}$ Cesário & 158 & 6 & 3,80 & $\mathrm{~B}^{\circ}$ Tijuco Preto & 295 & 12 & 4,07 \\
\hline $\mathrm{B}^{\circ}$ Chapada Gde. & 695 & 34 & 4.89 & $\mathrm{~B}^{\circ}$ dos Elias & 66 & 6 & 9,09 \\
\hline $\mathrm{B}^{\circ}$ Sabiá Una & 280 & 5 & 1.79 & & & & \\
\hline \multicolumn{8}{|c|}{ Itapeva } \\
\hline $\mathrm{B}^{\circ}$ Amarela Velha & 661 & 114 & 17.25 & $\mathrm{~B}^{\circ}$ da Sanbra & 330 & 17 & 5,15 \\
\hline $\mathrm{B}^{\circ}$ Areia Branca & 889 & 61 & 6.86 & $\mathrm{~B}^{\circ}$ Estação de Jaó & 240 & 22 & 9,17 \\
\hline Faz. Barreiro Gde. & 388 & 37 & 9.54 & $\mathrm{~B}^{\circ}$ da Serrinha & 475 & 23 & 4.84 \\
\hline$B^{\prime \prime}$ Mato Dentro & 247 & 19 & 7.69 & & & & \\
\hline \multicolumn{8}{|c|}{ Itaporanga } \\
\hline $\mathrm{B}^{\circ}$ Barra da Onça & 447 & 100 & 0.22 & $\mathrm{~B}^{\circ}$ Capituva & 64 & 10 & 15,62 \\
\hline $\mathrm{B}^{\circ}$ Lageado & 624 & 88 & 14,10 & $\mathrm{~B}^{\circ}$ do Soalho & 306 & 79 & 25,82 \\
\hline \multicolumn{8}{|c|}{ Itararé } \\
\hline $\mathrm{B}^{\circ}$ Embuia & 75 & 4 & 5,33 & $\mathrm{~B}^{\circ}$ Ibiti Sorocabana & 48 & 4 & 8,33 \\
\hline $\mathrm{B}^{\circ}$ Cerrado & 535 & 27 & 5.05 & $\mathrm{~B}^{\circ}$ Bom Sucesso & 269 & 2 & 0,74 \\
\hline $\mathrm{B}^{\circ}$ Serrinha I & 183 & 5 & 2.73 & $\mathrm{~B}^{\circ}$ Itambé & +47 & 3 & 0.67 \\
\hline \multicolumn{8}{|c|}{ Riversul } \\
\hline $\mathrm{B}^{\circ}$ da Lagem & 28 & 0 & 0,00 & $\mathrm{~B}^{\circ}$ Morro Alto & 178 & 6 & 3,37 \\
\hline $\mathrm{B}^{\circ}$ Can Can & 178 & 8 & 4.49 & $\mathrm{~B}^{\circ}$ Sapezal & +15 & 46 & 11.08 \\
\hline
\end{tabular}

A reatividade sorológica distribuiu-se igualmente entre os sexos $(p=0,130)$ (Tabela 
Tabela 4.3.1.3 - Sororreatividade para infecção chagásica, por grupo etário e sexo, em população de zona rural dos municipios da microrregião Campos de Itapetininga, Estado de São Paulo, 1976-1978.

\begin{tabular}{crrrrrrrrr}
\hline $\begin{array}{l}\text { Grupo } \\
\text { etario } \\
\text { (anos) }\end{array}$ & $\begin{array}{r}N^{\circ} \text { am } \\
\text { exam. }\end{array}$ & $\begin{array}{r}N^{\circ} \text { am } \\
\text { reag }\end{array}$ & $\begin{array}{r}\% \text { am. } \\
\text { reag. }\end{array}$ & $\begin{array}{r}N^{\circ} \text { am. } \\
\text { exam. }\end{array}$ & $\begin{array}{r}N^{\circ} \text { am. } \\
\text { reag. }\end{array}$ & $\begin{array}{r}\% \text { am. } \\
\text { reag. }\end{array}$ & $\begin{array}{r}N^{\circ} \text { am. } \\
\text { exam. }\end{array}$ & $\begin{array}{r}N^{\circ} \text { am. } \\
\text { reag. }\end{array}$ & $\begin{array}{r}\% \text { am. } \\
\text { reag. }\end{array}$ \\
\hline$<1$ & 136 & 0 & 0,00 & 122 & 0 & 0,00 & 258 & 0 & 0,00 \\
$1-4$ & 956 & 11 & 1,15 & 989 & 9 & 0,91 & 1945 & 20 & 1,03 \\
$5-9$ & 1303 & 26 & 2,00 & 1252 & 19 & 1,52 & 2555 & 45 & 1,76 \\
$10-14$ & 1091 & 77 & 7,06 & 1038 & 54 & 5,20 & 2129 & 131 & 6,15 \\
$15-19$ & 765 & 87 & 11,37 & 667 & 87 & 13,04 & 1432 & 174 & 12,15 \\
$20-29$ & 1164 & 216 & 18,56 & 941 & 229 & 24,34 & 2105 & 445 & 21,14 \\
$30-39$ & 904 & 159 & 17,59 & 709 & 161 & 22,71 & 1613 & 320 & 19,84 \\
$40-49$ & 686 & 97 & 14,14 & 608 & 109 & 17,93 & 1294 & 206 & 15,92 \\
$50-59$ & 426 & 57 & 13,38 & 468 & 44 & 9,40 & 894 & 101 & 11,30 \\
$60-69$ & 278 & 29 & 10,43 & 339 & 41 & 12,09 & 617 & 70 & 11,34 \\
$\geq 70$ & 111 & 11 & 9,91 & 164 & 20 & 12,19 & 275 & 31 & 11,27 \\
\hline Total & 7820 & 770 & 9,85 & 7297 & 773 & 10,59 & 15117 & 1543 & 10,21 \\
\hline
\end{tabular}

As idades da população trabalhada variaram de 1 mês a 94 anos, sendo a média igual a 22,81 anos, mediana, 17,0 anos, $25 \%$ com até 8,0 anos e $75 \%$ com até 35,0 anos. Quanto à distribuição por sexo, 7820 foram do grupo feminino $(51,7 \%)$ e 7297 do grupo masculino $(48,3 \%)$. No conjunto dos reagentes sorológicos, as idades variaram de 1 a 89 anos, com a média igual a 31,22 anos, mediana, 28,00 anos, $25 \%$ com até 20,00 anos e $75 \%$ com até 40,00 anos

$\mathrm{Na}$ distribuição de frequência de reatividade sorológica para infecção chagásica segundo grupos etários, em Campos de Itapetininga (CI), nota-se uma ascensão até o grupo 20-29 anos, seguida de declínio nos demais grupos, permanecendo praticamente invariável nas idades acima de 49 anos (Figura 4.3a). Do mesmo modo observamos na Figura 4.3b, curva bimodal de distribuição de frequêencias de títulos sorológicos. A média geométrica de títulos dos reagentes foi igual a 100, tendo variado de 20 a $5: 20$.

Na população geral ( $n=14327$ ), o tempo de moradia na residência atual foi de 5,8 anos em média, mediana de 3,0 anos, $25 \%$ com até 1,0 ano e $75 \%$ com até 8,0 anos. No grupo dos sororreagentes $(n=1516)$ os valores não foram significativamente diferentes: média igual a 5,9 anos e demais com os mesmos valores do grupo geral da população. Em 
ambas situações foram subtraidos os casos em que não se dispôs das informações sobre tempo de moradia, respectivamente 790 e 27 amostras. Em 2410 casos (16,82\%), o tempo de moradia na casa foi igual à idade. Nessa condição, a média da idade (e do tempo de moradia) foi de 8,1 anos, mediana, 5,0 anos, $25 \%$ com até 2,0 anos e $75 \%$ com até 11,0 anos

\subsubsection{Municípios da Microrregião Encosta Ocidental da Mantiqueira Paulista}

Os doze municipios dessa microrregião: Águas da Prata, Caconde, Divinolândia, Espirito Santo do Pinhal, Itobi, Mococa, Santo Antônio do Jardim, São João da Boa Vista, São José do Rio Pardo, São Sebastião da Grama, Tapiratiba e Vargem Grande do Sul pertencem a uma única Região de Governo, de São João da Boa Vista, do Serviço Regional da SUCEN de Campinas. Ocupam área de $3989 \mathrm{~km}^{2}$ (1,61\% do Estado) ${ }^{92}$.

A Tabela 4.3.2.1 apresenta o total de amostras examinadas e reagentes para infecção chagásica e o número de localidades existentes e trabalhadas. Os percentuais de reatividade variaram de 0,78 a 6,62, respectivamente nos municípios Santo Antônio do Jardim e Caconde. A positividade na população em geral foi de $3,00 \%$

Tabela 4.3.2.1 - Sorologia para infecção chagásica na microrregião Encosta Ocidental da Mantiqueira Paulista, Estado de São Paulo, 1980.

\begin{tabular}{|c|c|c|c|c|c|c|c|}
\hline Municipio & $\begin{array}{l}\mathrm{N}^{0} \mathrm{loc} . \\
\text { exist.* }\end{array}$ & $\begin{array}{r}N^{0} \text { loc. } \\
\text { trab. }\end{array}$ & $\begin{array}{c}\% \text { loc. } \\
\text { trab. }\end{array}$ & $\begin{array}{c}\mathrm{N}^{0} \text { am } \\
\text { colhidas }\end{array}$ & $\begin{array}{l}\mathrm{N}^{\circ} \text { am. } \\
\text { reagentes }\end{array}$ & $\begin{array}{r}\% \text { am } \\
\text { reagentes }\end{array}$ & $\begin{array}{l}\mathrm{IC}^{* *} \text { dos } \\
\text { reag. }(\%)\end{array}$ \\
\hline Águas da Prata & 21 & 5 & 23,81 & 794 & 8 & 1,01 & $0,51-1,98$ \\
\hline Caconde & 61 & 13 & 21,31 & 2371 & 157 & 6,62 & $5,69-7,69$ \\
\hline Divinolândia & 32 & 7 & 21.88 & 1278 & 35 & 2,74 & $1,98-3,78$ \\
\hline Espirito Sto. Pinhal & 67 & 14 & 20,90 & 1002 & 19 & 1,90 & $1,22-2,94$ \\
\hline Itobi & 32 & 5 & 15.63 & 288 & 10 & 3,47 & $1,90-6,27$ \\
\hline Mococa & 64 & 16 & 25,00 & 2822 & 101 & 3.58 & $2,95-4,33$ \\
\hline Sto Antônio Jardim & 27 & 7 & 25,93 & 773 & 6 & 6,78 & $0,36-1,68$ \\
\hline São João Boa Vista & 137 & 34 & 24.82 & 2685 & 53 & 1,97 & $1,51-2,57$ \\
\hline São José Rio Pardo & 89 & 19 & 21.35 & 2301 & 43 & 1,87 & $1,39-2,51$ \\
\hline S Sebastião Grama & 45 & 10 & 22,22 & 820 & 20 & 2,44 & $1.58-3,74$ \\
\hline Tapiratiba & 22 & 5 & 22,73 & 596 & 26 & 4,36 & $2,99-6,32$ \\
\hline Vargem Gde. Sul & 39 & 9 & 23.08 & 621 & 12 & 1,93 & $1,11-3,35$ \\
\hline Total & 636 & 144 & 22,64 & 16351 & 490 & 3.00 & $2,75-3,27$ \\
\hline
\end{tabular}

*Fonte: SUCEN/DCV/DOT-Listagem de localidades por municípios dos Serviços Regionais.

**IC=Intervalo de Confiança $(95 \%)$. 
Nas 144 localidades trabalhadas a reatividade variou de 0,00 a 11,63\% (Tabela 4.3.2.2)

Tabela 4.3.2.2 - Sorologia para infecção chagásica em localidades dos municípios da microrregião Encosta Ocidental da Mantiqueira Paulista, Estado de São Paulo, 1980.

\begin{tabular}{|c|c|c|c|c|c|c|c|}
\hline Localidade & $\begin{array}{l}N^{0} \text { am } \\
\text { exam. }\end{array}$ & $\begin{array}{l}\mathrm{N}^{\circ} \text { am. } \\
\text { reag. }\end{array}$ & $\begin{array}{r}\% \text { am. } \\
\text { reag. }\end{array}$ & Localidade & $\begin{array}{l}\mathrm{N}^{\circ} \text { am } \\
\text { exam. }\end{array}$ & $\begin{array}{c}\mathrm{N}^{\circ} \text { am. } \\
\text { reag. }\end{array}$ & $\begin{array}{r}\% \mathrm{am} . \\
\text { reag. }\end{array}$ \\
\hline \multicolumn{8}{|c|}{ Águas da Prata } \\
\hline Faz. Sta. Maria & 55 & 0 & 0.00 & $\mathrm{~B}^{\circ}$ Sobradinho & 24 & 1 & 4,17 \\
\hline$B^{\circ}$ São Roque & 557 & 6 & 1.08 & Periferia & 104 & 1 & 0,96 \\
\hline Faz. Prata & 54 & () & 0,00 & & & & \\
\hline \multicolumn{8}{|c|}{ Caconde } \\
\hline $\mathrm{B}^{\circ}$ Bom Jesus & 260 & 28 & 10,77 & $\mathrm{~B}^{\circ}$ Sta. Quitéria & 86 & 8 & 9,30 \\
\hline $\mathrm{B}^{\circ}$ Conceição & 81 & 2 & 2.47 & Faz. Barra Grande & 49 & 0 & 0,00 \\
\hline Faz. São Carlos & 100 & 10 & 10,00 & Faz. Zambuja & 132 & 6 & 4,54 \\
\hline $\mathrm{B}^{\circ}$ Braço Grande & 32 & 0 & 0.00 & Faz. Barreiro & 54 & 2 & 3,70 \\
\hline Faz. Boa Vista & 66 & 2 & 3,03 & $\mathrm{~B}^{\circ}$ Cór. do Engano & 90 & 8 & 8,89 \\
\hline $\mathrm{B}^{\circ}$ Cór da Vaca & 60 & 6 & 10,00 & $\mathrm{~B}^{\circ}$ Vila Barrânia & 270 & 5 & 1.85 \\
\hline Periferia & 1090 & 80 & 7.34 & & & & \\
\hline \multicolumn{8}{|c|}{ Divinolândia } \\
\hline Periferia & 319 & 16 & 5.02 & $\mathrm{~B}^{\circ}$ Pirapitinga III & 77 & 6 & 7,79 \\
\hline $\mathrm{B}^{\circ}$ Campestrinho & 359 & 4 & 1.11 & $\mathrm{~B}^{\circ}$ Vargem Grande & 234 & 4 & 1,71 \\
\hline $\mathrm{B}^{\circ}$ Conceiçăo & 118 & 4 & 3.39 & $\mathrm{~B}^{\circ}$ Plaino Alto & 19 & 0 & 0.00 \\
\hline $\mathrm{B}^{\circ}$ Pinhalzinho & 152 & 1 & 0.66 & & & & \\
\hline \multicolumn{8}{|c|}{ Espírito Santo do Pinhal } \\
\hline Faz. Sta. Vitória & 78 & 0 & 0.00 & Faz. Sta. Maria & 21 & 0 & 0,00 \\
\hline Faz. São João II & 73 & 0 & 0.00 & Faz. Sto. Antonio III & 72 & 0 & 0,00 \\
\hline Faz. Sta Tereza II & 76 & 1 & 1,32 & Faz. Sta. Hélida & 120 & 0 & 0,00 \\
\hline $\mathrm{B}^{\prime \prime}$ das Poças & 148 & 8 & 5,40 & Faz. Imbiruçu & 30 & 2 & 6,67 \\
\hline FazStoAnt Jangada & 48 & 0 & 0.00 & $\mathrm{~B}^{\circ}$ Areião & 103 & 4 & 3,88 \\
\hline Faz. Vila Verde & 21 & 1 & 4.76 & Faz. Sto. Antonio II & 29 & 1 & 3,45 \\
\hline $\mathrm{B}^{\circ}$ Catingueiro & 139 & 3 & 1.44 & Faz. Guarani & 44 & 0 & 0.00 \\
\hline \multicolumn{8}{|c|}{ Itobi } \\
\hline Faz. Rio Doce & 101 & 4 & 3.96 & $\mathrm{~B}^{\circ}$ Sítio São João & 12 & 0 & 0,00 \\
\hline Faz. Sta Cândida & 58 & 2 & 3,45 & Faz. Sto. Antônio & 35 & 0 & 0,00 \\
\hline Faz.Rio Doce Cima & 82 & 4 & 4,88 & & & & \\
\hline \multicolumn{8}{|c|}{ Mococa } \\
\hline Faz. Do Porto & 113 & 8 & 7,08 & Faz. Rozinha & 11 & 0 & 0,00 \\
\hline Chácara Recreio & 8 & 0 & 0.00 & Periferia & 450 & 23 & 5,11 \\
\hline $\mathrm{B}^{\circ}$ Ressaca & 23 & 1 &,+ 35 & Faz. São Bento & 277 & 9 & 3.25 \\
\hline Faz. Pessegueiro & 89 & 7 & 7,86 & Faz. Morro Azul & 474 & 15 & 3,16 \\
\hline $\mathrm{B}^{\circ}$ Cambuí & 240 & 2 & 0,83 & Faz. Alagoas & 79 & 0 & 0,00 \\
\hline $\mathrm{B}^{\circ}$ Sto. Antônio & 122 & 0 & 0.00 & Faz. Cafezal & 186 & 7 & 3,76 \\
\hline Faz.Sta Clara Serra & 88 & 3 & 3,41 & $\mathrm{~B}^{\circ}$ Caixeta I & 152 & 0 & 0,00 \\
\hline Di.S.Bened. Areias & 508 & 26 & 5.12 & Faz. Sta Eustáquia & 10 & 0 & 0,00 \\
\hline \multicolumn{8}{|c|}{ Santo Antônio do Jardim } \\
\hline Faz. Sta. Bárbara & 85 & 2 & 2,35 & Periferia & 225 & 2 & 0,89 \\
\hline $\mathrm{B}^{\circ}$ Sta. Bárbara I & 161 & () & 0,00 & Faz.Ret Sto Antônio & 118 & 1 & 0,85 \\
\hline $\mathrm{B}^{\circ}$ Sta. Maria & 50 & 0 & 0.00 & $\mathrm{~B}^{\circ}$ da Manteiga & 96 & 1 & 1,04 \\
\hline Faz. Santana & 30 & 0 & 0.00 & & & & \\
\hline
\end{tabular}




\begin{tabular}{|c|c|c|c|c|c|c|c|}
\hline Localidade & $\begin{array}{l}\mathrm{N}^{0} \text { am } \\
\text { exam }\end{array}$ & $\begin{array}{c}\mathrm{N}^{\circ} \text { am. } \\
\text { reag. }\end{array}$ & $\begin{array}{l}\% \text { am. } \\
\text { reag. }\end{array}$ & Localidade & $\begin{array}{l}N^{\circ} \text { am. } \\
\text { exam. }\end{array}$ & $\begin{array}{l}\mathrm{N}^{\circ} \text { am } \\
\text { reag. }\end{array}$ & $\begin{array}{l}\% \text { am. } \\
\text { reag. }\end{array}$ \\
\hline \multicolumn{8}{|c|}{ São João da Boa Vista } \\
\hline Periferia & 906 & 11 & 1.21 & $\mathrm{~B}^{\circ}$ Lagoa dos Patos & 32 & 0 & 0.00 \\
\hline Faz. Ribeirão & 14 & 1 & 7.14 & $B^{\circ}$ Serra dos Padres & 10 & 0 & 0,00 \\
\hline Faz. Da Barra & 24 & 2 & 8.33 & Sítio Boa Vista & 6 & 0 & 0,00 \\
\hline $\mathrm{B}^{\circ}$ Jaguari & 90 & 1 & 1.11 & Faz. Sta. Margarida & 28 & 0 & 0,00 \\
\hline Sítio São Pedro & 36 & 1 & 2.78 & $\mathrm{~B}^{\circ}$ Boa Vista & 70 & + & 5,71 \\
\hline Faz. Matãozinho & 36 & 0 & 0.00 & $\mathrm{~B}^{\circ}$ Cór. Fundo I & 48 & 1 & 2,08 \\
\hline Fda. Sta. Lzabel & 19 & 2 & 10.53 & $\mathrm{~B}^{\circ}$ Taquaral & 15 & 1 & 6,67 \\
\hline $\mathrm{B}^{\circ}$ Campo Belo & 139 & 3 & 2.16 & $\mathrm{~B}^{\circ}$ Pedregulho I & 31 & 1 & 3,23 \\
\hline Faz. Matão & 135 & 3 & 2.22 & Faz. Campo Novo & 98 & 0 & 0,00 \\
\hline $\mathrm{B}^{\circ}$ Estiva & 78 & 1 & 1,28 & Faz. Coqueiro & 54 & 0 & 0,00 \\
\hline Faz. São Geraldo & 133 & 3 & 2.26 & $\mathrm{~B}^{\circ}$ Serrinha & 15 & 0 & 0,00 \\
\hline $\mathrm{B}^{\circ}$ Paradouro & 29 & 0 & 0.00 & Faz. Morro Alto & 32 & 1 & 3,12 \\
\hline $\mathrm{B}^{\circ}$ Mamonal & 156 & 0 & 0,00 & $\mathrm{~B}^{\circ}$ Campo Redondo & 46 & 5 & 10.87 \\
\hline Faz. São Joaquim & 35 & 0 & 0.00 & Faz. Olaria Jaguary & 30 & 0 & 0,00 \\
\hline$B^{\circ}$ Demanda & 67 & 1 & 1.49 & Faz. Belém & 15 & 0 & 0,00 \\
\hline Faz da Lage & 95 & 1 & 1.05 & Faz. Larandeiro & 28 & 0 & 0,00 \\
\hline Faz Aliança & 34 & 1 & 2.94 & $\mathrm{~B}^{\circ}$ Cachoeirinha II & 101 & 9 & 8.91 \\
\hline \multicolumn{8}{|c|}{ São José do Rio Pardo } \\
\hline Faz. Sta. Helena & 137 & 1 & 0.73 & Faz. Tubaca & 115 & 2 & 1,74 \\
\hline Faz. Cór do Veado & 8 & () & 0,00 & Faz. Viradouro & 39 & 0 & 0,00 \\
\hline Faz. Sta. Matilde & 145 & 3 & 2.07 & $\mathrm{~B}^{\circ} \mathrm{N}$. Sra de Fátima & 97 & 1 & 1,03 \\
\hline Faz. Cascalho & 56 & 2 & 3,57 & Faz. Ouro Branco & +1 & 2 & 4,88 \\
\hline Faz. Água Fria & 97 & 0 & 0.00 & Faz. Vila Maria & 118 & 6 & 5,08 \\
\hline $\mathrm{B}^{\circ}$ Muladeiro & 137 & 6 & 4.38 & Faz. Modelo & 43 & 1 & 2,33 \\
\hline Faz. Est. V.Costina & 455 & 10 & 2.20 & $\mathrm{~B}^{\circ}$ Barreir. Gabiroba & 24 & 0 & 0,00 \\
\hline$B^{\circ}$ Sueiro & 40 & 0 & 0,00 & $\mathrm{~B}^{\circ}$ Sítio Novo & 263 & 5 & 1,90 \\
\hline Faz. Sta. Maria I & 39 & 1 & 2.56 & Faz. Santa Lúcia & 394 & 2 & 0.51 \\
\hline Faz. Sta. Luzia & 53 & 1 & 1.89 & & & & \\
\hline \multicolumn{8}{|c|}{ São Sebastião da Grama } \\
\hline $\mathrm{B}^{\circ}$ Campinho & 34 & 2 & 5.88 & $\mathrm{~B}^{\circ}$ Água Vertente & 30 & 0 & 0,00 \\
\hline $\mathrm{B}^{\circ}$ Bom Jardim & 43 & 5 & 11,63 & Faz. São Benedito & 8 & 0 & 0,00 \\
\hline $\mathrm{B}^{\circ}$ Cachoeirinha & 42 & 2 & 4.76 & $B^{\circ}$ Serrinha & 43 & 3 & 6,98 \\
\hline $\mathrm{B}^{\circ}$ Cocal & 64 & 1 & 1.56 & Faz. Água Limpa & 255 & 3 & 1,18 \\
\hline $\mathrm{B}^{\mathrm{o}}$ Farturinha & 79 & 3 & 3,80 & $\mathrm{~B}^{\circ}$ São Domingos & 223 & 1 & 0,45 \\
\hline \multicolumn{8}{|c|}{ Tapiratiba } \\
\hline Periferia & 90 & 4 & 4,44 & Faz. Santo Antônio & 119 & 5 & 4,20 \\
\hline $\mathrm{B}^{\circ}$ Macauba & 115 & 3 & 2,61 & Faz. Vila Flor & 102 & 2 & 1,96 \\
\hline Faz. Bela Vista & 170 & 12 & 7.06 & & & & \\
\hline \multicolumn{8}{|c|}{ Vargem Grande do Sul } \\
\hline $\mathrm{B}^{\circ}$ Fortaleza & 48 & 2 & 4.17 & $\mathrm{~B}^{\circ}$ Cór. Raso & 35 & 0 & 0,00 \\
\hline Faz. Barreirinho & 95 & 1 & 1,05 & Faz. Floresta & 60 & 1 & 1,67 \\
\hline $\mathrm{B}^{\circ}$ Retirão & 121 & 6 & +.96 & Faz. Chapadão & 36 & 0 & 0,00 \\
\hline $\mathrm{B}^{\circ}$ das Olarias & 72 & 1 & 1.39 & Faz. Bela Vista & 96 & 1 & 1,04 \\
\hline $\mathrm{B}^{\circ}$ Pinhalzinho & 58 & 0 & 0.00 & & & & \\
\hline
\end{tabular}


As idades da população examinada variaram de 3 meses a 97 anos, sendo a média igual a 24,41 anos, mediana, 19,0 anos, $25 \%$ com até 9,0 anos e $75 \%$ com até 37,0 anos. Quanto à distribuição por sexo, 8565 foram do grupo feminino $(52,38 \%)$ e 7786 do grupo masculino $(47,62 \%)$. No conjunto dos reagentes sorológicos, as idades variaram de 2 a 97 anos, com a média igual a 48,62 anos, mediana, 50,00 anos, 25\% com até 40,00 anos e $75 \%$ com até 58,00 anos. A reatividade sorológica distribuiu-se igualmente entre os sexos $(p=0,878)$ (Tabela 4.3.2.3). Em relação à positividade observada na microrregião Campos de Itapetininga, houve diferença significante $(p \cong 0,000)$

Tabela 4.3.2.3 - Sororreatividade para infecção chagásica, por grupo etário e sexo, em população de zona rural dos municípios da microrregião Encosta Ocidental da Mantiqueira Paulista. Estado de São Paulo, 1980.

\begin{tabular}{|c|c|c|c|c|c|c|c|c|c|}
\hline \multirow{2}{*}{$\begin{array}{l}\text { Grupo } \\
\text { etário } \\
\text { (anos) }\end{array}$} & \multicolumn{3}{|c|}{ Feminino } & \multicolumn{3}{|c|}{ Masculino } & \multicolumn{3}{|c|}{ Feminino + Masculino } \\
\hline & $\begin{array}{c}\mathrm{N}^{\circ} \mathrm{am} \\
\text { exam }\end{array}$ & $\begin{array}{l}\mathrm{N}^{\circ} \text { am } \\
\text { reag }\end{array}$ & $\begin{array}{l}\% \text { am } \\
\text { reag. }\end{array}$ & $\begin{array}{l}\mathrm{N}^{\mathrm{o}} \text { am } \\
\text { exam }\end{array}$ & $\begin{array}{l}\mathrm{N}^{0} \text { am. } \\
\text { reag. }\end{array}$ & $\begin{array}{r}\% \text { am } \\
\text { reag. }\end{array}$ & $\begin{array}{l}\mathrm{N}^{\mathrm{o}} \text { am } \\
\text { exam. }\end{array}$ & $\begin{array}{r}\mathrm{N}^{\mathrm{o}} \text { am. } \\
\text { reag. }\end{array}$ & $\begin{array}{l}\% \text { am. } \\
\text { reag. }\end{array}$ \\
\hline$<1$ & 25 & 0 & 0,00 & 25 & 0 & 0,00 & 50 & 0 & 0,00 \\
\hline $1-4$ & 787 & 1 & 0,13 & 789 & 2 & 0,25 & 1576 & 3 & 0,19 \\
\hline $5-9$ & 1375 & 3 & 0,22 & 1348 & 4 & 0,30 & 2723 & 7 & 0,26 \\
\hline $10-14$ & 1158 & 1 & 0,09 & 1214 & 3 & 0,25 & 2372 & 4 & 0,17 \\
\hline $15-19$ & 843 & 4 & 0,47 & 741 & 5 & 0,67 & 1584 & 9 & 0,57 \\
\hline $20-29$ & 1436 & 15 & 1,04 & 1148 & 9 & 0,78 & 2584 & 24 & 0,93 \\
\hline $30-39$ & 1019 & 41 & 4,02 & 800 & 28 & 3,50 & 1819 & 69 & 3,79 \\
\hline $40-49$ & 833 & 73 & 8,76 & 701 & 55 & 7,85 & 1534 & 128 & 8,34 \\
\hline $50-59$ & 588 & 61 & 10,37 & 530 & 78 & 14,72 & 1118 & 139 & 12,43 \\
\hline $60-69$ & 333 & 42 & 12,61 & 305 & 29 & 9,51 & 638 & 71 & 11,13 \\
\hline$\geq 70$ & 167 & 14 & 8,38 & 185 & 22 & 11,89 & 352 & 36 & 10,23 \\
\hline Total & 8564 & 255 & 2,98 & 7786 & 235 & 3,02 & 16350 & 790 & 3,00 \\
\hline
\end{tabular}

A distribuição de frequêencia de reatividade sorológica para infecção chagásica por grupos etários, para a microrregião Encosta Ocidental da Mantiqueira Paulista (EOMP) está apresentada na Figura 4.3a. A curva é ascendente até o grupo 50-59 anos, declinando discretamente nas idades superiores. 


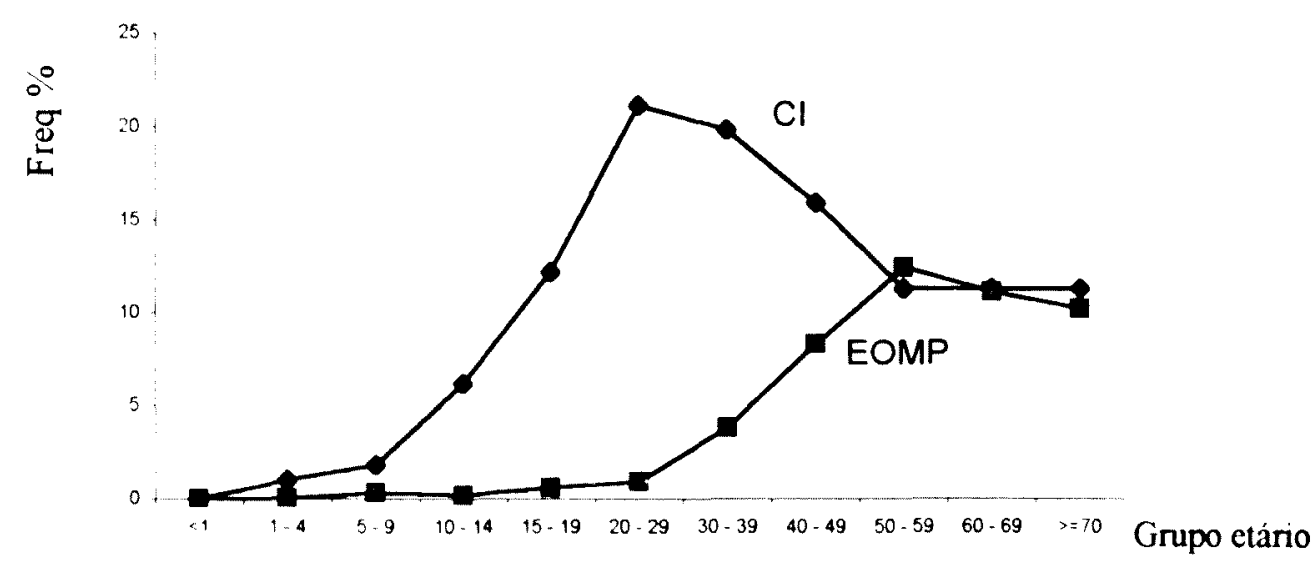

Figura 4.3a - Distribuição de frequência percentual de sororreatividade para infecção chagásica, por grupos etários, das populações dos municípios das microrregiões Campos de Itapetininga (CI) e Encosta Ocidental da Mantiqueira Paulista (EOMP), entre 1976 e 1980

Da mesma maneira como foi observado na microrregião Campos de Itapetininga, a curva de distribuição de frequências de títulos sorológicos para infecção chagásica, na população trabalhada na microrregião Encosta Ocidental da Mantiqueira Paulista (EOMP), em 1980, foi bimodal (Figura 4.3b). A média geométrica de títulos dos reagentes foi igual a 165 , tendo variado de 20 a 2560

Na população geral $(n=16276)$, o tempo de moradia na residência atual variou de 1 dia a 86 anos, com uma média de 7,1 anos, mediana de 3,0 anos, 25\% com até 1,0 ano e $75 \%$ com até 9,0 anos. No grupo dos sororreagentes $(n=490)$ os tempos de moradia variaram de 8 dias a 71 anos, com a média igual a 10,8 anos, mediana, 5,0 anos, 25\% com até 1 ano e 75\% dos casos com até 16 anos de residência. Em ambas situações foram subtraídos os casos em que não se dispôs das informações sobre tempo de moradia, respectivamente e amostras. Em 3090 casos (18,90\%), o tempo de moradia na casa foi igual à idade. Nessa condição, a média da idade (e do tempo de moradia) foi de 12,9 anos, mediana, 9,0 anos, $25 \%$ com até 4,0 anos e $75 \%$ com até 16,0 anos. 
100000

몰

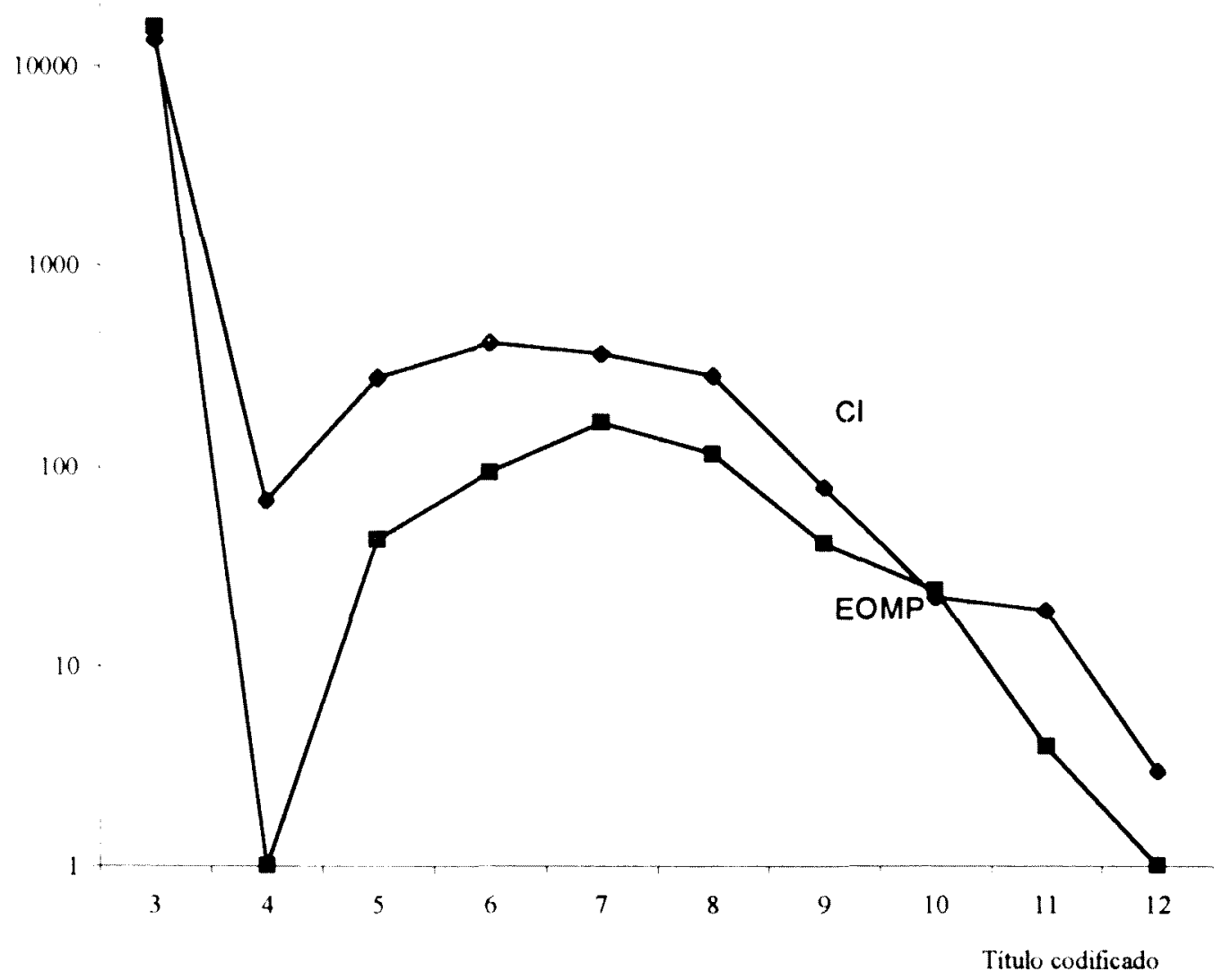

Figura 4.3b - Distribuição de freqüência de títulos de reação de imunofluorescência indireta para infecção chagásica, de população dos municípios das microrregiões Campos de Itapetininga ( $\mathrm{CI}$ ) e Encosta Ocidental da Mantiqueira Paulista (EOMP), entre 1976 e 1980

Titulos codificados: $3=<20 ; 4=20,5=40 ; 6=80 ; 7=160 ; 8=320 ; 9=640 ; 10=1280 ; 11=2560$, $12=5120$ 


\subsection{Do inquérito nos municipios de Cananéia, Iguape e Peruíbe, 1980 a 1982}

Os municípios Cananéia e Iguape pertencem à Região de Governo Registro e Peruíbe, à Região de Governo Santos, ambas do Serviço Regional da SUCEN de São Vicente (SR-2). Ocupam área de $3564 \mathrm{~km}^{2}(1,43 \% \text { do Estado })^{92}$.

Para análise neste capitulo, consideramos as populações de zona rural apenas, por analogia aos trabalhos desenvolvidos no Programa de Controle da Doença de Chagas no Estado. Assim, foram obtidas 17075 amostras, cujas distribuições de frequências e de percentuais de positividade para infecção chagásica nas localidades rurais dos três municípios são apresentadas nas Tabelas 4.4.1-3

Nas 38 localidades rurais de Cananéia, a reatividade variou de 0,00 a 4,76\%, com média igual a $0,24 \%$; em alguns casos os intervalos de confiança das percentagens, ao nivel de significância de $95 \%$, foram suficientemente amplos para denotar falta de precisão nos resultados. Em apenas 6 localidades (15,79\%) deste municipio houve alguma reatividade sorológica para infecção chagásica. Nas 43 localidades de Iguape, a variação foi de 0,00 a $6,22 \%$, com média de $1,18 \%$ e, nas 14 de Peruibe, de 0,00 a $6,33 \%$, com média de 2,59\%. A diferença entre proporções de Peruibe com as dos outros dois municipios foi significante $^{195}: G=82,28\left(\chi_{0,05[2]}^{2}=5,99\right)$. 
Tabela 4.4.1 - Sorologia para infecção chagásica na população rural do município de Cananéia, Estado de São Paulo, 1980-1982.

\begin{tabular}{|c|c|c|c|c|}
\hline Localidade & $\begin{array}{l}\mathrm{N}^{0} \text { am. } \\
\text { colhidas }\end{array}$ & $\begin{array}{l}\mathrm{N}^{0} \text { am. } \\
\text { reagentes }\end{array}$ & $\begin{array}{r}\% \text { am. } \\
\text { reagentes }\end{array}$ & IC* dos reag $(\%)$ \\
\hline Sítio Cordeiro & 11 & 0 & 0.00 & - \\
\hline Povoado Iririaia Mirim & 21 & 1 & 4.76 & $0.85-22.70$ \\
\hline Fazenda Aparecida do Sul & 43 & 0 & 0.00 & - \\
\hline Fazenda Folha Larga & 42 & 0 & 0.00 & - \\
\hline Povoado Itapitangui & 91 & 1 & 1.10 & $0.19-5.97$ \\
\hline Sítio Aleixo & 53 & 0 & 0,00 & - \\
\hline Povoado Mandira & 45 & 1 & 2.22 & $0.39-11.57$ \\
\hline Sítio Porto do Meio & 29 & 0 & 0,00 & - \\
\hline Povoado Rio da Mina & 57 & 0 & 0.00 & - \\
\hline Povoado Ex-Colônia & 57 & 0 & 0.00 & - \\
\hline Povoado Rio Branco & 57 & 0 & 0.00 & - \\
\hline Sítio Palmeiras & 33 & 0 & 0.00 & - \\
\hline Vila Porto Cubatão & 312 & 0 & 0.00 & - \\
\hline Povoado Prainha & 18 & 0 & 0.00 & - \\
\hline Povoado Estalciro & 59 & 0 & 0.00 & - \\
\hline Bairro Carijó & 255 & 2 & 0.78 & $0.22-2.81$ \\
\hline Bairro Morro São João & 105 & 0 & 0.00 & - \\
\hline Sítio Rio dos Cordeiros & 15 & 0 & 0.00 & - \\
\hline Povoado Pedrinhas & 118 & 0 & 0.00 & - \\
\hline Povoado Guaxixi de Dentro & 84 & 2 & 2.38 & $0.66-8.27$ \\
\hline Povoado Guaxixi de Fora & 61 & 0 & 0.00 & - \\
\hline Povoado Ilha Comprida I & 87 & 0 & 0.00 & - \\
\hline Povoado Ilha Comprida II & 85 & 0 & 0.00 & - \\
\hline Povoado Itacuruçá & 25 & 0 & 0.00 & - \\
\hline Povoado Costão dos Andradas & 27 & 0 & 0.00 & - \\
\hline Povoado Trapandré & 29 & 0 & 0.00 & - \\
\hline Povoado Praia do Lage & 56 & 0 & 0.00 & - \\
\hline Povoado Balneário Marujá & 86 & 0 & 0.00 & - \\
\hline Povoado Enseada da Baleia & 65 & 0 & 0.00 & - \\
\hline Distrito de Ariri & 162 & 0 & 0.00 & - \\
\hline Povoado Rio Vermelho & 17 & 0 & 0.00 & - \\
\hline Povoado Varadorzinho & 37 & 0 & 0.00 & - \\
\hline Povoado Retiro & 14 & 0 & 0.00 & - \\
\hline Povoado Itapanhapina & 23 & 0 & 0.00 & - \\
\hline Povoado Santa Maria & 116 & 0 & 0,00 & - \\
\hline Ilha Bom Abrigo & 0 & 0 & 0.00 & - \\
\hline Bairro Rocio I & 306 & 0 & 0,00 & - \\
\hline Bairro Rocio II & 268 & 1 & 0.37 & $0.07-2.08$ \\
\hline Bairro Rocio III & 391 & 0 & 0.00 & - \\
\hline Total & 3360 & 8 & 0.24 & $0.12-0.47$ \\
\hline
\end{tabular}

*IC=Intervalo de Confiança (95\%). 
Tabela 4.4.2 - Sorologia para infecção chagásica na população rural do municipio de Iguape, Estado de São Paulo, 1980-1982.

\begin{tabular}{|c|c|c|c|c|}
\hline Localidade & $\begin{array}{c}\mathrm{N}^{\circ} \text { am. } \\
\text { colhidas }\end{array}$ & $\begin{array}{c}\mathrm{N}^{0} \text { am. } \\
\text { reagentes }\end{array}$ & $\begin{array}{l}\% \text { am } \\
\text { reagentes }\end{array}$ & $\mathrm{IC}^{*}$ dos reag $(\%)$ \\
\hline Rio Comprido & 74 & 1 & 1.35 & $0.24-7.27$ \\
\hline Povoado Juréia & 118 & 1 & 0.85 & $0.15-4.64$ \\
\hline Povoado Barra do Ribeira & 364 & 1 & 0.27 & $0.05-1.54$ \\
\hline Povoado Pontal do Icapara & 221 & 3 & 1.36 & $0.46-3.91$ \\
\hline Povoado Icapara & 548 & 1 & 0.18 & $0.03-1.03$ \\
\hline Povoado Enseada & 34 & 1 & 2.94 & $0.52-14.9 ?$ \\
\hline Bairro Rocio & 1754 & 6 & 0.34 & $0.16-0.74$ \\
\hline Povoado Cerro Azul & 72 & 0 & 0.00 & - \\
\hline Fazenda Aguapê & 49 & 1 & 2,04 & $0.36-10.69$ \\
\hline Povoado Araçá & 102 & 1 & 0,98 & $0,17-5.35$ \\
\hline Povoado Ilha Comprida & 86 & 1 & 1.16 & $0.21-6.30$ \\
\hline Povoado Estirão da Ilha Grande & 248 & 0 & 0.00 & - \\
\hline Povoado Subaúna & 55 & 1 & 1.82 & $0.32-9.61$ \\
\hline Povoado Rio de Una & 96 & 1 & 1.04 & $0.18-5.67$ \\
\hline Povoado Rio Pequeno & 128 & 5 & 3.91 & $1.68-8.82$ \\
\hline Povoado Piunduva & 37 & 2 & 5.40 & $1.50-17.70$ \\
\hline Povoado Saputanduva & 41 & 0 & 0.00 & - \\
\hline Localidade Despraiado I & 126 & 3 & 2.38 & $0.81-6.77$ \\
\hline Localidade Despraiado II & 192 & 11 & 5.73 & $3,23-10,00$ \\
\hline Povoado Rio das Pedras & 35 & 0 & 0.00 & - \\
\hline Povoado Embú & 187 & 0 & 0,00 & - \\
\hline Povoado Peroupava & 225 & 14 & 6.22 & $3.74-10.17$ \\
\hline Povoado Barra das Areias & 186 & 5 & 2.69 & $1.15-6.14$ \\
\hline Povoado Volta do Saraiva & 219 & 5 & 2.28 & $0.98-5.23$ \\
\hline Povoado Pastinho (I e II) & 170 & 7 & 4.12 & $2.01-8.25$ \\
\hline Povoado Momuna & 133 & $j$ & 2.26 & $0.77-6.42$ \\
\hline Povoado Bocuy & 48 & 0 & 0.00 & - \\
\hline Povoado Jipovura & 72 & 0 & 0.00 & - \\
\hline Povoado Volta Grande & 195 & 2 & 1.03 & $0.28-3.66$ \\
\hline Povoado Jataetuba & 103 & 3 & 2.91 & $1,00-8.22$ \\
\hline Povoado Saputanduva & 306 & 6 & 1.96 & $0.90-4.21$ \\
\hline Povoado Porto Sanambi I & 276 & 0 & 0,00 & - \\
\hline Povoado Porto Sanambi II & 126 & 0 & 0.00 & - \\
\hline Povoado Porto Sanambi III & 160 & 0 & 0.00 & - \\
\hline Povoado Itimirim I & 504 & 15 & 2.98 & $1.81-+.85$ \\
\hline Povoado Itimirim II & 434 & 1 & 0.23 & $0.04-1.29$ \\
\hline Povoado Itimirim III & 213 & 0 & 0.00 & - \\
\hline Povoado Itimirim IV & 229 & 6 & 2.62 & $1.21-5.60$ \\
\hline Tucunduva I & 70 & 0 & 0.00 & - \\
\hline Tucunduva II & 56 & 0 & 0.00 & - \\
\hline Porto da Ribeira & 622 & 3 & 0.48 & $0.16-1.41$ \\
\hline Bairro Guaricana & 801 & 5 & 0.62 & $0.27-1.45$ \\
\hline Povoado Arataca & 182 & 2 & 1.10 & $0,30-3,92$ \\
\hline Total & 9897 & 117 & 1.18 & $0.99-1.41$ \\
\hline
\end{tabular}

*IC=Intervalo de Confiança (95\%) 
Tabela 4.4.3 - Sorologia para infecção chagásica na população rural do municipio de Peruibe, Estado de São Paulo, 1980-1982.

\begin{tabular}{|c|c|c|c|c|}
\hline Localidade & $\begin{array}{l}\mathrm{N}^{\circ} \text { am. } \\
\text { colhidas }\end{array}$ & $\begin{array}{r}\mathrm{N}^{\circ} \text { am. } \\
\text { reagentes }\end{array}$ & $\begin{array}{r}\% \text { am. } \\
\text { reagentes }\end{array}$ & $1 \mathrm{C}^{*}$ dos reag $(\%)$ \\
\hline Fazenda São Francisco I & 440 & 3 & 0,68 & $0.23-1.99$ \\
\hline Fazenda São Francisco II & 250 & 5 & 2.00 & $0.86-4.60$ \\
\hline Guaraú & 411 & 10 & 2,43 & $1.33-+.42$ \\
\hline Guaraú I & 422 & 13 & 3,08 & $1.81-5.20$ \\
\hline Aldeia dos Índios - $1^{a}$ Parte & 182 & 0 & 0,00 & - \\
\hline Aldeia dos Índios - $2^{a}$ Parte & 280 & 6 & 2,14 & $0.99-4.60$ \\
\hline Aldeia dos Índios $-3^{\bullet}$ Parte & 287 & 7 & 2,44 & $1.19-4.95$ \\
\hline Fazenda Rio Preto & 158 & 10 & 6.33 & $3,47-11,26$ \\
\hline Fazenda Rio Preto I & 60 & 3 & 5.00 & $1.71-13.70$ \\
\hline Km 77 & 357 & 3 & 0.84 & $0.29-2.44$ \\
\hline Fazenda Guaxiru & 255 & 6 & 2.35 & $1.08-5.04$ \\
\hline Fazenda Icatum & 473 & 25 & 5.29 & $3.61-7.69$ \\
\hline Rio Guanhaém & 222 & 8 & 3.60 & $1.84-6.95$ \\
\hline Sítio Varginha & 21 & 0 & 0.00 & - \\
\hline Total & 3818 & 99 & 2.59 & $2.13-3.15$ \\
\hline
\end{tabular}

*IC=Intervalo de Confianca (95\%)

Para os três municípios, as reatividades sorológicas, segundo sexo, encontram-se distribuidas nas Tabelas 4.4.4-6. No município de Iguape, très amostras do sexo feminino e uma do sexo masculino não possuiam registro de idade.

Tabela 4.4.4 - Sororreatividade para infeç̧ão chagásica, por grupo etário e sexo, em população de zona rural do nunicípio Cananéia, Estado de São Paulo, 1980-1982.

\begin{tabular}{|c|c|c|c|c|c|c|c|c|c|}
\hline \multirow{2}{*}{$\begin{array}{l}\text { Grupo } \\
\text { etário } \\
\text { (anos) }\end{array}$} & \multicolumn{3}{|c|}{ Feminino } & \multicolumn{3}{|c|}{ Masculino } & \multicolumn{3}{|c|}{ Feminino + Masculino } \\
\hline & $\begin{array}{l}\mathrm{N}^{\circ} \text { am. } \\
\text { exam. }\end{array}$ & $\begin{array}{r}\mathrm{N}^{\circ} \text { am. } \\
\text { reag. }\end{array}$ & $\begin{array}{l}\% \text { am. } \\
\text { reag. }\end{array}$ & $\begin{array}{l}\mathrm{N}^{\circ} \text { am } \\
\text { exam }\end{array}$ & $\begin{array}{l}\mathrm{N}^{0} \text { am. } \\
\text { reag. }\end{array}$ & $\begin{array}{l}\% \text { am. } \\
\text { reag. }\end{array}$ & $\begin{array}{l}\mathrm{N}^{0} \text { am. } \\
\text { exam. }\end{array}$ & $\begin{array}{l}\mathrm{N}^{\circ} \text { am } \\
\text { reag. }\end{array}$ & $\begin{array}{l}\% \text { am } \\
\text { reag. }\end{array}$ \\
\hline$<1$ & 4 & 0 & 0,00 & 0 & 0 & 0,00 & 4 & 0 & 0,00 \\
\hline $1-4$ & 105 & 0 & 0,00 & 155 & 0 & 0,00 & 260 & 0 & 0,00 \\
\hline $5-9$ & 253 & 0 & 0,00 & 308 & 0 & 0,00 & 561 & 0 & 0,00 \\
\hline $10-14$ & 178 & 0 & 0,00 & 199 & 0 & 0,00 & 377 & 0 & 0,00 \\
\hline $15-19$ & 139 & 0 & 0,00 & 122 & 0 & 0,00 & 261 & 0 & 0,00 \\
\hline $20-29$ & 344 & 2 & 0,58 & 206 & 1 & 0,48 & 550 & 3 & 0.54 \\
\hline $30-39$ & 236 & 1 & 0,42 & 182 & 1 & 0,55 & 418 & 2 & 0,48 \\
\hline $40-49$ & 190 & 1 & 0,53 & 137 & 0 & 0,00 & 327 & l & 0,31 \\
\hline $50-59$ & 154 & 1 & 0,65 & 129 & 1 & 0,78 & 283 & 2 & 0.71 \\
\hline $60-69$ & 97 & 0 & 0,00 & 95 & 0 & 0,00 & 192 & 0 & 0.00 \\
\hline$\geq 70$ & 64 & 0 & 0,00 & 63 & 0 & 0,00 & 127 & 0 & 0.00 \\
\hline Total & 1764 & 5 & 0,28 & 1596 & 3 & 0,19 & 3360 & 8 & 0.24 \\
\hline
\end{tabular}


Tabela 4.4.5 - Sororreatividade para infecção chagásica, por grupo etário e sexo, em população de zona rural do município Iguape, Estado de São Paulo, 1980-1982.

\begin{tabular}{c|rrr|rrr|rrr}
\hline $\begin{array}{c}\text { Grupo } \\
\text { etário } \\
\text { (anos) }\end{array}$ & $\begin{array}{r}\mathrm{N}^{\circ} \text { am. } \\
\text { exam. }\end{array}$ & $\begin{array}{r}\mathrm{N}^{\circ} \text { am. } \\
\text { reag. }\end{array}$ & $\begin{array}{r}\% \text { am. } \\
\text { reag. }\end{array}$ & $\begin{array}{r}\mathrm{N}^{\circ} \text { am. } \\
\text { exam. }\end{array}$ & $\begin{array}{r}\mathrm{N}^{\circ} \text { am. } \\
\text { reag. }\end{array}$ & $\begin{array}{r}\% \text { am. } \\
\text { reag. }\end{array}$ & $\begin{array}{r}\text { Feminino } \\
\mathrm{N}^{\circ} \text { am. } \\
\text { exam. }\end{array}$ & $\begin{array}{r}\mathrm{N}^{\circ} \text { am. } \\
\text { reag. }\end{array}$ & $\begin{array}{r}\% \text { am. } \\
\text { reag. }\end{array}$ \\
\hline$<-4$ & 41 & 0 & 0,00 & 41 & 0 & 0,00 & 82 & 0 & 0,00 \\
$5-9$ & 541 & 1 & 0,18 & 575 & 0 & 0,00 & 1116 & 1 & 0,09 \\
$10-14$ & 906 & 2 & 0,22 & 877 & 1 & 0,11 & 1783 & 3 & 0,17 \\
$15-19$ & 720 & 1 & 0,14 & 665 & 2 & 0,30 & 1385 & 3 & 0,22 \\
$20-29$ & 710 & 4 & 0,98 & 423 & 0 & 0,00 & 833 & 4 & 0,48 \\
$30-39$ & 632 & 11 & 1,48 & 610 & 23 & 3,77 & 1352 & 34 & 2,52 \\
$40-49$ & 454 & 14 & 2,22 & 471 & 19 & 4,03 & 1103 & 33 & 2,99 \\
$50-59$ & 326 & 4 & 1,10 & 443 & 11 & 2,48 & 897 & 16 & 1,78 \\
$60-69$ & 207 & 3 & 1,45 & 310 & 8 & 2,58 & 636 & 12 & 1,89 \\
$\geq 70$ & 116 & 0 & 0,00 & 135 & 4 & 2,96 & 251 & 4 & 1,59 \\
Ignor. & 3 & 0 & 0,00 & 1 & 0 & 0,00 & 4 & 0 & 0,00 \\
\hline Total & 5098 & 45 & 0,88 & 4799 & 72 & 1,50 & 9897 & 117 & 1,18 \\
\hline
\end{tabular}

Tabela 4.4.6 - Sororreatividade para infecção chagásica, por grupo etário e sexo, em população de zona rural do município Peruíbe, Estado de São Paulo, 1980-1982.

\begin{tabular}{|c|c|c|c|c|c|c|c|c|c|}
\hline \multirow{2}{*}{$\begin{array}{l}\text { Grupo } \\
\text { etário } \\
\text { (anos) }\end{array}$} & \multicolumn{3}{|c|}{ Feminino } & \multicolumn{3}{|c|}{ Masculino } & \multicolumn{3}{|c|}{ Feminino + Masculino } \\
\hline & $\begin{array}{l}N^{\circ} \text { am. } \\
\text { exam. }\end{array}$ & $\begin{array}{l}\mathrm{N}^{\circ} \text { am. } \\
\text { reag. }\end{array}$ & $\begin{array}{l}\% \text { am. } \\
\text { reag. }\end{array}$ & $\begin{array}{l}\mathrm{N}^{\circ} \text { am. } \\
\text { exam. }\end{array}$ & $\begin{array}{l}\mathrm{N}^{\circ} \text { am. } \\
\text { reag. }\end{array}$ & $\begin{array}{l}\% \text { am. } \\
\text { reag. }\end{array}$ & $\begin{array}{l}\mathrm{N}^{\circ} \text { am. } \\
\text { exam. }\end{array}$ & $\begin{array}{l}\mathrm{N}^{\circ} \text { am. } \\
\text { reag. }\end{array}$ & $\begin{array}{l}\% \text { am } \\
\text { reag. }\end{array}$ \\
\hline$<1$ & 0 & 0 & 0,00 & 1 & 0 & 0,00 & 1 & 0 & 0,00 \\
\hline $1-4$ & 238 & 1 & 0,42 & 220 & 0 & 0,00 & 458 & 1 & 0,22 \\
\hline $5-9$ & 349 & 2 & 0,57 & 327 & 0 & 0,00 & 676 & 2 & $(0,30$ \\
\hline $10-14$ & 280 & 4 & 1,43 & 264 & 3 & 1,14 & 544 & 7 & 1,29 \\
\hline $15-19$ & 147 & 1 & 0,68 & 163 & 0 & 0,00 & 310 & 1 & (),32 \\
\hline $20-29$ & 275 & 11 & 4,00 & 274 & 9 & 3,28 & 549 & 20 & 3,64 \\
\hline $30-39$ & 224 & 13 & 5,80 & 210 & 12 & 5,71 & 434 & 25 & 5,76 \\
\hline $40-49$ & 178 & 12 & 6,74 & 186 & 14 & 7,53 & 364 & 26 & 7,14 \\
\hline $50-59$ & 105 & 4 & 3,81 & 164 & 8 & 4,88 & 269 & 12 & 4,46 \\
\hline $60-69$ & 53 & 1 & 1,89 & 94 & 2 & 2,13 & 147 & 3 & 2,04 \\
\hline$\geq 70$ & 26 & 2 & 7,69 & 40 & 0 & 0,00 & 66 & 2 & 3,03 \\
\hline Total & 1875 & 51 & 2,72 & 1943 & 48 & 2,47 & 3818 & 99 & 2,59 \\
\hline
\end{tabular}


Nos municipios Cananéia e Peruíbe não foram observadas diferenças significantes de proporções nas positividades entre os $\operatorname{sexos}(p=0,567$ e $p=0,628$, respectivamente), porém no município de Iguape houve diferença significante entre os sexos $\left(p_{\text {masculino }}=0,043\right)$.

As idades da população trabalhada variaram de 1 mês a 100 anos, sendo a media igual a 24,9 anos, mediana, 18,0 anos, $25 \%$ com até 8,0 anos e $75 \%$ com até 37,0 anos Quanto à distribuição por sexo, 8736 foram do grupo feminino $(51,2 \%)$ e 8340 do grupo masculino $(48,8 \%)$. No conjunto dos reagentes sorológicos, as idades variaram de 3,0 a 91,0 anos, com a média igual a 36,2 anos, mediana, 33,0 anos, $25 \%$ com até 25,0 anos e $75 \%$ com até 45,0 anos.

A Figura $4.4 \mathrm{a}$ fornece a distribuição de frequência percentual de reatividade sorológica para infecção chagásica segundo grupos etários, ascendente até o grupo $30 \quad 39$ anos, seguida de declínio nos demais grupos.

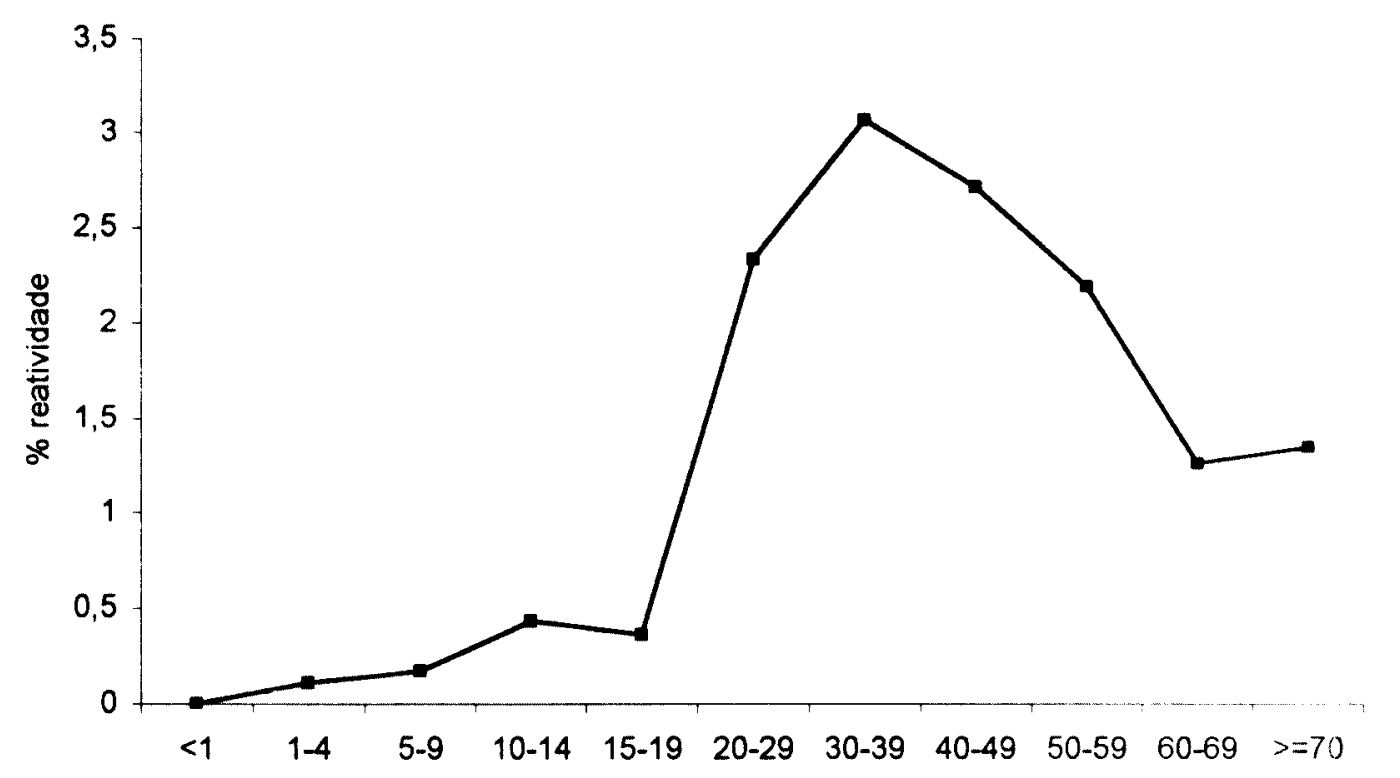

grupos etários

Figura 4.4a - Distribuição de frequência percentual de sororreatividade para infeç̧ão chagásica, por grupos etários, de população rural de Cananéia, Iguape e Peruibe, entre 1980 e 1982 . 
$\mathrm{Na}$ Figura $4.4 \mathrm{~b}$ observamos as curvas de distribuição de frequências de títulos sorológicos para infecção chagásica, nas populações dos três municipios, sendo bimodais em Iguape e Peruibe e unimodal em Cananéia. A média geométrica de títulos na totalidade dos reagentes foi de 90,2 , tendo variado de 16 a 512 .

\section{Freqüência}

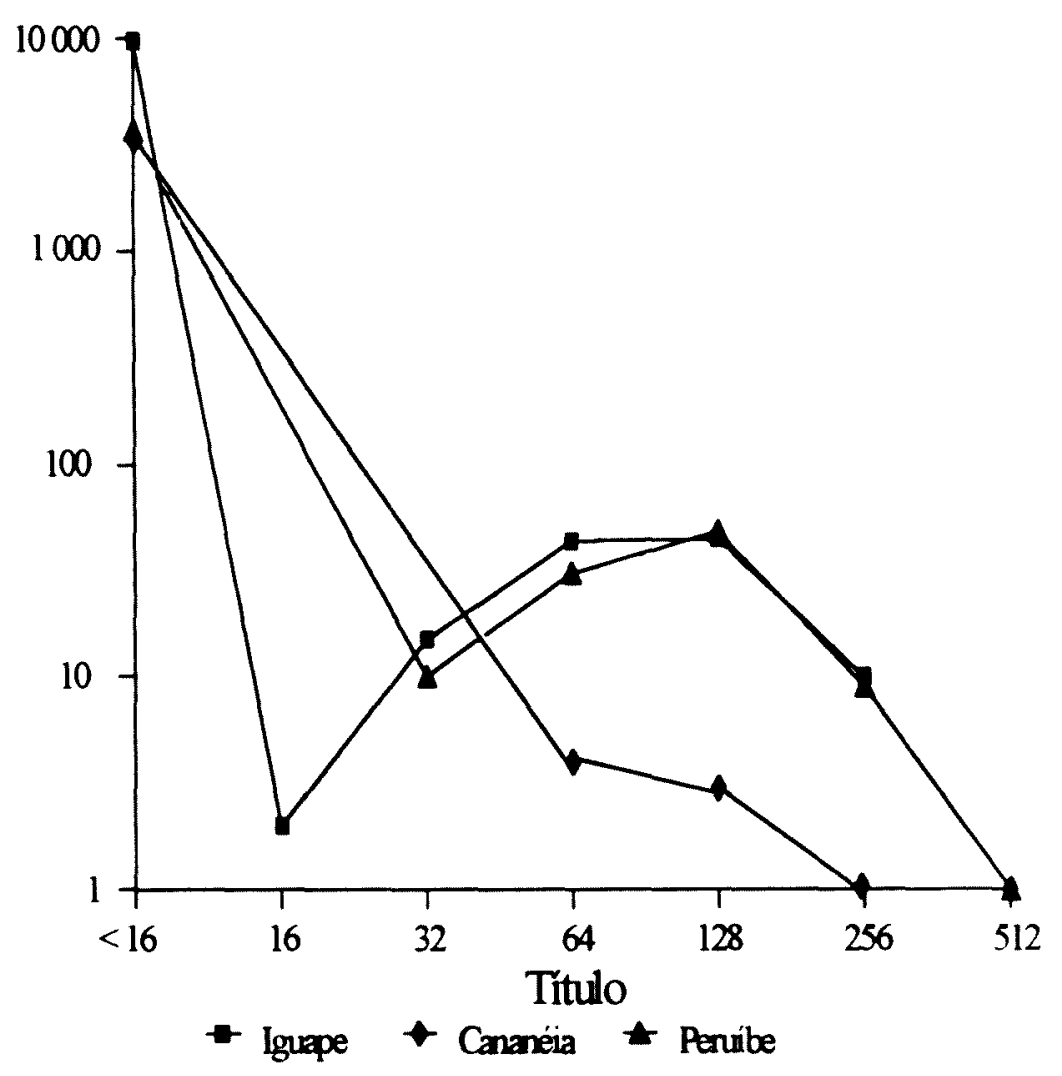

Figura 4.4b - Distribuição de frequência de títulos dos reagentes para infecção chagásica em populações rurais de Cananéia, Iguape e Peruibe, 1980 a 1982. 
$\mathrm{Na}$ população geral, o tempo de moradia no município variou de 1 dia a 92,0 anos; sendo 15,6 anos em média, mediana de 8,0 anos, $25 \%$ com até 2,0 anos e $75 \%$ com até 22,0 anos. No grupo dos sororreagentes, o tempo de moradia no municipio variou de 1 dia a 73,0 anos. Os valores para a média, mediana, $25 \%$ e $75 \%$ do tempo de moradia nos municipios podem ser visualizados no Quadro 4.4.1. No mesmo quadro é discriminada a procedência: imigrantes ou nativos dos municípios. No Quadro 4.42 seguem outras informações associadas aos casos de idades menores do que 15 anos

Quadro 4.4.1 - Características associadas aos casos sororreagentes para infecção chagásica de população rural em Cananéia, Iguape e Peruibe, 1980-1982: medidas de tendência central e de $25 \%$ e $75 \%$ para tempo de residência de sororreagentes procedência.

\begin{tabular}{|l|rrrr|rr|}
\hline & \multicolumn{3}{|c|}{ Tempo de moradia (em anos) no município } & \multicolumn{2}{c|}{ Procedència $(\%)^{*}$} \\
& Média & Mediana & $25 \%$ & $75 \%$ & Imigrantes & Nativos \\
\hline Cananéia & 9,96 & 2,00 & 0,08 & 10,00 & 72,73 & 27,27 \\
Iguape & 16,76 & 9,00 & 4,00 & 26,00 & 55,07 & 44,93 \\
Peruibe & 7,16 & 2,50 & 0,05 & 7,00 & 97,39 & 2,61 \\
\hline
\end{tabular}

*Fonte: COSTA et al. ${ }^{54} 1982$.

Quadro 4.4.2 - Características associadas aos casos sororreagentes para infeç̧ão chagásica em menores de 15 anos na população rural de Cananéia, Iguape e Peruíbe, 1980-1982*.

\begin{tabular}{|l|l|l|l|ll|l|}
\hline Idade & Sexo & Natura- & Classificação & \multicolumn{2}{|c|}{ Resultado } & Observações \\
(anos) & & lidade & & $1^{\circ}$ exame & $2^{\circ}$ exame & \\
\hline 3 & F & BA & Importado & Duvidoso & Negativo & \\
9 & F & SP & Autóctone & Duvidoso & Negativo & Oral ou Induzida \\
9 & F & BA & Importado & Positivo & Positivo & Mãe e irmão sororreag \\
11 & M & BA & Importado & Positivo & Positivo & \\
12 & F & SP & Autóctone & Duvidoso & Negativo & \\
12 & F & MG & Importado & Positivo & Positivo & \\
12 & M & MG & Importado & Positivo & Positivo & \\
13 & M & BA & Importado & Positivo & Positivo & Mãe e irmã sororreag. \\
14 & F & MG & Importado & Positivo & Positivo & Outros fam. sororreag. \\
\hline
\end{tabular}

*Fonte: COSTA et al. ${ }^{54} 1982$. 


\subsection{Do Programa de Controle da Doença de Chagas entre 1984 e 1997}

\subsubsection{No Serviço Regional da SUCEN da Grande São Paulo (SR-1)}

A Região Administrativa Metropolitana, correspondente à Regional da SUCFN da Grande São Paulo (SR-1), ocupa uma área de $8236 \mathrm{~km}^{2}, 3,31 \%$ do Estado ${ }^{92}$ (Fig. 1). I: constituida por 38 municípios: Arujá, Barueri, Biritiba-Mirim, Caieiras, Cajamar, Carapicuiba, Cotia, Diadema, Embu, Embu-Guaçu, Ferraz de Vasconcelos, Frarcisco Morato, Franco da Rocha, Guararema, Guarulhos, Itapecerica da Serra, Itapevi. Itaquaquecetuba, Jandira, Juquitiba, Mairiporã, Mauá, Mogi das Cruzes, Osasco, Pirapora do Bom Jesus, Poá, Ribeirão Pires, Rio Grande da Serra, Salesópolis, Santa Izabel, Santana do Parnaiba, Santo André, São Bernardo do Campo, São Caetano do Sul, São Paulo, Suzano, Taboão da Serra e Vargem Grande Paulista.

Por ser área"indene" para doença de Chagas, seus municípios não são objeto de programação na rotina do $\mathrm{PCDCh}$, a notificação de triatomíneos vetores é uma atividade esporádica $^{175}$. No periodo 1984-1997 foram colhidas 7 amostras de sangue, de crianças entre 1 e 15 anos de idade, com resultados negativos, em uma UD de uma localidade do município de Embú, trabalhada em 1988. Associado a essa UD ocorreu o encontro de $P$. megistus, não infectado, com resultado na prova de precipitina reagente para sangue humano. Foram as seguintes as idades observadas:

a) no sexo feminino - 2, 3, 9 e 15 anos;

b) no sexo masculino - 1 ano, 6 e 14 anos.

\subsubsection{No Serviço Regional da SUCEN de Taubaté (SR-3)}

A Regional da SUCEN de Taubaté (SR-3) integra municípios de 5 Regiões de Governo (RG): Caraguatatuba, Cruzeiro, Guaratinguetá, São José dos Campos e Taubaté, compondo a Região Administrativa São José dos Campos. Ocupa área de 16268 km? ou $6,54 \%$ do Estado ${ }^{92}$ (Fig. 1). Compreende 36 municípios, assim distribuídos

RG - Caraguatatuba - Caraguatatuba, Ilhabela, São Sebastião e Ubatuba;

RG - Cruzeiro - Areias, Bananal, Cruzeiro, Lavrinhas, Queluz, São José do Barreiı e Silveiras; 
RG - Guaratinguetá - Aparecida, Cachoeira Paulista, Cunha, Guaratinguetá, I orena, Piquete e Roseira

RG - São José dos Campos - Caçapava, Igaratá, Jacareí, Jambeiro, Monteiro Lobato, Paraibuna, Santa Branca e São José dos Campos.

RG - Taubaté - Campos do Jordão, Lagoinha, Natividade da Serra, Pindamonhangaba, Redenção da Serra, Santo Antônio do Pinhal, São Bento do Sapucai, São Luís do Paraitinga, Taubaté e Tremembé.

Como na Região Metropolitana de São Paulo, a atividade básica do PCDCh é a notificação de triatomíneos. Em 1984 esta Regional possuía 4 PIFTs instalados em Centros de Saúde na Região do Litoral Norte do Estado ${ }^{177}$. No ano de 1988, 30 amostras de sangue foram examinadas; a distribuição por faixa etária e sexo está discriminada na Tabela 4.5.2.1.

Tabela 4.5.2.1 - Sorologia de infecção chagásica, por grupo etário e sexo, no Serviço Regional da SUCEN de Taubaté (SR-3), 1984 a 1997.

\begin{tabular}{cccc}
\hline $\begin{array}{c}\text { Grupo etário } \\
\text { (anos) }\end{array}$ & $\begin{array}{c}\text { Feminino } \\
\mathrm{N}^{\circ} \text { exam. }\end{array}$ & $\begin{array}{c}\text { Masculino } \\
\mathrm{N}^{\circ} \text { exam. }\end{array}$ & Total \\
\hline$<1$ & 1 & 0 & 1 \\
$1-4$ & 1 & 3 & 4 \\
$5-9$ & 3 & 3 & 6 \\
$10-14$ & 2 & 2 & 4 \\
$15-19$ & 5 & 0 & 5 \\
$20-29$ & 2 & 4 & 6 \\
$30-39$ & 0 & 1 & 1 \\
$40-49$ & 2 & 0 & 2 \\
$50-69$ & 0 & 0 & 0 \\
$\geq 70$ & 0 & 1 & 1 \\
\hline Total & 16 & 14 & 30 \\
\hline
\end{tabular}

Essas amostras provieram de 6 UDs de uma localidade do município de Ubatuba todas com resultados negativos. Por razões desconhecidas, perderam-se as informações sobre espécie de triatomíneo, fase evolutiva, local de captura e resultados de reaçio de precipitina relacionadas. 


\subsubsection{No Serviço Regional da SUCEN de São Vicente (SR-2)}

O Serviço Regional da SUCEN de São Vicente (SR-2) compreende as Regiões Administrativas e de Governo de Registro e Santos. Engloba 12 municípios na primeira: Barra do Turvo, Cananéia, Eldorado, Iguape, Ilha Comprida, Itariri, Jacupiranga, Juquiá, Miracatu, Pariquera-Açu, Pedro de Toledo, Registro e Sete Barras e 8 na segunda: Cubatão, Guarujá, Itanhaém, Mongaguá, Peruíbe, Praia Grande, Santos e São Vicente. Em 1991 foram criados os municipios de Bertioga, desmembrado de Santos e Cajat, desmembrado de Jacupiranga. A área total abrangida possui $15597 \mathrm{~km}^{2}(6,27 \%$ do Estado) ${ }^{92}$. Para análise no PCDCh incluímos ainda, na Região de Governo Registro, o município de Iporanga, que por vezes pertenceu à Região de Governo Itapeva (localizada no SR-4, Sorocaba). Por outro lado, alguns passaram a pertencer, administrativamente, a essa Regional, como Apiaí e Ribeira, limítrofes da Regional de São Vicente. Os dados referentes a esses municipios transferiram-se para aquela Regional Os municipios abrangidos neste trabalho foram 5 de 8 pertencentes a Santos e a totalidade dos pertencentes a Registro, com as inclusões mencionadas anteriormente.

$\mathrm{Na}$ Tabela 4.5.3.1 verificamos que, das 1232 notificações atendidas, 96,5\% foran da Região do Vale do Ribeira.

Tabela 4.5.3.1 - Sorologia de infecção chagásica em Regiões de Governo do Serviço Regional da SUCEN de São Vicente (SR-2) entre 1984 e 1997.

\begin{tabular}{|c|c|c|c|c|}
\hline Região de Governo & existentes & $\begin{array}{l}\text { Municipios } \\
\text { trabalhados }\end{array}$ & $\begin{array}{c}\% \\
\text { trabalhados }\end{array}$ & $\begin{array}{c}\text { UDs* } \\
\text { trabalhadas }\end{array}$ \\
\hline Santos** & 9 & 5 & 62,50 & 43 \\
\hline Registro*** & 15 & 14 & 93,33 & 1189 \\
\hline TOTAL & 24 & 19 & 79,17 & 1232 \\
\hline
\end{tabular}


O Quadro 4.5.3.1 fornece um panorama geral dos municípios em que se inseri am as localidades trabalhadas e, portanto, as UDs notificantes, de cujos moradores eram obtidas amostras de sangue.

Quadro 4.5.3.1 - Municipios com localidades trabalhadas em sorologia ( $T$ ) e com presença de sororreagentes $(\mathrm{X})$, no Programa de Controle da Doença de Chagas (PCDCh) do Serviço Regional da SUCEN de São Vicente (SR-2), 1984-1997.

\begin{tabular}{|c|c|c|c|c|c|c|c|c|c|c|c|c|c|c|}
\hline MUNICIPIO & 1984 & 1985 & 1986 & 1987 & 1988 & 1989 & 1990 & 1991 & 1992 & 1993 & 1994 & 1995 & 1996 & 1997 \\
\hline \multicolumn{15}{|c|}{ REGIÃO DE GOVERNO REGISTRO } \\
\hline Barra do Turvo & & & & $T$ & $T$ & $T$ & $T$ & $T$ & $T$ & $T$ & & & & \\
\hline Cajat & & & & & & & & & & $T$ & & $T$ & $T$ & \\
\hline Cananeia & $T$ & & $T$ & $T$ & $T$ & $T$ & & $T$ & $T$ & $\bar{T}$ & $T$ & & $T$ & $T$ \\
\hline Eldorado & $T$ & $T$ & $T$ & $T X$ & $T X$ & $T$ & $T$ & $T$ & $T$ & $T$ & $T$ & $T$ & $T$ & $T$ \\
\hline Iguape & & $T$ & $T X$ & $T$ & $\mathrm{~T}$ & $T$ & $T$ & $T$ & $T$ & $T$ & & & & $T$ \\
\hline Iporanga & & $T$ & $T$ & & $T$ & $T$ & $T$ & & $T$ & $T$ & $T$ & & & \\
\hline Itarin & & $T X$ & $T$ & $T X$ & $T X$ & $T$ & $T$ & $T$ & & $T$ & & $T$ & & T \\
\hline Jacupiranga & $\bar{T}$ & $T$ & $\bar{T}$ & $T X$ & $T$ & $T$ & $\bar{T}$ & $T$ & $\bar{T}$ & $T$ & $T$ & $T$ & $T X$ & $T$ \\
\hline Juquiá & $T$ & $T X$ & $T$ & $T X$ & $T$ & $T$ & $T X$ & $\overline{T X}$ & $T$ & $T$ & $T$ & $T$ & $T$ & \\
\hline Miracatu & $T$ & $T$ & $T$ & $T$ & $T$ & $T$ & $T X$ & $T$ & $T$ & $T$ & & $T X$ & $T$ & \\
\hline Pariquera-Açu & $T$ & $T$ & $\bar{T}$ & $T$ & $T X$ & $T$ & $T$ & $T$ & $T$ & $T$ & & $T X$ & $T$ & $T X$ \\
\hline Pedro de Toledo & & $T$ & $T$ & $\bar{T}$ & $T$ & $T$ & $T$ & & $T$ & $T$ & & $T$ & & $T$ \\
\hline Registro & & $T$ & $T$ & $T$ & $T$ & $T$ & $T$ & $T$ & $T X$ & $T$ & $T X$ & $T$ & $T$ & $T$ \\
\hline Sete Barras & $T$ & & $T X$ & $T X$ & $T$ & \begin{tabular}{|l}
$T$ \\
\end{tabular} & $T$ & $T$ & $T$ & $T X$ & $T$ & $T$ & $T$ & $T$ \\
\hline \multicolumn{15}{|c|}{ REGIÁO DE GOVERNO SANTOS } \\
\hline Bertioga & & & & & & & & & & & & & $T X$ & \\
\hline Cubatāo & & & & & & & & $T$ & $T$ & & & & & $T$ \\
\hline Guarujá & & & & & & & & & & & $\mathrm{T}$ & $T$ & $T$ & $T$ \\
\hline Itanhaem & & & & & $T$ & & $T$ & $T$ & & & & & & \\
\hline Penuibe & & $T$ & $T$ & $T X$ & $T X$ & $T$ & $T$ & $T$ & & $T X$ & & & & \\
\hline
\end{tabular}

No Anexo I e na Tabela 4.5.3.2 distingue-se o trabalho concentrado na Regiko do Vale do Ribeira, com 5045 amostras obtidas e somente 187 na Baixada Santista. Nes a, os percentuais de sororreatividade foram mais expressivos, porém os intervalos de conf ança indicam que sofreram a influência de números pequenos de amostras pesquisadas. 
Tabela 4.5.3.2 - Distribuição de frequências de localidades existentes e trabalhadas e de UDs trabalhadas e com reagentes sorológicos para infecção chagásica, das Regiões de Gover no no Serviço Regional da SUCEN de São Vicente (SR-2), 1984 a 1997.

\begin{tabular}{|c|c|c|c|c|c|c|c|c|c|}
\hline \multirow{2}{*}{$\begin{array}{l}\text { Região } \\
\text { de } \\
\text { Governo } \\
\end{array}$} & \multicolumn{3}{|c|}{ Localidades } & \multicolumn{2}{|c|}{ UDs } & \multicolumn{2}{|c|}{ Amostras } & \multirow{2}{*}{$\begin{array}{c}\% \\
\text { reag. }\end{array}$} & \multirow{2}{*}{$\begin{array}{c}\mathrm{IC}^{* \pi} \\
\mathrm{dos} \\
\operatorname{reag}(1 / 0)\end{array}$} \\
\hline & exist. * & trab. & trab. & trab. & reag. & trab. & reag. & & \\
\hline Santos & & 18 & - & 43 & 4 & 187 & 4 & 2,14 & $0,83-5,37$ \\
\hline Registro & 480 & 239 & 49,79 & 1189 & 29 & 5045 & 35 & 0.69 & $0.50-11.96$ \\
\hline TOTAL & & 257 & - & 1232 & 33 & 5232 & 39 & 0.75 & $0.55-.02$ \\
\hline
\end{tabular}

A quantificação anual do trabalho de sorologia nas Unidades Domiciliares está discriminada na Tabela 4.5.3.3. Verifica-se que o número de notificações (número de UDS trabalhadas) que desencadeou os exames sorológicos dos moradores diminuiu cerca de 3 vezes, a partir de 1994

Tabela 4.5.3.3 - Variação anual da sororreatividade para infecção chagásica no Serviçı Regional da SUCEN de São Vicente (SR-2), 1984 a 1997.

\begin{tabular}{|c|c|c|c|c|c|c|}
\hline Ano & $\begin{array}{l}\mathrm{N}^{0} \mathrm{UDs} \\
\text { Trab. }\end{array}$ & $\begin{array}{l}\mathrm{N}^{\circ} \mathrm{Am} . \\
\text { Exam }\end{array}$ & $\mathrm{N}^{\circ}$ Reag. & $\%$ Reag. & $\mathrm{IC}^{*}(\%)$ & MGTR** \\
\hline 1984 & 24 & 124 & 0 & 0,00 & - & - \\
\hline 1985 & 68 & 309 & 5 & 1,62 & $0,69-3,73$ & 73,5 \\
\hline 1986 & 99 & 447 & 2 & 0,45 & $0,12-1,62$ & 512,0 \\
\hline 1987 & 168 & 765 & 13 & 1,70 & $1,00-2,89$ & 206,8 \\
\hline 1988 & 122 & 557 & 4 & 0,72 & $0,28-1,83$ & 181,0 \\
\hline 1989 & 126 & 553 & 0 & 0,00 & - & $\ldots$ \\
\hline 1990 & 100 & 455 & 2 & 0,44 & $0,12-1,59$ & 90,5 \\
\hline 1991 & 108 & 440 & 1 & 0,23 & $0,04-1,28$ & 64,0 \\
\hline 1992 & 167 & 614 & 1 & 0,16 & $0,03-0,92$ & 256,0 \\
\hline 1993 & 123 & 450 & 2 & 0,44 & $0,12-1,61$ & 256,0 \\
\hline 1994 & 44 & 151 & 2 & 1,32 & $0,36-4,70$ & 181,0 \\
\hline 1995 & 41 & 165 & 2 & 1,21 & $0,33-4,31$ & 181,0 \\
\hline 1996 & 21 & 100 & 2 & 2,00 & $0,55-7,00$ & 64,0 \\
\hline 1997 & 21 & 102 & 3 & 2,94 & $1,01-8,29$ & 64,0 \\
\hline TOTAL & 1232 & 5232 & 39 & 0,74 & $0,55-1,02$ & 150,2 \\
\hline
\end{tabular}

* IC = Intervalo de Confiança (95\%)

** MGTR = Média Geométrica dos Títulos dos Reagentes 
$\mathrm{Na}$ Tabela 4.5.3.4 estão apresentados os resultados dos exames sorologico؛; para infeç̧ão chagásica, segundo grupo etário e sexo, de população das Regiões da Baiixada Santista e do Vale do Ribeira, durante o periodo especificado. Não foram registrarłas as idades de 2 amostras do sexo feminino e 14 do sexo masculino

As idades variaram de 0,17 a 93,00 anos, com uma média de 22.94 anos, mediana de 16,00 anos e $75 \%$ da população possuía até 35,00 anos. Nos sororreagentes, a menor idade foi 14 anos e a maior, 77 anos. No grupo etário abaixo de 20 anos houve 4 sororreagentes $(10,26 \%$ dos casos), mas de uma maneira geral, os percentuass de sororreatividade foram relativamente baixos nas duas regiões.

Os títulos das reações variaram de 16 a 512, com a Média Geométrica dos Titulos; dos Reagentes (MGTR) igual a 150,2

Tabela 4.5.3.4 - Sorologia para infecção chagásica, por grupo etário e sexo, em população de municipios do Serviço Regional da SUCEN de São Vicente (SR-2). 1984 a 1997

\begin{tabular}{|c|c|c|c|c|c|c|c|c|c|}
\hline \multirow{2}{*}{$\begin{array}{l}\text { Grupo } \\
\text { etário } \\
\text { (anos) }\end{array}$} & \multicolumn{3}{|c|}{ Feminino } & \multicolumn{3}{|c|}{ Masculino } & \multicolumn{3}{|c|}{ Total } \\
\hline & $\begin{array}{c}\mathrm{N}^{\circ} \\
\text { exam. }\end{array}$ & $\begin{array}{c}\mathrm{N}^{\circ} \\
\text { Reag }\end{array}$ & $\begin{array}{c}\% \\
\text { Reag. }\end{array}$ & $\begin{array}{c}N^{\circ} \\
\text { exam. }\end{array}$ & $\begin{array}{c}\mathrm{N}^{\circ} \\
\text { Reag. }\end{array}$ & $\begin{array}{c}\% \\
\text { Reag. }\end{array}$ & $\begin{array}{c}\mathrm{N}^{\circ} \\
\text { exam }\end{array}$ & $\begin{array}{c}N^{\circ} \\
\text { Reag. }\end{array}$ & $\begin{array}{c}0_{0} \\
\text { Reag }\end{array}$ \\
\hline$<1$ & 32 & 0 & 0,00 & 22 & 0 & 0,00 & 54 & 0 & 0.00 \\
\hline $1-4$ & 288 & 0 & 0,00 & 296 & 0 & 0,00 & 584 & 0 & $C, 00$ \\
\hline $5-9$ & 461 & 0 & 0,00 & 445 & 0 & 0,00 & 906 & 0 & 0.00 \\
\hline $10-14$ & 410 & 1 & 0,24 & 439 & 0 & 0,00 & 849 & 1 & $c, 12$ \\
\hline $15-19$ & 258 & 1 & 0,39 & 260 & 2 & 0,77 & 518 & 3 & C. .58 \\
\hline $20-29$ & 386 & 2 & 0,52 & 253 & 3 & 1,19 & 639 & 5 & 0,78 \\
\hline $30-39$ & 350 & 7 & 2,00 & 250 & 8 & 3,20 & 600 & 15 & 2.50 \\
\hline $40-49$ & 237 & 4 & 1,69 & 244 & 2 & 0,82 & 481 & 6 & 1,25 \\
\hline $50-59$ & 140 & 2 & 1,43 & 167 & 4 & 2,40 & 307 & 6 & 1,95 \\
\hline $60-69$ & 82 & 0 & 0,00 & 105 & 2 & 1,90 & 187 & 2 & 1.07 \\
\hline$\geq 70$ & 46 & 0 & 0,00 & 45 & 1 & 2,22 & 91 & 1 & 1.10 \\
\hline Ignorado & 2 & 0 & 0,00 & 14 & 0 & 0,00 & 16 & 0 & 0.00 \\
\hline Total & 2692 & 17 & 0,63 & 2540 & 22 & 0,87 & 5232 & 39 & 0.74 \\
\hline
\end{tabular}

A reatividade não variou significativamente entre os sexos (limites de confiança a $95 \%$ : $-0,0023 \pm 0,0047) ; p=0,204$. 
A investigação dos sororreagentes foi possivel em 32 casos $(84,2 \%)$, com alguns dados resumidos no Quadro 4.5.3.2. Desses, 23 (71,9\%) foram classificados como importados de outros Estados da Federação; 3 (9,4\%), como autóctones do Estado de São Paulo - 2 na Região de Sorocaba e 1 na Região de São José do Rio Preto, 5 (15.6\%) como autóctones da área e $1(3,1 \%)$, como indeterminado, isto é, com moradia em ıreas endêmicas para doença de Chagas nos Estados de São Paulo, Minas Gerais e Paraná Foi ainda observado que 4 casos (12,5\%) tinham farniliares com doença de Chagas e que 11 $(34,4 \%)$ possuiam exames confirmatórios da infecção e/ou diagnóstico clínico da doenca

Dos casos autóctones da área, há indícios de que a transmissão tenha se dado por manipulação ou por ingestão de carne de caça mal cozida, portanto, pela via oral Dentre eles houve um caso de soroconversão, isto é, de negativo para reagente, com título $\lg G=64$ Foi identificado em decorrència de duas notificações de triatomíneos geradas na m:sma UD, em duas ocasiões distintas. É interessante informar que 13 casos $(40.6 \%)$ relataram prática de caça e/ou de manipulação e/ou de ingestão de carne mal cozida. Os animais citados foram: tatu (Dasypus sp, Priodontes sp), paca (Agouti paca paca L), cateto (Tayassu taiacu), veado (Mazama sp), gambá (Didelphis sp L.), raposa (Lycalopex vetu/lus), macacos (Callithrix sp, Allouatta sp, Cebus sp), tamanduá (Tamandua tetradactyla), laysarto (Tupinambis teguixin) e pássaros (sem discriminação de gênero) 
Quadro 4.5.3.2 - Relação de sororreagentes para infecção chagásica segundo municipio e localidade de residência, ano de deteç̧ão e características relacionadas ao caso no Serviço Regional da SUCEN de São Vicente (SR-2), 1984 a 1997.

\begin{tabular}{|c|c|c|c|c|c|c|}
\hline Municipio/Localidade & Ano & $\begin{array}{l}\text { Idade } \\
\text { (anos) }\end{array}$ & $S$ & Naturalidade & $\begin{array}{l}\text { Tempo } \\
\text { resid. }\end{array}$ & $\begin{array}{l}\text { Título } \\
\text { reação }\end{array}$ \\
\hline \multicolumn{7}{|c|}{ BAIXADA SANTISTA } \\
\hline Bertioga - Boraceia & 1996 & 60 & $\mathrm{M}$ & Estado da Bahia & 45 anos & 64 \\
\hline Peruibe - Rio Guanhanhã & 1987 & 57 & $\mathrm{M}$ & União Palmares. $\mathrm{AL}$ & 17 anos & 256 \\
\hline Peruibe - Aldeia dos İndios II & 1988 & 22 & $\bar{M}$ & & & 256 \\
\hline Peruibe - Jardim Caraguava & 1993 & 49 & $F$ & Teófilo Otoni. MG & 36 anos & 256 \\
\hline \multicolumn{7}{|c|}{ VALE DO RIBEIRA } \\
\hline Eldorado - B Rio Batatal & 1987 & 28 & $\mathrm{M}$ & Ipirá BA & 7 anos & 256 \\
\hline Eldorado - B Primeira Ilha & 1988 & 47 & $\mathrm{~F}$ & Capelinha. MG & 3 anos & 256 \\
\hline Iguape - B Itimirim II & 1986 & 54 & $\mathrm{~F}$ & Américo Campos. SP & 22 anos & 512 \\
\hline Itariri - B Guanhanhã I & 1987 & 38 & $\bar{M}$ & Teófilo Otoni. MG & 8 anos & 512 \\
\hline$" 1 "$ & $"$ & 38 & $\mathrm{~F}$ & Teófilo Otoni. MG & 6 anos & 256 \\
\hline Itariri - B Braço Feio & 1985 & 52 & $\mathrm{M}$ & Palmares. PE & 31 anos & 32 \\
\hline Itariri - B Rio das Pedras & 1988 & 39 & $\mathrm{~F}$ & Itariri. SP & 39 anos & 512 \\
\hline Jacupiranga - B Gracui & 1987 & 30 & $\mathrm{~F}$ & Surucucu. MG & 18 anos & 256 \\
\hline Jacupiranga - F Lageado & 1996 & 52 & $\mathrm{M}$ & Muritiba. BA & 15 anos & 64 \\
\hline Juquia - B Corujas & 1985 & 15 & $M$ & Arapiraca. AL & 11 anos & $N-64^{*}$ \\
\hline " & $"$ & 36 & $\mathrm{M}$ & Viçosa. AL & 11 anos & 64 \\
\hline Juquiá - B Corujas & 1985 & 26 & $\mathrm{~F}$ & Diamantina. $\mathrm{MG}$ & 2 anos & 128 \\
\hline Juquiá - B Corujas & $i 987$ & 38 & $\mathrm{M}$ & & & 256 \\
\hline " " " & " & 17 & $\bar{M}$ & & & 256 \\
\hline Juquiá - B Corujas & 1987 & 25 & $F$ & Juquiá. SP & 25 anos & 32 \\
\hline Juquiá - B Corujas & 1991 & 14 & $\mathrm{~F}$ & Paulistana. PI & 1 ano & 64 \\
\hline Juquiá - B Iporanga & 1990 & +1 & $\mathrm{~F}$ & Mundo Novo. Bahia & 15 anos & 64 \\
\hline Juquiá - Barra do Assungui & 1985 & 42 & $\mathrm{M}$ & & & 128 \\
\hline Miracatu - FAÚ & 1995 & 33 & $\mathrm{M}$ & N. Cruzeiro. MG & 11 anos & 256 \\
\hline Miracatu - B Barra Funda & 1990 & 33 & $\mathrm{M}$ & Itaipe, MG & 16 anos & 128 \\
\hline Pariquera-Açu - V Roseli. Cidade & 1997 & 55 & $\mathrm{~F}$ & Avaré. SP & Ign. & 128 \\
\hline " " " & $"$ & 60 & $\mathrm{M}$ & Avaré, SP & Ign. & 128 \\
\hline Pariquera-Açu - B 13 de Maio & 1995 & 77 & $\mathrm{M}$ & S. Gotardo. MG & 1 ano & 128 \\
\hline Pariquera-Açu - B Alto & 1988 & 23 & $\mathrm{M}$ & Pariquera-Açu. SP & 23 anos & 32 \\
\hline Registro - B Guaviruva ME & 1992 & 37 & $\mathrm{M}$ & Teófilo Otoni. MG & 16 anos & 256 \\
\hline Registro - B Guaviruva ME & 1994 & 39 & $\mathrm{~F}$ & Teófilo Otoni. MG & 1 ano & 512 \\
\hline " & $"$ & 45 & $\bar{M}$ & Teófilo Otoni. MG & 1 ano & 64 \\
\hline Sete Barras - B Formosa & 1993 & 55 & $\mathrm{M}$ & & & 256 \\
\hline Sete Barras - B Barra Rib. da Serra & 1987 & 36 & $\mathrm{~F}$ & S. José Caiana. PB & 1 ano & 128 \\
\hline Sete Barras - B Saibadela & 1986 & 39 & $\mathrm{M}$ & Eldorado, SP & 39 anos & 512 \\
\hline Sete Barras - B Rio Preto de Cima & 1987 & 39 & $\mathrm{~F}$ & Ladainha. MG & 1 ano & 64 \\
\hline & $"$ & 32 & $\mathrm{M}$ & Ladainha. $\mathrm{MG}$ & 1 ano & 256 \\
\hline Sete Barras - B Estrada Quilombo & 1987 & 42 & $\mathrm{~F}$ & & & 256 \\
\hline Sete Barras - B Onça Parda & 1987 & 31 & $\mathrm{~F}$ & Lins, SP & 15 anos & 512 \\
\hline Sete Barras - B Palmital & 1997 & 15 & $\mathbf{F}$ & & & 16 \\
\hline
\end{tabular}

Observação: foram colocadas aspas quando referiu-se à mesma casa da informação anterior. A coluna Ano refere-se ao ano do exame sorológico; o tempo de residência diz respeito ao tempo de moradia ná área, $S=$ sexo

* Caso de soroconversão observado no período. 
A Tabela 4.5.3.5 relaciona a presença de vetor e suas características quanto à espécie, fase de desenvolvimento e infecção, local de captura e resultado de reações para identificação de hábito alimentar, em dois grupos: constituídos por UDs com presença de sororreagente e por UDs sem presença de sororreagentes.

P. megistus e T. tibiamaculata foram as espécies mais frequentemente encontradas, tanto nas UDs em que havia pessoas sororreagentes quanto naquelas em que não as havia, mesmo após os cálculos efetuados para corrigir o efeito dos casos de perda de informação Do mesmo modo, a presença de vetor adulto superou a das formas ninfais. O local de captura intradomicilio foi significativamente maior que no peridomicilio.

Os percentuais de infecção dos triatomíneos por $T$. cruzi $(26.4 \%$ dos casos), não foram significativamente diferentes entre as UDs com e sem presença de pesioas sororreagentes (Limite de confiança 950: $-0,105 \pm 0,150$ ).

Perda de informação quanto às reações para identificação de hábitos alimentares dos triatomíneos foi da ordem de $50 \%$ dos casos, resultando, após ajuste de dados, diferenç̧as não significantes para sangue humano nos dois grupos considerados (Limite de confiança a $95 \%$ : $-0,0019 \pm 0,1246)$.

Quando avaliados os dois grupos de UDs com e sem presença de pesioas sororreagentes e de UDS com triatomineos infectados e não infectados por $T$. cruzi (dados da Tabela 4.5.3.6), observamos que não houve diferença entre eles ("odds ratio" = 0729 $95 \%: 0,313-1,696)$. 
Tabela 4.5.3.5 - Unidades Domiciliares com e sem presença de sororreagentes para infeç̧ão chagásica, de acordo com características associadas ao vetor, no Serviço Regional da SUCEN de São Vicente (SR-2), 1984 a 1997.

\begin{tabular}{|c|c|c|c|c|c|c|c|c|c|}
\hline \multirow[t]{2}{*}{ Característica } & \multicolumn{3}{|c|}{$\begin{array}{l}\text { UD c/ reag. sorol. } \\
n=33\end{array}$} & \multicolumn{3}{|c|}{$\begin{array}{l}\text { UD s/ reag. sorol. } \\
n=1199\end{array}$} & \multicolumn{3}{|c|}{$\begin{array}{l}\text { Total } \\
n=1232\end{array}$} \\
\hline & $\mathrm{N}^{\circ}$ & $\%$ & $\% *$ & $\mathrm{~N}^{\circ}$ & $\%$ & $\% *$ & $\mathrm{~N}^{\mathrm{O}}$ & $\%$ & $\%$ \% \\
\hline Espécie & & & & & & & & & \\
\hline P. megistus $(P m)$ & 20 & 60,7 & & 533 & 44,5 & 45,5 & 553 & $+4,9$ & 45,9 \\
\hline T. tibiamaculata $(T t i)$ & 11 & 33,3 & & 538 & 44,9 & 45,9 & 549 & 44,6 & 45.6 \\
\hline$R$. domesticus $(R d)$ & 1 & 3,0 & & 60 & 5,0 & 5,1 & 61 & 4,9 & 5.1 \\
\hline$P m \cdot T t i$ & 1 & 3,0 & & 29 & 2,4 & 2,5 & 30 & 2,4 & 2,5 \\
\hline$P m+R d$ & & & & 4 & 0,3 & 0,3 & 4 & 0,3 & 0,3 \\
\hline$T t i+R d$ & & & & 2 & 0,2 & 0,2 & 2 & 0,2 & 0.2 \\
\hline$T t i+$ Outros & & & & 1 & 0,1 & 0,1 & 1 & 0,1 & 0,1 \\
\hline$R d \cdot$ Outros & & & & 1 & 0,1 & 0,1 & 1 & 0.1 & 0.1 \\
\hline Outros & & & & 3 & 0,2 & 0,2 & 3 & 0,2 & 0.2 \\
\hline sem informação & & & & 28 & 2,3 & & 28 & 2,3 & \\
\hline Fase evolutiva e infecção & & & & & & & & & \\
\hline Ninfas & & & & 7 & 0,6 & 0,6 & 7 & 0,6 & 0,6 \\
\hline Ninfas infectadas & & & & & & & & & \\
\hline Ninfas e Adultos & & & & 4 & 0,3 & 0,3 & 4 & 0.3 & 0,3 \\
\hline Ninfas e Adultos infect. & & & & & & & & & \\
\hline Adultos & 26 & 78,8 & 81,2 & 842 & 70,2 & 72,4 & 868 & 70,4 & 72.7 \\
\hline Adultos infectados & 6 & 18,2 & 18,8 & 310 & 25,9 & 26,7 & 316 & 25,6 & 26.4 \\
\hline sem informação & 1 & 3,0 & & 36 & 3,0 & & 37 & 3,0 & \\
\hline Local de captura & & & & & & & & & \\
\hline interno & 26 & 78,8 & 89,7 & 1025 & 85,5 & 93,8 & 1051 & 85,3 & 93,6 \\
\hline externo & 1 & 3,0 & 3,4 & 58 & 4,8 & 5,3 & 59 & 4,8 & 5.3 \\
\hline interno e externo & 2 & 6,1 & 6,9 & 10 & 0,8 & 0,9 & 12 & 1,0 & 1,1 \\
\hline sem informação & 4 & 12,1 & & 106 & 8,9 & & 110 & 8,9 & \\
\hline Hábito alimentar & & & & & & & & & \\
\hline Sangue humano*** & 4 & 12,1 & 30,8 & 185 & 15,5 & 28,9 & 189 & 15,3 & 28.9 \\
\hline Outros**** & 4 & 12,1 & 30,8 & 118 & 9,8 & 18,4 & 122 & 9,9 & 18.6 \\
\hline Não reagente & 5 & 15,2 & 38,4 & 338 & 28,2 & 52,7 & 343 & 27,9 & 52.5 \\
\hline sem informação & 20 & 60,6 & & 558 & 46,5 & & 578 & 46,9 & \\
\hline
\end{tabular}

* Percentual calculado excluindo-se as perdas de informação

** 1 exemplar infectado por $T$. cruzi em UD com reagente sorológico e 5 exemplares infectado.; por T. cruzi em UDs sem reagente sorológico.

*** Reagente para sangue humano sozinho ou associado a outros

**** Outros: reagentes para sangue de ave, cão, gato, roedor ou marsupial 
Tabela 4.5.3.6 - Encontro de reagentes e de não reagentes sorológicos para infecçào chagásica, em UDs com e sem presença de triatomíneo infectado por $T$. cruzi, no serviço Regional da SUCEN de São Vicente (SR-2), 1984 a 1997.

\begin{tabular}{cc|cc|c}
\hline \multicolumn{2}{c|}{ Característica } & \multicolumn{2}{|c|}{ UD com presença de morador } & Total \\
& & Sororreagente & Negativo & \\
\hline $\begin{array}{l}\text { UD com } \\
\text { triatomineo }\end{array}$ & $\begin{array}{l}\text { infectado por } T . \\
\text { cruzi } \\
\text { não infectado } \\
\text { por } T \text {. cruzi }\end{array}$ & 7 & 315 & 322 \\
\hline & 26 & 853 & 879 \\
\hline & 33 & 1168 & 120 \\
\hline
\end{tabular}

Ainda que não tenham sido consideradas, na maior parte do periodo. as normas para desencadear a colheita de sangue para exames sorológicos, observamos essas condiçòes nas proporções especificadas na Tabela 4.5.3.7. A perda de informação esta relacionada, na quase a totalidade dos casos, à falta de resultados dos exames de hábitos alimentares dos vetores.

Tabela 4.5.3.7 - Condições para execução de exame sorológico, segundo presen ${ }_{r}$ - ou ausência de sororreagentes para infecção chagásica, em UDs no Serviço Regional diı SUCEN de São Vicente (SR-2), 1984 a 1997.

\begin{tabular}{|c|c|c|c|c|c|c|}
\hline \multirow[t]{2}{*}{ Condição p/gerar sorologia } & \multicolumn{2}{|c|}{$\begin{array}{l}\text { UD c/ reagente } \\
\text { sorológico } \\
(\mathrm{n}=33)\end{array}$} & \multicolumn{2}{|c|}{$\begin{array}{l}\text { UD s/ reagente } \\
\text { sorológico } \\
(\mathrm{n}=1199)\end{array}$} & \multicolumn{2}{|c|}{$\begin{array}{c}\text { Total } \\
(\mathrm{n}=1232)\end{array}$} \\
\hline & $N^{0}$ & $\%$ & $\mathrm{~N}^{\circ}$ & $\%$ & $\mathrm{~V}^{\mathrm{o}}$ & $\%$ \\
\hline Triatomineo infectado & 6 & 18,2 & 266 & 22.2 & 272 & $\therefore 2,1$ \\
\hline Triat. infect. + Reag. p/ sangue hum. & 1 & 3,0 & 49 & 4,1 & 50 & 4,0 \\
\hline Reagente $\mathrm{p} /$ sangue humano & 3 & 9,1 & 136 & 11,3 & 139 & 1,3 \\
\hline Dispensável* & 6 & 18,2 & 324 & 27,0 & 330 & $\therefore 6,8$ \\
\hline Sem informação & 17 & 51,5 & 424 & 35,4 & 441 & 5.8 \\
\hline
\end{tabular}

* Colheita de sangue realizada fora das normas do PCDCh, na ausência de triatomíneo infe tado por $T$. cruzi e/ou com ingesta reagente para sangue humano. 


\subsubsection{No Serviço Regional da SUCEN de Sorocaba (SR-4)}

O Serviço Regional da SUCEN de Sorocaba (SR-4) compreende 5 Regiòres de Governo: Avaré, Botucatu, Itapetininga, Itapeva e Sorocaba, com 63 municipios que ocupam uma área de $39797 \mathrm{~km} 2$, ou 16,00\% do Estado ${ }^{92}$. No periodo 1984-1997 foram trabalhados 597 focos domiciliares de triatomíneos vetores, em 298 localidades de 42 municípios (Tabela 4.5.4.1). Nesse total estão incluidos 11 municipios na Região de Governo Itapeva, entre eles o de Iporanga que, conforme assinalado anteriormente, foi anexado ao Vale do Ribeira, trabalhado pela Regional da SUCEN de São Vicente (SR-?).

Tabela 4.5.4.1 - Sorologia de infecção chagásica em Regiōes de Governo no Serviço Regional da SUCEN de Sorocaba (SR-4), 1984 a 1997

\begin{tabular}{lcccc}
\hline $\begin{array}{c}\text { Região de } \\
\text { Governo }\end{array}$ & $\begin{array}{c}\mathrm{N}^{\circ} \text { Munic. } \\
\text { exist. }\end{array}$ & $\begin{array}{c}\mathrm{N}^{\circ} \text { Munic. } \\
\text { trab. }\end{array}$ & $\begin{array}{c}\% \text { Mun. } \\
\text { trab. }\end{array}$ & $\begin{array}{c}\mathrm{N}^{\circ} \text { UDs } \\
\text { trab }\end{array}$ \\
\hline Avaré & 16 & 13 & 81,25 & 132 \\
Botucatu & 11 & 5 & 45,45 & 17 \\
Itapetininga & 10 & 8 & 80,00 & 147 \\
Itapeva & 10 & 10 & 100,00 & 271 \\
Sorocaba & 15 & 6 & 40,00 & 30 \\
\hline & 62 & 42 & 67,74 & 597 \\
\hline
\end{tabular}

No Quadro 4.5.4.1 estão relacionados os municípios, por Região de Governo. ınde o PCDCh foi executado, destacando a sororreatividade na população 
Quadro 4.5.4.1 - Municipios com localidades trabalhadas em sorologia (T) e com presença de sororreagentes (X), no Programa de Controle da Doença de Chagas (PCDCh) do Serviço Regional da SUCEN de Sorocaba (SR-4), 1984-1997

\begin{tabular}{|c|c|c|c|c|c|c|c|c|c|c|c|c|c|c|}
\hline MUNICIPIO & 1984 & 1985 & 1986 & 1987 & 1988 & 1989 & 1990 & 1991 & 1992 & 1993 & 1994 & 1995 & 1996 & 1997 \\
\hline \multicolumn{15}{|c|}{ RG AVARE } \\
\hline ÁguasStaBárbara & & & & & & & & & & & & $T$ & & \\
\hline Avaré & & $T$ & & & & $T$ & & & & & & & & \\
\hline BarãoDeAntonina & & $T$ & $T X$ & $T$ & $T$ & & & & & & & & & \\
\hline CoronelMacedo & $T X$ & $T X$ & $T X$ & $T X$ & $T$ & & & & & $T X$ & & $T$ & & \\
\hline Fartura & & $T$ & $T$ & & $T X$ & $T$ & $T$ & & & & & & & \\
\hline \begin{tabular}{|l} 
Itail \\
\end{tabular} & & $T X$ & & & & & & & & & & & & \\
\hline Itaporanga & $T$ & $T X$ & $T X$ & $T X$ & $T X$ & & $T X$ & & & $T$ & & & & \\
\hline Paranapanema & $T X$ & $T$ & $T X$ & & & & $T$ & & & & & & & \\
\hline Piraju & $T X$ & $T X$ & $T X$ & $T X$ & $T X$ & $T$ & $\bar{T}$ & & $T$ & $T$ & & $T$ & & \\
\hline Sarutaia & & & & & $T$ & & & & & & & & & \\
\hline Taguai & & $\mathrm{TX}$ & $T X$ & & $T X$ & & & & & & & & $T$ & \\
\hline Taquantuba & & $T X$ & $T X$ & $T X$ & $T X$ & $T X$ & $T$ & & & $T$ & & & & \\
\hline Tejupa & & $T X$ & $T x$ & $T X$ & $T X$ & $T$ & $T$ & $T$ & & & & & & \\
\hline \multicolumn{15}{|c|}{ RG BOTUCATU } \\
\hline Botucatu & & & & & $T$ & & & & & & & & & \\
\hline Conchas & & & $T$ & & & & $T$ & & & $T$ & & & & \\
\hline LaranjalPaulista & & & $T$ & & & & & & & & & & & \\
\hline Pereiras & & & & $T$ & & & $T$ & & & & & & & \\
\hline Porangaba & & & $T X$ & $T X$ & $T$ & $T$ & & & & & $T$ & & & \\
\hline \multicolumn{15}{|c|}{ RG ITAPETININGA } \\
\hline Angatuba & $T X$ & $T X$ & $T X$ & $T X$ & $T$ & $T$ & $T X$ & $T$ & $T$ & $T$ & $T$ & & & \\
\hline CapelaDoAlto & & & $\mathrm{TX}$ & $\mathrm{T}$ & $\bar{T}$ & $T X$ & & & & & & & & \\
\hline Cerquilho & & & $T$ & & & & & & & & $T$ & & & \\
\hline CesárioLange & & $T$ & & $T$ & $T$ & & & & & & & $T$ & & \\
\hline Guarei & $T X$ & $T$ & $T X$ & $T X$ & $T X$ & $T$ & $T$ & $T$ & $T$ & & $T$ & & & \\
\hline Itapetininga & & $T$ & $T$ & $T$ & $T$ & $T$ & $T$ & $T$ & & $T$ & $T$ & $T$ & & \\
\hline SMiguelArcanjo & $T$ & $T$ & $T$ & & $T$ & $T$ & & $T$ & & & $T$ & & & \\
\hline Tatui & & & $T$ & $T$ & $T$ & & & & & & & & & \\
\hline \multicolumn{15}{|c|}{ RGITAPEVA } \\
\hline Apiai & $T$ & $T$ & $T$ & $T$ & $T$ & $T$ & $T$ & $T$ & $T$ & $T$ & $T$ & $T$ & & \\
\hline Buri & & & $T X$ & & & $T$ & & & & & $T$ & & & \\
\hline CapãoBonito & $T$ & & $T$ & $T$ & $T$ & $T$ & $T$ & $T$ & $T$ & $T$ & & & & \\
\hline Guapiara & & $T$ & $T$ & & $T$ & & $T$ & & $T$ & $T$ & $T$ & & & \\
\hline |taberá & $T X$ & $T X$ & $T X$ & $T X$ & $T$ & $T$ & $T X$ & $T$ & $T$ & $T X$ & $T$ & & & \\
\hline Itapeva & & TX & $T$ & $T$ & & $T X$ & & $T$ & & $T$ & $T$ & & & \\
\hline \begin{tabular}{|l|} 
Itarare \\
\end{tabular} & $T$ & $T X$ & $T X$ & $T X$ & $T$ & $T X$ & $T X$ & $T$ & & $T$ & $T$ & & & $T$ \\
\hline Ribeira & & $T$ & $T$ & $T$ & $T X$ & $T$ & $T$ & $T$ & & $T$ & $T$ & & & \\
\hline RibeirãoBranco & $T$ & & & & $T$ & $T$ & $T$ & $T$ & $T$ & & $\bar{T}$ & $T$ & & \\
\hline Riversul & $T X$ & $T X$ & $T X$ & TX & $T X$ & $T X$ & $T$ & $T$ & $T$ & $T$ & $T$ & & & \\
\hline
\end{tabular}




\begin{tabular}{|l|c|c|c|c|c|c|c|c|c|c|c|c|c|}
\hline \multicolumn{10}{|c|}{ RG SOROCABA } \\
\hline \multicolumn{1}{|c|}{ MUNICIPIO } & 1984 & 1985 & 1986 & 1987 & 1988 & 1989 & 1990 & 1991 & 1992 & 1993 & 1994 & 1995 & 1996 \\
\hline Ibiuna & & & & T & T & & T & & & T & & & \\
\hline Piedade & $\mathrm{T}$ & & & $\mathrm{T}$ & $\mathrm{T}$ & $\mathrm{T}$ & & & $\mathrm{T}$ & & & & \\
\hline PilarDoSul & & & $\mathrm{T}$ & & $\mathrm{TX}$ & & $\mathrm{T}$ & & & $\mathrm{T}$ & & & \\
\hline Sorocaba & & & & & & & & & $\mathrm{T}$ & & & & \\
\hline Tapirai & & & $\mathrm{T}$ & & $\mathrm{T}$ & & $\mathrm{T}$ & $\mathrm{T}$ & & $\mathrm{T}$ & & & \\
\hline Tietê & & & & & $\mathrm{T}$ & & & & & & & & \\
\hline
\end{tabular}

Nota-se diminuição das atividades relacionadas com a sorologia, mais acentuada a partir de 1994, quando entrou em vigor a norma de que a colheita de sangue de moradores ocorreria somente nas UDs em que se detectasse a presença de triatomíneos infectidos no intradomicílio

O Anexo II e a Tabela 4542 fornecem uma idéia da extensão de áreas em que havia UDs com presença de vetores infectados e/ou com reação positiva para identificação de hábito alimentar sangue humano, mais a presença de $T$. infestans, motivo da realização de exames sorológicos

A Região de Governo Avaré distiguiu-se das demais pela reatividade sorolósica. embora fossem baixas as percentagens de pessoas examinadas em alguns de seus municípios. Na Região compreendida pelos municipios Angatuba, Barão de Antonina, Buri, Guarei, Itaberá, Itapetininga, Itapeva, Itaporanga, Itararé e Riversul, que compje a microrregião homogênea Campos de Itapetininga, um dos reconhecidos redutos da dosnça de Chagas no Estado de São Paulo ${ }^{25}$, a sororreatividade observada foi de $0.144^{0}$. praticamente a metade da registrada na região Avaré. 
Tabela 4.5.4.2 - Distribuição de frequências de localidades existentes e trabalhadas e de UDs trabalhadas e com reagentes sorológicos para infecção chagásica, nas Regiões de Gov erno do Serviço Regional da SUCEN de Sorocaba (SR-4), 1984 a 1997.

\begin{tabular}{|c|c|c|c|c|c|c|c|c|c|}
\hline \multirow{2}{*}{$\begin{array}{l}\text { Região de } \\
\text { Governo }\end{array}$} & \multicolumn{3}{|c|}{ Localidade } & \multicolumn{2}{|c|}{ UDs } & \multicolumn{3}{|c|}{ Amostras } & \multirow{2}{*}{$\begin{array}{c}I C^{* / k} \\
\text { dos reag }(\%)\end{array}$} \\
\hline & exist.* & trab. & $\begin{array}{c}\% \\
\text { trab. }\end{array}$ & trab. & reag. & trab. & reag. & $\begin{array}{c}0 \\
\text { reag. }\end{array}$ & \\
\hline Avaré & 302 & 68 & 22,52 & 132 & 53 & 549 & 64 & 11.60 & $9.24-14,61$ \\
\hline Botucatu & 255 & 14 & 5,49 & 17 & 2 & 54 & 2 & 3,70 & $1 .(2-12.54$ \\
\hline Itapetininga & 275 & 77 & 28,00 & 147 & 18 & 654 & 22 & 3,36 & $2,23-5,04$ \\
\hline Itapeva & 387 & 118 & 30,49 & 271 & 35 & 1156 & 45 & 3,89 & $2.35-5,07$ \\
\hline Sorocaba & 641 & 21 & 3,28 & 30 & 1 & 120 & 1 & 0.99 & 0. $.15+.57$ \\
\hline TOTAL & 1860 & 298 & 16,02 & 597 & 109 & 2533 & 134 & 5.29 & $4,48-0,23$ \\
\hline
\end{tabular}

* Fonte: SUCEN/DOT/Lista de localidades segundo municipios por Serviço Regional. 1981-1986,

** IC = Intervalo de Confiança (95\%)

A redução de sororreatividade ao longo dos anos, observada na Tabela $45+i$ deve ser objeto de particular atenção. Ao estimar alterações da soroprevalência a partir dessès dados, é necessário ter em conta a queda do número de amostras colhidas da população da Regional de Sorocaba e consequente perda da precisão dos resultados. Os tituliss dás reações variaram entre 16 e 2048 , sendo a média geométrica dos titulos dos reagentes (MGTR) igual a 127,3 .

Na Tabela 4.5.4.4 estão apresentados os resultados de sororreatividade para in iecção chagásica, segundo grupo etário e sexo. As idades variaram de 0,08 a 90,00 anos, com uma média de 25,24 anos, mediana de 20,00 anos e $75 \%$ da população com ate 38,00 anos. No grupo etário de 20 anos ou menos houve 5 sororreagentes $(3,73 \%$ dos zasos), sendo a menor idade observada 8,00 anos, para o sexo masculino e 13,00 anos, para o sexo feminino. Não houve diferença significante de reatividade entre os $\operatorname{sexos}(p=0,565)$ 
Tabela 4.5.4.3 - Variação anual da sororreatividade para infecção chagásica no Serviço Regional da SUCEN de Sorocaba (SR-4), 1984 a 1997.

\begin{tabular}{ccccccc}
\hline Ano & $\begin{array}{r}\mathrm{N}^{\circ} \text { UDs } \\
\text { Trab. }\end{array}$ & $\begin{array}{r}\mathrm{N}^{\circ} \text { Am. } \\
\text { Exam. }\end{array}$ & $\begin{array}{c}\mathrm{N}^{\circ} \\
\text { Reag. }\end{array}$ & \% Reag. & IC* $^{*} \%$ & MGTR $^{* *}$ \\
\hline 1984 & 30 & 154 & 15 & 9,74 & $5,99-15,45$ & 134,0 \\
1985 & 77 & 365 & 26 & 7,12 & $4,91-10,23$ & 121,3 \\
1986 & 116 & 514 & 40 & 7,78 & $5,77-10,42$ & 117,4 \\
1987 & 71 & 262 & 24 & 9,16 & $6,23-13,27$ & 170,9 \\
1988 & 70 & 273 & 15 & 5,49 & $3,36-8,87$ & 116,7 \\
1989 & 41 & 179 & 7 & 3,91 & $1,91-7,85$ & 115,9 \\
1990 & 59 & 235 & 5 & 2,13 & $0,91-4,88$ & 128,0 \\
1991 & 19 & 73 & 0 & 0,00 & - & - \\
1992 & 22 & 80 & 0 & 0,00 & - & - \\
1993 & 48 & 208 & 2 & 0,96 & $0,26-3,44$ & 64,0 \\
1994 & 32 & 134 & 0 & 0,00 & - & - \\
1995 & 10 & 49 & 0 & 0,00 & - & - \\
1996 & 1 & 3 & 0 & 0,00 & - & - \\
1997 & 1 & 4 & 0 & 0,00 & - & \\
\hline & & & & & & \\
TOTAL & 597 & 2533 & 134 & 5,29 & $4,48-6,23$ & 127,3 \\
\hline
\end{tabular}

* IC = Intervalo de Confiança (95\%)

** MGTR = Média Geométrica dos Títulos dos Reagentes

Tabela 4.5.4.4 - Sorologia para infecção chagásica, por grupo etário e sexo, em população de municípios do Serviço Regional da SUCEN de Sorocaba (SR-4), 1984 a 1997.

\begin{tabular}{|c|c|c|c|c|c|c|c|c|c|}
\hline \multirow{2}{*}{$\begin{array}{l}\text { Grupo } \\
\text { etário } \\
\text { (anos) }\end{array}$} & \multicolumn{3}{|c|}{ Feminino } & \multicolumn{3}{|c|}{ Masculino } & \multicolumn{3}{|c|}{ Total } \\
\hline & $\begin{array}{c}\mathrm{N}^{\circ} \\
\text { exam. }\end{array}$ & $\begin{array}{c}\mathrm{N}^{\circ} \\
\text { Reag }\end{array}$ & $\begin{array}{c}\% \\
\text { Reag. }\end{array}$ & $\begin{array}{c}\mathrm{N}^{\circ} \\
\text { exam. }\end{array}$ & $\begin{array}{c}\mathrm{N}^{\circ} \\
\text { Reag. }\end{array}$ & $\begin{array}{c}\% \\
\text { Reag. }\end{array}$ & $\begin{array}{c}N^{\circ} \\
\text { exam }\end{array}$ & $\begin{array}{c}N^{\circ} \\
\text { Reag. }\end{array}$ & $\begin{array}{c}\% \\
\text { Reays. }\end{array}$ \\
\hline$<1$ & 11 & 0 & 0,00 & 15 & 0 & 0,00 & 26 & 0 & $0,(10$ \\
\hline $1-4$ & 113 & 0 & 0,00 & 132 & 0 & 0,00 & 245 & 0 & $0,(10$ \\
\hline $5-9$ & 169 & 0 & 0,00 & 194 & 2 & 1,03 & 363 & 2 & 0,55 \\
\hline $10-14$ & 179 & 1 & 0,56 & 186 & 2 & 1,08 & 365 & 3 & 0,82 \\
\hline $15-19$ & 118 & 0 & 0,00 & 142 & 0 & 0,00 & 260 & 0 & $0,(10$ \\
\hline $20-29$ & 183 & 13 & 7,10 & 170 & 5 & 2,94 & 353 & 18 & 5,10 \\
\hline $30-39$ & 188 & 17 & 9,04 & 139 & 14 & 10,07 & 327 & 31 & 9,48 \\
\hline $40-49$ & 137 & 21 & 15,33 & 111 & 21 & 18,92 & 248 & 42 & 16,94 \\
\hline $50-59$ & 89 & 10 & 11,24 & 91 & 15 & 16,48 & 180 & 25 & 13,89 \\
\hline $60-69$ & 47 & 5 & 10,64 & 58 & 4 & 6,90 & 105 & 9 & 8,57 \\
\hline$\geq 70$ & 28 & 3 & 10,71 & 33 & 1 & 3,03 & 61 & 4 & 6,56 \\
\hline Total & 1262 & 70 & 5,55 & 1271 & 64 & 5,04 & 2533 & 134 & 5,29 \\
\hline
\end{tabular}


Informações associadas aos casos sororreagentes com idades inferiores a 15 anos ano da deteç̧ão, idade, sexo, município, localidade, número de moradores na casa, nımero de reagentes na casa, espécie do vetor, estágio evolutivo, local de captura e resultado de reação de determinação de hábitos alimentares são discriminadas no Quadro $454:$ Nos anos de 1985 e 1987 ocorreu a deteç̧ão de um mesmo caso de infecção chagásica em Itararé. Diante da notificação de triatomíneos, que implicou a colheita de sangue dos moradores da casa, este caso e os demais sororreagentes da casa não foram excluidos no segundo exame, sendo assim computados no ano de 1987.

Na Regional, o trabalho rotineiro de investigação de casos não foi efetuado por falta de infra-estrutura de apoio ao infectado chagásico. Essa é uma questão de dificil abordagem pelos serviços de controle de vetores. É digno de nota o registro de um caso de transrr issão transfusional nessa região ${ }^{212}$, evidenciando que o assunto deve ser solucionado, posto jue a investigação dos casos é fundamental para a vigilância epidemiológica da endemia.

Quadro 4.5.4.2 - Características associadas aos casos sororreagentes para infecção chagásica em menores de 15 anos, no Serviço Regional da SUCEN de Sorocaba (SR-4), 1984 a 1997.

\begin{tabular}{|l|r|r|l|l|r|l|l|l|l|l|}
\hline Ano & Id & S & Municipio & Localidade & NMC & NRC & Esp. & Fase & LC & PPT \\
\hline 1984 & 13 & F & Guarei & B $^{\circ}$ Jacutinga & 13 & 4 & Pm & N $_{3-5}$ & ext & Ou \\
1985 & 9 & M & Itararé & B $^{\circ}$ Sta. Cruz & 4 & 3 & Pm & Ad q & int & Hum \\
1986 & 14 & M & Capela Alto & B $^{\circ}$ Canguera & 6 & 1 & Pm+ & Ig & Ig & Ig \\
1987 & 12 & M & Itararé & B $^{\circ}$ Sta. Cruz & 3 & 3 & Pm & Ad q & int & Hum \\
1989 & 8 & M & Itapeva & B Lagoa Gde & 6 & 1 & Pm & N $_{3-5}$ & int & Ig \\
\hline
\end{tabular}

Legenda:

Id $=$ idade em anos

$S=$ sexo

$\mathrm{NMC}=$ número de moradores na casa

$\mathrm{NRC}=$ número de reagentes na casa

Esp.= espécie; $\mathrm{Pm}=P$. megistus $; \mathrm{Pm}+=P$. megistus infectado por $T$. cruzi

$\mathrm{N}_{3.5}=$ ninfa de terceiro a quinto estádio; Ad. $\mathrm{q}=$ adulto fêmea; $\mathrm{Ig}=$ ignorado

LC= local de captura: ext=externo; int=interno

PPT $=$ resultado de reação para determinação de hábito alimentar: $\mathrm{Ou}=$ outros; Hum=humano

As condições de atendimento que geraram a colheita de sangue nas casas em que se observou presença ou não de sororreagentes estão especificadas na Tabela 4.5.4.5. A pirda 
de informação foi mais acentuada nas UDs com sororreagentes. Descontadas essas perdas, observamos que a notificação predominou sobre a forma de atendimento de rotina. o que está de acordo com o planejado pelo Serviço Regional ${ }^{178}$.

Tabela 4.5.4.5 - Unidades Domiciliares com e sem presença de sororreagente; para infecção chagásica, de acordo com o tipo de atendimento, no Serviço Regional da SIJCEN de Sorocaba (SR-4), 1984 a 1997.

\begin{tabular}{|c|c|c|c|c|c|c|}
\hline \multirow{2}{*}{ Atendimento } & \multicolumn{2}{|c|}{$\begin{array}{l}\text { UD c/ reag. sorol. } \\
\qquad(n=109)\end{array}$} & \multicolumn{2}{|c|}{$\begin{array}{l}\text { UD s/ reag. sorol. } \\
\quad(n=488)\end{array}$} & \multicolumn{2}{|c|}{$\begin{array}{c}\text { Total } \\
(\mathrm{n}=597)\end{array}$} \\
\hline & $\mathrm{N}^{0}$ & $\%$ & $N^{\circ}$ & $\%$ & $N^{\circ}$ & $-\%$ \\
\hline Notificação & 62 & 56,88 & 380 & 77,87 & 442 & $7.4,04$ \\
\hline Rotina & 3 & 2,75 & 5 & 1,02 & 8 & 1,34 \\
\hline Sem informação & 44 & 40,37 & 103 & 21,11 & 147 & 24.62 \\
\hline
\end{tabular}

A Tabela 4.5.4.6 apresenta os resultados condensados de caracteristicas assoriadas ao vetor e sua frequência, de acordo com a presença ou não de sororreagentes nas casas investigadas

No SR-4 foram encontrados exemplares de $T$. infestans nos seguintes anos : municípios:

- 1984 e 1985 - Angatuba, B ${ }^{\circ}$ Figueira (UDs sem reagentes sorológicos);

- 1986, 1987 e 1988 - Itaberá, $B^{\circ}$ Toriba (UDs sem reagentes sorológicos),

- 1984 e 1985 - Paranapanema, Faz. Cruzeiro (UD com reagente sorológico) e $B^{\circ}$ Yalim (UD sem reagente sorológico), respectivamente. Apesar desses focos, contudo, a espécie mais frequente na região foi P.megistus, identificada em mais de $95 \%$ dos casos, nas UDs com ou sem a presença de pessoas sororreagentes. Captura de triatomíneo; no intradomicílio e reação para identificação de hábito alimentar reagente para sangue humano prevaleceram nas UDs pesquisadas.

Não foi demonstrada associação entre expostos aos triatomíneos infectados 'odds ratio" $=0,848$ 95\%: $0,476-1,513$ (Tabela 4.5.4.7). 
Tabela 4.5.4.6 - Unidades Dorniciliares com e sem presença de sororreagente; para infecção chagásica, de acordo com características associadas ao vetor, no Serviço Regional da SUCEN de Sorocaba (SR-4), 1984 a 1997.

\begin{tabular}{|c|c|c|c|c|c|c|c|c|c|}
\hline \multirow[t]{2}{*}{ Caracteristica } & \multicolumn{3}{|c|}{$\begin{array}{l}\text { UD c/ reag. sorol. } \\
n=109\end{array}$} & \multicolumn{3}{|c|}{$\begin{array}{l}\text { UD s/ reag. sorol. } \\
n=488\end{array}$} & \multicolumn{3}{|c|}{$\begin{array}{r}\text { Total } \\
n=597\end{array}$} \\
\hline & $\mathrm{N}^{\circ}$ & $\%$ & $\% *$ & $N^{\circ}$ & $\%$ & $\% *$ & $N^{\circ}$ & $\%$ & ${ }^{0}{ }_{0}^{*}{ }^{*}$ \\
\hline \multicolumn{10}{|l|}{ Espécie } \\
\hline T. infestans $(T i)$ & 2 & 1,8 & 1,8 & 6 & 1,2 & 1,3 & 8 & 1,3 & 1,4 \\
\hline P. megistus $(P m)$ & 106 & 97,3 & 98,2 & 432 & 88,6 & 96,3 & 538 & 90,1 & 96,5 \\
\hline T. sordida & & & & 2 & 0,4 & 0,5 & 2 & 0,3 & 0,4 \\
\hline T. tibiamaculata $(T t i)$ & & & & 5 & 1,0 & 1,1 & 5 & 0,8 & 0,9 \\
\hline$R$. domesticus $(R d)$ & & & & 1 & 0,2 & 0,2 & 1 & 0.2 & 0,2 \\
\hline$T i+P m$ & & & & 1 & 0,2 & 0,2 & 1 & 0.2 & 0,2 \\
\hline$P m-T t i$ & & & & 1 & 0,2 & 0,2 & 1 & 0.2 & 0,2 \\
\hline Outros & & & & 1 & 0,2 & 0,2 & 1 & 0.2 & 0.2 \\
\hline sem informação & 1 & 0,9 & & 39 & 8,0 & & 40 & 6.7 & \\
\hline \multicolumn{10}{|l|}{ Fase evolutiva e infecção } \\
\hline Ninfas & 4 & 3,7 & 5,9 & 19 & 3,9 & 5,2 & 23 & 3.8 & 5.3 \\
\hline Ninfas e Adultos & 2 & 1,8 & 2,9 & 8 & 1,6 & 2,2 & 10 & 1,7 & 2,3 \\
\hline Ninfas e Adultos infect. & 1 & 0,9 & 1,5 & 2 & 0,4 & 0,6 & 3 & 0,5 & 0.7 \\
\hline Adultos & 49 & 45,0 & 72,1 & 240 & 49,2 & 66,1 & 289 & 48,4 & 67,1 \\
\hline Adultos infectados & 12 & 11,0 & 17,6 & 94 & 19,3 & 25,9 & 106 & 17,8 & 24,6 \\
\hline sem informação & 41 & 37,6 & & 125 & 25,6 & & 166 & 27,8 & \\
\hline \multicolumn{10}{|l|}{ Local de captura } \\
\hline interno & 66 & 60,6 & 98,5 & 350 & 71,7 & 97,8 & 416 & 69,7 & 97,9 \\
\hline externo & 1 & 0,9 & 1,5 & 7 & 1,4 & 1,9 & 8 & 1,3 & 1,9 \\
\hline interno e externo & & & & 1 & 0,2 & 0,3 & 1 & 0,2 & 0.2 \\
\hline sem informação & 42 & 38,5 & & 130 & 26,7 & & 172 & 28,8 & \\
\hline \multicolumn{10}{|l|}{ Hábito alimentar } \\
\hline Sangue humano** & 63 & 57,8 & 90,0 & 241 & 49,4 & 80,9 & 304 & 50,9 & 82,6 \\
\hline Outros*** & 3 & 2,7 & 4,3 & 21 & 4,3 & 7,0 & 24 & 4,0 & 6.5 \\
\hline Não reagente & 4 & 3,7 & 5,7 & 36 & 7,4 & 12,1 & 40 & 6,7 & 10.9 \\
\hline sem informação & 39 & 35,8 & & 190 & 38,9 & & 229 & 38,4 & \\
\hline
\end{tabular}

* Percentual calculado excluindo-se as perdas de informação.

** Reagente para Sangue humano sozinho ou associado a outros.

*** Outros: reagentes para sangue de ave, cão, gato, roedor ou marsupial. 
Tabela 4.5.4.7 - Encontro de reagentes e de não reagentes sorológicos para infecçào chagásica, em UDs com e sem presença de triatomíneo infectado por $T$. cruzl, no Serviço Regional da SUCEN de Sorocaba (SR-4), 1984 a 1997

\begin{tabular}{ll|cc|c}
\hline \multicolumn{2}{c|}{ Caracteristica } & \multicolumn{2}{|c|}{ UD com presença de morador } & Total \\
& & Sororreagente & Negativo & \\
\hline $\begin{array}{l}\text { UD com } \\
\text { triatomineo }\end{array}$ & $\begin{array}{l}\text { infectado por } T . \\
\text { cruzi } \\
\text { não infectado } \\
\text { por } T \text {. cruzi }\end{array}$ & 18 & 103 & 121 \\
& & 55 & 267 & 322 \\
\hline & 73 & 370 & 443 \\
\hline
\end{tabular}

A atividade sorologia foi desencadeada pelo encontro de triatomíneos infectados por T. cruzi em aproximadamente $30 \%$ dos casos (Tabela 4.5.4.8). Quando exluid is as observações incompletas, o percentual subiu para 36,2\%. Do mesmo modo, reagentes para sangue humano no teste para determinação de hábitos alimentares ocorreram em cer ¿a de $50 \%$ dos casos e, após exclusão daqueles sem informação, o valor foi para cerca de $61 \%$.

Tabela 4.5.4.8 - Condições para execução de exame sorológico, segundo presença ou ausência de sororreagentes para infecção chagásica, em UDs no Regional da SUCEN de Sorocaba (SR-4), 1984 a 1997.

\begin{tabular}{|c|c|c|c|c|c|c|}
\hline \multirow[t]{2}{*}{ Condição p/gerar sorologia } & \multicolumn{2}{|c|}{$\begin{array}{l}\text { UD c/ reagente } \\
\text { sorológico } \\
\quad(n=109)\end{array}$} & \multicolumn{2}{|c|}{$\begin{array}{l}\text { UD s/ reagente } \\
\text { sorológico } \\
\quad(n=488)\end{array}$} & \multicolumn{2}{|c|}{$\begin{array}{l}\text { Total } \\
(\mathrm{n}=597)\end{array}$} \\
\hline & $\mathrm{N}^{\circ}$ & $\%$ & $\mathrm{~N}^{\circ}$ & $\%$ & $\mathrm{~N}^{\circ}$ & $\%$ \\
\hline Triatoma infestans & 1 & 0,9 & 6 & 1,2 & 7 & 1,2 \\
\hline Triatomineo infectado & 29 & 26,6 & 115 & 23,6 & 144 & $\therefore 4,1$ \\
\hline Triat. infect. + Reag. $p$ / sangue hum. & 2 & 1,8 & 19 & 3,9 & 21 & 3,5 \\
\hline Reagente $\mathrm{p} /$ sangue Humano & 60 & 55,1 & 218 & 44,7 & 278 & 46,6 \\
\hline Dispensável* & 1 & 0,9 & 5 & 1,0 & 6 & 1.0 \\
\hline Sem informação & 16 & 14,7 & 125 & 25,6 & 141 & $\because 3,6$ \\
\hline
\end{tabular}

* Colheita de sangue realizada fora das normas do PCDCh, na ausência de triatomineo infectado por $T$. cruzi e/ou com ingesta reagente para sangue humano. 


\subsubsection{No Serviço Regional da SUCEN de Campinas (SR-5)}

O Serviço Regional da SUCEN de Campinas (SR-5) é composto por 7 Regiìes de Governo: Bragança Paulista, Campinas, Jundiaí, Limeira, Piracicaba, Rio Claro e São João da Boa Vista, totalizando 83 municípios. Ocupa uma área de $27079 \mathrm{~km}^{2}$, equivalente a $10,89 \%$ do Estado ${ }^{2}$. Na rotina de trabalho da Regional, em 1984, só existiam localidades em Prioridades II e III.

No periodo 1984-1997, os trabalhos concentraram-se na Região de Governo de São João da Boa Vista (Tabela 4.5.5.1), que inclui os municípios da microrregião Er costál Ocidental da Mantiqueira Paulista ${ }^{91}$, de distribuição natural de P. meglstus Esta condição mereceu, por parte dessa Regional, um trabalho diferenciado de pesquisa sobre sua infestação ${ }^{112.179}$.

Tabela 4.5.5.1 - Sorologia de infecção chagásica em Regiões de Governo no Serviço Regional da SUCEN de Campinas (SR-5), 1984 a 1997

\begin{tabular}{lcccc}
\hline Região de Governo & $\begin{array}{c}\mathrm{N}^{\circ} \text { Munic. } \\
\text { exist. }\end{array}$ & $\begin{array}{c}\mathrm{N}^{\circ} \text { Munic. } \\
\text { trab. }\end{array}$ & $\begin{array}{c}\% \text { Mun. } \\
\text { trab. }\end{array}$ & $N^{\circ}$ UDs \\
\hline Bragança Paulista & 14 & 6 & 42,86 & 49 \\
Campinas & 18 & 13 & 72,22 & 73 \\
Jundiaí & 9 & 3 & 33,33 & 5 \\
Limeira & 8 & 6 & 75,00 & 16 \\
Piracicaba & 10 & 5 & 50,00 & 12 \\
Rio Claro & 8 & 2 & 25,00 & 3 \\
S. João da Boa Vista & 16 & 14 & 87,50 & 201 \\
\hline & 83 & 49 & 59,04 & 449 \\
\hline
\end{tabular}


O Quadro 4.5.5.1, a Tabela 4.5.5.2 e o Anexo III apresentam os dados referentes aos municipios trabalhados em cada Região de Governo do SR-5, quantificando locali dades, UDs e amostras sororreagentes.

Quadro 4.5.5.1 - Municipios com localidades trabalhadas em sorologia ( $T$ ) e com presença de sororreagentes (X), no Programa de Controle da Doença de Chagas (PCDCh) do Serviço Regional da SUCEN de Campinas (SR-5), 1984-1997.

\begin{tabular}{|c|c|c|c|c|c|c|c|c|c|c|c|c|c|c|}
\hline MUNICIPIO & 1984 & 1985 & 1986 & 1987 & 1988 & 1989 & 1990 & 1991 & 1992 & 1993 & 1994 & 1995 & 1996 & 1997 \\
\hline \multicolumn{15}{|c|}{ RG BRAGANÇA PAULISTA } \\
\hline AguasdeLindóia & $\bar{T}$ & $T$ & & $T$ & & & & $T$ & & & $T$ & & & \\
\hline Amparo & $\bar{T}$ & $T$ & & $T$ & $T$ & & & & & & & & & \\
\hline MonteAlegreSul & & $T X$ & $T$ & $T$ & & & & & & & $T$ & & & \\
\hline Pinhalzinho & & & & & & $T$ & & & & & & & & \\
\hline SerraNegra & $T$ & $T$ & $T$ & & $T X$ & $T$ & & $T$ & & & & & & \\
\hline Socurro & $T$ & $T$ & $\bar{T}$ & & $T$ & $\bar{T}$ & & $T$ & $T$ & & $T X$ & $T$ & & \\
\hline \multicolumn{15}{|c|}{ RG CAMPINAS } \\
\hline Campinas & $T$ & $T$ & $T$ & $T X$ & $T X$ & $T$ & & $T$ & & & & & & \\
\hline Cosmopolis & & & $T$ & & & & & & & & & & & \\
\hline Indaiatuba & & $T$ & $T$ & & $T$ & & & & & $T$ & & & & \\
\hline Itapira & $T$ & & & $T X$ & $T$ & $T$ & & $T$ & $T$ & & $T$ & & & \\
\hline Jaguariuna & & & & $T$ & & & & & & & & & & $T X$ \\
\hline MogiGuaçu & $T X$ & $\mathrm{~T}$ & & & $T$ & & & & & & $T$ & & & \\
\hline MogiMirim & & $T$ & & & & & & & & & & & & \\
\hline MonteMor & & & $T$ & & & $T$ & & & & $T$ & & & & \\
\hline Pedreira & & $T$ & $\overline{T X}$ & $T$ & $T$ & $T$ & & & & $T$ & & & & \\
\hline StoAntonioPosse & $T$ & & & & & & & & & & & & & \\
\hline Sumare & & $T$ & & & & & & & & & & & & \\
\hline Valinhos & & & & & $T$ & $T$ & & & & & & & & \\
\hline Vinhedo & & $T$ & $T$ & & & & & & & & & & & \\
\hline \multicolumn{15}{|c|}{ RG JUNDIAI } \\
\hline Itatiba & & $T$ & & & & & & & & & & & & \\
\hline Itupeva & & & & $T$ & $T$ & & & & & & & & & \\
\hline Jundiai & $T$ & $T$ & & & & & & & & & & & & \\
\hline \multicolumn{15}{|c|}{ RG LIMEIRA } \\
\hline Araras & & & & & $T$ & & & & & & & & & \\
\hline Cordeiropolis & & $T$ & & $T X$ & & & & & & & & & & \\
\hline Leme & $T$ & & & & $T$ & & & & & & & & & \\
\hline Limeira & & $T$ & $T$ & & $T$ & $T$ & & & & & $T$ & & & \\
\hline Pirassununga & $T X$ & & & & $T$ & & & & & & & & & \\
\hline StaCruzConc. & & $T$ & & & & & & & & & & & & \\
\hline
\end{tabular}




\begin{tabular}{|c|c|c|c|c|c|c|c|c|c|c|c|c|c|c|}
\hline MUNICIPIO & 1984 & 1985 & 1986 & 1987 & 1988 & 1989 & 1990 & 1991 & 1992 & 1993 & 1994 & 1995 & 1996 & 1997 \\
\hline \multicolumn{15}{|c|}{ RG PIRACICABA } \\
\hline Capivari & & & & & & $T$ & & & & & & & & \\
\hline EliasFausto & & & $T$ & & & & & & & & & & & \\
\hline Piracicaba & & $T$ & $\bar{T}$ & $T$ & & $T$ & & & & & & & & \\
\hline Rafard & & & $T$ & & $T$ & $T X$ & & & & $T$ & & & & \\
\hline StaMariadaSerra & $T$ & & & & & & & & & & & & & \\
\hline \multicolumn{15}{|c|}{ RG RIO CLARO } \\
\hline Itirapina & & $T$ & & & & & & & & & & & & \\
\hline RioClaro & & $T$ & & $T$ & & & & & & & & & & 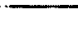 \\
\hline \multicolumn{15}{|c|}{ RG SÅO JOÅO DA BOA VISTA } \\
\hline ÁguasdaPrata & & & & & & $\mathrm{T}$ & & & & & & & & \\
\hline Aguai & & & & $T$ & & & & & & & & & & \\
\hline CasaBranca & & & $T$ & & & $\bar{T}$ & & & & & & & & - \\
\hline Caconde & $T$ & $T X$ & $T$ & $\overline{T X}$ & $T X$ & $\bar{T}$ & & $T X$ & $T X$ & $T X$ & $T X$ & $T$ & $T$ & $T$ \\
\hline Divinoländia & $T X$ & $T$ & $T$ & $T$ & & $T$ & & $T X$ & & & $T$ & & & \\
\hline EspStodoPinhal & $T$ & $\bar{T}$ & $T$ & $T$ & $T$ & $T$ & & $\bar{T}$ & & & $T$ & $T$ & & \\
\hline Itobi & & & & & & $T$ & & & & & & & & \\
\hline Mococa & $T X$ & & $T$ & & $T X$ & $T$ & & & & $T$ & & & & $\bar{T}$ \\
\hline StoAntonioJardim & $T$ & $\bar{T}$ & & & $T$ & $T$ & & $T$ & & & $T$ & $T X$ & & \\
\hline SJoãoBoaVista & $T$ & $\overline{T X}$ & $T X$ & $T$ & $T X$ & $T$ & & $T$ & $T$ & $T$ & $T X$ & $T X$ & $T$ & \\
\hline SJoseRioPardo & $T$ & $\bar{T}$ & $\bar{T}$ & $T$ & $\bar{T}$ & $\bar{T}$ & & $T$ & $T$ & & $T X$ & $T$ & $T$ & $T$ \\
\hline S.Seb.Grama & $T$ & $T$ & $T$ & $T$ & $T X$ & $T$ & & $T$ & & $T$ & $T$ & $T$ & $T$ & $T$ \\
\hline Tapiratiba & $T$ & & $T$ & $T$ & $T$ & & & $T$ & & & $T$ & & & \\
\hline VargemGde. Sul & $T$ & $T$ & $T$ & $T$ & $T$ & $\bar{T}$ & & $T$ & $T$ & $T$ & $T X$ & & & \\
\hline
\end{tabular}

No ano de 1990, a Regional não produziu colheitas de material para a sorolıgia Curiosamente, este foi um ano de mudanças no Programa de Chagas, com o estabelecimento de novos critérios para as Prioridades, agora PI, para aquelas com indices de infestação intradomiciliar $>=5 \%$ e peridomiciliar $>=10 \%$; PII, índices entre $0,1: 5 \%$ no intra- e 0,1 e $10 \%$ no peridomicílio; PIII, sem infestação. As pesquisas seriam bienais, casa-a-casa, em todas as localidades quando em PI e por amostragem, em PII O atendimento de notificações permeariam ambas prioridades e seria atividade exclusiva na PIII. Esses procedimentos representariam uma substancial redução no volume de trabalho, correspondendo à realização de pesquisas em 14 localidades em PII e em 26 localiclades em PIII. Apesar de preconizada, no Planejamento do SR-5, a investigação epidemiologica de sororreagentes não foi efetuada. Supõe-se que o remanejamento de recursos para o controle de Ae. aegypti e a intensificação das atividades de vigilância da dengue e da 
leishmaniose motivaram a falta da atividade. De outro lado, dificuldades de locomoção de pacientes infectados chagásicos, de outros municipios para Campinas, para atendimento na Faculdade de Ciências Médicas da UNICAMP, também prejudicou o desenvolvimento dessa atividade ${ }^{186}$.

Tabela 4.5.5.2 - Distribuição de frequências de localidades existentes e trabalhadas e de UDs trabalhadas e com reagentes sorológicos para infecção chagásica, nas Regiões de Governo do Serviço Regional da SUCEN de Campinas (SR-5), 1984 a 1997.

\begin{tabular}{|c|c|c|c|c|c|c|c|c|c|}
\hline \multirow{2}{*}{$\begin{array}{l}\text { Região de } \\
\text { Governo }\end{array}$} & \multicolumn{3}{|c|}{ Localidades } & \multicolumn{2}{|c|}{ UDs } & \multicolumn{3}{|c|}{ Amostras } & \multirow{2}{*}{$\begin{array}{c}1 \mathrm{C}^{* *} \\
\text { dos reag. }(\%)\end{array}$} \\
\hline & exist.* & trab. & $\%$ trab. & trab. & reag. & trab. & reag. & \%reag & \\
\hline Bragança & & & & & & & & & \\
\hline Paulista & 443 & 36 & 8,13 & 49 & 3 & 257 & 3 & 1,17 & $0,40-3,38$ \\
\hline Campinas & 773 & 55 & 7,12 & 73 & 6 & 307 & 7 & 2,28 & $1,11-4,63$ \\
\hline Jundiai & 266 & 5 & 1,88 & 5 & 0 & 26 & 0 & 0,00 & - \\
\hline Limeira & 239 & 14 & 5,86 & 16 & 2 & 82 & 3 & 3,66 & $1,25-10,2 \mathrm{i}$ \\
\hline Piracicaba & 253 & 8 & 3,16 & 12 & 1 & 62 & 2 & 3,23 & $0,8 \div-11,02$ \\
\hline $\begin{array}{l}\text { Rio Claro } \\
\text { São João da }\end{array}$ & 225 & 3 & 1,33 & 3 & 0 & 12 & 0 & 0,00 & - \\
\hline Boa Vista & 776 & 166 & 21,39 & 291 & 27 & 1239 & 29 & 2,34 & $1.63-3.34$ \\
\hline TOTAL & 2975 & 287 & 9,65 & 449 & 39 & 1985 & 44 & 2,22 & $1.60-2.96$ \\
\hline
\end{tabular}

* Fonte: SUCEN/DOT/Lista de localidades segundo municípios por Serviço Regional. 1981-1986 ** IC = Intervalo de Confiança (95\%).

Na Tabela 4.5.5.3 observa-se que, ao longo dos anos, os valores percentuais de sororreatividade estão associados a amplos intervalos de confiança, provavelmente devido ao pequeno número de amostras geradas no período. Os títulos das reações variaram entre 16 e 1 024, com a Média Geométrica dos Títulos dos Reagentes igual a 147,53. Duas; amostras que apresentaram resultados duvidosos ao Título $=16$ foram incluidas no côraputo geral dos sororreagentes, tendo-se em conta o espectro de variabilidade dos titulos sorológicos. 
Tabela 4.5.5.3 - Variação anual da sororreatividade para infecção chagásica no Sırviço Regional da SUCEN de Campinas (SR-5), 1984 a 1997.

\begin{tabular}{|c|c|c|c|c|c|c|}
\hline Ano & $\begin{array}{l}\mathrm{N}^{\circ} \mathrm{UDs} \\
\text { Exam. }\end{array}$ & $\begin{array}{l}\mathrm{N}^{\circ} \mathrm{Am} . \\
\text { Exam. }\end{array}$ & $\begin{array}{c}\mathrm{N}^{\circ} \\
\text { Reag. }\end{array}$ & $\%$ Reag. & $\mathrm{IC}^{*}(\%)$ & MGTR** \\
\hline 1984 & 51 & 245 & 5 & 2,04 & $0,87-4,67$ & $22 \therefore .9$ \\
\hline 1985 & 67 & 358 & 6 & 1,68 & $0,77-3,61$ & $20 \div 2$ \\
\hline 1986 & 39 & 158 & 2 & 1,27 & $0,35-4,50$ & $36: .0$ \\
\hline 1987 & 46 & 214 & 6 & 2,80 & $1,29-5,98$ & $51: 0$ \\
\hline 1988 & 49 & 219 & 8 & 3,65 & $1,86-7,04$ & $8 \therefore 0$ \\
\hline 1989 & 57 & 256 & 2 & 0,78 & $0,21-2,80$ & $3 \therefore 0$ \\
\hline 1990 & 0 & - & - & - & - & - \\
\hline 1991 & 42 & 142 & 4 & 2,82 & $1,10-7,02$ & 181,0 \\
\hline 1992 & 20 & 69 & 2 & 2,90 & $0,80-9,97$ & $36: .0$ \\
\hline 1993 & 19 & 99 & 1 & 1,01 & $0,18-5,50$ & 512,0 \\
\hline 1994 & 35 & 132 & 5 & 3,79 & $1,63-8,56$ & 48,5 \\
\hline 1995 & 13 & 45 & 2 & 4,44 & $1,23-14,83$ & 64.0 \\
\hline 1996 & 5 & 21 & 0 & 0,00 & - & - \\
\hline 1997 & 6 & 27 & 1 & 3,70 & $0,66-18.28$ & 16,0 \\
\hline TOTAL & 449 & 1985 & 44 & 2.22 & $1.66-2.96$ & $14 \div .5$ \\
\hline
\end{tabular}

* IC = Intervalo de Confiança (95\%)

** MGTR = Média Geométrica dos Títulos dos Reagentes

Na Tabela 4.5.5.4 são mostrados os resultados dos exames sorológicos para infecção chagásica, por grupo etário e sexo. As idades variaram entre 0,08 e 85,00 anos, con uma média de 27,58 anos, mediana de 24,00 anos e $75 \%$ da população com até 41,00 anos No grupo etário inferior a 20 anos houve $1(2,27 \%)$ sororreagente, com idade 12 anos sexo masculino, Título=32. As reações cujos resultados foram duvidosos pertenciam a dois casos: um de 51 anos, sexo feminino, moradora da localidade Fazenda Glória, municíio de Santo Antônio do Jardim e outro de 54 anos, sexo masculino, morador da localidade Indústria Tozan, município de Jaguariuna. Embora os resultados da investigação dos 44 casos sororreagentes não estivessem disponíveis, é presumível que alguns deles devam ter tido acompanhamento no GEDOCH de Campinas, dadas as informações apresentadas recentemente por WANDERLEY et al. ${ }^{213}$ (1999). 
Tabela 4.5.5.4 - Sorologia para infecção chagásica, por grupo etário e sexo, em população de municípios do Serviço Regional da SUCEN de Campinas (SR-5), 1984 a 1997.

\begin{tabular}{|c|c|c|c|c|c|c|c|c|c|}
\hline \multirow{2}{*}{$\begin{array}{l}\text { Grupo } \\
\text { etário } \\
\text { (anos) }\end{array}$} & \multicolumn{3}{|c|}{ Feminino } & \multicolumn{3}{|c|}{ Masculino } & \multicolumn{3}{|c|}{ Total } \\
\hline & $\begin{array}{c}\text { No. } \\
\text { exam }\end{array}$ & $\begin{array}{c}\mathrm{N}^{\circ} \\
\text { Reag. }\end{array}$ & $\begin{array}{c}\% \\
\text { Reag. }\end{array}$ & $\begin{array}{c}\mathrm{N}^{\mathrm{O}} \\
\text { exam }\end{array}$ & $\begin{array}{c}N^{\circ} \\
\text { Reag. }\end{array}$ & $\begin{array}{c}\% \\
\text { Reag. }\end{array}$ & $\begin{array}{c}\mathrm{N}^{\circ} \\
\text { exam }\end{array}$ & $\begin{array}{c}N^{\circ} \\
\text { Reag. }\end{array}$ & $\begin{array}{c}\% \\
\text { Reag. }\end{array}$ \\
\hline$<1$ & 3 & 0 & 0,00 & 2 & 0 & 0,00 & 5 & 0 & 0,00 \\
\hline $1-4$ & 87 & 0 & 0,00 & 83 & 0 & 0,00 & 170 & 0 & 0,00 \\
\hline $5-9$ & 119 & 0 & 0,00 & 132 & 0 & 0,00 & 251 & 0 & 0,00 \\
\hline $10-14$ & 129 & 0 & 0,00 & 130 & 1 & 0,77 & 259 & 1 & 0,39 \\
\hline $15-19$ & 86 & 0 & 0,00 & 82 & 0 & 0,00 & 168 & 0 & 0,00 \\
\hline $20-29$ & 152 & 2 & 1,32 & 155 & 1 & 0,65 & 307 & 3 & 0,98 \\
\hline $30-39$ & 142 & 3 & 2,11 & 152 & 3 & 1,97 & 294 & 6 & 2,04 \\
\hline $40-49$ & 96 & 0 & 0,00 & 117 & 4 & 3,42 & 213 & 4 & 1,88 \\
\hline $50-59$ & 66 & 6 & 9,09 & 70 & 5 & 7,14 & 136 & 11 & 8,09 \\
\hline $60-69$ & 63 & 11 & 17,46 & 67 & 5 & 7,46 & 130 & 16 & 12,31 \\
\hline$\geq 70$ & 21 & 2 & 9,52 & 31 & 1 & 3,23 & 52 & 3 & 5,77 \\
\hline Total & 964 & 24 & 2.49 & 1021 & 20 & 1,96 & 1985 & 44 & 2,22 \\
\hline
\end{tabular}

Não foram observadas diferenças significantes nas reatividade entre os sexos $(p=0,422)$.

Merece destaque a identificação, em 1994, de um caso sororreagente, com 12 anos de idade, natural do município de São João da Boa Vista, localidade Bairro Córrego Fundo I. Dentre os 5 moradores na casa, nenhum outro foi sororreagente. A espécie do vetor encontrado foi $P$. megistus. Na oportunidade foram capturadas no intradomicílio 2 ninfas de terceiro a quinto estádios e 1 fềmea. Nelas, a pesquisa de hábito alimentar resultou negativa para sangue humano

Na Tabela 4.5.5.5 observou-se o predomínio de notificações sobre as atividades de rotina, tanto nas UDs com presença quanto naquelas com ausência de sororreagentes. 
Tabela 4.5.5.5 - Unidades Domiciliares com e sem presença de sororreagentes para infecção chagásica, de acordo com o tipo de atendimento, no Serviço Regional da SUCEN de Campinas (SR-5), 1984 a 1997.

\begin{tabular}{|c|c|c|c|c|c|c|}
\hline \multirow{2}{*}{ Atendimento } & \multicolumn{2}{|c|}{$\begin{array}{l}\text { UD c/ reag. sorol } \\
\qquad(\mathrm{n}=39)\end{array}$} & \multicolumn{2}{|c|}{$\begin{array}{l}\text { UD s/ reag. sorol. } \\
\qquad(n=410)\end{array}$} & \multicolumn{2}{|c|}{$\begin{array}{c}\text { Total } \\
(n=449)\end{array}$} \\
\hline & $\mathrm{N}^{\mathrm{o}}$ & $\%$ & $\mathrm{~N}^{\circ}$ & $\%$ & $\mathrm{~N}^{\circ}$ & $\%$ \\
\hline Notificação & 16 & 41,03 & 200 & 48,78 & 216 & 48,11 \\
\hline Rotina & 5 & 12,82 & 35 & 8,54 & 40 & 8,91 \\
\hline Rotina e Notificação & 0 & 0,00 & 1 & 0,24 & 1 & 0,22 \\
\hline Sem informação & 18 & 46,15 & 174 & 42,14 & 192 & 42,76 \\
\hline
\end{tabular}

A Tabela 4.5.6 condensa os resultados de caracteristicas associadas ao vetor $\mathrm{e}$ suas frequências, de acordo com a presença ou não de sororreagentes nas casas investigadas

Capturas no intradomicílio e identificações de hábito alimentar reagentes para sangue humano prevaleceram nas UDs examinadas. A espécie $P$. megistus foi dominante, antes e após correção das perdas de informações, na região.

Triatomineos infectados por T. cruzi foram confirmados em cerca de $50 \%$ das UDs trabalhadas, sendo observada maior proporção entre as formas adultas.

A descoberta de T. infestans motivou a sorologia em uma UD com 12 residentes, do município de Tapiratiba, Praça Cae Silva Foi capturado, no intradomicilio, um exemplar fêmea infectado por $T$. cruzl, com reação para identificação de hábitos alimentares positiva para sangue humano. Os resultados dos exames sorológicos foram negativos para infecção chagásica. 
Tabela 4.5.5.6 - Unidades Domiciliares com e sem presença de sororreagentes para infeç̧ão chagásica, de acordo com características associadas ao vetor, no Serviço Regional da SUCEN de Campinas (SR-5), 1984 a 1997

\begin{tabular}{|c|c|c|c|c|c|c|c|c|c|}
\hline \multirow[t]{2}{*}{ Caracteristica } & \multicolumn{3}{|c|}{$\begin{array}{l}\text { UD c/ reag. sorol. } \\
n=39\end{array}$} & \multicolumn{3}{|c|}{$\begin{array}{l}\text { UD s/ reag. sorol. } \\
n=410\end{array}$} & \multicolumn{3}{|c|}{$\begin{array}{l}\text { Total } \\
n=449\end{array}$} \\
\hline & $\mathrm{N}^{\circ}$ & $\%$ & $\% *$ & $\mathrm{~N}^{0}$ & $\%$ & $\% *$ & $N^{\circ}$ & $\%$ & $\% *$ \\
\hline Espécie & & & & & & & & & \\
\hline T. infestans $(T i)$ & & & & 1 & 0,2 & 0,3 & 1 & 0,2 & 0,2 \\
\hline$P$. megistus $(P m)$ & 30 & 76,9 & 93,8 & 344 & 83,9 & 92,2 & 374 & 83,4 & 92,4 \\
\hline R. domesticus $(R d)$ & 2 & 5,1 & 6,2 & 23 & 5,6 & 6,2 & 25 & 5,6 & 6,2 \\
\hline T. arthurneivai (Tar) & & & & 2 & 0,5 & 0,5 & 2 & 0,4 & 0,5 \\
\hline$P m \cdot R n$ & & & & 2 & 0,5 & 0,5 & 2 & 0,4 & 0,5 \\
\hline$R n$. Tar & & & & 1 & 0,2 & 0,3 & 1 & 0,2 & 0,2 \\
\hline sem informação & 7 & 18,0 & & 37 & 9,1 & & 44 & 9,8 & \\
\hline Fase evolutiva e infecção & & & & & & & & & \\
\hline Ninfas & 5 & 12,8 & 15,2 & 32 & 7,8 & 8,6 & 37 & 8,2 & 9,2 \\
\hline Ninfas infectadas & 4 & 10,3 & 12,1 & 22 & 5,4 & 6,0 & 26 & 5,8 & 6,5 \\
\hline Ninfas e Adultos & 2 & 5,1 & 6,1 & 10 & 2,4 & 2,7 & 12 & 2,7 & 3,0 \\
\hline Ninfas e Adultos infect & 3 & 7,7 & 9,1 & 22 & 5,4 & 6,0 & 25 & 5,6 & 6,2 \\
\hline Adultos & 8 & 20,5 & 24,2 & 146 & 35,6 & 39,7 & 154 & 34,3 & 38,4 \\
\hline Adultos infectados & 11 & 28,2 & 33,3 & 136 & 33,2 & 37,0 & 147 & 32,7 & 36,7 \\
\hline sem informação & 6 & 15,4 & & 42 & 10,2 & & 48 & 10,7 & \\
\hline Local de captura & & & & & & & & & \\
\hline interno & 23 & 59,0 & 67,7 & 299 & 72,9 & 81,9 & 322 & 71,7 & 80,7 \\
\hline externo & 8 & 20,5 & 23,5 & 61 & 14,9 & 16,7 & 69 & 15,4 & 11,3 \\
\hline interno e externo & 3 & 7,7 & 8,8 & 5 & 1,2 & 1,4 & 8 & 1,8 & 2,0 \\
\hline sem informação & 5 & 12,8 & & 45 & 11,0 & & 50 & 11,1 & \\
\hline Hábito alimentar & & & & & & & & & \\
\hline Sangue humano** & 19 & 48,7 & 61,3 & 204 & 49,7 & 57,3 & 223 & 49,7 & 57,6 \\
\hline Outros $* * *$ & 11 & 28,2 & 35,5 & 139 & 33,9 & 39,0 & 150 & 33,4 & 38,8 \\
\hline Não reagente & 1 & 2,6 & 3,2 & 13 & 3,2 & 3,7 & 14 & 3,1 & 3,6 \\
\hline sem informação & 8 & 20,5 & & 54 & 13,2 & & 62 & 13,8 & \\
\hline
\end{tabular}

* Percentual calculado excluindo-se as perdas de informação.

** Reagente para Sangue humano sozinho ou associado a outros

*** Outros: reagentes para sangue de ave, cão, gato, roedor ou marsupial.

Como nos casos anteriores, não foi observada associação entre expostos ao triatomineo infectado e soropositividades: "odds ratio" $=1,086$ 95\%: 0,5:27 - 2,238 (Tabela 4.5.5.7). 
Tabela 4.5.5.7 - Encontro de reagentes e de não reagentes sorológicos para infecção chagásica, em UDs com e sem presença de triatomíneo infectado por T. cruzi, na Regional da SUCEN de Campinas (SR-5), 1984 a 1997.

\begin{tabular}{ll|cc|c}
\hline \multicolumn{2}{c|}{ Caracteristica } & \multicolumn{2}{c|}{ UD com presença de morador } & Total \\
& \multicolumn{2}{c|}{ Sororreagente } & Negativo & \\
\hline $\begin{array}{l}\text { UD com } \\
\text { triatomineo }\end{array}$ & $\begin{array}{l}\text { infectado por } T: \\
\text { cruz: } \\
\text { não infectado } \\
\text { por } T \text {. cruzi }\end{array}$ & 17 & 191 & 208 \\
\hline & 15 & 183 & 198 \\
\hline & 32 & 374 & 406 \\
\hline
\end{tabular}

Das condições para gerar exame sorológico dos moradores das UDs com presença de triatomineos vetores, os valores para a infecção por $T$. cruzi e a reação para sangue humano no hábito alimentar estiveram próximos (Tabela 4.5.5.8). Em 2 casos a sorologia foi realizada sem as condições exigidas pelo Programa.

Tabela 4.5.5.8 - Condições para execução de exame sorológico para infecção chagásica, segundo presença ou ausência de sororreagentes em UDs no Serviço Regional da SUCEN de Campinas (SR-5), 1984 a 1997.

\begin{tabular}{|c|c|c|c|c|c|c|}
\hline \multirow[t]{2}{*}{ Condição p/gerar sorologia } & \multicolumn{2}{|c|}{$\begin{array}{l}\text { UD c/ reagente } \\
\text { sorológico } \\
\qquad(\mathrm{n}=39)\end{array}$} & \multicolumn{2}{|c|}{$\begin{array}{l}\text { UD s/ reagente } \\
\text { sorológico } \\
\qquad(n=410)\end{array}$} & \multicolumn{2}{|c|}{$\begin{array}{c}\text { Total } \\
(n=449)\end{array}$} \\
\hline & $\mathrm{N}^{\circ}$ & $\%$ & $\mathrm{~N}^{\mathrm{O}}$ & $\%$ & $\mathrm{~N}^{\circ}$ & $\%$ \\
\hline Triatoma infestans infectado & 0 & 0,0 & 1 & 0,2 & 1 & 0,2 \\
\hline Triatomineo infectado & 13 & 33,3 & 169 & 41,3 & 182 & 40,5 \\
\hline Triat infect + Reag sangue Hum. & 4 & 10,3 & 21 & 5,1 & 25 & 5,6 \\
\hline Reagente $\mathrm{p} /$ sangue Humano & 14 & 35,9 & 182 & 44,4 & 196 & 43,7 \\
\hline Dispensável* & 1 & 2,6 & 1 & 0,2 & 2 & 0,4 \\
\hline Sem informação & 7 & 17,9 & 36 & 8,8 & 43 & 9,6 \\
\hline
\end{tabular}

* Colheita de sangue realizada fora das normas do PCDCh, na ausência de triatomineo infectado por $T$. cruzi e/ou com ingesta reagente para sangue humano. 


\subsubsection{No Serviço Regional da SUCEN de Ribeirão Preto (SR-6)}

O Serviço Regional da SUCEN de Ribeirão Preto, SR-6, compreende 4 Regiões Administrativas: Ribeirão Preto, Central (com duas Regiões de Governo: Araraquara e São Carlos), Barretos e Franca (com duas Regiões de Governo: Franca e São Joaquim da Barra). Ocupa área de $39044 \mathrm{~km}^{2}, 15,70 \%$ do Estado ${ }^{92}$. O trabalho de sorologia envolveu 115 focos domiciliares de triatomíneos vetores situados em 44 de 86 municípios existentes (Tabela 4.5.6.1)

Tabela 4.5.6.1 - Sorologia de infecção chagásica em Regiões de Governo no Serviço Regional da SUCEN de Ribeirão Preto (SR-6), 1984 a 1997.

\begin{tabular}{lcccc}
\hline \multicolumn{1}{c}{ Região de Governo } & $\begin{array}{c}N^{\circ} \text { Munic. } \\
\text { exist. }\end{array}$ & $\begin{array}{c}N^{\circ} \text { Munic } \\
\text { trab. }\end{array}$ & $\begin{array}{c}\% \text { Mun. } \\
\text { trab. }\end{array}$ & $N^{\circ}$ UDs \\
\hline Ribeirão Preto & 22 & 12 & 54,55 & 35 \\
Araraquara & 16 & 2 & 12,5 & 4 \\
São Carlos & 7 & 1 & 14,29 & 1 \\
Barretos & 18 & 14 & 77,78 & 37 \\
Franca & 17 & 11 & 64,71 & 32 \\
São Joaquim da Barra & 6 & 4 & 66,67 & 6 \\
\hline
\end{tabular}

O Quadro 4.5.6.1, a Tabela 4.5.6.2 e o Anexo IV ilustram a abrangência da cobertura oferecida pela sorologia na Região 
Quadro 4.5.6.1 - Municípios com localidades trabalhadas (T) e com presença de sororreagentes $(\mathrm{X})$ no Programa de Controle da Doença de Chagas (PCDCh) do Serviço Regional da SUCEN de Ribeirão Preto (SR-6), 1984 - 1997

\begin{tabular}{|c|c|c|c|c|c|c|c|c|c|c|c|c|c|c|}
\hline MUNICIPIO & 1984 & 1985 & 1986 & 1987 & 1988 & 1989 & 1990 & 1991 & 1992 & 1993 & 1994 & 1995 & 1996 & 1997 \\
\hline \multicolumn{15}{|c|}{ RG RIBEIRÅO PRETO } \\
\hline Brodosqui & $T$ & & & & & & & & & & & & & \\
\hline Cajuru & & & $T$ & & & $T$ & & & & & & & & \\
\hline Dumont & $T$ & & & & & & & & & & & & & \\
\hline Guariba & & & & $T X$ & & & & & & & & & & \\
\hline Jaboticabal & & & & $T$ & $T$ & $T$ & & & & & & & $T$ & \\
\hline Jardinópolis & $\bar{T}$ & $\bar{T}$ & & & $T$ & $T X$ & & & & & & & & \\
\hline MonteAlto & $T$ & & & & $T$ & & & & & & & & & \\
\hline Pitanguerras & & $T$ & & & & & & & & & & & & \\
\hline Pontal & $T$ & $T X$ & & & & & & & & & & & & \\
\hline RibeirãoPreto & $T$ & $T X$ & $T$ & $T$ & $T$ & & & & & & & & & \\
\hline StoAntonioAlegria & & & & & & & & & & & $\bar{T}$ & & & \\
\hline \begin{tabular}{|l|} 
Serãozinho \\
\end{tabular} & $T$ & $T X$ & $T$ & & $T$ & & & & & & & & & \\
\hline \multicolumn{15}{|c|}{ RG ARARAQUAA $\overline{R A}$} \\
\hline FernandoPrestes & & & $T$ & $T$ & $T$ & & & & & & & & & \\
\hline Taquantinga & & $T$ & & & & & & & & & & & & \\
\hline \multicolumn{15}{|c|}{ RG SÃO CARLOS } \\
\hline Dourado & $T$ & & & & & & & & & & & & & \\
\hline \multicolumn{15}{|c|}{ RG BARRETOS } \\
\hline Altair & & & & & $T$ & & & & & & & & & \\
\hline Barretos & $T$ & $T$ & & & & & & & & & & & & \\
\hline Bebedouro & & & & $T$ & & & & & & & & & & \\
\hline Cajobi & & & $T$ & & & & & & & & & & & \\
\hline Colina & $T$ & & & & & & & & & & & & & \\
\hline Colômbia & $T X$ & $T X$ & & & & & & & & & & & & \\
\hline Guaira & $T X$ & $T$ & $T$ & $T$ & & & & & & & & & & \\
\hline Guaraci & $T X$ & $T$ & & $T X$ & & & & & & $T$ & & & & \\
\hline \begin{tabular}{|l|} 
Jaborandi \\
\end{tabular} & & & $T$ & & & & & & & & & & & \\
\hline MteAzulPaulista & & & & $T$ & & & & & & & & & & \\
\hline Olimpia & $T$ & $T$ & $T X$ & $T$ & $T$ & & & & & & & & & \\
\hline \begin{tabular}{|l|} 
Pirangi \\
\end{tabular} & $T$ & & & & & & & & & & & & & \\
\hline \begin{tabular}{|l|} 
Viradouro \\
\end{tabular} & $T$ & & & & & & & & & & & & & \\
\hline VistaAlegredoAlto & & & & & $T X$ & & & & & & & & & \\
\hline
\end{tabular}

(cont.) 


\begin{tabular}{|c|c|c|c|c|c|c|c|c|c|c|c|c|c|c|}
\hline MUNICIPIO & 1984 & 1985 & 1986 & 1987 & 1988 & 1989 & 1990 & 1991 & 1992 & 1993 & 1994 & 1995 & 1996 & 1997 \\
\hline \multicolumn{15}{|c|}{ RG FRANCA } \\
\hline Batatais & $T$ & $T$ & & & & & & & & & & & & \\
\hline Buritizal & $T X$ & $T$ & & & & & & & & & & & & \\
\hline Franca & & $T$ & $T$ & $T$ & $T$ & & & & & & & & & \\
\hline Guara & & & & & $T$ & & & & & & & & & \\
\hline Igarapava & & $T$ & & $T$ & & & & & & $T X$ & & & & \\
\hline Itrapuã & & $T X$ & & $T X$ & & $T$ & & & & & & & & \\
\hline Ituverava & & $T$ & & & & & & & & & & & & \\
\hline Miguelopolis & & $T X$ & & & & & & & & $T$ & & & & \\
\hline Pedregulho & $T X$ & & & & $T$ & $T$ & & & & & & & & \\
\hline RibeirãoCorrente & $T X$ & & & & & & & & & & & & & \\
\hline SJoseBelaVista & & $\mathrm{T}$ & & & & & & & & & & & & \\
\hline MUNICIPIO & 1984 & 1985 & 1986 & 1987 & 1988 & 1989 & 1990 & 1991 & 1992 & 1993 & 1994 & 1995 & 1996 & 1997 \\
\hline \multicolumn{15}{|c|}{ RG SÅO JOAQUIM DA BARRA } \\
\hline |puã & & $T X$ & & & & & & & & & & & & \\
\hline MorroAgudo & & & $T$ & & & & & & & & & & & \\
\hline Nuporanga & & & & & $T$ & & & & & & & & & \\
\hline S Jcaquim Barra & $T$ & & $T$ & $T$ & & & & & & & & & & \\
\hline
\end{tabular}

Tabela 4.5.6.2 - Distribuição de frequências de localidades existentes e trabalhadas e de UDs trabalhadas e com reagentes sorológicos para infeç̧ão chagásica, nas Regiões de Governo do Serviço Regional da SUCEN de Ribeirão Preto (SR-6), 1984 a 1997.

\begin{tabular}{|c|c|c|c|c|c|c|c|c|c|}
\hline \multirow{2}{*}{$\begin{array}{l}\text { Região de } \\
\text { Governo }\end{array}$} & \multicolumn{3}{|c|}{ Localidades } & \multicolumn{2}{|c|}{ UDs } & \multicolumn{3}{|c|}{ Amostras } & \multirow[b]{2}{*}{$\begin{array}{l}\mathrm{IC}^{* *} \text { dos } \\
\text { reag }(\%)\end{array}$} \\
\hline & exist. ${ }^{*}$ & trab. & $\begin{array}{c}\% \\
\text { trab. }\end{array}$ & trab. & reag. & trab. & reag. & $\begin{array}{c}\% \\
\text { reag. }\end{array}$ & \\
\hline Ribeirão Preto & 560 & 12 & 2,14 & 35 & 5 & 164 & 8 & 4,88 & $2,49-9,33$ \\
\hline Araraquara & 437 & 4 & 0,92 & 4 & 0 & 17 & 0 & 0,00 & - \\
\hline São Carlos & 246 & 1 & 0,41 & 1 & 0 & 5 & 0 & 0,00 & - \\
\hline Barretos & 501 & 36 & 7,19 & 37 & 8 & 140 & 9 & 6,43 & $3,42-11,77$ \\
\hline Franca & 484 & 27 & 5,58 & 32 & 7 & 133 & 9 & 6,77 & $3,60-12,36$ \\
\hline $\begin{array}{l}\text { São Joaquim } \\
\text { da Barra }\end{array}$ & 161 & 6 & 3,73 & 6 & 1 & 25 & 1 & 4,00 & $0,71-19,54$ \\
\hline TOTAL & 2389 & 86 & 3,60 & 115 & 21 & 484 & 27 & 5,58 & $3,86-7,99$ \\
\hline
\end{tabular}

* Fonte: SUCEN/DOT/Lista de localidades segundo municipios por Serviço Regional. 1981-1986

** IC = Intervalo de Confiança (95\%). 
$\mathrm{Na}$ Tabela 4.5.6.2 ficam salientados valores de percentuais de reatividade nas diversas Regiões de Governo, exceto para Araraquara e São Carlos, que não devem ser vistos como decorrência de maiores ou menores prevalências de infecção chagásica na área, senão por baixos valores absolutos trabalhados (valores de intervalos de confiança muito amplos). O mesmo raciocínio é válido para a variação anual da sororreatividade (Tabela $4.5 .6 .3)$

Tabela 4.5.6.3 - Variação anual da sororreatividade para infecção chagásica no Serviço Regional da SUCEN de Ribeirão Preto (SR-6), 1984 a 1997.

\begin{tabular}{|c|c|c|c|c|c|c|}
\hline Ano & $\begin{array}{l}\mathrm{N}^{0} \text { UDs } \\
\text { Trab. }\end{array}$ & $\begin{array}{l}\mathrm{N}^{0} \mathrm{Am} \\
\text { Exam. }\end{array}$ & $\begin{array}{c}\mathrm{N}^{\circ} \\
\text { Reag }\end{array}$ & \% Reag. & IC* $(\%)$ & MGTR** \\
\hline 1984 & 27 & 98 & 7 & 7,14 & $3,50-14,02$ & 128,0 \\
\hline 1985 & 29 & 140 & 9 & 6,43 & $3,42-11,77$ & 188,1 \\
\hline 1986 & 20 & 78 & 3 & 3,85 & $1,32-10,71$ & 406,4 \\
\hline 1987 & 15 & 62 & 5 & 8,06 & $3,49-17,53$ & 445,7 \\
\hline 1988 & 14 & 64 & 1 & 1,56 & $0,28-8,33$ & 32,0 \\
\hline 1989 & 5 & 24 & 1 & 4,17 & $0,74-20,24$ & 128,0 \\
\hline 1990 & 0 & 0 & - & - & - & - \\
\hline 1991 & 0 & 0 & - & - & - & - \\
\hline 1992 & 0 & 0 & - & - & - & - \\
\hline 1993 & 3 & 10 & 1 & 10.00 & $1,79-40,42$ & 64,0 \\
\hline 1994 & 1 & 5 & 0 & 0,00 & - & - \\
\hline 1995 & 0 & 0 & - & - & - & - \\
\hline 1996 & 1 & 3 & 0 & 0,00 & - & - \\
\hline 1997 & 0 & 0 & - & - & - & - \\
\hline TOTAL & 115 & 484 & 27 & 5,58 & $3,86-7,99$ & 193,0 \\
\hline
\end{tabular}

* IC = Intervalo de Confiança (95\%)

** MGTR = Média Geometrica dos Títulos dos Reagentes

Em 1990, a infestação dos municipios por Ae. aegypti absorveu todos os recursos disponíveis da Regional, levando à interrupção dos trabalhos de sorologia. Nos anos subsequientes, o aparecimento crescente de focos de Ae. aegypti e de sucessivos surtos de transmissão de dengue, determinaram a quase interrupção das atividades de sorologia na área $^{180}$.

A reatividade sorológica, por grupo etário e sexo, da população moradora nas UDs com os triatomineos vetores, infectados por $T$. cruzi ou com reação para verificação de 
hábito alimentar reagente para sangue humano, detectados no periodo especificado, está demonstrada na Tabela 4.5.6.4.

Tabela 4.5.6.4 - Sorologia para infecção chagásica, por grupo etário e sexo, em população de municípios do Serviço Regional da SUCEN de Ribeirão Preto (SR-6), 1984 a 1997.

\begin{tabular}{|c|c|c|c|c|c|c|c|c|c|}
\hline \multirow{2}{*}{$\begin{array}{l}\text { Grupo } \\
\text { etario } \\
\text { (anos) }\end{array}$} & \multicolumn{3}{|c|}{ Feminino } & \multicolumn{3}{|c|}{ Masculino } & \multicolumn{3}{|c|}{ Total } \\
\hline & $\begin{array}{c}N^{\circ} \\
\text { exam }\end{array}$ & $\begin{array}{c}\mathrm{N}^{\circ} \\
\text { Reag }\end{array}$ & $\begin{array}{c}\% \\
\text { Reag } \\
\end{array}$ & $\begin{array}{c}\mathrm{N}^{\circ} \\
\text { exam }\end{array}$ & $\begin{array}{c}\mathrm{N}^{\circ} \\
\text { Reag. }\end{array}$ & $\begin{array}{c}\% \\
\text { Reag }\end{array}$ & $\begin{array}{c}N^{\circ} \\
\text { exam }\end{array}$ & $\begin{array}{c}\mathrm{N}^{\circ} \\
\text { Reag. }\end{array}$ & $\begin{array}{c}\% \\
\text { Reag }\end{array}$ \\
\hline$<1$ & 7 & 0 & 0,00 & 2 & 0 & 0,00 & 9 & 0 & 0,00 \\
\hline $1-4$ & 21 & 0 & 0,00 & 26 & 0 & 0,00 & 47 & 0 & 0,00 \\
\hline $5-9$ & 35 & 0 & 0,00 & 41 & 1 & 2,44 & 76 & 1 & 1,32 \\
\hline $10-14$ & 18 & 0 & 0,00 & 34 & 0 & 0,00 & 52 & 0 & 0,00 \\
\hline $15-19$ & 22 & 0 & 0,00 & 21 & 0 & 0,00 & 43 & 0 & 0,00 \\
\hline $20-29$ & 39 & 0 & 0,00 & 34 & 1 & 2,94 & 73 & 1 & 1,37 \\
\hline $30-39$ & 36 & 1 & 2,78 & 33 & 2 & 6,06 & 69 & 3 & 4,35 \\
\hline $40-49$ & 23 & 4 & 17,39 & 40 & 3 & 7,50 & 63 & 7 & 11,11 \\
\hline $50-59$ & 13 & 2 & 15,38 & 16 & 7 & 43,75 & 29 & 9 & 31,03 \\
\hline $60-69$ & 7 & 3 & 42,86 & 7 & 2 & 28,57 & 14 & 5 & 35,71 \\
\hline$\geq 70$ & 6 & 0 & 0,00 & 3 & 1 & 33,33 & 9 & 1 & 11,11 \\
\hline Total & 227 & 10 & 4,41 & 257 & 17 & 6,61 & 484 & 27 & 5,58 \\
\hline
\end{tabular}

Percebe-se o aumento dos percentuais de sororreatividade com a idade. Teste de diferença entre proporções não revelou diferença significante de reatividade sorológica entre os sexos $\left(\mathrm{IC}_{0.05}=-0,0631-0,0189\right) ; \mathrm{p}=0,285$. As idades variaram de 0,08 a 86,00 anos, com uma média de 25,02 anos, mediana de 21,00 anos e $75 \%$ da população com até 38,50 anos. A reatividade sorológica dá-se a partir do grupo etário 30 - 39 anos no sexo feminino (Tabela 4.5.6.4). No sexo masculino houve 1 caso reagente sorológico na idade de 9 anos, Título $=256$. Detectado em 1987, este caso foi proveniente do Municipio de Guaraci, R. Casemiro Cezar, quando esse município pertencia administrativamente ao Serviço Regional da SUCEN de São José do Rio Preto (SR-8). A investigação preliminar revelou que a criança era nascida no próprio município (em 1978) e que a mãe também era sororreagente (Título=256), sugerindo possibilidade de transmissão congênita. Em sua casa, os dados sobre ocorrência de triatomineos não foram disponiveis

Outros 3 casos detectados no Serviço Regional da SUCEN de São José do Rio Preto, por meio de pesquisas geradas por Notificação, possuiam as seguintes informações 
a) Municipio Guaraci, Localidade Fazenda Corredeira, detectados em 1984

1) 46 anos, sexo feminino, Título $=64$, classificado como importado de Delfino, MG. Presença de $T$. sordida, 1 exemplar de ninfa de $2^{\circ}$ estádio capturada no intradomicílio e com reação reagente para sangue humano na determinação de hábito alimentar e 1 adulto fêmea, capturado no peridomicílio, com reações reagentes para sangue humano e outros. Exame sorológico em mais 1 morador da casa resultou negativo

2) 25 anos, sexo masculino, Título=64, classificado como autóctone da Região (São José do Rio Preto). Presença de $T$. sordida, l exemplar macho, capturado no intradomicílio e com reações reagentes para sangue humano e outros na determinação de hábito alimentar. Exames sorológicos em mais 2 moradores da casa não revelou reatividade.

b) Municipio Olímpia, Localidade Vila São José, detectado em 1986. Idade: 44 anos, sexo masculino, Título=512. Exames sorológicos em mais 2 moradores da casa resultaram negativos. Em sua residência havia sido encontrado 1 exemplar de $T$. sordida. capturado no intradomicílio, fase não informada, reagente para sangue humano. Tendo classificação de procedência indeterminada, este caso era portador de outros exames reagentes sorológicos não realizados na SUCEN

A notificação de triatomíneo vetor predominou sobre a atividade de rotina no desencadeamento das atividades de sorologia para infecção chagásica no Programa (Tabela 4.5.65). A perda de informação aconteceu em um único caso, no município de Cajobi, quando este pertencia ao SR-8 (São José do Rio Preto). 
Tabela 4.5.6.5 - Unidades Domiciliares com e sem presença de sororreagentes para infecção chagásica, de acordo com o tipo de atendimento, no Serviço Regional da SUCEN de Ribeirão Preto (SR-6), 1984 a 1997.

\begin{tabular}{|c|c|c|c|c|c|c|}
\hline \multirow{2}{*}{ Atendimento } & \multicolumn{2}{|c|}{$\begin{array}{l}\text { UD c/ reag. sorol. } \\
(\mathrm{n}=21)\end{array}$} & \multicolumn{2}{|c|}{$\begin{array}{l}\text { UD s/ reag. sorol. } \\
\qquad(n=94)\end{array}$} & \multicolumn{2}{|c|}{$\begin{array}{c}\text { Total } \\
(\mathrm{n}=115)\end{array}$} \\
\hline & $\mathrm{N}^{\circ}$ & $\%$ & $\mathrm{~N}^{\circ}$ & $\%$ & $\mathrm{~N}^{\circ}$ & $\%$ \\
\hline Notificação & 17 & 81,0 & 72 & 76,6 & 89 & 77,4 \\
\hline Rotina & 4 & 19,0 & 21 & 22,3 & 25 & 21,7 \\
\hline Sem informação & 0 & 0,0 & 1 & 1,1 & 1 & 0,9 \\
\hline
\end{tabular}

Na Tabela 4 5.6.6 estão dispostas as informações sobre os vetores capturados nas 115 Unidades Domiciliares, representantes de focos detectados no periodo 1984-1997, no SR-6

T. sordida foi a espécie mais frequente nas UDs com e sem presença de sororreagentes. Neste caso também houve algumas perdas de informação, atribuídas à Regional em que os municípios pertenciam originalmente. Quanto à fase evolutiva, adultos prevaleceram sobre ninfas de modo significante, em ambas condições de presença e ausência de sororreagentes nas UDs Infecção por $T$. cruzi foi observada em pequena proporção (4,3\% dos casos) Quanto ao hábito alimentar, a fonte sangue humano, sozinha ou combinada com o de outros animais, predominou de forma significante 
Tabela 4.5.6.6 - Unidades Domiciliares com e sem presença de sororreagentes para infecção chagásica, de acordo com caracteristicas associadas ao vetor, no Serviço Regional da SUCEN de Ribeirão Preto (SR-6), 1984 a 1997

\begin{tabular}{|c|c|c|c|c|c|c|c|c|c|}
\hline \multirow[t]{2}{*}{ Caracteristica } & \multicolumn{3}{|c|}{$\begin{array}{l}\text { UD c/ reag. sorol. } \\
n=21\end{array}$} & \multicolumn{3}{|c|}{$\begin{array}{l}\text { UD s/ reag. sorol. } \\
n=94\end{array}$} & \multicolumn{3}{|c|}{$\begin{array}{l}\text { Total } \\
\mathrm{n}=115\end{array}$} \\
\hline & $N^{\circ}$ & $\%$ & $\% *$ & $N^{\circ}$ & $\%$ & $\% *$ & $N^{\circ}$ & $\%$ & $\% *$ \\
\hline Espécie & & & & & & & & & \\
\hline P. megistus $(P m)$ & 4 & 19,0 & 20,0 & 20 & 21,3 & & 24 & 20,9 & 21,1 \\
\hline T. sordida $(T s)$ & 13 & 61,9 & 65,0 & 64 & 68,1 & & 77 & 67,0 & 67,5 \\
\hline R. neglectus $(R n)$ & 2 & 9,5 & 10,0 & 9 & 9,5 & & 11 & 9,6 & 9,6 \\
\hline$P m+T s$ & & & & 1 & 1,1 & & 1 & 0,9 & 0,9 \\
\hline$T s+R n$ & 1 & 4,8 & 5,0 & & & & 1 & 0,9 & 0,9 \\
\hline sem informação & 1 & 4,8 & & & & & 1 & 0,9 & \\
\hline Fase evolutiva e infecção & & & & & & & & & \\
\hline Ninfas & 4 & 19,0 & 21,0 & 16 & 17,0 & 18,0 & 20 & 17,4 & 18,6 \\
\hline Ninfas infectadas & 1 & 4,8 & 5,3 & & & & 1 & 0,9 & 0,9 \\
\hline Ninfas e Adultos & 6 & 28,6 & 31,6 & 17 & 18,1 & 19,1 & 23 & 20,0 & 21,3 \\
\hline Ninfas e Adultos infect. & & & & 2 & 2,1 & 2.2 & 2 & 1,7 & 1,8 \\
\hline Adultos & 7 & 33,3 & 36,8 & 53 & 56,4 & 59,6 & 60 & 52,2 & 55,6 \\
\hline Adultos infectados & 1 & 4,8 & 5,3 & 1 & 1,1 & 1,1 & 2 & 1,7 & 1,8 \\
\hline sem informação & 2 & 9,5 & & 5 & 5,3 & & 7 & 6,1 & \\
\hline Local de captura & & & & & & & & & \\
\hline interno & 16 & 76,2 & 80,0 & 81 & 86,2 & & 97 & 84,3 & 85,1 \\
\hline externo & 1 & 4,8 & 5,0 & 3 & 3,2 & & 4 & 3,5 & 3,5 \\
\hline interno e externo & 3 & 14,2 & 15,0 & 10 & 10,6 & & 13 & 11,3 & 11,4 \\
\hline sem informação & 1 & 4,8 & & & & & 1 & 0,9 & \\
\hline Hábito alimentar & & & & & & & & & \\
\hline Sangue humano** & 18 & 85,7 & 94,7 & 91 & 96,8 & & 109 & 94,8 & 96,5 \\
\hline Não reagente & 1 & 4,8 & 5,3 & 3 & 3,2 & & 4 & 3,5 & 3,5 \\
\hline sem informação & 2 & 9,5 & & & & & 2 & 1,7 & \\
\hline
\end{tabular}

* Percentual calculado excluindo-se as perdas de informação.

** Reagente para Sangue humano sozinho ou associado a outros

O valor de "odds ratio" = 3,370 950. 0,525 - 21,635 indica que não houve diferença entre reagentes e não reagentes sorológicos, moradores de UDs com e sem presença de triatomineos infectados por T. cruzi ( Tabela 4.5.6.7). 
Tabela 4.5.6.7 - Encontro de reagentes e de não reagentes sorológicos para infecção chagásica em UDs com e sem presença de triatomineo infectado por $T$. cruzi, no Serviço Regional da SUCEN de Ribeirão Preto (SR-6), 1984 a 1997.

\begin{tabular}{cc|cc|c}
\hline \multicolumn{2}{c|}{ Caracteristica } & \multicolumn{2}{|c|}{ UD com presença de morador } & Total \\
\hline $\begin{array}{l}\text { UD com } \\
\text { triatomineo }\end{array}$ & $\begin{array}{l}\text { infectado por } T . \\
\text { cruzi } \\
\text { não infectado } \\
\text { por } T \text {. cruzi }\end{array}$ & 2 & 3 & 5 \\
\hline & 18 & 91 & 109 \\
\hline & 20 & 94 & 114 \\
\hline
\end{tabular}

O resultado reagente para sangue humano predominou sobre a infecção do triatomineo vetor por T. cruzi, nas UDs com e sem presença de sororreagentes em mais de 90\% dos casos. Em 1 caso a sorologia foi desencadeada fora das normas preconizadas no Programa (Tabela 4 5.6.8)

Tabela 4.5.6.8 - Condições para execução de exame sorológico, segundo presença ou ausência de sororreagentes para infecção chagásica, em UDs no Serviço Regional da SUCEN de Ribeirão Preto (SR-6), 1984 a 1997

\begin{tabular}{|c|c|c|c|c|c|c|}
\hline \multirow[t]{2}{*}{ Condição para gerar sorologia } & \multicolumn{2}{|c|}{$\begin{array}{l}\text { UD c/ reag. } \\
\text { sorol. } \\
\qquad(\mathrm{n}=21)\end{array}$} & \multicolumn{2}{|c|}{$\begin{array}{l}\text { UD s/ reag. } \\
\text { sorol } \\
\qquad(\mathrm{n}=94)\end{array}$} & \multicolumn{2}{|c|}{$\begin{array}{c}\text { Total } \\
(n=115)\end{array}$} \\
\hline & $N^{0}$ & $\%$ & $\mathrm{~N}^{\circ}$ & $\%$ & $\mathrm{~N}^{\circ}$ & $\%$ \\
\hline Triatomineo infectado & 2 & 9,5 & 2 & 2,1 & 4 & 3,4 \\
\hline Triat infect + Reag p/ sangue hum & 0 & 0,0 & 1 & 1,1 & 1 & 0,9 \\
\hline Reagente para sangue humano & 18 & 85,7 & 90 & 95,7 & 108 & 93,9 \\
\hline Dispensável* & 0 & 0,0 & 1 & 1,1 & 1 & 0,9 \\
\hline Sem informação & 1 & 4,8 & 0 & 0,0 & 1 & 0,9 \\
\hline
\end{tabular}

* Colheita de sangue realizada fora das normas do PCDCh, na ausência de triatomíneo infectado por $T$. cruzl e/ou com ingesta reagente para sangue humano. 


\subsubsection{No Serviço Regional da SUCEN de São José do Rio Preto (SR-8)}

O Serviço Regional da SUCEN de São José do Rio Preto, SR-8, compreende 5 Regiões de Governo: Catanduva, Fernandópolis, Jales, São José do Rio Preto e Votuporanga. Ocupa área de $25308 \mathrm{~km}^{2}, 10,18 \%$ do Estado ${ }^{92}$. O trabalho de sorologia envolveu 1169 focos domiciliares de triatomíneos vetores, em 713 localidades pertencentes a 80 de 81 municipios existentes (Tabela 4.5.7.1).

Tabela 4.5.7.1 - Sorologia de infecção chagásica em Regiões de Governo no Serviço Regional da SUCEN de São José do Rio Preto (SR-8), 1984 a 1997.

\begin{tabular}{lcccc}
\hline \multicolumn{1}{c}{ Região de Governo } & $\begin{array}{c}\mathrm{N}^{\circ} \text { Munic. } \\
\text { exist }\end{array}$ & $\begin{array}{c}\mathrm{N}^{\circ} \text { Munic. } \\
\text { trab }\end{array}$ & $\begin{array}{c}\% \text { Mun. } \\
\text { trab. }\end{array}$ & $\mathrm{N}^{\circ}$ UDs \\
\hline Catanduva & 13 & 13 & 100,00 & 185 \\
Fernandópolis & 11 & 11 & 100,00 & 84 \\
Jales & 15 & 15 & 100,00 & 332 \\
São José do Rio Preto & 28 & 28 & 100,00 & 417 \\
Votuporanga & 14 & 13 & 92,86 & 151 \\
\hline & 81 & 80 & 98,76 & 1169 \\
\hline
\end{tabular}

No Quadro 4.5.7.1 estão listados os municípios trabalhados e aqueles em que houve a detecção de sororreagentes. $O$ encontro de infectados chagásicos deu-se em $70,37 \%$ dos municipios em que houve a atividade sorologia no Programa, variando a sororreatividade de $0,60 \%$, no município de Urupês a $18,75 \%$ no de Mendonça, com uma média para a Regional de 3,77\% (Anexo V). Das Regiões de Governo, Catanduva foi a que apresentou menor reatividade sorológica entre moradores (Tabela 4.5.7.2). 
Quadro 4.5.7.1 - Municipios com localidades trabalhadas em sorologia (T) e com presença de sororreagentes (X) no Programa de Controle da Doença de Chagas (PCDCh) do Serviço Regional da SUCEN de São José do Rio Preto (SR-8), 1984 - 1997.

\begin{tabular}{|c|c|c|c|c|c|c|c|c|c|c|c|c|c|c|}
\hline MUNICIPIO & 1984 & 1985 & 1986 & 1987 & 1988 & 1989 & 1990 & 1991 & 1992 & 1993 & 1994 & 1995 & 1996 & 1997 \\
\hline \multicolumn{15}{|c|}{ RG CATANDUVA } \\
\hline Ariranha & & $T$ & & & & & & & & & & & & \\
\hline Catanduva & $T$ & $T$ & $T$ & $T X$ & & $T$ & $T$ & $T$ & $\mathrm{~T}$ & $T$ & $T X$ & $\mathrm{~T}$ & & \\
\hline Catigua & & $T$ & & & & & & & & & & & & \\
\hline Irapuã & $\mathrm{T}$ & $T X$ & $T$ & $T X$ & & $T$ & $\mathrm{~T}$ & $T X$ & $T$ & T & $T$ & $T$ & & \\
\hline Itajobi & $\mathrm{T}$ & $T$ & $T$ & T & $\mathrm{T}$ & $T$ & $\mathrm{~T}$ & $T$ & & $T$ & & & & \\
\hline NovoHonzonte & & $T$ & & $T$ & $T$ & & $T$ & $T$ & & $T$ & & & & \\
\hline PalmaresPaulista & $T X$ & $T X$ & & $T X$ & & & $\mathrm{~T}$ & & & & & & & \\
\hline \begin{tabular}{|l|} 
Paraiso \\
\end{tabular} & $T$ & $T$ & $T$ & $T$ & & $T$ & & $T$ & $T$ & $T$ & & & & \\
\hline Pindorama & & & & & & & & $T$ & & & & & & \\
\hline Sales & & $T$ & $T$ & $T$ & & & & $T X$ & $\mathrm{~T}$ & $T$ & & & & \\
\hline SantaAdélia & $\mathrm{T}$ & & & $T X$ & & T & $\mathrm{T}$ & $T$ & & $T$ & & & & \\
\hline Tabapuã & & $T$ & $T$ & & $T X$ & $T$ & & & $T$ & $T$ & $T$ & & & \\
\hline Urupés & $T$ & $T$ & $T$ & TX & & $T$ & $\mathrm{~T}$ & $\mathrm{~T}$ & $\mathrm{~T}$ & & & & & \\
\hline \multicolumn{15}{|c|}{ RG FERNANDOPOLIS } \\
\hline EstrelaDOeste & & $\mathrm{T}$ & & $T$ & $\mathrm{~T}$ & & & & & & & & & \\
\hline Femandopolis & $T X$ & $T$ & $T$ & & $T$ & & $T$ & & & & & & & \\
\hline GuaraniDOeste & $T X$ & $T X$ & $T$ & & $T$ & & & & & & & & & \\
\hline Indiaporã & $T$ & $T X$ & & $T$ & $T X$ & $T$ & & & & & & & & \\
\hline Macedônia & & $T X$ & & $T$ & & & & & & & & & & \\
\hline Meridiano & $T$ & $T$ & & $T$ & & & & TX & & & & & & \\
\hline MiraEstrela & & $T$ & & $T X$ & & & & & & & & & & \\
\hline Pedranopolis & & $T$ & $T$ & & $T$ & & & & & $T$ & & & & \\
\hline Populina & $T$ & $T$ & & $T$ & & & & $T X$ & & & & & & \\
\hline SJDuasPontes & & $T$ & & $T$ & & & & & & & & & & \\
\hline Turmalina & $T$ & $T$ & & $T$ & $T$ & & $T$ & & & & & & & \\
\hline \multicolumn{15}{|c|}{ RG JALES } \\
\hline Apda DOeste & $T X$ & $T$ & & $T$ & & & & & & & & & & \\
\hline Dolcinopolis & & & $\mathrm{T}$ & & & & & $T$ & & & & & & \\
\hline Jales & $T$ & $T X$ & $T X$ & $T$ & TX & $T$ & $T X$ & $T X$ & & $\mathrm{~T}$ & & & & \\
\hline Marinopolis & TX & $T$ & $T$ & $T$ & & & $T$ & & & & & & & \\
\hline PalmeiraDOeste & $T$ & $T$ & $T$ & $T X$ & $\mathrm{~T}$ & $T X$ & $T X$ & $T$ & & $T$ & & & & \\
\hline Paranapuã & $T X$ & $T X$ & $T X$ & $T$ & $T X$ & $T$ & $T$ & $T$ & & & & & & \\
\hline Rubinéia & & $T$ & $T$ & $\mathrm{~T}$ & $T$ & & $T$ & & & & & & $T$ & \\
\hline SantaAlbertina & $T X$ & $T X$ & $T X$ & $T X$ & & $T$ & $T$ & $T$ & & & & & & \\
\hline StaClaraDoeste & & $T X$ & $\mathrm{~T}$ & $T X$ & $T$ & $T$ & $T$ & $T X$ & & & & & & \\
\hline SantaFè do Sul & $T$ & $T X$ & $T$ & $T X$ & & $T$ & $T X$ & $T$ & & $T$ & & & & \\
\hline SantaRitaDOeste & & $T$ & $T X$ & $T X$ & TX & & $T$ & $T$ & & & & & & \\
\hline SantanaPPensa & $T$ & $T$ & $T$ & $T X$ & & $\mathrm{TX}$ & $T$ & & & & & & & \\
\hline SãoFrancisco & $T$ & $T X$ & $T$ & $T X$ & $T$ & $\mathrm{~T}$ & $T$ & $T$ & & & & & & \\
\hline TrêsFronteiras & & $T$ & $T$ & $T$ & $T$ & $T$ & $T$ & $\mathrm{TX}$ & & & & & & \\
\hline Urânia & $T X$ & $T X$ & $T X$ & $T X$ & $T$ & $T$ & & & & & & & & \\
\hline
\end{tabular}




\begin{tabular}{|c|c|c|c|c|c|c|c|c|c|c|c|c|c|c|}
\hline MUNICIPIO & 1984 & 1985 & 1986 & 1987 & 1988 & 1989 & 1990 & 1991 & 1992 & 1993 & 1994 & 1995 & 1996 & 1997 \\
\hline \multicolumn{15}{|c|}{ RG SÃO JOSE DO RIO PRETO } \\
\hline Adolifo & & $T X$ & $T X$ & $T X$ & & TX & & $T$ & $T$ & $T$ & & & & \\
\hline Bady Bassit & $T$ & $\mathrm{~T}$ & $T$ & $T$ & $T$ & $T$ & $T$ & $T$ & & $T$ & $T$ & & & \\
\hline Bálsamo & & $T$ & $T$ & $T$ & & & & & & $T$ & & & & \\
\hline Cedral & $\mathrm{T}$ & $\mathrm{TX}$ & $T X$ & $T$ & & & & $T$ & & & & & & \\
\hline Guapiaçú & & $\mathrm{T}$ & $T$ & $T$ & $T$ & & & & $T$ & & & $T$ & & \\
\hline Ibirá & & & & $\bar{T}$ & $T$ & $T$ & & $T$ & $T$ & & & & & \\
\hline Icem & & & & $T$ & $T$ & $T$ & $T$ & $T$ & & $T$ & $T$ & & & \\
\hline Jaci & $T$ & $T$ & & $T$ & $T$ & $T$ & & $T$ & $T$ & & & & & \\
\hline JoséBonifacio & $T X$ & $T X$ & $\mathrm{TX}$ & $T$ & $T$ & $T$ & $T X$ & $T$ & $T$ & $T$ & & & & $T$ \\
\hline Mendonça & & $T$ & $T X$ & & & & & $T$ & $T X$ & & & & & \\
\hline Mirassol & $T$ & $T$ & & $T$ & & $T$ & $T$ & $T$ & $T$ & & & & & \\
\hline Mirassolândia & $T$ & & $T$ & $T$ & & & & & & $T X$ & & & & \\
\hline MonteAprazivel & & $T$ & $T$ & $T X$ & $T$ & $T$ & $T$ & $T$ & $T$ & $T$ & $T$ & & & \\
\hline NevesPaulista & $T$ & & $T X$ & $T$ & $T$ & $T$ & & $T$ & $T$ & $T$ & & & & \\
\hline Nipoã & & & $T$ & $T X$ & & $T X$ & $T$ & & $T$ & $T$ & & & & \\
\hline NovaAliança & $T X$ & $T$ & $T$ & $T$ & $T$ & $T$ & $T$ & $T$ & $T$ & & $T$ & & & $\mathrm{~T}$ \\
\hline NovaGranada & & $T$ & & $T X$ & & & & & & $T$ & & & & \\
\hline OndaVerde & & & & $T$ & & $T X$ & & & & & & & & \\
\hline Orindiúva & $T$ & & & & $T$ & $T$ & $\mathrm{~T}$ & & $T$ & & & $T$ & & $T X$ \\
\hline Palestina & & $T X$ & & $T X$ & $T$ & $T$ & & $T$ & $T$ & $T$ & & $T$ & & \\
\hline Paulo deFaria & $T$ & $T$ & $T X$ & $T$ & $T$ & $T X$ & & $T X$ & $T$ & $T$ & $T$ & & & \\
\hline Planalto & & $T$ & $T$ & $T X$ & $T X$ & $T$ & $T$ & $T$ & $T$ & & $T$ & & & $T$ \\
\hline \begin{tabular}{|l|} 
Poloni \\
\end{tabular} & $T$ & $T$ & $T$ & $\mathrm{~T}$ & $T$ & $T$ & $T$ & $T$ & $T$ & & & & & \\
\hline Potirendaba & $T$ & $T$ & $T$ & $T X$ & $T$ & $T$ & & $T$ & $T X$ & $T$ & & $T$ & $T$ & $T$ \\
\hline SJoséRioPreto & $T$ & $T X$ & $T$ & $T X$ & $T X$ & $T$ & $T$ & & & $T$ & & & & \\
\hline Tanabi & $T$ & $T$ & $T X$ & $T$ & $T$ & $T$ & $\bar{T}$ & $T X$ & $T$ & $T X$ & & & & \\
\hline Uchoa & $T$ & $T$ & & & & & $T$ & & $T$ & & & & & \\
\hline UniãoPaulista & & $T$ & & $T$ & $\mathrm{~T}$ & $T$ & & $\mathrm{~T}$ & $T$ & & $T X$ & & & \\
\hline \multicolumn{15}{|c|}{ RG VOTUPORANGA } \\
\hline Alvaresflorence & $T$ & $T X$ & $T$ & $T$ & $T$ & & & $T X$ & & & & & & \\
\hline AmericoCampos & & $\mathrm{TX}$ & $T$ & $T X$ & & & & & & & & & & \\
\hline Cardoso & $T$ & $T X$ & $T$ & $T X$ & & & & $T$ & & & & & & \\
\hline \begin{tabular}{|l|} 
Cosmorama \\
\end{tabular} & $T$ & $T X$ & $T X$ & $T$ & $T$ & & & $T$ & & & & & & \\
\hline \begin{tabular}{|l|} 
Floreal \\
\end{tabular} & $T X$ & $\mathrm{~T}$ & & $T$ & $T$ & & & & & & & & & $T X$ \\
\hline Macaubal & $T X$ & $\mathrm{TX}$ & $T X$ & $T$ & $T$ & $T$ & $T X$ & $T$ & & & & & & \\
\hline \begin{tabular}{|l|} 
Magda \\
\end{tabular} & $T$ & $T$ & & & $T$ & & & $T$ & & & & & & \\
\hline Nhandeara & $T$ & $T X$ & $T$ & $T$ & $T X$ & & & & & & & & & \\
\hline PontesGestal & & & & $T$ & & & & & & & & & & \\
\hline \begin{tabular}{|l|} 
Riolândia \\
\end{tabular} & & $T X$ & $T X$ & $T X$ & $\mathrm{TX}$ & $\mathrm{T}$ & & & & & & & & \\
\hline Sebast.doSul & & $T$ & & $\mathrm{~T}$ & $T X$ & & & $T$ & & & & & & \\
\hline ValentimGentil & & $T$ & & $\mathrm{~T}$ & & & & & & & & & & \\
\hline Votuporanga & $T X$ & $T X$ & & $T X$ & $T$ & $T X$ & & $\mathrm{~T}$ & & & & & & \\
\hline
\end{tabular}


Tabela 4.5.7.2 - Distribuição de frequências de localidades existentes e trabalhadas e de UDs trabalhadas e com reagentes sorológicos para infecção chagásica, das Regiões de Governo no Serviço Regional da SUCEN de São José do Rio Preto (SR-8), 1984 a 1997

\begin{tabular}{|c|c|c|c|c|c|c|c|c|c|}
\hline \multirow{2}{*}{$\begin{array}{l}\text { Região de } \\
\text { Governo }\end{array}$} & \multicolumn{3}{|c|}{ Localidades } & \multicolumn{2}{|c|}{ UDs } & \multicolumn{3}{|c|}{ Amostras } & \multirow[b]{2}{*}{$\begin{array}{l}\mathrm{IC}^{* *} \text { dos } \\
\text { reag. }(\%)\end{array}$} \\
\hline & exist * & trab. & $\begin{array}{r}\% \\
\text { trab. }\end{array}$ & trab. & reag. & trab. & reag. & $\begin{array}{c}\% \\
\text { reag. }\end{array}$ & \\
\hline Catanduva & 509 & 107 & 21,02 & 185 & 12 & 750 & 12 & 1,60 & $0,92-2,78$ \\
\hline Fernandopolis & 405 & 68 & 16,79 & 84 & 16 & 298 & 17 & 5,70 & $3,59-8,95$ \\
\hline Jales & 671 & 176 & 26,23 & 332 & 46 & 1497 & 61 & 4,07 & $3,19-5,20$ \\
\hline $\begin{array}{l}\text { São Jose do } \\
\text { Rio Preto }\end{array}$ & 1123 & 254 & 22,62 & 417 & 44 & 1633 & 57 & 3,49 & $2,70-4,50$ \\
\hline Votuporanga & 457 & 108 & 23.63 & 151 & 30 & 576 & 32 & 5,56 & $3,96-7,74$ \\
\hline TOTAL & 3165 & 713 & 22,53 & 1169 & 148 & 4754 & 179 & 3,77 & $3,26-4,35$ \\
\hline
\end{tabular}

* Fonte SUCEN/DOT/Lista de localidades segundo municipios por Serviço Regional. 1981-1986.

** IC = Inter alo de confiança $(95 \%)$.

A diminuição gradual dos trabalhos, ao longo dos anos, é evidenciada na Tabela 4.5.7.3. Os valores de sororreatividade praticamente se mantêm inalterados, com uma média no período de $3,77 \%$, com exceção das amostras muito reduzidas, que detêm largos intervalos de confiança. 
Tabela 4.5.7.3 - Variação anual da sororreatividade para infecção chagásica no Serviço Regional da SUCEN de São José do Rio Preto (SR-8), 1984 a 1997.

\begin{tabular}{|c|c|c|c|c|c|c|}
\hline Ano & $\begin{array}{c}\mathrm{N}^{\circ} \text { UDs } \\
\text { Trab. }\end{array}$ & $\begin{array}{l}\mathrm{N}^{\circ} \mathrm{Am} \\
\text { Exam. }\end{array}$ & $\mathrm{N}^{0}$ Reag. & $\%$ Reag. & IC* $(\%)$ & MGTR** \\
\hline 1984 & 103 & 468 & 18 & 3,85 & $2,45-6,00$ & 123,2 \\
\hline 1985 & 254 & 1095 & 43 & 3,93 & $2,93-5,25$ & 141,0 \\
\hline 1986 & 111 & 457 & $2 \mathrm{I}$ & 4,60 & $3,02-6,92$ & 92,0 \\
\hline 1987 & 192 & 822 & 40 & 4,87 & $3,59-6,56$ & 568,1 \\
\hline 1988 & 95 & 429 & 14 & 3,26 & $1,95-5,40$ & 99,9 \\
\hline 1989 & 113 & 429 & 12 & 2,80 & $1,61-4,83$ & 107,6 \\
\hline 1990 & 85 & 298 & 6 & 2,01 & $0,93-4,32$ & 128,0 \\
\hline 1991 & 09 & 375 & 13 & 3,47 & $2,04-5,84$ & 54,5 \\
\hline 1992 & 43 & 143 & 4 & 2,80 & $1,09-6,97$ & 107,6 \\
\hline 1993 & 44 & 143 & 3 & 2,10 & $0,72-5,99$ & 32,0 \\
\hline 1994 & 12 & 42 & 2 & 4,76 & $1,32-15,79$ & 90,5 \\
\hline 1995 & 6 & 14 & 0 & 0,00 & - & - \\
\hline 1996 & 3 & 8 & 0 & 0,00 & - & - \\
\hline 1997 & 9 & 31 & 3 & 9.68 & $3,35-24,90$ & 40,3 \\
\hline TOTAL & 1169 & 4754 & 179 & 3.77 & $3,26-4.35$ & 151,8 \\
\hline
\end{tabular}

* IC = Intervalo de Confiança (95\%)

** MGTR = Média Geometrica dos Títulos dos Reagentes

A distribuição de reatividade sorológica, por grupo etário e sexo, da população examinada está demonstrada na Tabela 4.5 7.4. A menor idade entre sororreagentes foi 11 anos, no sexo feminino e 18 anos, no masculino. A maior idade dentre os sororreagentes foi 80 anos A média encontrada entre eles foi de 47,87 anos, mediana, 47,00 anos e $25 \%$ dos casos com até 40,00 anos Na população em geral, os valores para média, mediana e $75 \%$ das idades foram, respectivamente, $26,09,24,00$ e 38,00 anos. A menor idade dentre as amostras examinadas foi 0,17 anos e a maior, 90,00 anos.

Os percentuais de sororreatividade aumentaram com a idade e o teste de diferença entre proporções não revelou diferença significante de reatividade sorológica entre os sexos (IC $95 \%=0,0025 \pm 0,0108), p=0,647$. A amostra que inclui um contigente maior de mulheres em idade fértil (de 15 a 49 anos) constituiu $26,84 \%$ da população total examinada e sua reatividade sorológica, $4,15 \%$. 
Tabela 4.5.7.4 - Sorologia para infecção chagásica, por grupo etário e sexo, em população de municípios de Serviço Regional da SUCEN de São José do Rio Preto (SR-8), 1984 a 1997.

\begin{tabular}{|c|c|c|c|c|c|c|c|c|c|}
\hline \multirow{3}{*}{$\begin{array}{l}\text { Grupo } \\
\text { etário } \\
\text { (anos) }\end{array}$} & \multicolumn{3}{|c|}{ Feminino } & \multicolumn{3}{|c|}{ Masculino } & \multicolumn{3}{|c|}{ Total } \\
\hline & $N^{o}$ & $N^{o}$ & $\%$ & $\mathrm{~N}^{\mathrm{o}}$ & $N^{\circ}$ & $\%$ & $N^{0}$ & $N^{\circ}$ & $\%$ \\
\hline & exam & Reag & Reag. & exam. & Reag & Reag. & exam. & Reag. & Reag. \\
\hline$<1$ & 16 & 0 & 0,00 & 11 & 0 & 0,00 & 27 & 0 & 0,00 \\
\hline $1-4$ & 221 & 0 & 0,00 & 225 & 0 & 0,00 & 446 & 0 & 0,00 \\
\hline $5-9$ & 287 & 0 & 0,00 & 316 & 0 & 0,00 & 603 & 0 & 0,00 \\
\hline $10-14$ & 255 & 2 & 0,78 & 247 & 0 & 0,00 & 502 & 2 & 0,40 \\
\hline $15-19$ & 206 & 0 & 0,00 & 251 & 1 & 0,40 & 457 & 1 & 0,22 \\
\hline $20-29$ & 456 & 2 & 0,44 & 414 & 3 & 0,73 & 870 & 5 & 0,58 \\
\hline $30-39$ & 398 & 17 & 4,27 & 373 & 13 & 3,49 & 771 & 30 & 3,89 \\
\hline $40-49$ & 216 & 34 & 15,74 & 285 & 35 & 12,28 & 501 & 69 & 13,77 \\
\hline $50-59$ & 161 & 21 & 13,04 & 160 & 21 & 13,12 & 321 & 42 & 13,08 \\
\hline $60-69$ & 71 & 9 & 12,68 & 90 & 11 & 12,22 & 161 & 20 & 12,42 \\
\hline$\geq 70$ & 50 & 6 & 12,00 & 45 & 4 & 8,89 & 95 & 10 & 10,53 \\
\hline Total & 2337 & 91 & 3,89 & 2417 & 88 & 3,64 & 4754 & 179 & 3,77 \\
\hline
\end{tabular}

Dos 179 casos sororreagentes detectados no periodo, foi possivel obter as classificações epidemiológicas de 153 deles $(85,47 \%)$, resumidas por Regiões de Governo e municipios no Quadro 4.5.7.2. 
Quadro 4.5.7.2 - Classificação epidemiológica de casos sororreagentes para infecção chagásica nas Regiões de Governo no Serviço Regional da SUCEN de São José do Rio Preto (SR-8), 1984-1997.

\begin{tabular}{|c|c|c|c|}
\hline Municipio & $N^{\circ}$ reag. & $N^{0}$ invest. & Classificação* \\
\hline \multicolumn{4}{|c|}{ Região de Governo Catanduva } \\
\hline Catanduva & 2 & 2 & 2 AR \\
\hline Irapuã & 3 & 2 & $2 \mathrm{AM}$ \\
\hline Palmares Paulista & 3 & 3 & $3 \mathrm{AR}$ \\
\hline Sales & 1 & 1 & $1 \mathrm{AM}$ \\
\hline Santa Adélia & 1 & 1 & $1 \mathrm{AM}$ \\
\hline Tabapuã & 1 & 1 & $1 \mathrm{AM}$ \\
\hline Urupês & 1 & 1 & 1 Autóctone da Região de Campinas \\
\hline Sub-Total & 12 & 11 & $5 \mathrm{AM}-5 \mathrm{AR}-1 \mathrm{ASR}-5$ \\
\hline \multicolumn{4}{|c|}{ Região de Governo Fernandópolis } \\
\hline Fernandópolis & 3 & 2 & $2 \mathrm{IMP}(\mathrm{MG})$ \\
\hline Guarani d'Oeste & 4 & 4 & $1 \mathrm{AM}-1 \mathrm{AR}-1 \mathrm{IND}(\mathrm{MG} / \mathrm{SP})-1 \mathrm{INC}$ \\
\hline Indiaporà & 3 & 3 & $2 \mathrm{AR}-1 \mathrm{IND}(\mathrm{MG} / \mathrm{SP})$ \\
\hline Macedônia & 3 & 3 & $1 \mathrm{AR}-1 \mathrm{IND}(\mathrm{PE} / \mathrm{SP})$ \\
\hline Meridiano & 1 & 1 & $1 \mathrm{AR}$ \\
\hline Mira Estrela & 1 & 1 & $1 \mathrm{AM}$ \\
\hline Populina & 2 & 2 & $1 \mathrm{AR}-1 \mathrm{IMP}(\mathrm{MG})$ \\
\hline Sub-Total & 17 & 16 & $2 \mathrm{AM}-6 \mathrm{AR}-2 \mathrm{IMP}-3 \mathrm{IND}-1 \mathrm{INC}$ \\
\hline \multicolumn{4}{|c|}{ Região de Governo Jales } \\
\hline Aparecida d'Oeste & 1 & 1 & $1 \mathrm{IND}(\mathrm{PE} / \mathrm{SP})$ \\
\hline Jales & 8 & 5 & $5 \mathrm{AR}$ \\
\hline Marinopolis & 1 & 1 & I AR \\
\hline Palmeira d'Oeste & 8 & 8 & $4 \mathrm{AR}-4 \mathrm{IND}(3 \mathrm{BA} / \mathrm{SP}$ e $1 \mathrm{MG} / \mathrm{SP})$ \\
\hline Paranapuã & 5 & 4 & $2 \mathrm{AR}-2 \mathrm{IND}(\mathrm{BA} / \mathrm{SP})$ \\
\hline Santa Albertina & 7 & 7 & $1 \mathrm{AM}-3 \mathrm{AR}-3 \mathrm{IND}(2 \mathrm{MG} / \mathrm{SP} ; 1 \mathrm{BA} / \mathrm{SP})$ \\
\hline Santa Clara d'Oeste & 5 & 4 & $3 \mathrm{AR}-1 \mathrm{IND}(\mathrm{MG} / \mathrm{SP})$ \\
\hline Santa Fé do Sul & 6 & 6 & $3 . \mathrm{AR}-1 \mathrm{IMP}(\mathrm{MG})-2 \mathrm{IND}(\mathrm{MG} / \mathrm{SP})$ \\
\hline Santa Rita d'Oeste & 6 & 6 & $1 \mathrm{AM}-5 \mathrm{AR}$ \\
\hline Sant da Ponte Pensa & 4 & 4 & 1 ASR-9-2 IND (MG/SP) - 1 CONG \\
\hline São Francisco & 3 & 1 & $1 \mathrm{AR}$ \\
\hline Três Fronteiras & 2 & 2 & $2 \mathrm{ND}(\mathrm{MG} / \mathrm{SP})$ \\
\hline Urânia & 5 & 3 & $3 \mathrm{AR}$ \\
\hline Sub-Total & 61 & 52 & $\begin{array}{l}2 \mathrm{AM}-30 \mathrm{AR}-1 \mathrm{IMP}-17 \mathrm{IND}-1 \mathrm{ASR}-9 \\
1 \mathrm{CONG}\end{array}$ \\
\hline \multicolumn{4}{|c|}{ Região de Governo São José do Rio Preto } \\
\hline Adolfo & 4 & 4 & $2 \mathrm{AM}-2 \mathrm{AR}$ \\
\hline Cedral & 2 & 1 & $1 \mathrm{AM}$ \\
\hline
\end{tabular}




\begin{tabular}{|c|c|c|c|}
\hline Municipio & $\mathrm{N}^{\circ}$ reag. & $\mathrm{N}^{\circ}$ invest & Classificação* \\
\hline José Bonifácio & 10 & 10 & $3 \mathrm{AM}-6 \mathrm{AR}-1 \mathrm{IMP}(\mathrm{BA})$ \\
\hline Mendonça & 3 & 3 & $1 \mathrm{AM}-2 \mathrm{AR}$ \\
\hline Monte Aprazivel & 1 & 1 & $1 \mathrm{AM}$ \\
\hline Neves Paulista & 1 & 1 & $1 \mathrm{AM}$ \\
\hline Nipoã & 2 & 1 & $1 \mathrm{AR}$ \\
\hline Nova Aliança & 1 & 1 & $1 \mathrm{AR}$ \\
\hline Nova Granada & 5 & 5 & $3 \mathrm{AR}-2 \mathrm{CONG}$ \\
\hline Onda Verde & 1 & 1 & $1 \mathrm{AR}$ \\
\hline Palestina & 2 & 2 & $1 \mathrm{AM}-1 \mathrm{AR}$ \\
\hline Paulo de Faria & 7 & 5 & $2 \mathrm{AM}-1 \mathrm{AR}-2 \mathrm{IND}(\mathrm{MG} / \mathrm{SP})$ \\
\hline Planalto & 3 & 3 & $1 \mathrm{AM}-1 \mathrm{AR}-1 \mathrm{CONG}$ \\
\hline Potirendaba & 4 & 4 & $4 \mathrm{AR}$ \\
\hline São José do Rio Preto & 3 & 3 & $2 \mathrm{AR}-1 \mathrm{INC}$ \\
\hline Tanabi & 3 & 3 & $2 \mathrm{AR}-1 \mathrm{IMP}(\mathrm{BA})$ \\
\hline União Paulista & 1 & 1 & $1 \mathrm{AR}$ \\
\hline Sub-Total & 57 & 49 & $\begin{array}{l}13 \mathrm{AM}-28 \mathrm{AR}-2 \mathrm{IMP}-2 \mathrm{IND}-1 \mathrm{INC}- \\
3 \mathrm{CONG}\end{array}$ \\
\hline \multicolumn{4}{|c|}{ Região de Governo Votuporanga } \\
\hline Alvares Florence & 2 & 2 & $2 \mathrm{AR}$ \\
\hline Américo de Campos & 2 & 2 & $1 \mathrm{AM}-1 \mathrm{IMP}(\mathrm{MS})$ \\
\hline Cardoso & 2 & 2 & $2 \mathrm{AR}$ \\
\hline Cosmorama & 3 & 3 & $1 \mathrm{AM}-2 \mathrm{AR}$ \\
\hline Macaubal & 5 & 5 & $3 \mathrm{AM}-2 \mathrm{AR}$ \\
\hline Nhandeara & 3 & 3 & $2 \mathrm{AR}-1 \mathrm{IND}(\mathrm{MG} / \mathrm{SP})$ \\
\hline Riolândia & 7 & 7 & $3 \mathrm{AM}-3 \mathrm{AR}-1 \mathrm{IMP}(\mathrm{MG})$ \\
\hline Sebastianópolis do Sul & 1 & 1 & $1 \mathrm{AR}$ \\
\hline Votuporanga & 5 & 2 & $1 \mathrm{AR}-1 \mathrm{IND}$ \\
\hline Sub-Total & 32 & 27 & $8 \mathrm{AM}-15 \mathrm{AR}-2 \mathrm{IMP}-2 \mathrm{IND}$ \\
\hline
\end{tabular}

*Legenda: $\mathrm{AR}=$ Autóctone da Região: $\mathrm{AM}=$ Autóctone do Municipio: ASR-5 = Autóctone da Região 5 Campinas: IND = Indeterminado: INC = Inconclusivo: ASR-9 = Autóctone da Região 9- Araçatuba: $C O N G=$ Congênito: IMP = Importado.

A notificação de triatomíneo vetor predominou sobre a atividade de rotina no desencadeamento das atividades de sorologia para infecção chagásica no Programa (Tabela 4.7.5). A perda de informação esteve ao redor de $20,0 \%$ dos casos 
Tabela 4.5.7.5 - Unidades Domiciliares com e sem presença de sororreagentes para infeç̧ão chagásica, de acordo com o tipo de atendimento, no Serviço Regional de São José do Rio Preto (SR-8), 1984 a 1997

\begin{tabular}{|c|c|c|c|c|c|c|}
\hline \multirow{2}{*}{ Atendimento } & \multicolumn{2}{|c|}{$\begin{array}{l}\text { UD c/ reag. sorol } \\
(\mathrm{n}=148)\end{array}$} & \multicolumn{2}{|c|}{$\begin{array}{l}\text { UD s/ reag. sorol. } \\
\qquad(\mathrm{n}=1021)\end{array}$} & \multicolumn{2}{|c|}{$\begin{array}{c}\text { Total } \\
(\mathrm{n}=1 \quad 169)\end{array}$} \\
\hline & $\mathrm{N}^{\circ}$ & $\%$ & $N^{0}$ & $\%$ & $N^{0}$ & $\%$ \\
\hline Notificação & 99 & 66,9 & 729 & 71,4 & 828 & 70,8 \\
\hline Rotina & 17 & 11,5 & 96 & 9,4 & 113 & 9,7 \\
\hline Rotina + Notificação & 1 & 0.7 & 3 & 0,3 & 4 & 0,3 \\
\hline Sem informação & 31 & 20,9 & 193 & 18,9 & 224 & 19,2 \\
\hline
\end{tabular}

As informações disponiveis sobre os vetores nas 1169 UDs estão apresentadas na Tabela 4.5.76. T. sordida foi a espécie mais frequente nas UDs com e sem presença de sororreagentes, seguida por $R$ neglectus A perda de informação representou cerca de $20,0 \%$ do total. A descoberta de triatomineos adultos prevaleceu sobre ninfas, porém é digna de nota a perda em torno de $50,0 \%$ dos registros de ocorrência das espécies

Infecção por $T$. cruzi foi observada em 6,9\% dos casos. No ano de 1985 foram encontrados dois exemplares fêmeas de T. infestans no município de Meridiano, localidade Fazenda Alto Alegre, em uma UD com 3 moradores, todos negativos no exame sorológico. Foi confirmada a reação para identificação de hábito alimentar para sangue humano, o local de captura foi o intradomicílio. Ainda quanto ao hábito alimentar, a fonte sangue humano, sozinha ou combinada com o de outros animais predominou de forma significante, mesmo com a perda de informação da ordem de $35,0 \%$ 
Tabela 4.5.7.6 - Unidades Domiciliares com e sem presença de sororreagentes para infecção cnagásica, de acordo com características associadas ao vetor, no Serviço Regional de São José do Rio Preto (SR-8),1984 a 1997.

\begin{tabular}{|c|c|c|c|c|c|c|c|c|c|}
\hline \multirow[t]{2}{*}{ Característica } & \multicolumn{3}{|c|}{$\begin{array}{l}\text { UD c/ reag. sorol } \\
n=148\end{array}$} & \multicolumn{3}{|c|}{$\begin{array}{l}\text { UD s/ reag. sorol. } \\
n=1021\end{array}$} & \multicolumn{3}{|c|}{$\begin{aligned} & \text { Total } \\
& n=1169\end{aligned}$} \\
\hline & $\mathrm{N}^{\circ}$ & $\%$ & $\% *$ & $\mathrm{~N}^{\circ}$ & $\%$ & $\% *$ & $\mathrm{~N}^{\circ}$ & $\%$ & $\% *$ \\
\hline \multicolumn{10}{|l|}{ Especie } \\
\hline P. megistus $(P m)$ & & & & 1 & 0,1 & 0,1 & 1 & 0,1 & 0,1 \\
\hline I. sordida (Ts) & 89 & 60,1 & 77,4 & 655 & 64,1 & 81,2 & 744 & 63,6 & 80,7 \\
\hline R. neglectus $(R n)$ & 23 & 15,5 & 20,0 & 128 & 12,5 & 15,9 & 151 & 12,9 & 16,4 \\
\hline$P m+T s$ & & & & 1 & 0,1 & 0,1 & 1 & 0,1 & 0,1 \\
\hline$T s+R n$ & 2 & 1,4 & 1,7 & 21 & 2,1 & 2,6 & 23 & 2,0 & 2,5 \\
\hline$I^{\prime} m+R n$ & 1 & 0,7 & 0,9 & & & & 1 & 0,1 & 0,1 \\
\hline T. infestans + Ts & & & & 1 & 0,1 & 0,1 & 1 & 0,1 & 0,1 \\
\hline sem informação & 33 & 22,3 & & 214 & 21,0 & & 247 & 21,1 & \\
\hline \multicolumn{10}{|l|}{ Fase evolutiva e infecção } \\
\hline Ninfas & 9 & 6,1 & 11,7 & 68 & 6,7 & 11,4 & 77 & 6,6 & 11,5 \\
\hline Ninfas infectadas & 2 & 1,3 & 2,6 & 11 & 1,1 & 1,8 & 13 & 1,1 & 2,0 \\
\hline Ninfas e Adultos & 10 & 6,8 & 13,0 & 91 & 8,9 & 15,3 & 101 & 8,6 & 15,1 \\
\hline Ninfas e Adultos infect. & 9 & 6,1 & 11,7 & 34 & 3,3 & 5,7 & 43 & 3,7 & 6,4 \\
\hline Adultos & 45 & 30,4 & 58,4 & 356 & 34,9 & 59,8 & 401 & 34,3 & 60,0 \\
\hline Adultos infectados & 2 & 1,3 & 2,6 & 24 & 2,3 & 4,0 & 26 & 2,1 & 4,0 \\
\hline sem informação & 71 & 48,0 & & 427 & 41,8 & & 498 & 42,6 & \\
\hline \multicolumn{10}{|l|}{ Local de captura } \\
\hline Interno & 103 & 69,6 & 77,5 & 769 & 75,3 & 82,8 & 872 & 74,6 & 82,1 \\
\hline Externo & 18 & 12.2 & 13,5 & 110 & 10,8 & 11,8 & 128 & 11,0 & 12,1 \\
\hline Interno e externo & 12 & 8,1 & 9,0 & 50 & 4,9 & 5,4 & 62 & 5,3 & 5,8 \\
\hline sem informação & 15 & 10,1 & & 92 & 9,0 & & 107 & 9,1 & \\
\hline \multicolumn{10}{|l|}{ Hábito alimentar } \\
\hline Sangue humano** & 92 & 62,2 & 91,1 & 580 & 56,8 & 87,2 & 672 & 57,5 & 87,7 \\
\hline Outros*** & 3 & 2,0 & 3,0 & 32 & 3,1 & 4,8 & 35 & 3,0 & 4,6 \\
\hline Não reagente & 6 & 4,0 & 5,9 & 53 & 5,2 & 8,0 & 59 & 5,0 & 7,7 \\
\hline sem informação & 47 & 31,8 & & 356 & 34,9 & & 403 & 34,5 & \\
\hline
\end{tabular}

* Percentual calculado excluindo-se as perdas de informação.

** Reagente para Sangue humano sozinho ou associado a outros

*** Outros: reagente para sangue de ave, cão, gato, roedor ou marsupial. 
Com um valor de "odds ratio" $=0,9499$ 950: $0,5099-1,7693$, verifica-se que não houve associação entre UDs com reagentes sorológicos e presença de triatomíneos infectados por T. cruzi (Tabela 4.5.7.

Tabela 4.5.7.7 - Encontro de reagentes e de ñ̃o reagentes sorológicos para infecção chagásica em UDs com e sem presença de triatomineo infectado por $T$. cruzi, no Serviço Regional da SUCEN de São José do Rio Preto (SR-8), 1984 a 1997

\begin{tabular}{lc|cc|c}
\hline \multicolumn{2}{c|}{ Caracteristica } & \multicolumn{2}{|c|}{ UD com presença de morador } & Total \\
\hline $\begin{array}{l}\text { UD com } \\
\text { triatomineo }\end{array}$ & $\begin{array}{l}\text { infectado por } T . \\
\text { cruzi } \\
\text { não infectado } \\
\text { por } l . \text { cruzi }\end{array}$ & 13 & 88 & 101 \\
& & 93 & 598 & 691 \\
\hline & 106 & 686 & 792 \\
\hline
\end{tabular}

Sobre as condições necessarias para a geração de exames sorológicos dos moradores, em 3,0\% dos casos não se justificou a colheita de sangue (Tabela 4.5.7.8). Do mesmo modo que nas outras Regionais, o resultado reagente para sangue humano no hábito alimentar predominou sobre as outras formas de desencadeamento da sorologia.

Tabela 4.5.7.8 - Condições para execução de exame sorclógico, segundo presença ou ausência de sororreagentes para infecção chagásica, em UDs no Serviço Regional da SUCEN de São José do Rio Preto (SR-8), 1984 a 1997.

\begin{tabular}{|c|c|c|c|c|c|c|}
\hline \multirow[t]{2}{*}{ Condição para gerar sorologia } & \multicolumn{2}{|c|}{$\begin{array}{l}\text { UD c/ reag. sorol } \\
\qquad(\mathrm{n}=148)\end{array}$} & \multicolumn{2}{|c|}{$\begin{array}{l}\text { UD s/ reag. sorol } \\
(n=1021)\end{array}$} & \multicolumn{2}{|c|}{$\begin{array}{c}\text { Total } \\
(n=1 \quad 169)\end{array}$} \\
\hline & $\mathrm{N}^{\circ}$ & $\%$ & $N^{\circ}$ & $\%$ & $\mathrm{~N}^{\circ}$ & $\%$ \\
\hline T. infestans & 0 & 0,0 & 1 & 0,1 & 1 & 0,1 \\
\hline Triatomineo infectado & 11 & 7,4 & 74 & 7,3 & 85 & 7,3 \\
\hline Triat Infect + Reag $p /$ sangue hum & 2 & 1,4 & 14 & 1,4 & 16 & 1,4 \\
\hline Reagente para sangue humano & 90 & 60,8 & 566 & 55,4 & 656 & 56,1 \\
\hline Dispensável* & 3 & 2,0 & 32 & 3,1 & 35 & 3,0 \\
\hline Sem informação & 42 & 28,4 & 335 & 32,8 & 377 & 32,2 \\
\hline
\end{tabular}




\subsubsection{No Serviço Regional da SUCEN de Araçatuba (SR-9)}

A Região Administrativa Araçatuba compõe-se pelas Regiões de Governo Andradina e Araçatuba, com 37 municipios existentes em uma area de $18574 \mathrm{~km}^{2}$, que representa $7,47 \%$ da extensão do território paulista ${ }^{92}$. No periodo 1984-1997, os encontros de triatomineos vetores ocorreram em 32 municipios, perfazendo 374 focos domiciliares (Tabela 4.5.8.1)

Tabela 4.5.8.1 - Sorologia de infecção chagásica em Regiões de Governo no Serviço Regional da SUCEN de Araçatuba (SR-9), 1984 a 1997

\begin{tabular}{lcccc}
\hline Regiào de Governo & $\begin{array}{c}\mathrm{N}^{\circ} \text { Munic } \\
\text { exist. }\end{array}$ & $\begin{array}{c}\mathrm{N}^{\circ} \text { Munic. } \\
\text { trab. }\end{array}$ & $\begin{array}{c}\% \text { Mun } \\
\text { trab. }\end{array}$ & $\mathrm{N}^{\circ}$ UDs \\
\hline Andradina & 11 & 10 & 90,91 & 55 \\
Araçatuba & 26 & 22 & 84,62 & 319 \\
\hline TOTAL & 37 & 32 & 86,49 & 374 \\
\hline
\end{tabular}

Os detalhamentos qualitativo e quantitativo dos municipios trabalhados com a sorologia para infecção chagásica, encontram-se no Quadro 4.5.8.1, na Tabela 4.5.8 2 e no Anexo VI

Tabela 4.5.8.2 - Distribuição de frequências de localidades existentes e trabalhadas e de UDs trabalhadas e com reagentes sorológicos para infecção chagásica, das Regiões de Governo no Serviço Regional da SUCEN de Araçatuba (SR-9), 1984 a 1997.

\begin{tabular}{lrrrrrrrrr}
\hline $\begin{array}{l}\text { Região de } \\
\text { Governo }\end{array}$ & \multicolumn{3}{c}{ Localidades } & \multicolumn{2}{c}{ UDs } & \multicolumn{3}{c}{ Amostras } & IC** \\
exist. & trab & $\%$ trab & trab. & reag & trab. & reag. & \%reag & dos reag (\%) \\
Andradina & 289 & 40 & 13,84 & 55 & 3 & 218 & 3 & 1,38 & $0,47-3,97$ \\
Araçatuba & 607 & 192 & 31,63 & 319 & 25 & 1200 & 25 & 2,08 & $1,42-3,06$ \\
\hline \multirow{2}{*}{ TOTAL } & 896 & 232 & 25,89 & 374 & 28 & 1418 & 28 & 1,97 & $1,37-2,84$ \\
\hline
\end{tabular}

* Fonte: SUCEN/DOT/Lista de localidades segundo municipios por Serviço Regional. 1981-1986

** IC = Intervalo de Confiança (95\%) 
Quadro 4.5.8.1 - Municipios com localidades trabalhadas em sorologia ( $T$ ) e com presença de sororreagente $(\mathrm{X})$ no Programa de Controle da Doença de Chagas (PCDCh) do Serviço Regional da SUCEN de Araçatuba (SR-9), 1984 - 1997

\begin{tabular}{|c|c|c|c|c|c|c|c|c|c|c|c|c|c|c|}
\hline MUNICIPIO & 1984 & 1985 & 1986 & 1987 & 1988 & 1989 & 1990 & 1991 & 1992 & 1993 & 1994 & 1995 & 1996 & 1997 \\
\hline \multicolumn{15}{|c|}{ RG ANDRADINA } \\
\hline Andradina & & & & $T$ & $T$ & & & & & $T$ & & & & \\
\hline Castilho & $T$ & $T$ & & $T$ & $\mathrm{~T}$ & & & & & & & & & \\
\hline Guaraçaı & & & & $T X$ & $T$ & & & & & & & & & \\
\hline IthaSolteira & & & & & & & & & & & $T$ & & & \\
\hline Itapura & & & & $T$ & $T$ & & & & & & & & & \\
\hline Lavinıa & & $T$ & & & & & & & & & & & & \\
\hline Mirandopolis & & & & $T$ & $T$ & & & & & & & & & \\
\hline NIndependència & & & & $T X$ & & & & & & & & & & \\
\hline PereiraBarreto & TX & & & $T$ & & & & & & & & & & \\
\hline Sud-Menucci & $\mathrm{T}$ & & & $\bar{T}$ & $T$ & & & & & & & & & \\
\hline \multicolumn{15}{|c|}{ RG ARAÇATUBA } \\
\hline AltoAlegre & $T$ & $T$ & & $T$ & & $T$ & & & & & & & & \\
\hline Araçatuba & $T X$ & $T X$ & & $T X$ & $T X$ & $T$ & & $T$ & & & $T$ & $T$ & & \\
\hline Aunflama & $T$ & $\mathrm{~T}$ & & & & & & & & & & & & \\
\hline Avanhandava & & $T$ & & $T$ & & & & & & & & & & $\mathrm{~T}$ \\
\hline Barbosa & & $T X$ & & & & & & & & & & & & \\
\hline Bilac & & $\mathrm{T}$ & & $T$ & & & & & & & & & & \\
\hline Birigui & $T$ & $T$ & & $T X$ & $T$ & & & & & & & & & \\
\hline Brauna & $T$ & $T$ & & $T$ & $T$ & & & & & & & & & \\
\hline Buritama & & $\mathrm{TX}$ & & $T X$ & & & & & & $T X$ & & & & \\
\hline Clementina & & $T$ & & $\mathrm{~T}$ & & $T$ & & & & & & & & \\
\hline Coroados & $\mathrm{T}$ & $T$ & & $\mathrm{~T}$ & $T$ & & & & & & & & & \\
\hline GabrielMonteiro & $T$ & $T$ & & $T$ & & & & & & & & & & \\
\hline \begin{tabular}{|l|} 
GastãoVidigal \\
\end{tabular} & $T$ & $T X$ & & & & & & & & & & & $T$ & \\
\hline Gal.Salgado & $T$ & $T$ & & $T$ & & & & & & & & $T X$ & & \\
\hline Gliceno & $T$ & $T X$ & & $T$ & & & & & & & & & & \\
\hline Guararapes & $T$ & $T$ & & $T$ & & & & & & & & & & \\
\hline Guzolàndia & $T$ & $\mathrm{~T}$ & & $T$ & $\mathrm{~T}$ & & & & & & & & & \\
\hline Luizània & & $T X$ & & $T$ & $T$ & & & & & & & & & \\
\hline NLusitània & $T$ & $T X$ & & & & & & & & & & & & \\
\hline Penapolis & $T X$ & $T X$ & & $T X$ & $T$ & & & & & & & & & $T$ \\
\hline Piacatu & $T$ & $T$ & & $T$ & $T$ & & & & & & & & & \\
\hline Tunuba & $T$ & $T$ & & $T$ & & & & & & $T$ & & & & \\
\hline
\end{tabular}

Durante os anos de 1986, 1990 e 1992 a Regional não produziu trabalho em sorologia, como pode ser visualizado no Quadro 4 5.8.1 e na Tabela 4.5.8.3 
Tabela 4.5.8.3 - Variação anual da sororreatividade para infecção chagásica no Serviço Regional da SUCEN de Araçatuba (SR-9), 1984 a 1997.

\begin{tabular}{|c|c|c|c|c|c|c|}
\hline Ano & $\begin{array}{l}N^{\circ} \text { UDs } \\
\text { Trab. }\end{array}$ & $\begin{array}{l}\mathrm{N}^{0} \text { Am. } \\
\text { Exam. }\end{array}$ & $\begin{array}{c}\mathrm{N}^{\circ} \\
\text { Reag. }\end{array}$ & $\%$ Reag. & IC* $(\%)$ & MGTR** \\
\hline 1984 & 80 & 287 & 4 & 1,39 & $0,54-3,53$ & 152,2 \\
\hline 1985 & 139 & 516 & 14 & 2,71 & $1,62-4,50$ & 115,9 \\
\hline 1986 & 0 & 0 & - & - & - & - \\
\hline 1987 & 103 & 389 & 7 & 1,80 & $0,87-3,67$ & 231,9 \\
\hline 1988 & 34 & 149 & 1 & 0,67 & $0,12-3,70$ & 512,0 \\
\hline 1989 & 3 & 17 & 0 & 0,00 & - & - \\
\hline 1990 & 0 & 0 & - & - & - & - \\
\hline 1991 & 1 & 4 & 0 & 0,00 & - & - \\
\hline 1992 & 0 & 0 & - & - & - & - \\
\hline 1993 & 3 & 10 & 1 & 10.00 & $1,79-40,42$ & 128,0 \\
\hline 1994 & 5 & 19 & 0 & 0,00 & - & - \\
\hline 1995 & 3 & 10 & 1 & 1000 & $1,79-40,72$ & 128,0 \\
\hline 1996 & 1 & 4 & 0 & 0,00 & - & - \\
\hline 1997 & 2 & 13 & 0 & 0.00 & - & - \\
\hline TOTAL & 374 & 1418 & 28 & 1,97 & $1,37-2,84$ & 152,2 \\
\hline
\end{tabular}

* IC = Intervalo de Confiança (95\%)

** MGTR = Media Geometrica dos Titulos dos Reagentes

A distribuição da sororreatividade por idade e sexo encontra-se na Tabela 4.5.8.4 Não houve sorologia reagente até a idade de 19 anos, em ambos os sexos. Quanto à positividade entre sexos, verificou-se não haver diferença significante a $95 \%$ de confiança $(-0,003 \pm 0,0159), p=0,458$ Dentre os reagentes sorológicos, a menor idade observada foi 22,00 anos para o sexo feminino e 27,00 anos para o masculino e a maior idade, 70,00 anos para o feminino e 68,00 anos para o masculino. A média de idade para os sororreagentes foi 45,56 anos para o sexo feminino e 47,75 anos para o masculino. Na população geral a menor idade foi 0,25 anos e a maior, 85,00 anos; a média foi de 24,79 anos, a mediana, 21,00 anos e $75 \%$ da população possuía até 37,00 anos. Os casos sororreagentes detectados não sofreram investigação epidemiológica, à semelhança de outras Regionais. 
Tabela 4.5.8.4 - Sorologia para infecção chagásica, por grupo etário e sexo, em população de municipios do Serviço Regional da SUCEN de Araçatuba (SR-9), 1984 a 1997.

\begin{tabular}{|c|c|c|c|c|c|c|c|c|c|}
\hline \multirow{2}{*}{$\begin{array}{l}\text { Grupo } \\
\text { etario } \\
\text { (anos) }\end{array}$} & \multicolumn{3}{|c|}{ Feminino } & \multicolumn{3}{|c|}{ Masculino } & \multicolumn{3}{|c|}{ Total } \\
\hline & $\begin{array}{c}N^{\circ} \\
\text { exam }\end{array}$ & $\begin{array}{c}N^{\circ} \\
\text { Reag. }\end{array}$ & $\begin{array}{c}\% \\
\text { Reag. }\end{array}$ & $\begin{array}{c}N^{\circ} \\
\text { exam }\end{array}$ & $\begin{array}{c}N^{\circ} \\
\text { Reag. }\end{array}$ & $\begin{array}{c}\% \\
\text { Reag. }\end{array}$ & $\begin{array}{c}\mathrm{N}^{\circ} \\
\text { exam }\end{array}$ & $\begin{array}{c}N^{\circ} \\
\text { Reag. }\end{array}$ & $\begin{array}{c}\% \\
\text { Reag. }\end{array}$ \\
\hline$<1$ & 8 & 0 & 0,00 & 5 & 0 & 0,00 & 13 & 0 & 0,00 \\
\hline $1-4$ & 74 & 0 & 0,00 & 92 & 0 & 0,00 & 166 & 0 & 0,00 \\
\hline $5-9$ & 81 & 0 & 0,00 & 123 & 0 & 0,00 & 204 & 0 & 0,00 \\
\hline $10-14$ & 72 & 0 & 0,00 & 72 & 0 & 0,00 & 144 & 0 & 0,00 \\
\hline $15-19$ & 73 & 0 & 0.00 & 63 & 0 & 0,00 & 136 & 0 & 0,00 \\
\hline $20-29$ & 139 & 2 & 1,44 & 102 & 2 & 1,96 & 241 & 4 & 1,66 \\
\hline $30-39$ & 124 & 3 & 2,42 & 90 & 1 & 1,11 & 214 & 4 & 1,87 \\
\hline $40-49$ & 63 & 4 & 6,35 & 73 & 4 & 5,48 & 136 & 8 & 5,88 \\
\hline $50-59$ & 38 & 4 & 10,53 & 43 & 3 & 6,98 & 81 & 7 & 8,64 \\
\hline $60-69$ & 30 & 2 & 6,67 & 18 & 2 & 11,11 & 48 & 4 & 8,33 \\
\hline$\geq 70$ & 10 & 1 & 10.00 & 24 & 0 & 0,00 & 34 & 1 & 2,94 \\
\hline Ignorado & 0 & 0 & 0.00 & 1 & 0 & 0.00 & 1 & 0 & 0.00 \\
\hline Total & 712 & 16 & 2.25 & 706 & 12 & 1,70 & 1418 & 28 & 1,97 \\
\hline
\end{tabular}

Como em outras Regionais, o tipo de atividade que predominou na geração da colheita de sangue para reação sorológica foi o atendimento de notificação de triatomineos, ainda que a perda de informação sobre o tipo de atendimento tenha sido elevada (Tabela $45.8 .5)$ Foram obtidas 28 UDs $(7,49 \%)$ com presença de sororreagentes.

Tabela 4.5.8.5 - Unidades Domiciliares com e sem presença de sororreagentes para infecção chagásica, de acordo com o tipo de atendimento, no Serviço Regional da SUCEN de Araçatuba (SR-9), 1984 a 1997

\begin{tabular}{|c|c|c|c|c|c|c|}
\hline \multirow{2}{*}{ Atendimento } & \multicolumn{2}{|c|}{$\begin{array}{l}\text { UD c/ reag. sorol. } \\
\qquad(\mathrm{n}=28)\end{array}$} & \multicolumn{2}{|c|}{$\begin{array}{l}\text { UD s/ reag. sorol. } \\
\qquad(n=346)\end{array}$} & \multicolumn{2}{|c|}{$\begin{array}{c}\text { Total } \\
(\mathrm{n}=374)\end{array}$} \\
\hline & $\mathrm{N}^{\circ}$ & $\%$ & $N^{0}$ & $\%$ & $N^{\circ}$ & $\%$ \\
\hline Notificação & 7 & 25,00 & 85 & 24,57 & 92 & 24,59 \\
\hline Rotina & 3 & 10,71 & 38 & 10,98 & 41 & 10,96 \\
\hline Sem informação & 18 & 64,29 & 223 & 64,45 & 241 & 64,45 \\
\hline
\end{tabular}

Exemplares adultos predominaram nas capturas e a taxa de infecção por $T$. cruzi foi observada em $4,9 \%$ dos casos (incluidos adultos e ninfas). Local de captura interno também 
prevaleceu sobre o externo. Quanto ao hábito alimentar, a fonte sangue humano, sozinha ou combinada com o de outros animais ocorreu em cerca de $90 \%$ dos casos. As perdas de informações quanto a especie, fase evolutiva e ao local de captura estiveram em torno de $50 \%$.

As características associadas aos vetores, nas UDs com presença ou ausência de sororreagentes estão apresentadas na Tabela 4.5.8.6.

Tabela 4.5.8.6 - Unidades Domiciliares com e sem presença de sororreagentes para infeç̧ão chagásica, de acordo com características associadas ao vetor, no Serviço Regional da SUCEN de Araçatuba (SR-9), 1984 a 1997.

\begin{tabular}{|c|c|c|c|c|c|c|c|c|c|}
\hline \multirow[t]{2}{*}{ Caracteristica } & \multicolumn{3}{|c|}{$\begin{array}{l}\text { UD c/ reag. sorol. } \\
n=28\end{array}$} & \multicolumn{3}{|c|}{$\begin{array}{l}\text { UD s/ reag sorol } \\
n=346\end{array}$} & \multicolumn{3}{|c|}{$\begin{array}{l}\text { Total } \\
n=374\end{array}$} \\
\hline & $\mathrm{N}^{\circ}$ & $\%$ & $\% *$ & $N^{\circ}$ & $\%$ & $0 \%$ & $N^{0}$ & $\%$ & $\% *$ \\
\hline Espécie & & & & & & & & & \\
\hline T. sordida (Ts) & 17 & 60,7 & 89,5 & 171 & 49,4 & 90,0 & 188 & 50,3 & 89,9 \\
\hline R. neglectns $(R n)$ & & & & 15 & 4,3 & 7,9 & 15 & 4,0 & 7,2 \\
\hline$T s \cdot R n$ & 2 & 7,1 & 10,5 & 4 & 1,2 & 2,1 & 6 & 1,6 & 2,9 \\
\hline sem informação & 9 & 32,2 & & 156 & 45,1 & & 165 & 44,1 & \\
\hline Fase evolutiva e infecção & & & & & & & & & \\
\hline Ninfas & 2 & 7,1 & 13,3 & 15 & 4,3 & 9,1 & 17 & 4,5 & 9,4 \\
\hline Ninfas infectadas & & & & 1 & 0,3 & 0,6 & 1 & 0,3 & 0,6 \\
\hline Ninfas e Adultos & & & & 13 & 3,8 & 7,9 & 13 & 3,5 & 7,2 \\
\hline Ninfas e Adultos infect. & 1 & 3,6 & 6,7 & 3 & 0,9 & 1,8 & 4 & 1,1 & 2,2 \\
\hline Adultos & 12 & 42,9 & 80,0 & 120 & 34,7 & 72,7 & 132 & 35,3 & 73,4 \\
\hline Adultos infectados & & & & 13 & 3,8 & 7,9 & 13 & 3,5 & 7,2 \\
\hline sem informação & 13 & 46,4 & & 181 & 52,3 & & 194 & 51,8 & \\
\hline Local de captura & & & & & & & & & \\
\hline interno & 13 & 46,4 & 92,9 & 140 & 40,5 & 88,6 & 153 & 40,9 & 90,0 \\
\hline externo & 1 & 3,6 & 9,1 & 10 & 2,9 & 6,3 & 11 & 3,0 & 6,4 \\
\hline interno e externo & & & & 8 & 2,3 & 5,1 & 8 & 2,1 & 4,6 \\
\hline sem informação & 14 & 50,0 & & 188 & 54,3 & & 202 & 54,0 & \\
\hline Hábito alimentar & & & & & & & & & \\
\hline Sangue humano** & 25 & 89,3 & 100,0 & 310 & 89,6 & 97,2 & 335 & 89,6 & 97,4 \\
\hline Outros $* * *$ & & & & 3 & 0,9 & 0,9 & 3 & 0,8 & 0,9 \\
\hline Não reagente & & & & 6 & 1,7 & 1,9 & 6 & 1,6 & 1,7 \\
\hline sem informação & 3 & 10,7 & & 27 & 7,8 & & 30 & 8,0 & \\
\hline
\end{tabular}

* Percentual calculado excluindo-se as perdas de informação.

** Reagente para Sangue humano sozinho ou associado a outros

*** Outros: reagentes para sangue de ave, cão, gato, roedor ou marsupial. 
Com um valor de "odds ratio" $=0,5569_{95^{\circ}}: 0,069-4,473$ verifica-se que não houve diferença entre reagentes e não reagentes sorológicos. moradores de UDs com e sem presença de triatomineos infectados por $T$. cruzi (Tabela 4 5.8.7)

Tabela 4.5.8.7 - Encontro de reagentes e de não reagentes sorológicos para infecção chagásica, em UDs com e sem presença de triatomineo infectado por T. cruzl, no Serviço Regional da SUCEN de Araçatuba (SR-9), 1984 a 1997.

\begin{tabular}{|c|c|c|c|c|}
\hline \multirow{2}{*}{\multicolumn{2}{|c|}{ Caracteristica }} & \multicolumn{2}{|c|}{ UD com presença de morador } & \multirow[t]{2}{*}{ Total } \\
\hline & & Sororreagente & Negativo & \\
\hline \multirow[t]{2}{*}{$\begin{array}{l}\text { UD com } \\
\text { triatomineo }\end{array}$} & $\begin{array}{l}\text { infectado por } T \text {. } \\
\text { cruzl }\end{array}$ & 1 & 19 & 20 \\
\hline & $\begin{array}{l}\text { não infectado } \\
\text { por } T \cdot \text { cruzl }\end{array}$ & 14 & 148 & 162 \\
\hline \multicolumn{2}{|c|}{ Total } & 15 & 167 & 182 \\
\hline
\end{tabular}

As condições necessarias para o exame sorologico dos moradores estão na Tabela 4 5.8.8. Predominou a reação reagente para sangue humano sobre a infecção por $T$. cruzi do triatomineo vetor

Tabela 4.5.8.8 - Condições para execução de exame sorológico, segundo presença ou ausência de sororreagentes para infecção chagásica, em UDs do Serviço Regional da SUCEN de Araçatuba (SR-9), 1984 a 1997

\begin{tabular}{|c|c|c|c|c|c|c|}
\hline \multirow[t]{2}{*}{ Condição para gerar sorologia } & \multicolumn{2}{|c|}{$\begin{array}{l}\text { UD c/ reag. } \\
\text { sorol. } \\
\qquad(\mathrm{n}=28)\end{array}$} & \multicolumn{2}{|c|}{$\begin{array}{l}\text { UD s/ reag } \\
\text { sorol } \\
\quad(n=346)\end{array}$} & \multicolumn{2}{|c|}{$\begin{array}{l}\text { Total } \\
(\mathrm{n}=374)\end{array}$} \\
\hline & $\mathrm{N}^{\mathrm{o}}$ & $\%$ & $\mathrm{~N}^{\mathrm{o}}$ & $\%$ & $\mathrm{~N}^{\circ}$ & $\%$ \\
\hline Triatomineo infectado & 0 & 0,0 & 13 & 3,8 & 13 & 3,5 \\
\hline Triat. Infect. + Reag. p/ sangue Hum. & 1 & 3,6 & 5 & 1,4 & 6 & 1,6 \\
\hline Reagente para sangue Humano & 25 & 89,3 & 305 & 88,2 & 330 & 88,2 \\
\hline Sem informação & 2 & 7,1 & 23 & 6,6 & 25 & 6,7 \\
\hline
\end{tabular}




\subsubsection{No Serviço Regional da SUCEN de Presidente Prudente (SR-10)}

A Região Administrativa de Presidente Prudente é composta por três Regiões de Governo Adamantina. Dracena e Presidente Prudente. São 50 municípios, ocupando area de $23952 \mathrm{~km}^{2}$ ou $9,63 \%$ do Estado ${ }^{2}$.

No periodo 1984-1997, os trabalhos de sorologia envolveram 64 focos domiciliares de triatomineos vetores localizados em 54 localidades de 20 municípios (Tabela 4.5.9.1).

Tabela 4.5.9.1 - Sorologia de infecção chagásica em Regiões de Governo no Serviço Regional da SUCEN de Presidente Prudente (SR-10), 1984 a 1997.

\begin{tabular}{lcccc}
\hline Região de Governo & $\begin{array}{c}N^{0} \text { Munic } \\
\text { exist }\end{array}$ & $\begin{array}{c}\mathrm{N}^{\circ} \text { Munic } \\
\text { trab. }\end{array}$ & $\begin{array}{c}\% \text { Mun. } \\
\text { trab. }\end{array}$ & $\mathrm{N}^{0}$ UDs \\
Adamantina & 11 & 2 & 18,18 & 2 \\
Dracena & 10 & 9 & 90,00 & 48 \\
Presidente Prudente & 29 & 9 & 31,03 & 14 \\
\hline & 50 & 20 & 40,00 & 64 \\
\hline
\end{tabular}

A relação de municipios trabalhados (T) e que apresentaram sororreatividade (TX) consta do Quadro 4.5.9.1. Observa-se neste Quadro que a Regional não desenvolveu as atividades do PCDCh nos anos de 1991, 1994 e 1996, devido a deslocamentos de recursos humanos para o controle do vetor da dengue e da febre amarela 
Quadro 4.5.9.1 - Municipios com localidades trabalhadas $(\mathrm{T})$ e com presença de sororreagente (X) no Programa de Controle da Doença de Chagas (PCDCh) do Serviço Regional da SUCEN de Presidente Prudente (SR-10), 1984-1997.

\begin{tabular}{|c|c|c|c|c|c|c|c|c|c|c|c|c|c|c|}
\hline MUNICIPIO & 1984 & 1985 & 1986 & 1987 & 1988 & 1989 & 1990 & 1991 & 1992 & 1993 & 1994 & 1995 & 1996 & 1997 \\
\hline \multicolumn{15}{|c|}{ RG ADAMANTINA } \\
\hline Adamantina & & $T$ & & & & & & & & & & & & \\
\hline Inubia Paulista & $T$ & & & & & & & & & & & & & \\
\hline \multicolumn{15}{|c|}{ RG DRACENA } \\
\hline Dracena & $T$ & $T$ & & & & $\mathrm{~T}$ & $T$ & & & & & & & \\
\hline Junquerropolis & & $T X$ & & & & & & & $T$ & & & & & \\
\hline MonteCastelo & $T$ & $T$ & & & & & & & & $T$ & & & & \\
\hline NGuataporanga & & & $T$ & & & $T$ & & & & & & $T$ & & \\
\hline Panorama & & & & & & $T$ & & & & & & & & \\
\hline Pauliceia & $T$ & $T$ & $T$ & & $T$ & & & & & & & & & \\
\hline StaMercedes & & & & & $T$ & & & & & & & & & \\
\hline SJPauDAlho & $T$ & $T$ & . & & $T$ & & & & & $T$ & & & & \\
\hline TupiPaulista & $T$ & $T$ & $T$ & & $T$ & $T$ & & & $\bar{T}$ & $T$ & & & & \\
\hline \multicolumn{15}{|c|}{ RG PRESIDENTE PRUDENTE } \\
\hline AlvaresMachado & & & & & $T$ & & & & & & & & & \\
\hline lepé & & & & $T X$ & & $T X$ & & & & & & & & \\
\hline PresEpitacio & & $T$ & & & & $T$ & & & & & & & & \\
\hline PresPrudente & $T X$ & & & & $T$ & & & & & & & & & \\
\hline PresVenceslau & & & $T$ & & & & & & & & & & & \\
\hline Ranchana & & & & & & $\mathrm{T}$ & & & & & & & & \\
\hline Rosana & & & & & & & & & $T$ & & & & & $T$ \\
\hline StoAnastacio & & $T$ & & & & & & & & & & & & \\
\hline Taciba & & & & $T$ & & & & & & & & & & \\
\hline
\end{tabular}

No Anexo VII estão relacionados os municipios distribuidos por Regiões de Governo, destacando os trabalhos de sorologia em termos quantitativos, quanto a número de localidades, de UDs, de amostras trabalhadas e de amostras reagentes. O condensado da Regional está colocado na Tabela 4 5.9.2 
Tabela 4.5.9.2 - Distribuição de frequências de localidades existentes e trabalhadas e de UDs trabalhadas e com reagentes sorológicos para infecção chagásica, das Regiões de Governo no Serviço Regional da SUCEN de Presidente Prudente (SR-10), 1984 a 1997.

\begin{tabular}{|c|c|c|c|c|c|c|c|c|c|}
\hline \multirow{2}{*}{$\begin{array}{c}\text { Região de } \\
\text { Governo }\end{array}$} & \multicolumn{3}{|c|}{ Localidades } & \multicolumn{2}{|c|}{ UDs } & \multicolumn{3}{|c|}{ Amostras } & \multirow{2}{*}{$\begin{array}{c}\mathrm{IC}^{* *} \\
\text { dos reag }(\%)\end{array}$} \\
\hline & exist * & trab & $\%$ trab & trab & reag. & trab. & reag. & $\%$ reag & \\
\hline Adamantina & 233 & 2 & 0.86 & 2 & 0 & 6 & 0 & 0.00 & - \\
\hline Dracena & 254 & 39 & 15.35 & 48 & 1 & 156 & 1 & 0.64 & $0.11-3.54$ \\
\hline $\begin{array}{l}\text { Presidente } \\
\text { Prudente }\end{array}$ & 1021 & 13 & 1.27 & 14 & 3 & 57 & 3 & 5.26 & $1.81-14.37$ \\
\hline TOTAL & 1508 & 54 & 3,58 & 64 & 4 & 219 & 4 & 1,83 & $0.71-4.60$ \\
\hline
\end{tabular}

* Fonte SUCEN/DOT/Lista de localıdades segundo municipios por Serviço Regional. 1981-1986.

** IC = Inter alo de Confiança $(95 \%)$

Na Tabela 459.3 é apresentada a extensão do trabalho realizado anualmente pela Regional Salientam-se os baixos valores de focos de triatomineos domiciliares existentes e do percentual de sororreatividade elevado no ano 1987, decorrência do pequeno número de amostras examinadas (amplo intervalo de confiança)

Tabela 4.5.9.3 - Variação anual da sororreatividade para infeç̧ão chagásica no Serviço Regional da SUCEN de Presidente Prudente (SR-10), 1984 a 1997.

\begin{tabular}{crrrrcr}
\hline Ano & $\begin{array}{c}\mathrm{N}^{0} \text { UDs } \\
\text { Trab }\end{array}$ & $\begin{array}{c}\mathrm{N}^{*} \text { Am } \\
\text { Exam }\end{array}$ & $\mathrm{N}^{\mathbf{0}}$ Reag & \% Reag & IC* $\left.^{*} \%\right)$ & MGTR** $^{* *}$ \\
\hline 1984 & 10 & 31 & 1 & 3,23 & $0,57-16,19$ & 256,0 \\
1985 & 19 & 80 & 1 & 1,25 & $0,22-6,75$ & 32,0 \\
1986 & 10 & 28 & 0 & 0,00 & - & - \\
1987 & 2 & 7 & 1 & 14,29 & $2,57-51,31$ & 1024,0 \\
1988 & 6 & 16 & 0 & 0,00 & - & - \\
1989 & 7 & 23 & 1 & 4,35 & $0,77-20,99$ & 128,0 \\
1990 & 1 & 4 & 0 & 0,00 & - & - \\
1991 & 0 & 0 & - & - & - & - \\
1992 & 3 & 9 & 0 & 0,00 & - & - \\
1993 & 4 & 10 & 0 & 0,00 & - & - \\
1994 & 0 & 0 & - & - & - & - \\
1995 & 1 & 3 & 0 & 0,00 & - & - \\
1996 & 0 & 0 & - & - & - & - \\
1997 & 1 & 8 & 0 & 0,00 & - & 181,0 \\
\hline TOTAL & 64 & 219 & 4 & 1,83 & $0,71-4,60$ & - \\
\hline
\end{tabular}

* IC = Intervalo de Confiança (95\%)

** MGTR = Média Geometrica dos Titulos dos Reagentes 
Na Tabela 4.5.9.4 são reportados, por grupo etário e sexo, os totais de exames sorológicos e reatividade para infecção chagásica no período. As idades variaram de 1 a 85 anos, com uma média de 28,36 anos, mediana de 25,00 anos e com $75 \%$ da população com até 40,00 anos. Não foi verificada sororreatividade nas idades até 19 anos $(39,27 \%$ das amostras), nem no grupo das mulheres.

Tabela 4.5.9.4 - Sorologia para infecção chagásica, por grupos etários e sexo, em população de municipios no Serviço Regional da SUCEN de Presidente Prudente (SR-10), 1984 a 1997

\begin{tabular}{|c|c|c|c|c|c|c|c|c|c|}
\hline \multirow{2}{*}{$\begin{array}{l}\text { Grupo } \\
\text { etário } \\
\text { (anos) }\end{array}$} & \multicolumn{3}{|c|}{ Feminino } & \multicolumn{3}{|c|}{ Masculino } & \multicolumn{3}{|c|}{ Total } \\
\hline & $\begin{array}{c}N^{\circ} \\
\text { exam } \\
\end{array}$ & $\begin{array}{c}\mathrm{N}^{\circ} \\
\text { Reag. }\end{array}$ & $\begin{array}{c}\% \\
\text { Reag. }\end{array}$ & $\begin{array}{c}\mathrm{N}^{\circ} \\
\text { exam }\end{array}$ & $\begin{array}{c}\mathrm{N}^{\circ} \\
\text { Reag. }\end{array}$ & $\begin{array}{r}\% \\
\text { Reag. }\end{array}$ & $\begin{array}{r}N^{\circ} \\
\text { exam } \\
\end{array}$ & $\begin{array}{c}\mathrm{N}^{\circ} \\
\text { Reag. }\end{array}$ & $\begin{array}{c}\% \\
\text { Reag. }\end{array}$ \\
\hline$<1$ & 0 & 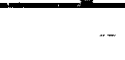 & - & 0 & - & - & 0 & - & - \\
\hline $1-4$ & 5 & 0 & 0,00 & 11 & 0 & 0,00 & 16 & 0 & 0,00 \\
\hline $5-9$ & 16 & 0 & 0,00 & 10 & 0 & 0,00 & 26 & 0 & 0,00 \\
\hline $10-14$ & 10 & 0 & 0,00 & 10 & 0 & 0,00 & 20 & 0 & 0,00 \\
\hline $15-19$ & 10 & 0 & 0,00 & 14 & 0 & 0,00 & 24 & 0 & 0,00 \\
\hline $20-29$ & 19 & 0 & 0,00 & 24 & 1 & 4,17 & 43 & 1 & 2,33 \\
\hline $30-39$ & 17 & 0 & 0,00 & 16 & 0 & 0,00 & 33 & 0 & 0,00 \\
\hline $40-49$ & 10 & 0 & 0,00 & 11 & 1 & 9,09 & 21 & 1 & 4,76 \\
\hline $50-59$ & 9 & 0 & 0,00 & 6 & 1 & 16,67 & 15 & 1 & 6,67 \\
\hline $60-69$ & 9 & 0 & 0,00 & 8 & 1 & 12,50 & 17 & l & 5,88 \\
\hline$\geq 70$ & 3 & 0 & 0,00 & 1 & 0 & 0,00 & 4 & 0 & 0,00 \\
\hline Total & 108 & 0 & 0,00 & 111 & 4 & 3,60 & 219 & 4 & 1,83 \\
\hline
\end{tabular}

Quanto ao tipo de atividade que resultou na colheita de sangue para reação sorológica, constatou-se uma perda de mais de $80 \%$ da informação (Tabela 4.5.9.5). Quando corrigido o percentual, tomando-se em conta apenas os dados existentes, verificamos que predominou a notificação sobre a atividade de pesquisa de triatomíneo em rotina, numa proporção de $75 \% / 25 \%$. Essa situação, segundo os relatos da Regional de Presidente Prudente, decorreu das dificuldades de cumprir suas metas do PCDCh, no tocante à rotina, por interferência de outros Programas emergenciais, associado à falta de recursos humanos ${ }^{183}$. 
Tabela 4.5.9.5 - Unidades Domiciliares com e sem presença de sororreagentes para infecção chagásica, de acordo com o tipo de atendimento, no Serviço Regional da SUCEN de Presidente Prudente (SR-10), 1984 a 1997.

\begin{tabular}{|c|c|c|c|c|c|c|}
\hline \multirow{2}{*}{ Atendimento } & \multicolumn{2}{|c|}{$\begin{array}{l}\text { UD c/ reag. sorol. } \\
\qquad(n=4)\end{array}$} & \multicolumn{2}{|c|}{$\begin{array}{l}\text { UD s/ reag. sorol } \\
\qquad(n=60)\end{array}$} & \multicolumn{2}{|c|}{$\begin{array}{c}\text { Total } \\
(\mathrm{n}=64)\end{array}$} \\
\hline & $\mathrm{N}^{0}$ & $\%$ & $N^{o}$ & $\%$ & $\mathrm{~N}^{0}$ & $\%$ \\
\hline Notificação & 1 & 25,00 & 8 & 13,33 & 9 & 14,06 \\
\hline Rotina & - & - & 3 & 5,00 & 3 & 4,69 \\
\hline Sem informação & 3 & 75,00 & 49 & 81,67 & 52 & 81,25 \\
\hline
\end{tabular}

A Tabela 45.96 mostra as condições que desencadearam os exames sorológicos nas pessoas moradoras das UDs com presença de triatomineos vetores.

Tabela 4.5.9.6 - Condições para execução de exame sorológico, segundo presença ou ausència de sororreagentes para infecção chagásica, em UDs no Serviço Regional da SUCEN de Presidente Prudente (SR-10), 1984 a 1997.

\begin{tabular}{|c|c|c|c|c|c|c|}
\hline \multirow[t]{2}{*}{ Condição para gerar sorologia } & \multicolumn{2}{|c|}{$\begin{array}{l}\text { UD c/ reag. } \\
\text { sorol. } \\
\qquad(n=4)\end{array}$} & \multicolumn{2}{|c|}{$\begin{array}{l}\text { UD s/ reag. } \\
\text { sorol. } \\
\qquad(\mathrm{n}=60)\end{array}$} & \multicolumn{2}{|c|}{$\begin{array}{l}\text { Total } \\
(\mathrm{n}=64)\end{array}$} \\
\hline & $\mathrm{N}^{\mathrm{o}}$ & $\%$ & $\mathrm{~N}^{\circ}$ & $\%$ & $\mathrm{~N}^{\mathrm{o}}$ & $\%$ \\
\hline Triatomineo infectado & 0 & 0,0 & 5 & 8,3 & 5 & 7,8 \\
\hline Triat. Infect + Reag $p /$ sangue hum & 1 & 25,0 & 0 & 0,0 & 1 & 1,6 \\
\hline Reagente para sangue humano & 0 & 0,0 & 32 & 53,3 & 32 & 50,0 \\
\hline Dispensável* & 1 & 25,0 & 1 & 1,7 & 2 & 3,1 \\
\hline Sem informação & 2 & 50,0 & 22 & 36,7 & 24 & 37,5 \\
\hline
\end{tabular}

* Colheita de sangue realizada fora das normas do PCDCh, na ausência de triatomineo infectado por $T$. cruzi e/ou com ingesta reagente para sangue humano.

Os baixos valores referentes à presença de triatomíneo infectado por $T$. cruzi em UDs com pessoas sororreagentes para infecção chagásica, inviabilizaram a análise de possivel associação entre tais condições. 
Os dados sobre vetores, local de captura e hábito alimentar, no SR-10, estão na Tabela 4.5 .9 .7

Tabela 4.5.9.7 - Unidades Domiciliares com e sem presença de sororreagentes para infecção chagásica. de acordo com caracteristicas associadas ao vetor, no Serviço Regional da SUCEN de Presidente Prudente (SR-10), 1984 a 1997

\begin{tabular}{|c|c|c|c|c|c|c|c|c|c|}
\hline \multirow[t]{2}{*}{ Característica } & \multicolumn{3}{|c|}{$\begin{array}{l}\text { UD c/ reag. sorol. } \\
n=4\end{array}$} & \multicolumn{3}{|c|}{$\begin{array}{l}\text { UD s/ reag. sorol. } \\
n=60\end{array}$} & \multicolumn{3}{|c|}{$\begin{array}{l}\text { Total } \\
\mathrm{n}=64\end{array}$} \\
\hline & $N^{\circ}$ & $\%$ & $\% *$ & $\mathrm{~N}^{\circ}$ & $\%$ & $\% *$ & $N^{\circ}$ & $\%$ & $\% *$ \\
\hline \multicolumn{10}{|l|}{ Espécie } \\
\hline P. megistus & 1 & 25,0 & 50,0 & 1 & 1,7 & 2,6 & 2 & 3,1 & 5,0 \\
\hline T. sordida & 1 & 25,0 & 50,0 & 27 & 45,0 & 71,1 & 28 & 43,8 & 70,0 \\
\hline R. neglectus & & & & 10 & 16,7 & 26.3 & 10 & 15,6 & 25,0 \\
\hline sem informação & 2 & 50.0 & & 22 & 36.6 & & 24 & 37,5 & \\
\hline \multicolumn{10}{|l|}{ Fase evolutiva e infecção } \\
\hline Ninfas & 1 & 25,0 & 50,0 & 5 & 8,3 & 20,0 & 6 & 9,4 & 22,2 \\
\hline Ninfas infectadas & & & & 1 & 1.7 & 4,0 & 1 & 1,6 & 3,7 \\
\hline Ninfas e Adultos & & & & 1 & 1,7 & 4,0 & 1 & 1,6 & 3,7 \\
\hline Ninfas e Adultos infect. & 1 & 25,0 & 50,0 & 1 & 1,7 & 4,0 & 2 & 3,1 & 7,4 \\
\hline Adultos & & & & 16 & 26,7 & 64,0 & 16 & 25,0 & 59,3 \\
\hline Adultos infectados & & & & 1 & 1,7 & 4,0 & 1 & 1,6 & 3,7 \\
\hline sem informação & 2 & 50,0 & & 35 & 58,3 & & 37 & 57,7 & \\
\hline \multicolumn{10}{|l|}{ Local de captura } \\
\hline interno & & & & 21 & 35,0 & 84,0 & 21 & 32,8 & 77,8 \\
\hline externo & 1 & 25,0 & 50,0 & 3 & 5,0 & 12,0 & 4 & 6,3 & 14,8 \\
\hline interno e externo & 1 & 25,0 & 50,0 & 1 & 1,7 & 4,0 & 2 & 3,1 & 7,4 \\
\hline sem informação & 2 & 50,0 & & 35 & 58,3 & & 37 & 57,8 & \\
\hline \multicolumn{10}{|l|}{ Hábito alimentar } \\
\hline Sangue humano** & 1 & 25,0 & 50,0 & 32 & 53,3 & 86,5 & 33 & 51,6 & 84,6 \\
\hline Outros*** & 1 & 25,0 & 50,0 & 3 & 5,0 & 8,1 & 4 & 6,2 & 10,3 \\
\hline Não reagente & & & & 2 & 3,3 & 5,4 & 2 & 3,1 & 5,1 \\
\hline sem informação & 2 & 50,0 & & 23 & 38,4 & & 25 & 39,1 & \\
\hline
\end{tabular}

* Percentual calculado excluindo-se as perdas de informação.

** Reagente para Sangue humano sozinho ou associado a outros

*** Outros: reagentes para sangue de ave, cão, gato, roedor ou marsupial. 


\subsubsection{No Serviço Regional da SUCEN de Marília (SR-11)}

O Serviço Regional da SUCEN de Marília (SR-11) é abrangido pela Regiões Administrativas de Marília e de Bauru. Compreende as seguintes Regiões de Governo: Assis. Marília. Ourinhos e Tupã, na primeira, e Bauru, Jaú e Lins, na segunda, com um total de 82 municipios, ocupando $34563 \mathrm{~km}^{2}$ ou 13,90\% do Estado ${ }^{92}$.

Na Tabela 4 5.10 I observa-se que o trabalho de sorologia envolveu, ao todo, menos de $50 \%$ dos municipios existentes, com um número reduzido de focos domiciliares de triatomineos vetores

Tabela 4.5.10.1 - Sorologia de infecção chagasica em Regiões de Governo no Serviço Regional da SUCEN de Marilia (SR-11), 1984 a 1997

\begin{tabular}{lcccc}
\hline Regiào de Governo & $\begin{array}{c}N^{0} \text { Munic } \\
\text { exist }\end{array}$ & $\begin{array}{c}N^{0} \text { Munic } \\
\text { trab }\end{array}$ & $\begin{array}{c}\% \text { Mun } \\
\text { trab. }\end{array}$ & $N^{\circ}$ UDs \\
\hline Assis & 11 & 6 & 54,55 & 23 \\
Marilia & 13 & 4 & 30,77 & 13 \\
Ourinhos & 10 & 10 & 100,00 & 47 \\
Tupã & 11 & 3 & 27,27 & 3 \\
Bauru & 17 & 8 & 47,06 & 16 \\
Jaú & 10 & 2 & 20,00 & 2 \\
Lins & 10 & 6 & 60,00 & 40 \\
\hline \multirow{2}{*}{ TOTAL } & 82 & 39 & 47,56 & 144 \\
\hline
\end{tabular}

No Quadro 4.5.10.1 podem-se visualizar, ainda que de uma forma não quantitativa, os municipios de cada Região de Governo onde se desenvolveram trabalhos de sorologia e naqueles em que houve positividade sorológica. 
Quadro 4.5.10.1 - Municipios com localidades trabalhadas ( $T$ ) e com presença de sororreagentes (TX), no Programa de Controle da Doença de Chagas (PCDCh) do Serviço Regional da SUCEN de Marília (SR-11), 1984-1997.

\begin{tabular}{|c|c|c|c|c|c|c|c|c|c|c|c|c|c|c|}
\hline MUNICIPIO & 1984 & 1985 & 1986 & 1987 & 1988 & 1989 & 1990 & 1991 & 1992 & 1993 & 1994 & 1995 & 1996 & 1997 \\
\hline \multicolumn{15}{|c|}{ RG ASSIS } \\
\hline Assis & $T$ & $T X$ & & & & & & & & & & & & \\
\hline ONPaulista & & & & & $T X$ & & & & & & & & & \\
\hline CMota & $T X$ & $T X$ & & $\bar{T}$ & $T X$ & $T$ & & & & & & & & \\
\hline birarema & & & $T X$ & & $T$ & & & & & & & & & \\
\hline Palmital & & & $T$ & & & & & & & & & & & \\
\hline ParPaulista & $T X$ & & & & & & & & & & & & & \\
\hline \multicolumn{15}{|c|}{ RG MARILIA } \\
\hline Gália & & & & & & & & $T$ & & T & & & & \\
\hline Garça & & & & & $T$ & & & & & & & & & \\
\hline Marilia & & r & $T$ & $T X$ & $T$ & $T$ & & $T$ & & & & & & \\
\hline Pompela & & & $T$ & & & & & & & & & & & \\
\hline \multicolumn{15}{|c|}{ RG OURINHOS } \\
\hline 8 de Camoos & & $T$ & & & & $T$ & & & & & $T$ & $T$ & $T$ & \\
\hline Chavantes & & $T$ & $T$ & & & & & & & & & & & \\
\hline pauçu & & & & $T X$ & & & & & & $T$ & & & & \\
\hline Oleo & & & 1 & & & & & & & & & & & \\
\hline Ournhos & $T$ & $T$ & & & & & $T$ & & & & & & & \\
\hline Rib do Sul & & & $T X$ & & & & & & & $T$ & & & & \\
\hline Salto Grande & & $T$ & $T$ & $T X$ & & $T$ & & & & 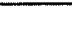 & $T$ & & & \\
\hline StaCruzRioPardo & & $T X$ & $T$ & $T X$ & & & & $T X$ & & $\mathrm{~T}$ & $T X$ & & & \\
\hline Spedro Turvo & & $T x$ & & & & & & & & & & & & \\
\hline Timburn & & $T$ & & $T$ & $T$ & & & & & & $T$ & $T$ & $T$ & \\
\hline \multicolumn{15}{|c|}{ RG TUPA } \\
\hline lacn & & & & & $\mathrm{T}$ & & & & & & & & & \\
\hline Rinópolis & $T$ & & & & & & & & & & & & & \\
\hline Tupā & & & $T$ & & & & & & & & & & & \\
\hline \multicolumn{15}{|c|}{ RG BAURU } \\
\hline Arealva & $T$ & & & & & & & $T$ & & $T$ & & & & \\
\hline Baibinos & & & $T$ & & & & & & & & & & & \\
\hline Bauru & & & $T X$ & & & & & & $T X$ & & & & & \\
\hline CabPaulisia & & $T$ & & & & & & & & & & & & \\
\hline lacanga & & $T$ & & & $T$ & & & & $T$ & & & & & \\
\hline Lucianopolis & & & & & $T X$ & & & & & & & & & \\
\hline Reginopolis & & & $T$ & $T$ & & & & & & & & & & \\
\hline Ubiralara & & $T$ & & & & & & & & & & & & \\
\hline \multicolumn{15}{|c|}{ RG JAU } \\
\hline Barin & & $T$ & & & & & & & & & & & & \\
\hline Dors Corregos & & & & & & & & & & $T$ & & & & \\
\hline
\end{tabular}




\begin{tabular}{|c|c|c|c|c|c|c|c|c|c|c|c|c|c|c|}
\hline MUNICIPIO & 1984 & 1985 & 1986 & 1987 & 1988 & 1989 & 1990 & 1991 & 1992 & 1993 & 1994 & 1995 & 1996 & 1997 \\
\hline \multicolumn{15}{|c|}{ RG LINS } \\
\hline Cafelàndıa & & $T$ & & & & & & & & & & & & \\
\hline Setulina & & & & $T$ & & & & & & & & & & \\
\hline Gualçara & $T$ & $T$ & & & & $\mathrm{~T}$ & & & & & & & & \\
\hline Lins & & & $T$ & & & & & & & $T$ & & & & \\
\hline Promissao & $T X$ & $T x$ & $T$ & $T$ & & & & & & $T X$ & & & & \\
\hline Sabino & & & & $T$ & & & & & & & & & & \\
\hline
\end{tabular}

O Anexo VIII discrimina, por Região de Governo, os municípios da Regional com atividade de sorologia, relacionando-os a numero de localidades existentes e trabalhadas, bem como numero de casas trabalhadas e com presença de sororreagentes, no período 1984-1997 Alguns percentuais mais elevados em alguns municipios, como os verificados na Região de Governo de Assis Campos Novos Paulista, Ibirarema e Paraguaçu Paulista; na Região de Governo de Ourinhos. Ipauçu e Ribeirão do Sul e na RG de Bauru: Bauru e Lucianópolis, por influência de números absolutos trabalhados muito reduzidos, tornam imprecisos os valores obtidos

A Tabela 4 5.102 resume as informações obtidas por Região de Governo Do total de 144 UDs trabalhadas, 23 apresentaram sororreagentes $(16,08 \%)$. Observaram-se percentuais de sororreatividade variando de 0,00 a 8,99 , com uma média para a Regional, de $4,01 \%$ 
Tabela 4.5.10.2 - Distribuição de frequências de localidades existentes e trabalhadas e de UDs trabaihadas e com reagentes sorológicos para infecção chagásica, das Regiões de Governo no Serviço Regional da SUCEN de Marilia (SR-11), 1984 a 1997.

\begin{tabular}{|c|c|c|c|c|c|c|c|c|c|}
\hline \multirow{2}{*}{$\begin{array}{l}\text { Região de } \\
\text { Governo }\end{array}$} & \multicolumn{3}{|c|}{ Localidades } & \multicolumn{2}{|c|}{ UDs } & \multicolumn{3}{|c|}{ Amostras } & \multirow{2}{*}{$\begin{array}{c}\mathrm{IC}^{* *} \\
\text { dos reag. } \\
(\%)\end{array}$} \\
\hline & exist * & trab. & $\%$ trab. & trab. & reag. & trab. & reag. & $\%$ reag & \\
\hline Assis & 224 & 18 & 8,04 & 23 & 7 & 89 & 8 & 8,99 & $4,63-16,75$ \\
\hline Marilia & 421 & 13 & 3,09 & 13 & 1 & 62 & 1 & 1,61 & $0,00-8,59$ \\
\hline Ourinhos & 235 & 34 & 14,47 & 47 & 9 & 190 & 9 & 4,74 & $2,51-8,76$ \\
\hline Tupã & 325 & 3 & 0,92 & 3 & 0 & 12 & 0 & 0,00 & - \\
\hline Bauru & 512 & 14 & 2,73 & 16 & 2 & 70 & 2 & 2,86 & $0,80-9,97$ \\
\hline Jaú & 291 & 2 & 0.69 & 2 & 0 & 5 & 0 & 0,00 & - \\
\hline Lins & 247 & 18 & 7.29 & 40 & 4 & 196 & 5 & 2,55 & $1,09-5,83$ \\
\hline TOTAL & 2255 & 102 & 4.52 & 144 & 23 & 624 & 25 & 4,01 & $2.73-5,86$ \\
\hline
\end{tabular}

* Fonte: SUCEN/DOT/Lista de localidades segundo municipıos por Serviço Regional, 1981-1986.

** IC = Intervalo de Confiança (95\%)

A variação anual da reatividade sorológica está expressa na Tabela 45.103 e reflete o trabalho descontinuado observado nesta Regional. No ano de 1997 não foram recebidas amostras de sangue 
Tabela 4.5.10.3 - Variação anual da sororreatividade para infecção chagásica no Serviço Regional da SUCEN de Marilia (SR-11), 1984 a 1997.

\begin{tabular}{|c|c|c|c|c|c|c|}
\hline Ano & $\begin{array}{c}\mathrm{N}^{\circ} \text { UDs } \\
\text { Trab }\end{array}$ & $\begin{array}{l}\mathrm{N}^{\circ} \mathrm{Am} \\
\text { Exam. }\end{array}$ & $\mathrm{N}^{0}$ Reag. & $\%$ Reag. & $I^{*}(\%)$ & MGTR** \\
\hline 1984 & 14 & 41 & 3 & 7,32 & $2,52-19,43$ & 101,6 \\
\hline 1985 & 30 & 146 & 5 & 3,42 & $1,47-7,77$ & 64,0 \\
\hline 1986 & 21 & 88 & 3 & 3,41 & $1,17-9,55$ & 50,8 \\
\hline 1987 & 14 & 70 & 5 & 7,14 & $3,09-15,66$ & 194,0 \\
\hline 1988 & 12 & 53 & 4 & 7,69 & $3,03-18,17$ & 152,2 \\
\hline 1989 & 8 & 29 & 0 & 0,00 & - & - \\
\hline 1990 & 1 & 1 & 0 & 0,00 & - & - \\
\hline 1991 & 5 & 24 & 1 & 4,17 & $0,74-20,24$ & 64,0 \\
\hline 1992 & 2 & 7 & 0 & 0,00 & - & - \\
\hline 1993 & 26 & 118 & 3 & 2,54 & $0,87-7,21$ & 50,8 \\
\hline 1994 & 4 & 21 & 1 & 4,76 & $0,85-22,67$ & 64,0 \\
\hline 1995 & 4 & 13 & 0 & 0,00 & - & - \\
\hline 1996 & 3 & 13 & 0 & 0,00 & - & - \\
\hline 1997 & 0 & 0 & - & - & - & - \\
\hline TOTAL & 144 & 624 & 25 & 4,01 & $2,73-5,86$ & 91,8 \\
\hline
\end{tabular}

$\mathrm{Na}$ Tabela 4 5.104 estão apresentados os resultados dos exames sorológicos para infecção chagásica, segundo grupo etário e sexo da população envolvida, durante o período especificado

Tabela 4.5.10.4 - Sorologia para infecção chagásica, por grupos etários e sexo, em população de municípios no Serviço Regional da SUCEN de Marilia (SR-11), 1984 a 1997.

\begin{tabular}{|c|c|c|c|c|c|c|c|c|c|}
\hline \multirow{2}{*}{$\begin{array}{r}\text { Grupo } \\
\text { etário } \\
\text { (anos) }\end{array}$} & \multicolumn{3}{|c|}{ Feminino } & \multicolumn{3}{|c|}{ Masculino } & \multicolumn{3}{|c|}{ Total } \\
\hline & $\begin{array}{c}N^{\circ} \\
\text { exam }\end{array}$ & $\begin{array}{c}N^{\circ} \\
\text { Reag. }\end{array}$ & $\begin{array}{c}\% \\
\text { Reag. }\end{array}$ & $\begin{array}{c}\mathrm{N}^{\circ} \\
\text { exam. }\end{array}$ & $\begin{array}{c}N^{\circ} \\
\text { Reag. }\end{array}$ & $\begin{array}{c}\% \\
\text { Reag. }\end{array}$ & $\begin{array}{c}N^{\circ} \\
\text { exam. }\end{array}$ & $\begin{array}{c}\mathrm{N}^{\circ} \\
\text { Reag. }\end{array}$ & $\begin{array}{c}\% \\
\text { Reag. }\end{array}$ \\
\hline$<1$ & 3 & 0 & 0,00 & 0 & 0 & 0,00 & 3 & 0 & 0,00 \\
\hline $1-4$ & 30 & 0 & 0,00 & 28 & 0 & 0,00 & 58 & 0 & 0,00 \\
\hline $5-9$ & 38 & 0 & 0,00 & 33 & 0 & 0,00 & 71 & 0 & 0,00 \\
\hline $10-14$ & 39 & 0 & 0,00 & 49 & 0 & 0,00 & 88 & 0 & 0,00 \\
\hline $15-19$ & 33 & 0 & 0,00 & 36 & 0 & 0,00 & 69 & 0 & 0,00 \\
\hline $20-29$ & 48 & 0 & 0,00 & 47 & 0 & 0,00 & 95 & 0 & 0,00 \\
\hline $30-39$ & 41 & 4 & 9,76 & 48 & 4 & 8,33 & 89 & 8 & 8,99 \\
\hline $40-49$ & 38 & 7 & 18,42 & 37 & 3 & 8,11 & 75 & 10 & 13,33 \\
\hline $50-59$ & 17 & 4 & 23,53 & 23 & 1 & 4,35 & 40 & 5 & 12,50 \\
\hline $60-69$ & 9 & 0 & 0,00 & 16 & 1 & 6,25 & 25 & 1 & 4,00 \\
\hline$\geq 70$ & 5 & 1 & 20,00 & 6 & 0 & 0,00 & 11 & 1 & 9,09 \\
\hline Total & 301 & 16 & 5,33 & 323 & 9 & 2,79 & 624 & 25 & 4,01 \\
\hline
\end{tabular}


As idades variaram de 2 meses a 97 anos, com uma média de 25,96 anos, mediana de 22,00 anos e $75 \%$ da população trabalhada com até 39 anos. Observa-se que a reatividade sorológica inicia-se a partir do grupo etário 30 - 39 anos e que os grupos etários inferiores representaram $61,48 \%$ da população examinada. Teste de diferença entre proporções não revelou diferença significante de reatividade sorológica entre os sexos $\left(\mathrm{IC}_{0.05}=-0,0054-0,0563\right), \mathrm{p}=0,105$

$\mathrm{Na}$ Tabela 4 5.10.5 estão os resultados relacionados com o tipo de atividade (rotina ou notificação) nos dois grupos de UDs assim constituídos: com e sem presença de reagentes sorológicos

Tabela 4.5.10.5 - Unidades Domiciliares com e sem presença de sororreagentes para infeç̧ão chagasica. de acordo com o tipo de atendimento, no Serviço Regional da SUCEN de Marilia (SR-11), 1984 a 1997

\begin{tabular}{|c|c|c|c|c|c|c|}
\hline \multirow{2}{*}{ Atendimento } & \multicolumn{2}{|c|}{$\begin{array}{l}\text { UD c/ reag. sorol } \\
(n=23)\end{array}$} & \multicolumn{2}{|c|}{$\begin{array}{l}\text { UD s/ reag. sorol. } \\
\qquad(n=121)\end{array}$} & \multicolumn{2}{|c|}{$\begin{array}{c}\text { Total } \\
(n=144)\end{array}$} \\
\hline & $N^{\circ}$ & $\%$ & $\mathrm{~N}^{0}$ & $\%$ & $\mathrm{~N}^{\circ}$ & $\%$ \\
\hline Notificação & 5 & 21,74 & 22 & 18,33 & 27 & 18,88 \\
\hline Rotina & - & - & 1 & 0,83 & 1 & 0,70 \\
\hline Sem informação & 18 & 78,26 & 97 & 80,84 & 117 & 80,42 \\
\hline
\end{tabular}

Das 144 UDs com focos domiciliares de triatomíneos vetores, nas condições necessárias para desencadear sorologia dos moradores, foi possivel obter informações apenas parciais sobre os triatomineos capturados quanto à espécie, fase evolutiva, infecção por $T$. cruzi, local de captura e resultado de identificação de hábito alimentar. Essas informações estão na Tabela 4.5.10.6, segundo a presença ou ausência de reagentes sorológicos 
Tabela 4.5.10.6 - Unidades Domiciliares com e sem presença de sororreagentes para infecção chagásica, de acordo com características associadas ao vetor, no Serviço Regional da SUCEN de Marilia (SR-11), 1984 a 1997.

\begin{tabular}{|c|c|c|c|c|c|c|c|c|c|}
\hline \multirow[t]{2}{*}{ Caracteristica } & \multicolumn{3}{|c|}{$\begin{array}{l}\text { UD c/ reag. sorol. } \\
n=23\end{array}$} & \multicolumn{3}{|c|}{$\begin{array}{l}\text { UD s/ reag. sorol. } \\
n=121\end{array}$} & \multicolumn{3}{|c|}{$\begin{array}{l}\text { Total } \\
n=144\end{array}$} \\
\hline & $\mathrm{N}^{\circ}$ & $\%$ & $\% *$ & $\mathrm{~N}^{\mathrm{o}}$ & $\%$ & $\% *$ & $\mathrm{~N}^{\mathrm{o}}$ & $\%$ & $\% *$ \\
\hline \multicolumn{10}{|l|}{ Espécie } \\
\hline P. megistus & 5 & 21,7 & 33,3 & 28 & 23,3 & 40,7 & 33 & 23,1 & 39,3 \\
\hline T. sordida & 4 & 17,4 & 26,7 & 24 & 20,0 & 34,8 & 28 & 19,6 & 33,3 \\
\hline R. neglectus & 6 & 26,1 & 40,0 & 17 & 14,2 & 24,6 & 23 & 16,1 & 27,4 \\
\hline sem informação & 8 & 34,8 & & 52 & 42,5 & & 60 & 41,3 & \\
\hline \multicolumn{10}{|l|}{ Fase evolutiva e infecção } \\
\hline Ninfas & & & & 1 & 0,8 & 2,4 & 1 & 0,7 & 2,1 \\
\hline Ninfas infectadas & & & & 1 & 0,8 & 2,4 & 1 & 0,7 & 2,1 \\
\hline Ninfas e Adultos & 1 & 4,3 & 14,3 & 4 & 3,3 & 9,8 & 5 & 3,5 & 10,4 \\
\hline Ninfas e Adultos infect. & & & & 1 & 0,8 & 2,4 & 1 & 0,7 & 2,1 \\
\hline Adultos & 5 & 21,7 & 71,4 & 26 & 21,7 & 63,4 & 31 & 21,7 & 64,6 \\
\hline Adultos infectados & 1 & 4,4 & 14,3 & 8 & 6,7 & 19,5 & 9 & 6,3 & 18,7 \\
\hline sem informação & 16 & 69,6 & & 80 & 65,8 & & 96 & 66,4 & \\
\hline \multicolumn{10}{|l|}{ Local de captura } \\
\hline interno & 6 & 26,1 & 85,7 & 36 & 30,0 & 87,8 & 42 & 29,4 & 87,5 \\
\hline externo & & & & 1 & 0,8 & 2,4 & 1 & 0,7 & 2,1 \\
\hline interno e externo & 1 & 4,3 & 14,3 & 4 & 3,3 & 9,8 & 5 & 3,5 & 10,4 \\
\hline sem informação & 16 & 69,6 & & 80 & 65,9 & & 96 & 66,4 & \\
\hline \multicolumn{10}{|l|}{ Hábito alimentar } \\
\hline Sangue humano** & 13 & 56,5 & 100,0 & 51 & 42,5 & 85,0 & 64 & 44,8 & 87,7 \\
\hline Outros $* * *$ & & & & 8 & 6,7 & 13,3 & 8 & 5,6 & 10,9 \\
\hline Não reagente & & & & 1 & 0,8 & 1,7 & 1 & 0,7 & 1,4 \\
\hline sem informação & 10 & 43,5 & & 61 & 50,0 & & 71 & 48,9 & \\
\hline
\end{tabular}

* Percentual calculado excluindo-se as perdas de informação.

** Reagente para Sangue humano sozinho ou associado a outros.

*** Outros: reagentes para sangue de ave, cão, gato, roedor ou marsupial.

Considerando-se as condições que desencaderiam o exame sorológico da população, observamos que o resultado reagente para sangue humano predominou sobre a infecção do triatomineo vetor, nas UDs com e sem presença de sororreagentes (Tabela 4.5.10.7). 
Tabela 4.5.10.7 - Condições para execução de exame sorológico, segundo presença ou ausência de sororreagentes para infecção chagásica, em UDs no Serviço Regional da SUCEN de Marilia (SR-11), 1984 a 1997

\begin{tabular}{|c|c|c|c|c|c|c|}
\hline \multirow[t]{2}{*}{ Condição para gerar sorologia } & \multicolumn{2}{|c|}{$\begin{array}{c}\text { UD c/ reag. } \\
\text { sorol. } \\
(n=23)\end{array}$} & \multicolumn{2}{|c|}{$\begin{array}{l}\text { UD s/ reag. } \\
\text { sorol. } \\
(n=121)\end{array}$} & \multicolumn{2}{|c|}{$\begin{array}{c}\text { Total } \\
(n=144)\end{array}$} \\
\hline & $\mathrm{N}^{\circ}$ & $\%$ & $N^{0}$ & $\%$ & $N^{\circ}$ & $\%$ \\
\hline Triat infectado & 0 & 0,0 & 17 & 14,2 & 17 & 11,9 \\
\hline Triat infect + Reag p/ sangue hum. & 1 & 4,3 & 0 & 0,0 & 1 & 0,7 \\
\hline Reag p/ sangue hum. & 12 & 52,2 & 51 & 42,5 & 63 & 44,0 \\
\hline Dispensável* & 0 & 0,0 & 1 & 0,8 & 1 & 0,7 \\
\hline Sem informação & 10 & 43.5 & 52 & 42,5 & 62 & 42,7 \\
\hline
\end{tabular}

* Colheita de sangue realizada fora das normas do PCDCh, na ausência de triatomineo infectado por $T$. cruzi e/ou com ingesta reagente para sangue humano

Obteve-se um valor de "odds ratio" $=0,25595^{\circ}$. $0,031-2,107$, denotando que não houve diferença entre expostos e não expostos (dados da Tabela 4.5.10.8)

Tabela 4.5.10.8 - Encontro de reagentes e de não reagentes sorológicos para infecção chagásica em UDs com e sem presença de triatomíneo infectado por T. cruzi, no Serviço Regional da SUCEN de Marília (SR-11), 1984 a 1997.

\begin{tabular}{ll|cc|c}
\hline \multicolumn{2}{c|}{ Característica } & \multicolumn{2}{|c|}{ UD com presença de morador } & Total \\
& & Sororreagente & Negativo & \\
\hline $\begin{array}{l}\text { UD com } \\
\text { triatomineo }\end{array}$ & $\begin{array}{l}\text { infectado por } T . \\
\text { cruzi } \\
\text { não infectado } \\
\text { por T. cruzi }\end{array}$ & 1 & 17 & 18 \\
\hline & 12 & 52 & 64 \\
\hline
\end{tabular}




\section{DISCUSSÃO}

A partir de 1972 a SUCEN adquiriu autonomia para a execução de reações sorológicas aplicadas ao diagnóstico da infecção chagásica, quando foram estabelecidas prioridades para o controle de triatomineos vetores. Para aquilatar os efeitos da campanha de controle do vetor, de acordo com o recomendado em tais situações (DIAS ${ }^{64}$ 1967), foi proposta a continuidade da avaliação iniciada por GUARITA et al. ${ }^{96}(1978)$, determinandose a sororreatividade em crianças nascidas após a fase de "arrastão", levada a efeito entre 1965 e 1967.

Nessa investigação, a população-alvo era constituida por escolares da primeira série do primeiro grau de escolas da zona rural do Estado tendo, em media, 8 anos de idade em 1973, a época do inicio do trabalho. Eram, portanto, nascidos em 1965. Os valores percentuais de reatividade mostraram tendência a decréscimo até 1975. Nesses três primeiros anos, portanto, as crianças incluídas na pesquisa eram nascidas ainda na vigência da fase "arrastão" e, sendo 9 anos a média de idade das sororreagentes, estas eram nascidas, em 1973, anteriormente àquela fase, justificando-se o percentual mais elevado nesse ano. A evolução do comportamento sorológico dessa população durante os anos subsequentes, mantendo-se baixos até 1982 e tornando-se negativos em 1983 (Figura 4.1.2), ocasião em que o controle dos vetores no Estado encontrava-se na fase de "consolidação das atividades de vigilância entomológica", reflete nitidamente o efeito da fase de "arrastão".

Exemplos de avaliações semelhantes foram citados em estudos de controle e vigilância da doença de Chagas por DIAS ${ }^{65}$ (1974), em Bambuí, MG, e por MARSDEN et al. ${ }^{125}$ (1994), em Mambai, GO. No primeiro caso, o autor observou sensivel diminuição de prevalência sorológica nos grupos etários representados por crianças em idade escolar, entre 1963 e 1974, após adoção de expurgos sistemáticos na área, em relação a períodos anteriores, da década de 50. Em áreas circunvizinhas e epidemiologicamente semelhantes quanto a aspectos fisicos, sociais e culturais para a transmissão da doença de Chagas, e que não haviam recebido tratamento químico anti-triatomínico continuado, demonstrou DIAS ${ }^{65}$ (op. cit.), para esse grupo etário, percentuais de positividade quatro a cinco vezes maiores 
do que nas áreas tratadas com regularidade. No segundo caso, de Mambai, GO, verificou-se queda de $15,5 \%$ para $2,2 \%$ da soropositividade entre crianças menores de 8 anos, respectivamente antes e após a fase de ataque aos triatomíneos

No Estado de São Paulo, a redução da reatividade sorológica para infecção chagásica, entre escolares dos municípios selecionados, foi evidente logo no primeiro inquérito, mesmo considerando que, em algumas situações, os valores de prevalência apresentados entre 1968 e 1970 por GUARITA et al. ${ }^{96}$ (op. cit.) estivessem superestimados, como resultado de cobertura amostral insuficiente (Tabela 4.1.1). Tomando-os como pontos de referência, tal redução foi mais expressiva -- nesta ordem - nos municípios pertencentes aos SRs de Presidente Prudente, São José do Rio Preto, Ribeirão Preto, Sorocaba, Marilia e Araçatuba. A exceção observada foi o SR de Campinas, em que o percentual médio de positividade entre os municípios selecionados sofreu pequeno aumento (de $0.68 \%$ para $0,96 \%$ ). (Tabelas 4.1 .1 e 4.1 .2 .1 ).

Durante a década de 70 , dentre os SRs, o de Sorocaba destacou-se quanto à sororreatividade observada no inquérito escolar, contribuindo como a maior parcela da soma dos valores obtidos em cada um deles (Tabela 4.1.2.3). Mesmo após a fase "arrastão", todos os 6 municípios selecionados deste SR permaneciam em PI; Itaí passaria à PIII apenas em 1981. Portanto, os trabalhos de busca de vetores e de desinsetização continuaram a ser realizados naquele SR durante todo o período do inquérito escolar. A Região de Sorocaba terá um destaque especial nesta discussão, pois foi alvo de trabalho soroepidemiológico mais abrangente em alguns de seus municipios, motivado pela permanência intradomiciliar de $T$. infestans ainda nos primeiros anos da década de 1970.

Dentre os municípios dos demais SRs, à exceção daqueles aos quais não se aplicava esse tipo de classificação, como nos de São Vicente e de Taubaté, 23 estavam em PI $(54,8 \%), 11$ em PII (26,2\%) e 8 em PIII (19,0\%). Ao encerramento do inquérito escolar, em 1983, 5 deles (11,9\%) - todos da Região de Sorocaba - permaneciam em PI, 21 (50,0\%) em PII e $16(38,1 \%)$ em PIII (Tabela 4.1.2.1)

No SR-2 (São Vicente), área "indene", com 1,2\% de sororreatividade em 1970 (Tabela 4.1.1), observamos uma variação de 0,1 a 1,4\% ao longo de 1973-1983: média 
igual a 0,3\%. Apenas em 1978 e 1983 é que os percentuais se tornaram nulos. Os municípios de Itariri e Juquiá responderam pela maior parte dos casos. É interessante notar que a investigação preliminar logrou classificá-los, na maioria, como importados (Tabela 4 1.2.6), corroborando a informação de crescimento populacional da Região de Registro, na década de 70 , por um componente migratório de quase $40 \%{ }^{92}$, de áreas brasileiras endêmicas para doença de Chagas

Ressalte-se a descoberta, em 1980, de um caso autóctone, cuja transmissão foi atribuida a contaminação por manipulação de carcaças de mamiferos silvestres, no município de Cananeia (FORATTINI et $a l .{ }^{85}$ 1981). Através de colheitas de sangue sucessivas foi possivel verificar a subida nos títulos sorológicos de 40 para 160 e 520 . Nas mesmas ocasiões, as amostras de familiares da escolar não apresentaram resultados reagentes para infecção chagásica, denotando a importância da investigação epidemiológica, que neste caso envolveu, além da SUCEN, a Universidade de São Paulo e o Setor de Xenodiagnóstico do Instituto "Dante Pazzanese" de Cardiologia ${ }^{85}$. Este e outro caso de criança anteriormente verificado no municipio (FORATTINI et al. ${ }^{84} 1980$ ), indicaram aos autores a hipótese da existência da tripanosomíase americana em nivel endêmico na região

No restante do Estado, entretanto, as respostas foram distintas no que diz respeito às investigações: predominaram os casos autóctones na Região de Sorocaba, enquanto que nas demais houve certo equilibrio entre autóctones e importados (Tabela 4.1.2.6). A Região de Sorocaba não apresentou, entre as décadas de 60/70, diminuição de sua população rural como foi observado em outras (SILVA ${ }^{189} 1981$ ), sendo os dados sobre crescimento populacional por componente migratório, na década de 70 , importantes apenas nas regiões de Campinas e Ribeirão Preto ${ }^{92}$.

É presumível a ocorrência de casos de infecção adquiridos pela via congênita, incluída nos conjuntos classificados como autóctone, importado e no inconclusivo, em decorrência da observação da investigação preliminar realizada entre familiares e vizinhos dos estudantes sororreagentes. A presença de mães sororreagentes $(n=38)$, dentre os casos em que a informação sobre o grau de parentesco era disponivel e também naqueles em que se colheu o sangue das mães $(n=76)$ representa, em área endêmica, dificuldade para essa 
distinção, sem contar com a possibilidade de transmissão de segunda geração, como assinalado por SCHENONE et al. ${ }^{170}$ (1987). DIAS ${ }^{65}$ (1974) e MARSDEN et al. ${ }^{125}$ (1994) supõem que pode ser baixa a ocorrência de casos de transmissão congênita nessas situações.

De qualquer modo, é lícito admitir-se a possibilidade de interrupção da transmissão vetorial antes do "arrastão", pelo menos nos municipios que apresentaram percentuais nulos de positividade nas Regionais de Campinas: Iracemápolis, Itapira e Mogi Guaçu; de Ribeirão Preto: Luiz Antônio, Restinga e Ribeirão Corrente, de São José do Rio Preto Macaubal e Paraiso; de Araçatuba: Guararapes, Penápolis e Piacatu e de Presidente Prudente: Mariápolis e Salmorão, mostrados na Tabela 4.1.2.1 enquanto que, o inquérito de GUARITA et al. $^{96}(1978)$, apresentava os seguintes valores de positividade: Iracemápolis, 3,23\%: Itapira, 0,42\%, Mogi Guaçu, 0,85\%; Luiz Antônio, 5,55\%; Restinga, 20,00\%; Ribeirão Corrente, 12,50\%, Macaubal, 12,50\%; Paraiso, 10,53\%; Guararapes, 0,69\%; Penápolis, 0,55\%, Piacatu, 1,03\%, Mariápolis, 8,33\% e Salmorão, 5,40\%. Embora seja dificil atribuir essas quedas, tomadas isoladamente nesses municipios, ao reflexo das atividades, mesmo descontinuadas e sem grande abrangência, do combate ao vetor ocorridas anteriormente à fase de "arrastão", que se sabe contribuiram também para a diminuição de infecção de $T$. infestans por $T$. cruzi, exceto nas regiões de Marilia e de Sorocaba (BURALLI $^{25}$ 1985), os dados também são consistentes com a tese defendida por SILVA ${ }^{189}$ (1981), sobre a interrupção da transmissão vetorial da doença de Chagas ter ocorrido naquelas áreas geográficas do meio rural paulista, após desarticulação complexa de sua estrutura agrária.

A análise das datas de nascimento dos escolares reagentes, dos quais foi possível obter informações, e dos autóctones (Tabelas 4.1.2.5 e 4.1.2.6), revela que, até 1974, ainda poderia registrar-se transmissão vetorial no Estado, considerando-se a maior probabilidade de transmissão na infầncia (DIAS ${ }^{66} 1982$ )

A consolidação dos resultados obtidos no último ano do inquérito escolar, em 1983, poderia ter sido observada, mantendo-se o estudo por mais alguns anos. Mudanças de municípios que seguidamente forneceram resultados negativos, por outros apontados pelo próprio Serviço Regional, segundo suas prioridades em rotina, ou mesno por notificações 
de triatomineos, seriam indicadas. A investigação minuciosa de casos reagentes sorológicos complementaria a análise epidemiológica.

Os 54 municípios do inquérito escolar observados durante a continuação dos trabalhos de sorologia até 1997 foram incluidos em investigações de focos domiciliares de triatomíneos vetores. Os de área "indene”, da Regional de São Vicente, estiveram presentes quase que anualmente, em decorrência de notificações existentes (Quadro 4.5.3.1), confirmando um padrão de transmissão ou de origem de casos autóctones distinto do das demais regiões. Esta área merecerá consideração à parte na discussão, por ter sido abordada como controle negativo na metodologia sorológica. Nos municipios da Regional de Taubaté, também considerada indene, até o ano de 1997 não houve notificação de triatomíneos vetores que justificasse colheita de sangue de moradores para o diagnóstico sorológico da infecção chagásica

Na Regional de Sorocaba, em todos os municípios, houve encontro de triatomíneos vetores em domicilios humanos, com as características necessárias ao desencadeamento de atividades de sorologia: Itaí (até 1985), Paranapanema (até 1990), Itaporanga (até 1993) e Coronel Macedo (até 1995) - da Região de Governo Avaré e Itaberá e Riversul (até 1994), ambos da Região de Governo Itapeva (Quadro 4.5.4.1). Todavia não foram assinaladas pessoas sororreagentes com idades inferiores a 15 anos (Quadro 4.5.4.2).

Em Campinas (SR-5), os municipios de Caconde, Itapira e Mogi Guaçu tiveram Unidades Domiciliares notificantes. No primeiro foram colhidas amostras para exame sorológico até 1997 e, nos dois seguintes, até 1994 (Quadro 4.5.5.1). Nos municípios de Atibaia, Conchal e Iracemápolis a programação de sorologia não foi realizada desde 1984.

Da Regional de Ribeirão Preto, os municípios Ribeirão Corrente, Miguelópolis e Guariba tiveram trabalhos de sorologia associados a notificações de triatomíneos vetores, respectivamente em 1984, 1985 e 1987. Aramina, Luiz Antônio e Restinga estiveram ausentes dessa programação (Quadro 4.5.6.1)

Da Regional de São José do Rio Preto, todos os 6 municipios participaram de sorologia de moradores em casas notificantes: Estrela d'Oeste, até 1988; Dolcinópolis, 
Macaubal e São Francisco, até 1991; Paraiso, até 1993 e União Paulista, até 1994 (Quadro 4.5.7.1)

Também na Região de Araçatuba, todos os 6 municípios forneceram amostras para exames sorológicos: Auriflama, até 1985, Guararapes e Pereira Barreto, até 1987 e Penápolis, Piacatu e Sud-Menucci, até 1988 (Quadro 4.5.8.1)

Da Região de Presidente Prudente, apenas Iepê e Rancharia foram trabalhados até 1989, Estrela do Norte, João Ramalho, Mariápolis e Salmorão estiveram ausentes (Quadro 4.5.9.1)

Na Região de Marilia ocorreram exames sorológicos até 1986 em Palmital, e até 1989 em Cândido Mota, Lutécia e Oscar Bressane não forneceram material para análise e 2 municipios passaram a pertencer ao SR-4: Fartura e Taguai, trabalhados até 1990 e 1996, respectivamente (Quadros 4.5.4.1 e 4.5.10.1)

A despeito de falhas na cobertura e das dificuldades do cumprimento da programação de rotinas de buscas de triatomíneos nas Unidades Domiciliares nos SRs, em nenhum dos 54 municípios anteriormente envolvidos no inquérito escolar foi revelada sororreatividade para infeç̧ão chagásica nas idades inferiores a 15 anos, até o ano de 1997.

\section{A Região de Sorocaba}

A Região de Sorocaba constituiu, por certo tempo, um excelente campo de investigação e estudo da transmissão da doença de Chagas no Estado. Envolvendo aspectos de natureza soro-epidemiológica, dois estudos destacaram-se nessa região, ainda na década de 1970, desenvolvidos simultaneamente ao inquérito entre escolares. O primeiro, no municipio de Taquarituba, pertencente à Região de Governo Avaré, entre os anos de 1974 e 1976; o segundo nos dez municípios da microrregião homogênea Campos de Itapetininga, entre 1976 e 1978 .

SILVA $^{190}$ (1986) aventou a possibilidade de a doença ter-se estabelecido nessa região independentemente da "marcha para o oeste", processo observado alhures no Estado e correspondente ao desbravamento de fronteiras agricolas ocorrido entre fins do século 19 e metade do século 20. A introdução do vetor $T$. infestans fora provavelmente uma 
consequència do comercio de muares e equinos vindos do sul do continente para o polo comercial de Sorocaba ${ }^{91}$. A Depressão Periférica, onde se situavam os municípios estudados, era definida como area de passagem, em que a difusão da doença encontrou condições favoráveis, dado o sistema peculiar de produção agrária baseado no trabalho assalariado, concentrado na cafeicultura ${ }^{17.190}$ O café beneficiado foi produto de destaque na economia dos municípios, ao lado do milho e do arroz em casca ${ }^{91}$, por ocasião dos inquéritos soroepidemiológicos de 1974/1976, o café deixara de ser o produto principal, substituído pelo milho ${ }^{167}$. Tal tendência aconteceu em todo o Estado de São Paulo ${ }^{17,190}$ Entre 1950 e 1957, no município de Taquarituba, a infecção de T. infestans por T. cruzi correspondia a 17,2\% (CODA et al. ${ }^{48}$ 1958). Praticamente a mesma proporção $(17,9 \%)$ havia sido observada por ALVES e NODA ${ }^{6}$ (1964), de 1950 a 1961

Durante a década de 60 , intensificou-se a transformação do espaço agrário paulista, com o deslocamento da população rural para as cidades ${ }^{17,190}$. Trabalhadores temporários e maquinaria substituiram a força local de trabalho, fato que, a par do controle químico dos vetores, possivelmente contribuiu para reduzir a transmissão natural da doença de Chagas em São Paulo. Um dos objetivos da ação contra o vetor fora incentivar a retomada da atividade agricola nas décadas de 50 e 60 , com a "marcha para o leste" dos agricultores. Em muitos municipios da Região de Sorocaba, entretanto, a população havia sofrido pequena variação (-1,2\%, uma das menores do Estado) entre os anos de 1960 e 1970, portanto, o êxodo rural foi menos marcante (SILVA ${ }^{190}$ 1986). Os dados referentes aos nascidos em Taquarituba mostram população nativa estável, migração infrequente de e para outros Estados e mobilidade restrita aos municípios das vizinhanças.

Estimou-se haver, no inicío da década de 50, 66,7\% de sororreagentes entre os habitantes do municipio de Taquarituba. Embora naquela ocasião a colheita de amostras de sangue estivesse restrita aos residentes das casas infestadas por triatomíneos ${ }^{111 .}{ }^{202}$, foi possivel observar que a sororreatividade reduziu-se 5 vezes em 25 anos no município como um todo e 30 vezes no grupo etário de até 10 anos - de $41,7 \%$ para 1,4\% ( 13 casos/940 amostras examinadas). No passado, a proporção de sororreagentes fora maior neste grupo porque, como acentuaram UNTI et al. ${ }^{203}$ (1952), as crianças, permanecendo dentro das 
casas por mais tempo e indo dormir mais cedo que os adultos, serviam de "anteparo protetor aos maiores das casas" por serem picados em primeiro lugar, saciando os triatomíneos.

A análise dos dados soroepidemiológicos relacionados com o grupo etário inferior indica a interrupção da transmissão natural da doença de Chagas em Taquarituba no fim da década de 60. Apesar da sororreatividade em duas crianças de 6 anos (nascidas em 1968), esta não foi demonstrada em crianças de menos idade. De fato, foi assinalada sororreatividade em uma criança de 5 meses de idade, filha de mãe sororreagente Resultados subsequentes, duvidosos e negativos, permitiram atribuir a sororreatividade inicial a anticorpos maternos circulantes

$\mathrm{Na}$ Região de Sorocaba, o declínio da doença de Chagas, segundo CALDAS JR. ${ }^{26}$ (1980), foi acentuadamente influenciado pelo controle quimico de triatomíneos. A densidade da população de triatomineos, infectados ou não, mostrou-se também significantemente correlacionada com a incidência da doença de Chagas, como foi demonstrado em áreas endêmicas nos Estados de Minas Gerais, por DIAS ${ }^{65}$ (1974) e da Bahia, por PIESMAN et $a l^{144}$ (1985). Em Taquarituba, foi demonstrada infecção por $T$. cruzi em 13,3\% dos triatomineos capturados nas casas e $5,1 \%$ dos capturados nos anexos, durante o ano de 1968. Em 1974, exemplares de T. infestans foram capturados em 6 de 575 casas e 2 de 871 anexos: 16 no primeiro caso e 7 no segundo. Os vetores intradomiciliares revelaram-se infectados na proporção de 6,6\% (MELLO et al. ${ }^{128} 1977$ ). Naquela ocasião encontrou-se apenas um exemplar de $P$. megistus intradomiciliar (infectado por $T$. cruzi). De acordo com BURALLI ${ }^{25}$ (1985), a captura de 10 exemplares de T. infestans por 100 casas e infecção da ordem de $1,5 \%$ deles por $T$. cruzi, representam boa situação de controle. Deste modo, a despeito da presença residual de vetores, as condições epidemiológicas em Taquarituba indicavam a possibilidade de controle da transmissão da doença de Chagas.

A distribuição de frequências de sororreagentes mostrou aumentos regulares associados às idades das pessoas nascidas entre 1947 e 1970 (6 a 29 anos). No grupo etário de 30 a 39 anos (nascidos entre 1935 e 1946, antes da campanha de combate ao vetor) a sororreatividade mostrou sua proporção mais elevada. Entre os indivíduos com mais de 39 anos (nascidos entre 1898 e 1934), as proporções de sororreatividade tornaram-se 
irregulares (Tabela 4.2.3). Isto pode ter sido causado por perda natural de anticorpos ${ }^{224}$, menor exposição ao agente etiológico ou morte por doença de Chagas. Segundo SILVA ${ }^{190}$ (1986), a transmissão natural da doença de Chagas foi mais freqüente, em território paulista, por volta de 1950. Contudo, os achados sorológicos para Taquarituba não confirmam essa colocação. Há também a ponderar o fato de que, no intervalo entre 1950 e 1958, a campanha de combate ao vetor foi descontínua e, portanto, insuficiente para interromper a transmissão. Apesar disso, diminuiu a proporção de sororreagentes nos grupos etários entre 15 e 26 anos. Ao uso intensivo de inseticidas (fase "arrastăo"), durante o período entre 1965 e 1967, seguiu-se acentuada redução do número de sororreagentes com idades entre 7 e 11 anos. A ausência de sororreagentes no grupo etário mais baixo é indicação do sucesso da campanha Em território brasileiro, excluindo-se São Paulo, AKHAVAN ${ }^{1}$ (2000) constatou, no inquerito sorológico de 1975 a 1980, uma curva ascendente até a idade de 25 anos, seguida de declínio e ascensão nas idades maiores, atribuídos a períodos de controle descontinuados, em que se observaram incidências nos intervalos entre atividades de prevenção e controle. Em área em que se desconhecem as medidas de controle de vetor, PUIGBÓ et al. ${ }^{148}$ (1969), na Venezuela, observaram uma curva contínua, ascendente com a idade, do tipo modelo de transmissão sem descontinuidade; entretanto, as incidências foram inversamente proporcionais à idade, para o quê não encontraram justificativa razoável.

A longa permanência das pessoas em uma mesma casa (a atual) reflete a estabilidade da população na área, embora a mobilidade interna não tenha sido levada em conta. A média e a mediana do tempo de permanência das pessoas de sororreagentes em uma mesma casa foram, para os nascidos em Taquarituba, de 14,5 e 16,8 anos, respectivamente. Observou-se autoctonia da ordem de 97,1\% no Estado de São Paulo e de 95,3\% na Região de Sorocaba (Tabela 4.2.2). Só uma pequena proporção dessas pessoas $(3,8 \%)$ procedia de outros Estados do Brasil ( $n=11$ ). Deste modo, a idade (tempo de permanência na casa), equivalente a exposição ao risco, foi tratada como dose e a proporção de sororreagentes dentro de cada grupo etário, a resposta. A relação dose-resposta foi estimada por meio de cálculo de probitos. Na ausência de medidas de controle da transmissão, seria de esperar que, à idade de 26 anos (tempo de exposição), cerca de $25 \%$ dos habitantes da região seriam sororreagentes e, à idade de 51 anos, cerca de $50 \%$. Este último valor é menos preciso por 
ter sido calculado por extrapolação (Fig. 4.2). Tais percentagens dão uma idéia da gravidade da situação em Taquarituba, àquela época.

Dos municípios da Microrregião Campos de Itapetininga, Itararé foi o que apresentou menor percentual de sororreatividade (2,89\%); Itaporanga, o maior: $19,22 \%$ (Tabela 4.3.1.1). Com exceção de uma localidade, das 55 trabalhadas nos 10 municípios, a população examinada apresentou sororreatividade para infecção chagásica variável de $0,22 \%$ até $33,15 \%$ (Tabela 4.3.1.2). Na década de 50, UNTI e SILVA ${ }^{202}$ (1952) demonstraram, para os municipios de Angatuba, Itapetininga e Itaporanga (que incluía os então Distritos de Barão de Antonina e Ribeirão Vermelho do Sul) ${ }^{91}$, os valores de $27,69 \%$, $15,15 \%$ e $30,36 \%$ de positividade para a infecção chagásica, respectivamente. Em Itapeva e Itararé, não observaram positividade; entretanto, a amostra examinada foi insuficiente para representar o quadro real das repercussões humanas da transmissão da doença de Chagas. Nos municípios de Buri e Guareí não foram examinadas amostras de sangue da população nessa época. Já CODA et $a l^{48}$, em 1958, listavam os seguintes municípios com sororreativos para infecção chagásica: Angatuba, Itaberá, Itapetininga, Itapeva, Itaporanga (com Barão de Antonina) e Itararé. Esses autores relataram, nesse mesmo trabalho, a presença de $T$. infestans nos municípios de Buri, Guarei e Riversul.

A despeito da falta da informações sobre naturalidade e tempo de permanência de seus habitantes na área, infere-se, a partir dos dados populacionais da Região de Sorocaba, anteriormente mencionados, que ocorreram nesta as menores variações observadas no Estado entre os anos de 1960 e 1970, sem perdas importantes por evasões ${ }^{190}$. Buri, Itaberá, Itapeva, Itararé e Riversul situam-se na Região de Governo Itapeva, que equilibrou sua população, nos anos 70, com evasão e crescimento vegetativo; Angatuba, Itapetininga e Guarei, da Região de Governo Itapetininga, com o componente de crescimento vegetativo apenas e Barão de Antonina e Itaporanga, da Região de Governo Avaré, com crescimento populacional em que teve maior peso o componente migratório ${ }^{92}$.

A sororreatividade dos grupos etários superiores a 20 anos evidencia a intensa exposição à transmissão a que foram submetidos os habitantes de Campos de Itapetininga nascidos antes de 1956. O valor médio de idade dos sororreagentes, 31,2 anos, permite 
situar suas datas de nascimento entre 1945 e 1947. Mesmo assim, as faixas de idades menores que 20 anos fizeram-se representar na proporção nada desprezível de $4,45 \%$ (Tabela 4.3.1.3). A presença de sororreagentes nas idades entre 1 e 4 anos, isto é, nascidos entre 1972 e 1977, revela ter ocorrido transmissão da infeç̧ão chagásica nessa área, embora não se possa descartar a possibilidade de contribuição da via congênita. Nesse particular, o inquérito demonstrou soroprevalência de $15,89 \%$ na maior parte do grupo das mulheres em idade fértil, de 15 a 49 anos (Tabela 4.3.1.3), tornando-se necessária uma avaliação de riscos para estabelecer seu papel na produção de casos observados em anos subsequentes, como sugerem AZOGUE et al. ${ }^{12}$ (1985) e BITTENCOURT ${ }^{21}$ (1992).

\section{Soroepidemiologia das Microrregiões Campos de Itapetininga e Encosta Ocidental da Mantiqueira Paulista}

A situação descrita anteriormente contrasta vivamente com aquela observada na Microrregião homogênea Encosta Ocidental da Mantiqueira Paulista, na Região de Campinas. Nesta, já em 1970, estava sob controle T. infestans, o principal vetor do Estado e surgia um novo desafio: a ocorrência de P. megistus, considerado vetor secundário, encontrado em habitações humanas, seus anexos e terrenos circunjacentes, infectado por $T$. cruzl, com ingesta reagente para sangue humano e de animais reservatórios, principalmente Didelphis azarae e Rattus rattus, também infectados ${ }^{82,156,157 .}$

Quanto à sororreatividade, a Microrregião Encosta Ocidental da Mantiqueira Paulista apresentou níveis bem distintos: variação de $0,00 \%$ a 11,63\% (Tabela 4.3.2.2), sendo sua média, 3,00\%, quase um terço da observada em Campos de Itapetininga.

Quanto às idades dos sororreagentes, obteve-se média de 48,6 anos, correspondente aos nascidos no ano de 1932. Dos 10 casos sororreagentes, após nova colheita de amostra, observaram-se em 9 deles, títulos situados no limiar de sensibilidade da técnica, isto é, iguais a 20, sendo assim considerados como duvidosos. Apenas em um caso o título, anteriormente 40 , passou a 160 . Alterações em títulos já considerados baixos, como os observados em diluição de corte, para negativos ou então reagentes apenas para uma diluição menor, não são infrequentes em inquéritos sorológicos e tampouco desmerecem o trabalho realizado (DIAS ${ }^{65}$ 1974). Em 8 casos houve o encontro de outros sororreagentes 
na casa; em duas delas, irmãos da mesma faixa etária. Os familiares de apenas 2 casos não eram sororreagentes. A presença de mãe sororreagente foi observada em 6 casos, razão suficiente para incluir-se a formulação de hipótese de infecção congênita, merecedora de investigação mais minuciosa. Aliás, faltaram informações sobre: naturalidade; tempo de permanència dos atuais habitantes em cada localidade; história da movimentação dos casos; presença de triatomineos vetores nas casas, em diferentes oportunidades. Essas lacunas constituem lamentável falha nesse tipo de inquérito, impedindo a classificação de casos como autóctones e importados. LITVOC $^{113}$ (1985) apresentou, de dois municípios dessa microrregião, Caconde e São José do Rio Pardo, resultados de entrevista por ele realizada entre sororreagentes, concluindo que $66,07 \%$ e $22,86 \%$ dos casos, respectivamente, classificavam-se como autóctones dos municípios e 33,93\% e 77,14\% como importados de outros municipios de São Paulo e de outros Estados da Federação. Calculou, ainda, as prevalências de autoctonia e de importados para Caconde em 4,08\% e 4,80\% e para São José do Rio Pardo, $0,48 \%$ e 3,19\%, respectivamente. Tais diferenças o autor justificou por "condições sociais mais favoráveis em Caconde para essa maior transmissão pretérita", relacionada ao menor desenvolvimento de capital, nesse município, em épocas em que $T$. infestans era o principal vetor.

Dos 12 municípios que compõem a microrregião, Caconde foi o que apresentou o maior percentual de sororreatividade, contribuindo com $32,04 \%$ de todos os reagentes verificados, seguido por Mococa, com 20,61\% (Tabela 4.3.2.1). A curva de distribuição dos sororreagentes, por grupo etário, demonstra que o quadro da infecção assumiu maior importância, na população amostrada, por volta dos anos 20-30, observando-se o pico de sororreatividade nas idades entre 50 e 59 anos (Figura 4.3a). A curva sobe gradualmente até as idades 20-29 anos, sem ultrapassar a unidade e, entre 30 e 49 anos sofre um incremento maior, para atingir o ápice nas idades 50-59 anos; declinando discretamente nas idades maiores. Entretanto, mesmo sem conhecer dados que permitam correlação dos resultados sorológicos e naturalidade da população da área, pela importância da economia cafeeira de muitos de seus municípios ${ }^{91}$, supõe-se que a Microrregião Encosta Ocidental da Mantiqueira Paulista teve o apogeu da transmissão pelo menos 30 anos antes da Microrregião Campos 
de Itapetininga. É possivel que migrantes do Estado de Minas Gerais também fossem uma parcela do contingente de sororreagentes verificado na região

Excetuando Águas da Prata e Caconde, FREITAS ${ }^{87}$, em 1950, não registra outros municipios da Encosta Ocidental da Mantiqueira Paulista com sororreagentes. $O$ autor relaciona apenas os casos comprovadamente autóctones dos municipios mencionados. Já os dados entomológicos demonstravam a presença, em 1941, de T. infestans em onze deles, excluindo-se apenas Águas da Prata, onde havia relato de $P$. megistus ${ }^{162}$. Em 1951, T. infestans é relatado em todos eles e $P$. megistus é descrito em Mococa, São José do Rio Pardo e Vargem Grande do Sul ${ }^{111}$. Nos dados de CODA et al ${ }^{48}$ (1958), correspondentes a levantamentos sorológicos realizados entre os anos de 1951 a 1957, está registrada sororreatividade, sem os percentuais, em Caconde, Divinolândia (então pertencente a São José do Rio Pardo), Espirito Santo do Pinhal, Itobi (então Distrito de Casa Branca), Mococa, Santo Antônio do Jardim (então Distrito de Pinhal), São João da Boa Vista, São José do Rio Pardo, São Sebastião da Grama, Tapiratiba e Vargem Grande do Sul Águas da Prata figura como tendo "reações negativas" de Guerreiro \& Machado. UNTI et al. ${ }^{203}$ (1952) relataram, para o ano 1951, reações positivas de Guerreiro \& Machado em crianças do municipio de Pinhal. Segundo SILVA ${ }^{189}$ (1981), essa Microrregião fazia parte da "área endêmica", responsável pela maior parte da produção cafeeira do Estado, em fins do século $\mathrm{XIX}^{91}$

A caracterização das duas áreas quanto aos títulos dos sororreagentes não diferiu significativamente. Ambas apresentaram curva bimodal de distribuição de títulos, típica de área de baixa endemicidade ${ }^{106}$, apenas distinguindo-se a correspondente à Microrregião Campos de Itapetininga por frequências um pouco mais elevadas (Figura 4.3b). As médias geométricas dos títulos dos reagentes, 100 em Campos de Itapetininga e 165 na Encosta Ocidental da Mantiqueira Paulista não chegam a diferir o equivalente a um intervalo entre diluições de soro. De qualquer modo, os resultados dos exames da população de Campos de Itapetininga denotam a obtenção do controle em épocas mais recentes do que na área de Campinas: o ângulo observado na curva de distribuição de sororreatividade por grupos etários é maior na Microrregião Campos de Itapetininga e atinge o máximo no grupo etário de 20 a 29 anos. Apenas nos grupos etários acima de 50 anos é que as curvas são similares. 
Um dos efeitos das alterações da distribuição dos sororreagentes é a redução dos riscos de transmissão congênita na area da Encosta, em parte devido ao fato de a média de idade dos sororreagentes ser mais elevada.

Após a nova estratégia de uso de sorologia adotada a partir de 1984 e até o ano de 1997, a atividade foi mantida nos municípios da Microrregião Campos de Itapetininga devido às notificações de triatomíneos vetores e como decorrência de trabalhos de rotina lá realizados. Itaporanga, Itaberá e Riversul já foram mencionados na discussão do inquérito entre escolares. Barão de Antonina esteve presente até 1988; Angatuba, Buri, Guareí e Itapeva, até 1994; Itapetininga, até 1995 e Itararé, até 1997 (Quadro 4.5.4.1). Dos 10 municipios, apenas Itapetininga não apresentou sororreagentes no periodo. As colheitas de sangue estiveram vinculadas ao encontro de T. infestans em Angatuba, em 1984 e 1985, em Itaberá, em 1986, 1987 e 1988 e em Itapetininga, em 1985, bem como de $P$. megistus, que nos demais municípios foi a espécie prevalente. Quanto aos resultados da sorologia, 4 dos 5 casos registrados com idades inferiores a 15 anos foram detectados nessa Microrregião: um deles foi re-examinado após dois anos, em Itararé, 1985 e 1987, ocasião em que exames de seus familiares revelaram outros sororreagentes. $O$ de Guareí também se mostrou relacionado com sororreagentes da mesma família (Quadro 4.5.4.2). Obviamente, a atualização de dados referentes aos municípios está sujeita a erros decorrentes da diminuição da amostra examinada, posto que o encontro de infectados chagásicos torna-se cada vez menos frequiente, após o controle da transmissão. Importa esclarecer que, em locais de expressivo passado chagásico, as condições favoráveis à transmissão tornaram-se eventos raros. Para determinação da prevalência atual da infecção chagásica, seria necessária a colheita de amostras mais abrangentes. É esperado que o controle da transmissão da doença de Chagas implique a redução do número de sororreagentes dos grupos etários menores, uma vez que não se espera cura espontânea dos já infectados. Os sororreagentes, antes de desaparecerem por óbito, deverão ser encontrados em grupos etários cada vez mais altos.

Considerando-se a totalidade dos municípios da Microrregião Encosta Ocidental da Mantiqueira Paulista, observa-se pequena redução da sororreatividade: de 3,00\% para 2,37\% (Tabelas 4.3.2.1 e Anexo III). Todos esses municípios integram a Região de Governo São João da Boa Vista, objeto de pesquisa ativa por LIMA et al. ${ }^{112} \mathrm{e}$, por este motivo, 
respondeu por $62,42 \%$ das amostras de sangue colhidas em toda a Regional de Campinas no periodo entre 1984 e 1997 (Tabela 4 5.5.2). Caconde, Mococa, São José do Rio Pardo e São Sebastião da Grama apresentaram condições de desencadeamento de sorologia até 1997, Águas da Prata, até 1989; Divinolândia, Tapiratiba e Vargem Grande do Sul, até 1994, Espírito Santo do Pinhal e Santo Antônio do Jardim, até 1995 e São João da Boa Vista, até 1996. É neste último municipio que, em 1994, ocorreu um caso reagente de criança de 12 anos de idade, no limiar estabelecido para positividade (titulo $=32$ ), sem entretanto colher-se nova amostra para confirmação de resultado; exames de outros moradores da mesma casa resultaram negativos

Quanto à presença de vetores, P. megistus foi predominante em todos os municípios; em Itobi, Mococa, São João da Boa Vista, São José do Rio Pardo e Vargem Grande do Sul também foi identificada a ocorrência de R. neglectus. Em Espírito Santo do Pinhal, além desta espécie, foi encontrado Triatoma arthurneivai Lent e Martins, 1940. Em São Sebastião da Grama, P. megistus e T. arthurneivai e, em Tapiratiba, em 1984, T. infestans com ingesta com reação positiva para sangue humano, não foi associado a casos humanos sororreagentes

Nesta área, como em outras sob controle da transmissão vetorial, é essencial o rigor da vigilância epidemiológica, como o demonstram os trabalhos iniciados pela SUCEN na década de 70, com ROCHA E SILVA et al. ${ }^{156,157}(1975,1978)$, incluindo a pesquisa em animais domésticos e sinantropicos, afora o estímulo e pronto atendimento às denúncias efetuadas por moradores ${ }^{160}$. Apenas é questionável o uso da sorologia aplicada na ocasião em que há suspeita de transmissão recente, por ser sobejamente conhecido que o método sorológico, isoladamente, não é apropriado para diagnosticar caso recente de infecção (LUQUETTI ${ }^{117}$ 1992, SCHATTSCHNEIDER et al. ${ }^{168}$ 1992), embora TEIXEIRA ${ }^{201}$ (1977) tenha conseguido demonstrar reações fortemente positivas em testes "Chagas látex" de casos agudos aparentes e inaparentes em São Felipe, Bahia. À suspeita de infecção recente, os métodos de visualização de formas sanguíneas diretos e indiretos, são soberanos (CHUIT et $a l .^{46} 1989$, FREITAS ${ }^{86}$ 1947). Para evitar-se a ocorrência de falsos negativos, possivel nesses casos, o valor da sorologia estará na comprovação de soroconversão. 


\section{A área controle negativo}

Em 1980, com o delineamento do emprego de sorologia aplicada ao diagnóstico da malária em locais de baixa transmissão dos municípios de Cananéia. Iguape e Peruibe, decidiu-se pelo uso das amostras destinadas àquele fim para a realização de reações sorológicas para infeç̧ão chagásica. Justificaram tal decisão: descoberta de casos autóctones de infecção chagásica em Cananéia, um deles durante inquérito escolar ${ }^{84.85}$ e de leishmaniose tegumentar americana ${ }^{83}{ }^{159}$ (passiveis de produzir reações cruzadas, a esclarecer ulteriormente, com antigenos de $T$. cruzi) ${ }^{116}$ e encontros de exemplares de $P$. megistus e de T. tibiamaculata infectados por T. cruzt ${ }^{61.62 .53}$

Os municipios da Baixada Santista e do Vale do Ribeira integram área considerada indene, apesar do encontro de triatomineos vetores, de espécies consideradas secundárias, como foi relatado por ROSENFELD e CARDOSO ${ }^{162} \mathrm{em}^{1941}$ COSTA e GUARITA $^{53}$ (1967) assinalaram o encontro de T. infestans no municipio de Miracatu, nos anos de 1964 e 1965 e de P. geniculatus, P. megistus, R. domesticus, Triatoma rubrofasciata (De Geer, 1773) e $T$. tibiamaculata, em pesquisa levada a cabo logo após o controle da malária, em 1965, na "Baixada Litorânea" do Estado, compreendida pelo litoral propriamente dito e municipios do interior próximo, relacionados com o ecossistema da Serra do Mar. Há relatos esporádicos de casos da infecção chagásica, atribuídos a contaminação, por manipulação de carcaças de animais silvestres para consumo ${ }^{84.85}$.

Apesar desses registros, o perfil da área permite seu uso como controle negativo das reações sorológicas. Os casos aí detectados merecem investigação minuciosa de procedência pelas razões expostas e, principalmente, pela probabilidade de reações cruzadas com leishmaniose tegumentar americana, presente na Região do Vale do Ribeira ${ }^{83,}{ }^{159} \mathrm{e}$ responsável, nos últimos anos, por cerca de $40,0 \%$ dos casos notificados no Estado ${ }^{70}$.

No municipio de Cananéia a sororreatividade para infecção chagásica foi de $0,24 \%$, distribuindo-se em apenas 6 de suas 38 localidades rurais. A distribuição de títulos (Figura 4.4b) foi característica de área negativa, com curva semelhante à exponencial. $O$ número reduzido de reagentes em uma área de muito baixa endemicidade e a utilização de um único teste sorológico contribuem para a obtenção de baixos valores de predição dos resultados ${ }^{205}$. 
A análise doe tempo de moradia na área, idade e migração, indicam que todos os casos detectados eram de adultos entre 23 e 59 anos, na sua maioria migrantes (COSTA et al. ${ }^{53}$ 1982), com tempo médio de moradia igual a 7,2 anos (Quadro 4.4.1), fatos que apontam para a possibilidade de a infecção ter sido adquirida em outros Estados da Federação.

Comparados Peruibe e Iguape, os percentuais de sororreatividade foram maiores no primeiro, porém, similares quanto aos padrões de distribuição bimodal de títulos sorológicos: ambos típicos de área de baixa endemicidade, com grande predominância de soronegativos e baixas frequências de sororreagentes (Figura 4.4b).

Os sororreagentes de Peruibe são, na sua quase totalidade, importados, enquanto que os de Iguape se distribuem equitativamente entre migrantes e nativos (Quadro 4.4.1). Esta distribuição é explicada à luz de dados de recenseamento. Iguape, pertencente ao Vale do Ribeira, Região Administrativa de Registro, teve seu crescimento desacelerado na década de 70 , tendo ainda sido observada evasão populacional no decênio 80/91; o componente vegetativo é o maior responsável por seu crescimento. Peruibe, município turístico pertencente à Baixada Santista, Região Administrativa de Santos, teve uma taxa anual de crescimento de 5,44\% entre os anos 70/80 e taxa de urbanização de 95,56\%, tendo mesclado os componentes vegetativo e migratório de maneira equitativa ${ }^{92}$. O tempo de moradia em Peruibe foi a metade do observado em Iguape. E neste, o sexo masculino foi significativamente mais sororreagente que o feminino, padrão não comumente observável em áreas endêmicas, dada a equiprobabilidade de aquisição da infecção, para ambos os sexos, no ambiente domiciliar.

Nas Tabelas 4.4 .5 e 4.4 .6 observamos que, em Iguape e Peruibe, 7 e 10 casos ocorreram, respectivamente, em crianças com idades inferiores a 15 anos. Das informações constantes no Quadro 4.4 .2 vê-se que, em 4 e 9 casos de cada um deles houve uma segunda colheita de sangue para confirmação de resultado, ainda que com o uso do mesmo teste sorológico. Em área de passado chagásico significativo, no município de Taquarituba, havíamos empregado o mesmo teste sorológico na população, em material obtido em duas colheitas intervaladas por dois anos e verificamos que a reprodutibilidade dos testes ocorreu em $98,37 \%$ dos casos, um grau de concordância quase perfeito. Considerando-se que em 5 
dos casos o primeiro resultado havia sido no título de corte (igual a 32), a negativação da segunda amostra não chega a chamar a atenção, como jả foi salientado por DIAS ${ }^{65}$ (1974) $O$ ideal aqui seria utilizar pelo menos duas técnicas para confirmação dos resultados Situações como a observada são dadas como exemplo de problemas ainda não solucionados, inerentes aos testes diagnósticos (LUQUETTI ${ }^{116} 1990$ ).

Além da constatação da dominância de individuos adultos sororreagentes, fazendo parte de uma população economicamente ativa, entre os casos importados de Estados onde a doença de Chagas é endêmica, como Minas Gerais, Bahia, Alagoas, Pernambuco, Paraíba, merece destaque o fato de a infecção de $T$. cruzi nesta área ter-se revelado distinta da que ocorre no planalto. Os resultados da sorologia, sem informações adicionais quanto a procedência, movimentação e hábitos que favorecem o contato entre hospedeiro e agente etiológico, como a prática de caça de animais silvestres, manipulação de suas carcaças e ingestão de carne crua ou mal cozida, tornariam a análise sorológica na área trabalhada, desprovida de significado epidemiológico. Se fosse considerada apenas a distribuição dos resultados por grupos etários na Figura 4.4a, por exemplo, poder-se-ia pensar a priori que se tratasse de uma área como tantas outras do nosso Estado, com passado chagásico bem conhecido

CIARAVOLO et $a .^{47}$ (1997) descreveram um caso agudo de doença de Chagas em 1995, em paciente que foi a óbito. Sua história era sugestiva de aquisição por via vetorial, durante excursão em ambiente silvestre localizado entre os municípios de Itanhaém e Peruibe. FORATTINI et al. ${ }^{84}$ (1980) chamaram a atenção para a possibilidade de ocorrência de casos da doença nesses ambientes restritos de existência de vetores silvestres e animais sinantrópicos infectados por T. cruzi, referenciando situações assinaladas desde a década de 1940

A contaminação pela via oral é uma possibilidade concreta, mesmo que em níveis não elevados, em regiões como as ora estudadas ${ }^{84.85}$, sobretudo porque do rol de animais citados pelos moradores, utilizados como fonte de alimentação, muitos constituem reservatórios de $T$. cruzi $^{18}$. BASOMBRIO et al. ${ }^{19}$ (1999), estudando populações indígenas moradoras em áreas rurais isoladas, endêmicas para a doença de Chagas, situadas entre o 
Norte da Argentina e o Oeste do Paraguai, compararam diferenças de comportamento que algumas adotavam, relacionadas à ingestão de carnes de animais reservatórios silvestres, cruas ou mal cozidas, explicando assim as diferentes respostas sorologicas que obtiveram entre comunidades

Na programação rotineira do controle da doença de Chagas percebe-se que, entre os anos de 1984 e 1997, em 40,6\% dos casos investigados $(34,21 \%$ do total de casos detectados) na Regional da SUCEN de São Vicente, houve associação com manipulação e/ou ingestão de carne de caça silvestre, crua ou mal cozida. Todos os casos classificados como autóctones da área mencionaram essa prática; em um deles ocorreu soro-conversão Portanto, do ponto de vista de transmissão, a área merece um trabalho diferenciado por parte do pessoal de educação em saúde pública, tendente a alertar a população sobre riscos da citada pratica.

Outra peculiaridade da área do SR-2 (São Vicente) foi a implantação modelar, na década de $80^{62}$, da rede de Postos de Identificação sobre Focos de Triatomíneos, os PIFTs. $\mathrm{Na}$ década anterior, os primeiros haviam sido instalados na Região de Marilia ${ }^{154}$. Os PIFTs permitiram à Regional um trabalho de atendimento às denúncias de presença de triatomíneos vetores, feitas por moradores, como preconizado por ROCHA E SILVA et al. ${ }^{153}$ (1969), para áreas de vigilância. Os achados eram encaminhados às Unidades Básicas de Saúde, Escolas ou mesmo à SUCEN. Essa atividade desencadeava, além da pesquisa minuciosa dos insetos nas casas e seu expurgo, quando indicado, o encaminhamento de pessoas infectadas, identificadas por meio de exames sorológicos, ao Sistema de Saúde, para exames confirmatórios ou assistenciais. $E$ isto se deveu em grande parte à iniciativa dos responsáveis pelo Sistema de Saúde local e ao bom entrosamento com as Equipes Técnicas da SUCEN, um exemplo que deveria ser seguido por outros grupos, como uma solução alternativa em áreas ou setores em que não vigoram normas pré-estabelecidas no atendimento do infectado chagásico

Saliente-se que esse tipo de trabalho foi dirigido a atendimento de notificação, uma vez que a programação de rotina praticamente inexistia nos moldes preconizados pelo PCDCh, até o ano de 1993. Esta iniciativa levou a Regional a produzir um volume de 
colheita de sangue que atingiu cerca de um terço do total $(5232 / 17286)$, bem superior à média das demais Regionais que desenvolveram tanto atividades de rotina quanto de atendimento às notificações (Tabelas 4.5.3-8.2). Vale a pena destacar que as amostras de sangue dos moradores deveriam ser colhidas sempre que o triatomineo vetor fosse encontrado infectado ou quando apresentasse ingesta reagente para sangue humano, na identificação do hábito alimentar. No SR-2 o trabalho foi realizado independentemente da resposta do exame de conteúdo intestinal dos "barbeiros" quanto ao hábito alimentar, por necessidade de racionalizar custos de deslocamento de equipes ao campo ${ }^{176}$. Assim sendo, a amostra da população obtida se concentrou na área do Vale do Ribeira ( $n=5$ 045) em relação à da Baixada Santista $(n=187)$ (Tabela 4.5.3.2). Desses totais, $28,1 \%$ teriam sido dispensáveis, por não preencherem as condições exigidas pelo Programa na obtenção de sangue dos moradores para exame sorológico (Tabela 4.5.3.7)

Analogamente ao que foi já salientado a respeito dos municípios Cananéia, Iguape e Peruibe, nos demais municípios da Região, predominaram casos importados (Quadro $4.5 .3 .2)$

Ao verificar as médias geométricas dos títulos dos reagentes (MGTR) não se denotaram diferenças entre as observadas em área controle negativo e nas demais do Estado (dados das Tabelas 4.5.3-10.3). PEREIRA e COURA ${ }^{142}$ (1993) presumem diferenças entre MGTRs produzidas por cepas diversas de $T$. cruzi, em distintas condições epidemiológicas de transmissão da doença de Chagas. LUQUETTI et al. ${ }^{119}$ (1999), por outro lado, não observaram diferenças entre concentrações de anticorpos em amostras de sangue de chagásicos brasileiros e hondurenhos, ainda que considerassem os resultados desse experimento como preliminares.

Se houvesse maior número de casos atribuiveis à infecção oral, por cepas silvestres de $T$. cruzi, talvez fosse possivel distinguir alguma diferença; entretanto, como a grande maioria dos casos sororreagentes da área controle deu-se entre importados, essa diferença não pode ser avaliada. Ocorreu ainda que, em alguns anos, com o pequeno número de casos sororreagentes, os dados não foram suficientes para uma correta interpretação, devido a esse viés. Quando comparadas as MGTRs de casos autóctones da área e de importados, 
nestes incluídos os originários de outras áreas do Estado de São Paulo, obteve-se uma diferença de cerca de uma diluição menor para os primeiros (correspondente aos títulos 111,43 contra 168,19 - dados no Quadro 45.3.2). Não se pode atribuir a essa diferença uma significância estatística, semelhantemente ao que PEREIRA e COURA ${ }^{142}$ (1993) concluíram, em suas observações clínicas e laboratoriais, em camundongos infectados por duas cepas isoladas da população de duas áreas distintas no Estado da Paraiba. Nos títulos de IgG, os autores consideraram como tendo havido diferença significante entre os valores 182 e 84 , que também correspondem a uma diferença de cerca de uma diluição. Em sorologia, as diferenças entre títulos somente são consideradas significantes quando correspondem a 2 ou mais diluições (WIDMANN \& ITATANI ${ }^{215} 1998$ )

No periodo de 14 anos do trabalho analisado (1984-1997), cabe colocar algumas questões quanto às cepas de $T$. cruzi : a) poderiam estas ter sofrido modificações evolutivas? e b) tendo sido os casos de transmissão oral procedentes de municípios diversos ( 2 de Juquiá, 1 de Itariri, 1 de Pariquera-Açu e 1 de Sete Barras), seriam esperadas diferenças entre isolados? Essas lacunas de conhecimento apontam para a necessidade de se desenvolverem, na área, linhas de pesquisa de isolamento e caracterização de cepas de $T$. cruzi a partir de casos humanos infectados, de vetores, de animais domésticos, sinantrópicos e silvestres, para verificar a ocorrência de zimodemas de T. cruzi que possam ser associados aos ambientes doméstico e silvestre, evidenciando a circulação entre eles, como verificado por DIOTAIUTI et $a l^{69}$ (1995), em regiões de Minas Gerais e por ZINGALES et $a l^{223}$ (1998), em áreas de Minas Gerais, Paraíba e Piauí.

A Tabela 4.5.3.3 mostra diminuição do número de notificações geradoras de exames sorológicos da população com o passar dos anos, tendência percebida em todas as Regiões do Estado (Tabelas 4.5.3-10.3). O fato, sem dúvida, reflete a eficiência do trabalho de divulgação e manutenção do controle vetorial diferenciado na região

P. megistus e $T$. tibiamaculata foram as espécies mais frequentes. Dentre as capturas, predominaram as de exemplares adultos no intradomicílio, fato sugestivo de invasões desses vetores ${ }^{41}, 191,211$. Sua taxa de infecção por $T$. cruzi foi da ordem de $26 \%$ (Tabela 4.5.3.5). Nesse particular, seria interessante a determinação dos niveis da infecção 
entre animais domésticos, como o fizeram WISNIVESKY-COLLI et al. ${ }^{217}$ (1985) na Argentina. Apesar do trabalho em área com elevada prevalência de casos humanos, verificou-se positividade mais frequente em cães do que em humanos, supondo que esses animais atuem como anteparo protetor aos moradores das casas

Embora a associação entre presença de vetores nas casas e de moradores sororreagentes não tenha sido comprovada estatisticamente (dados da Tabela 4.5.3.6), a análise dos dados disponiveis sugere claramente que a adoção da vigilância epidemiológica da doença de Chagas, nas áreas do Litoral, que inicialmente parecera super-dimensionada do ponto de vista operacional, pois não se limitava às normas preconizadas pelo PCDCh, demonstrou a importância de seu papel ao permitir a detecção de casos que, provavelmente, de outro modo não se revelariam. Por ser aplicado a biocenose silvestre, o Programa merece uma articulação e direcionamento de esforços para a busca de pesquisa de cepas ou isolados de tripanossomatideos presentes em vetores, reservatórios (domésticos ou não) e humanos Deve-se buscar atualização de métodos de investigação laboratorial aplicáveis a estudos de suscetibilidade, relação parasita-hospedeiro ou, como sugeridos por $\operatorname{MELLO}^{127}$ (1991), estudos de interação, do ponto de vista evolutivo, de patogenia e de ecologia de linhagens de tripanossomatideos

\section{Planalto}

As regiões da Grande São Paulo e de Taubaté, que não integraram a "área endêmica" para a doença de Chagas no Estado de São Paulo ${ }^{25 .}{ }^{189}$, poderiam ser incluídas como controles negativos, não fosse a inexistência de notificações, além de inexpressivos relatos de encontro de vetores no periodo 1984-1997. Na Grande São Paulo, P. megistus foi observado em 1988, com ingesta reagente para sangue humano, associado a moradias próximas a matas. Nessas áreas, o acampamento e a exploração de turismo ecológico podem suscitar uma demanda educativa para esclarecimentos ao público sobre a atenção para com os vetores da doença de Chagas. Em Taubaté, nem ao menos dados originais sobre os vetores provenientes de Ubatuba, em 1988, estavam disponiveis. As amostras de sangue de moradores foram todas negativas em ambos os casos 
Assim, excluídas as áreas cobertas pelos SRs 1 (Grande São Paulo) e 3 (Taubaté), segue-se a análise soroepidemiológica nas demais regiões.

Nos primeiros anos da utilização da sorologia como parte de investigação de focos domiciliares de triatomineos vetores, identificaram-se, no Estado de São Paulo, regiões com similaridades em diversas situações epidemiológicas, às quais foram atribuidas prioridades $^{173}$.

- Prioridade I: populações residuais de T. Infestans - Regional de Sorocaba

- Prioridade II transmissor secundário - P. megistus, "colonizando ou frequentando esporadicamente o domicilio e anexos", principalmente na Regional de Campinas. Transmissor secundário $T$. sordida, presente na maioria dos municipios das Regionais de Ribeirão Preto, São José do Rio Preto e Marilia, "com densidade apreciável no ecotopo humano" e "com baixo poder de infecção para $T$. cruzi e marcante preferência alimentar por sangue de aves".

- Prioridade III presença eventual de quaisquer espécies, de triatomíneos, introduzidas por transporte passivo ou oriundos de focos residuais de pequena importância. Áreas de focos "enzoóticos naturais com invasão esporádica dos domicilios por triatomíneos", localizadas no Vale do Ribeira e Pontal do Paranapanema, desvinculadas de trabalho programado em Prioridades, sendo atribuído destaque às notificações.

Apesar da orientação para o desenvolvimento dos trabalhos de vigilância entomológica por Prioridades, no periodo de 1984 a 1997, a área litorânea gerou quase a terça parte dos trabalhos de sorologia, conforme especificado anteriormente, representando 1186 UDs/4 098 UDs ou 28,94\% do total de focos domiciliários de triatomíneos. Dessa forma foram 2912 focos restantes para a área de planalto, distribuidos na seguinte ordem: São José do Rio Preto $(40,14 \%)$, Sorocaba (20,51\%), Campinas (15,42\%), Araçatuba (12,84\%), Marília (4,94\%), Ribeirão Preto (3,95\%) e Presidente Prudente (2,20\%). Como já foi assinalado, algumas Regionais tiveram prejuizo das atividades do PCDCh por conta da interferência de outros Programas Institucionais, como as de Campinas, Ribeirão Preto, Araçatuba e Presidente Prudente. Admitindo-se que as perdas decorrentes de não atendimentos às notificações não tivessem sido a regra no Programa, resultou ao final um 
quadro do que representa a distribuição de vetores infectados por $T$. cruzi ou que haviam sugado sangue humano, consideradas ambas condições com potencialidade de risco de transmissão da infecção para o homem

Como consequência disto foram atualizados os percentuais de sororreatividade para infecção chagásica em todos os municipios do Estado que, devido à presença de triatomineos em Unidades Domiciliares, fizeram parte das atividades de rotina do Serviço e de atendimentos a notificações (Anexos I a VIII). É importante salientar que esses dados, excetuando aqueles do inquérito escolar dos anos $1968-1970^{96}$, datavam dos anos $1950^{198}$. Vale a pena esclarecer que o trabalho de sorologia do PCDCh, independentemente de falhas de cobertura de busca de triatomíneos nas localidades programadas e de atendimento das notificações pelos SRs, era focal, limitado por Localidades. Poderiam representar apenas UDs, situadas em locais de encontro dos triatomineos vetores domiciliários no Estado. Em muitos municípios nos quais colheitas de sangue revelaram pequenos números de casos, os percentuais de positividade perderam significância por não permitir, o tamanho da amostra, qualquer estimativa de prevalência. $\mathrm{O}$ frequente desconhecimento da procedência dos casos detectados torna dificil afirmar que, mesmo nos agrupamentos por Regiões de Governo, tenha sido obtida uma aproximação do que deve ser hoje (1997) a positividade da infecção chagásica nessas áreas do Estado. No passado, os trabalhos de sorologia também eram dirigidos à população moradora em casas com triatomineos vetores, de modo que, metodologicamente, os dados poderiam ser comparáveis entre si, desde que a população fosse nativa das áreas consideradas.

A Região de Sorocaba desenvolveu, de forma rotineira, pesquisas exaustivas nas áreas em que $T$. infestans havia sido identificado entre 1980 e 1985. Afora isso, o trabalho incluiu outras localidades que estavam em Prioridades II e III passando, em 1987, a contar com apenas 6 localidades de 5 municípios em Prioridade I e 429 localidades de 16 municípios em Prioridade III. No mesmo ano incorporaram-se a essa Regional alguns municípios pertencentes à Regional de Marilia, nos quais a infeç̧ão chagásica fora proeminente, como Manduri, Fartura, Tejupá, Sarutaiá, Piraju e Taguaí. Mantendo-os em Prioridade I (associação à presença de T. infestans) em 1988, no ano seguinte, 1989, desenvolveu trabalho extensivo em toda uma localidade do município de Itararé, no qual 
foi detectada a presença daquela espécie ${ }^{178}$. Apesar das dificuldades de conciliação das atividades dos diversos Programas, como controle de vetores de leishmaniose, em áreas contiguas às Regionais da Grande São Paulo e do Vale do Ribeira e de Aedes, esta Regional manteve-se na vanguarda do PCDCh, principalmente pelo seu passado chagásico recente, e pelo desafio da eliminação do último reduto de T. infestans do Estado

A Região de Campinas, como Sorocaba, foi objeto de estudos soroepidemiológicos em alguns de seus municipios, pela presença de $P$. megistus, dedicando especial atenção à microrregião Encosta Ocidental da Mantiqueira Paulista (LIMA et al. ${ }^{112}$ 1990). A Regional manteve inalterada a programação prevista, em detrimento de outras áreas que sofreram as pressões do controle de Aedes. De maneira exemplar, manteve um fluxo de encaminhamento de infectados chagásicos detectados no $\mathrm{PCDCh}$, principalmente os originários dos municípios da Encosta, ao Grupo de Estudos em Doença de Chagas (GEDOCH) da Faculdade de Medicina da UNICAMP, em Campinas ${ }^{179.186 .187}$

A Região de Ribeirão Preto, de expressivo passado chagásico como salientado por BURALLI $^{25}$ (1985), CARINI e MACIEL ${ }^{34}$ (1914), CODA et al. ${ }^{48}$ (1958), COUTINHO (1962), FREITAS ${ }^{86.87}(1947,1950)$, GUARITA et al. ${ }^{96}$ (1978), SILVA $^{189}$ (1981), iniciou a nova fase de controle de vetor, em 1984, com localidades em Prioridades II e III. O trabalho seguiu regularmente até 1988 (Quadro 4.5.6.1), embora já fossem mencionadas, nessa época, dificuldades do atendimento às notificações e do cumprimento das atividades de rotina, devido às demandas operacionais crescentes do controle de Aedes. Entretanto, esta Regional se preocupava com a melhoria do atendimento a notificações de triatomíneos vetores, considerada insuficiente para os padrões exigidos no $\mathrm{PCDCh}^{180}$.

A Região de São José do Rio Preto possuia, em 1984, municípios em Prioridades II e III; foi a segunda com maior número de focos geradores de sorologia de moradores $(n=1$ 169), sendo de notar que os mesmos distribuiram-se na quase totalidade dos municípios (Tabela 4.5.7.1). Dois deles, criados em 1991, figuraram junto aos de origem: Eliziário e Zacarias, desmembrados de Catanduva e Planalto ${ }^{181}$. Nas Regiões de Governo Fernandópolis, Jales e Votuporanga, a redução dos trabalhos acentuou-se a partir do ano 1992, em decorrência do deslocamento de recursos para o Programa de Controle de Aedes, 
por um lado e, a partir de 1994, pela re-orientação do uso de sorologia. As investigações em $85,47 \%$ dos casos sororreagentes indicaram que a população infectada era nativa do município ou da região (assinalados no Quadro 4.5.7.2) em 74,5\% deles; 15,7\% dos casos estavam na região durante periodo compativel com a ocorrência da transmissão, porém haviam residido anteriormente em outros Estados onde a endemia chagásica se fazia presente (Minas Gerais, Bahia, Pernambuco) e em que havia relato de conhecimento de "barbeiros", 4,6\% foram classificados como importados de outros Estados; 2,6\% tinham mãe sororreagente e idades abaixo do limite de aquisição da infecção por vetor, na área, ou por outros mecanismos, sugerindo possivel transmissão congênita; $1,3 \%$ dos casos foram autóctones de outras regiões do Estado e em 1,3\% dos casos, a classificação foi inconclusiva, por apresentar possibilidades simultâneas quanto à origem, como autóctone e indeterminada de dois Estados da Federação e quanto ao mecanismo de transmissão, via oral e transmissão vertical (dados no Quadro 4.5.7.2)

A Regional de Araçatuba foi, no PCDCh, pioneira na implantação de unidade de trabalho Localidade, em substituição a Municipio. Apesar de inicialmente possuir apenas 34 localidades programadas para trabalhar de rotina em Prioridade II e 185 em Prioridade III, não conseguiu sequer o atendimento de todas as notificações de triatomíneos, em parte por dificuldade de localização de endereços e, em parte pelo esgotamento de recursos no Programa de Controle de Aedes ${ }^{182}$. É possivel que a queda brusca do número de UDs trabalhadas a partir de 1988 possa parcialmente ser explicada pela falta de cumprimento das metas da programação de rotina, tendo eventualmente sido atendidas apenas as notificações, do que resultou pequeno volume de colheita de sangue de moradores.

Sendo área de $T$. sordida ${ }^{172}$, Presidente Prudente classificava todos os municípios em Prioridades II e III em 1984, passando no ano seguinte à Prioridade III. Possuia alguns PIFTs instalados em Escolas Rurais e em Centros de Saúde. De todas as Regionais da SUCEN, foi a que apresentou menor volume de trabalho, representado por atividades de sorologia em 54 localidades de 1021 existentes (3,6\%), como é visto na Tabela 4.5.9.2. A reatividade sorológica, quando vista isoladamente por município, apresentou valores elevados, influência de pequenos números absolutos trabalhados. A Região de Governo Dracena concentrou as atividades de sorologia, em parte explicada por encontros frequentes 
de T. sordida nos municípios de Dracena e Tupi Paulista, motivando o aumento da rede de PIFTs a todas as escolas de zona rural destes e de outros municipios, como Monte Castelo, Nova Guataporanga, Paulicéia e São João do Pau d'Alho ${ }^{183}$

A Regional de Marilia, entre os anos de 1984 e 1989, antes das alterações dos critérios de Prioridades das Localidades, teve dificuldades para o cumprimento das metas de rotina de busca de tritomíneos, também devido ao aumento das atividades de controle de Aedes. Não pôde fechar o quadriênio 1985-1988, que incluía a pesquisa em 4 localidades em Prioridade II e 2264 em Prioridade III, englobando cerca de 130000 UDs. Nos anos de 1988 e 1989 não executou a rotina, atendendo apenas a notificações de triatomíneos, cerca de 200 por ano, em média. Após mudança de critérios de Prioridades, em 1990, ficou com o volume de trabalho anual reduzido cerca de 10 vezes em relação ao ano anterior. Naturalmente, essa redução se fez sentir no volume de trabalho de sorologia. É importante destacar que, embora não tenha sido possivel resgatar a informação sobre a forma do atendimento que gerou sorologia em cerca de $80 \%$ dos casos, supõe-se que tenha predominado a de notificação de triatomíneos, como se depreende da leitura de planejamentos anuais, em que são relatadas dificuldades para cumprimento da rotina de trabalho estipulado no $\mathrm{PCDCh}^{184}$

Verificando-se que as perdas de informações sobre tipos de atendimentos que geraram sorologia foram muito acentuadas, como nos casos dos SRs de Campinas, Araçatuba, Presidente Prudente e Marília (condensados das Tabelas 4.5.4-10.5), consideraram-se os relatos de WANDERLEY ${ }^{209}$ (1993) e de SILVA et al. ${ }^{191}$ (1999), como sendo os de maiores frequências para localização de focos domiciliares, em todas as Regionais, aqueles de atendimento de notificação do que os de rotina de busca de vetores.

Das condições que determinam a realização de exames sorológicos, "barbeiro" com reação para ingesta de sangue humano foi a mais frequente, exceto no SR de Campinas, em que "barbeiro" infectado por $T$. cruzi, ocorreu praticamente na mesma proporção (Tabelas 4.5.4-8.8, 4.5.9.6 e 4.5.10.7). A ausência de informações nessas Tabelas foram devidas, na maior parte das vezes, à falta de resultado dos exames de hábito alimentar. A queda verificada na produção de exames a partir de 1994 torna-se compreensível diante dos 
dados apresentados: neste ano houve alteração das condições de uso de exames sorológicos, passando a ser restrita a moradores de UDs em que se verificasse somente a presença de triatomíneos vetores infectados por $\boldsymbol{T}$. cruzi (Tabelas 4.5.3-10.3). Na Região de Campinas, conforme salientado no capitulo dos resultados, a produção esteve quase sempre associada aos municipios que compõem a Microrregião Encosta Ocidental da Mantiqueira Paulista, área de P. megistus, objeto de estudos da Regional ${ }^{112}$.

A distribuição de espécies esteve de acordo com o apresentado por SILVA et al. ${ }^{191}$ (1999), respeitando-se os limites do periodo analisado (1990-1995) e considerando que os autores registraram dados de todos os focos de triatomíneos, não só daqueles que apresentaram condições necessárias para desencadear a atividade de sorologia. Descontadas as lacunas por falta de informação (variação de 0,9 a 44,1\% nas Regionais), T. sordida foi mais frequente em Ribeirão Preto, São José do Rio Preto, Araçatuba e Presidente Prudente. $P$. megistus foi mais frequente em Sorocaba e Campinas. Em Marilia, observou-se equilíbrio entre P. megistus, T. sordida e R. neglectus. Entretanto, a perda de informação na Regional foi muito acentuada $(41,3 \%)$, com influência importante nos dados apresentados nas Tabelas 4.5.4-8.6, 4.5.9.7 e 4.5.10.6

Fase evolutiva e infecção dos triatomineos vetores tiveram um padrão uniforme de distribuição nas diversas Regiões, isto é, maior número de capturas de exemplares adultos e infectados, do que ninfas isoladas ou associadas a adultos. Entretanto, distinguiu-se a Região de Campinas, por apresentar percentuais de presença e de ausência de infecção praticamente nas mesmas proporções $(36,7 \%$ e $38,4 \%)$. Todavia é digno de nota que as perdas de informações variaram de 6,1 a $66,4 \%$, e que foram maiores do que um terço do total em São José do Rio Preto, Araçatuba, Presidente Prudente e Marilia. (Tabelas 4.5.4 $8.6,4.5 .9 .7$ e 4.5 .10 .6$)$

A captura de triatomíneos dentro dos domicilios predominou em todos os casos, associada a resultados de reação positiva para ingesta de sangue humano, mesmo quando consideradas perdas de informações, superiores a 50,0\% em Araçatuba, Presidente Prudente e Marília. O resultado de verificação de hábito alimentar dos triatomineos somente foi distinto novamente na Região de Campinas, que evidenciou cerca 38,8\% de reação positiva 
para outras fontes que não a humana. Nesta Regional, anteriormente domínio de $T$. infestans, CORRÊA et al. ${ }^{51}$, em 1963, BARRETTO ${ }^{16}$, em 1967, ROCHA E SILVA et al. ${ }^{156,}$ 157, em 1975 e em 1978, já demonstravam preocupação com P. megistus como vetor substituto de $T$. infestans na transmissão da doença de Chagas na região.

Das UDs-focos de triatomíneos vetores, pesquisadas entre 1984 e 1997, 12,43\% apresentaram moradores sororreagentes; os maiores percentuais correspondem às Regionais de Ribeirão Preto (18,26\%), Sorocaba (16,58\%), Marilia $(15,97 \%)$ e São José do Rio Preto $(12,66 \%)$. As demais estiveram abaixo da média: Campinas $(8,69 \%)$, Araçatuba $(7,49 \%)$ e Presidente Prudente (6,25\%) Contudo, analisando os resultados obtidos para dois grupos constituídos por UDs com e sem moradores sororreagentes e UDs com e sem triatomineos infectados por $T$. cruzi, vimos que não houve associação entre UD com infectado chagásico e UD com presença de triatomíneo infectado por $T$. cruzi, não só na Regional de Campinas, como em nenhuma outra, reforçando a idéia inicial de que estamos lidando com infecções humanas pretéritas e que a descoberta do infectado chagásico dá-se provavelmente ao acaso. Isto não significa a inexistência do risco de transmissão. Espera-se que, apesar dos obstáculos previsíveis, o controle dos vetores prossiga de modo a evitar um retorno dos triatomíneos à situação de risco potencial de domiciliação (ANDRADE et al. ${ }^{10}$ 2000, ROCHA E SILVA et al. ${ }^{160}$ 1998, WANDERLEY ${ }^{209}$ 1993)

ANDRADE $^{8}$ (1994), trabalhando com diversos fatores de risco associados à transmissão da doença de Chagas na infância, observou que, o encontro de vestígios de vetores prediziam mais a infecção em crianças do que, tomados isoladamente, encontro ou captura de exemplares adultos. Portanto, não se pode apenas considerar a presença de sororreatividade na população para aceitar ou rejeitar a hipótese de transmissão local. A investigação minuciosa dos casos sororreagentes é prática a ser implantada visando a obtenção de um máximo de informações relevantes.

Ao mencionar infeç̧ões pretéritas esbarra-se na questão da idade dos sororreagentes, tida no PCDCh como referencial para a demonstração da interrupção da transmissão vetorial no Estado ${ }^{41-43.160,210}$. Nas idades inferiores a 15 anos existem 9 casos registrados no período 1984-1997, dos quais um foi classificado como induzido ${ }^{212}$ e 2 
importados de outros Estados. Aos 6 restantes faltam informações suficientes para serem rotulados como de transmissão congênita, embora estivessem acompanhados por outras pessoas sororreagentes nas casas, supostamente com algum grau de parentesco próximo ${ }^{210}$. Uma vez mais ressalte-se a importância das investigações, não só de crianças, mas também de todos os sororreagentes e, sobretudo, das mulheres em idade fértil, dados os riscos de transmissão de $T$. cruzi às suas proles ${ }^{12.21 .}{ }^{170}$, para as quais se recomenda o tratamento imediato $^{12,67.68}$. A falha de investigações por parte de alguns SRs parece estar associada ao temor de estressar pessoas reagentes sorológicas com resultados de exames laboratoriais positivos, sem condições de encaminhá-las a serviços que promovam o atendimento de pacientes chagásicos.

Todavia, a identificação de portadores da infecção chagásica durante as pesquisas domiciliares de triatomíneos vetores foi alvo de preocupação por parte dos SRs da SUCEN. Nas atividades educativas, a associação da existência de vetores nas casas e risco de aquisição de infecção chagásica era abordada. O planejamento de ações educativas previa divulgação de informações sobre doença de Chagas e suas formas de transmissão junto a Escolas Rurais e Periféricas, Centros de Saúde ou outras Unidades Básicas de Saúde, Sindicatos de Trabalhadores Rurais, dentre outros; motivavam sempre o morador para a notificação da descoberta de triatomíneos nas moradias ${ }^{175-186}$. Mas, se por um lado a Instituição dispunha de sólida infra-estrutura de controle do vetor, através de sua minuciosa busca no intra- e no peri-domicílio, seguida de ações de desinsetização, de outro, ficava com o ônus de ter em mãos um resultado de exame sorológico que significaria um problema junto ao morador, uma vez que não havia um esquema para seu encaminhamento e/ou tratamento. Segundo LACOSTE ${ }^{109}$ (1977), a responsabilidade do pesquisador face aos homens e mulheres que estuda e cujo território analisa, não pode se seguir pelo desinteresse pela sua sorte. Assim, os resultados dos exames a que foi submetida a população deveriam ser a ela comunicados. Sob esse aspecto, o Programa não previa soluções. Excluindo os procedimentos adotados nos SRs de São Vicente e de Campinas, o assunto é um problema a ser equacionado pela Instituição. A solução estaria no estabelecimento de parcerias que permitissem o acesso do infectado chagásico ao Sistema de Atenção Médica, Psico-Social e Previdenciária do Estado ${ }^{67}$. Este tem sido um aspecto discutido em eventos científicos ${ }^{15,22 .}$ 
55.67.95.213.214, considerando que o iltimo elo da cadeia de transmissão - o ser humano - tem permanecido, com frequência, alijado da atenção a que tem direito. Mesmo do encaminhamento ao GEDOCH, de Campinas, o baixo poder aquisitivo dos pacientes obstruiam a continuidade de tratamento, pela impossibilidade de transporte, nos deslocamentos inter-municipais e pelo custo dos medicamentos ${ }^{179 .}{ }^{186}$. Tentativas de promover atenção médica em localidades mais próximas aos pacientes também foram frustradas $^{186}$.

Tomando o Estado de São Paulo como um exemplo a ser seguido por outros Estados Federativos ou mesmo outros paises em que a doença de Chagas ainda se constitui um problema de proporções maiores, é mister expor as limitações observadas no PCDCh para que, nas fases iniciais de planejamento de eventuais trabalhos, já possam ser previstas e evitadas:

falhas na cobertura de atividades programadas, por insuficiência de recursos e pela priorização de outros Programas;

falta de segunda amostra para observação de eventuais soro-conversões, mesmo que a colheita de sangue fosse realizada sempre em um período superior a 30 dias, após o encontro do triatomineo vetor;

intervalo de tempo demasiado longo, em muitos episódios, decorrido entre o encontro do vetor, classificação, verificação de infecção por $T$. cruzi e identificação de ingesta;

inexistência de um esquema voltado para a comunicação de diagnóstico e de encaminhamento dos infectados à atenção médica, com o resultado da sorologia servindo quase que exclusivamente para avaliações de prevalência;

falta de preenchimento de dados como procedência, tempo de moradia no local e de estudos simultâneos de migração, que complementariam sua apropriação na investigação epidemiológica, permitindo melhor análise de classificação de casos;

perda de informações em determinados periodos. Cumpre esclarecer que a SUCEN perdeu dados originais, de campo, dos anos 1984 a 1990, da maior parte dos Serviços Regionais; 
falta de controle negativo na mesma localidade, programando-se também UDs sem as condições estabelecidas no Programa para desencadear exames sorológicos (ampliação dos casos dispensáveis),

falta e insuficiência de investigações em menores de 15 anos, bem como nos adultos, dificultando os estudos epidemiológicos sobre transmissão da doença;

nos casos suspeitos de transmissão da infecção, falta de exames diretos e indiretos de pesquisa de parasitas.

A questão que se colocaria, antes da do encaminhamento do infectado chagásico, seria sua própria deteç̧ão no Programa de Controle de Vetores, tendo-se em conta a baixa endemicidade observada em diversas regiões do Estado de São Paulo na atualidade. A aplicação de uma única técnica sorológica, viável no passado, teria pouca utilidade hoje, uma vez que a situação epidemiológica oferece resultados com baixos valores preditivos. Com a adoção de mais uma técnica (de imunoensaio enzimático - ELISA) a partir de 1996, no PCDCh, espera-se melhorar a interpretação de resultados, embora BASOMBRIO et al. ${ }^{19}$ (1999) alertem para o fato de que o critério de só ser aceito como positivo o caso que o for em duas técnicas, pode eliminar um conjunto de falsos negativos, mesmo considerando a predição baixa de um único teste utilizado. LUQUETTI et al. ${ }^{119}$ (1999) consideram títulos baixos, passiveis de serem encontrados entre casos discordantes, típicos de população não infectada. Todavia, no México, de acordo com SÁNCHEZ et al. ${ }^{166}$ (1999), foram obtidos casos de baixos títulos associados a parasitismo, detectados por técnica de Western-Blot, que parece concordar com resultados das técnicas convencionais, como imunofluorescência, imunoensaio enzimático e hemaglutinação ${ }^{129}$, bem avaliadas com o sangue absorvido em suporte de papel-filtro ${ }^{107.120}$. É certo que o diagnóstico precisará ser refinado e torna-se necessário buscar a participação de sistemas de controle de qualidade externos, nos moldes

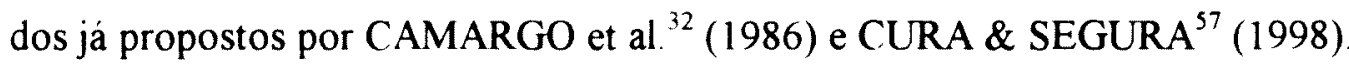

Ainda assim, valeria a pena re-direcionar o instrumental sorológico no Estado de São Paulo, para estratégias de seguimentos de grupos específicos, como o de crianças filhas de mães sororreagentes, pesquisa em grupos de risco, como imigrantes de áreas endêmicas do Brasil ou do exterior, inquéritos em grupos indicadores de transmissão, como o que se 
pretende desenvolver no Brasil pelo Ministério da Saude, sempre visando o apoio logístico para a atenção médica 


\section{CONCLUSÕES}

1. Análise de amostra de escolares da $1^{\mathrm{a}}$ série do $1^{\circ}$ grau de zona rural de 54 municipios do Estado, obtida entre 1973 e 1983 evidenciou tendência decrescente para a infecção chagásica, com o maior componente representado pela Região de Sorocaba, anteriormente reduto de $T$. infestans

2. Em área de T. infestans intradomiciliar, após vigência de medidas anti-triatominicas no municipio de Taquarituba, a aplicação do modelo dose/resposta de análise de probitos mostrou associação entre idade (dose) e sororreatividade (resposta) para infecção chagásica no grupo etário entre 6 e 30 anos, correspondente aos nascidos entre 1944 e 1970. indicando a persistència do risco de adquirir a infecção no município durante esse periodo.

3. Nos municipios da Microrregião Campos de Itapetininga, situada na Região de Sorocaba, a interrupção da transmissão se deu há pelo menos 17 anos, em média, após a ocorrida nos da Encosta Ocidental da Mantiqueira Paulista, Região de Campinas, conforme evidenciado na análise de sororreatividade por grupos etários (5-9 e 20-29 anos). Em ambas Microrregiões constatou-se, pela distribuição de frequências de títulos sorológicos, um padrão de área de baixa endemicidade para a infecção chagásica, em fins da década de 70. A diferença entre positividades sorológicas em Campos de Itapetininga e na Encosta Ocidental da Mantiqueira Paulista dá-se nas idades inferiores a 50 anos, indicando diferenças nos padrões de exposição à infecção.

4. $\mathrm{Na}$ área considerada como controle negativo, representada por municípios do Serviço Regional da SUCEN de São Vicente, a investigação de casos autóctones evidenciou um padrão de transmissão distinto do restante do Estado, associado à manipulação de carcaças de animais silvestres ou ingestão de sua carne crua ou mal cozida. Esta área requer um trabalho especial visando à divulgação de formas alternativas de transmissão da infecção chagásica. De outro lado, há necessidade de desenvolvimento de pesquisa relativa à transmissão humana a partir do ciclo silvestre da doença. Entre os municípios trabalhados nessa Região, Cananéia foi o que apresentou perfil 
sorologico de área negativa (distribuição unimodal de títulos sorológicos), enquanto que Iguape e Peruíbe, já apresentaram perfis sorológicos de área de baixa endemicidade

5. Não se detectou associação entre Unidades Domiciliares com presença de triatomíneos vetores infectados por $T$. cruzi e moradores reagentes sorológicos para infecção chagásica. Esse fato pode significar que estamos diante de casos em que a infecção foi adquirida em periodos anteriores à interrupção da transmissão vetorial no Estado ou provenientes de outros Estados do Brasil.

6. Sugere-se o re-direcionamento da sorologia no PCDCh tendo em vista a diminuição do número de casos, dependente do tamanho da amostra examinada. Nesse ponto, os resultados se ressentem de valores preditivos baixos. Técnicas mais recentes. como as que possibilitam a deteç̧ão de antígenos circulantes, aplicar-se-iam para a confirmação de resultados discordantes obtidos entre as usuais e, na suspeita de transmissão, exames clássicos, como xenodiagnóstico, gota espessa, esfregaço, ou de outros processos de enriquecimento, como PCR, seriam os mais indicados 


\section{REFERÊNCIAS}

1. Akhavan D. Análise de custo-efetividade do programa de controle da doença de Chagas no Brasil: relatório final. Brasília: Programa de desenvolvimento de recursos humanos/OPAS/OMS; 2000

2. Albarracin-Veizaga H, Carvalho ME de, Nascimento EMM, Rodrigues VLCC, Casanova C, Barata JMS. Chagas disease in an area of recent occupation in Cochabamba, Bolivia. Rev Saúde Pública 1999, 33: 201-7.

3. Almeida $\mathrm{J}$ de $\mathrm{O}$, Fife Jr EH. Métodos de fijación del complemento estandarizado cuantitativamente para evaluación critica de antígenos preparados com Trypanosoma cruzi. Washington (DC): Pan American Health Organization, 1976 (PAHO - Publicação Científica, 319)

4. Alvarez MA, Cerisola JA, Rohwedder RW. Test de inmunofluorescencia para diagnostico de la enfermedad de Chagas. Bol Chil Parasitol 1968, 23: 4-9

5. Alves UP, Alves FP. A moléstia de Chagas no município de Laranjal Paulista, Estado de São Paulo. Notas sobre epidemiologia e profilaxia. Arq Hig Saúde Pública 1952; 17 : $109-15$

6. Alves UP, Noda J. Os transmissores da doença de Chagas na Região de Sorocaba, Estado de São Paulo, Brasil. Arq Hig Saúde Pública 1964; 29: 141-57.

7. Anderson RI, Sadun EH, Williams JS. A technique for the use of minute amounts of dried blood in the fluorescent antibody test for schistosomiasis. Exp Parasitol 1961; 11 : $111-6$.

8. Andrade ALSS de. Avaliação de possiveis fatores de risco para a infecção pelo Trypanosoma cruzi em crianças - estudo caso-controle em área rural do Estado de Goiás. São Paulo; 1994. [Tese de doutorado - Faculdade de Saúde Pública da USP].

9. Andrade ALSS de, Zicker F, Luquetti AO, Oliveira RM, Silva AS, Souza JMP, Martelli CMT. Surveillance of Trypanosoma cruzi transmission by serological screening of schoolchildren. Bull World Health Organ 1992, 70: 625-9

10. Andrade V, Souza CE, Alves MJCP, Fernandez M, Leite OF, Rangel O, Mayo R, Souza S, Rodrigues VLCC, Lima VLC, Wanderley DMV. Triatoma infestans em área sob vigilância entomológica para a doença de Chagas no Estado de São Paulo, Brasil. Parte III - Atividades de Controle. Rev Soc Bras Med Trop 2000; 33 Supl 1: 419.

11. Araujo FG de. Batista SM. Observações sobre os testes de fixação de complemento e imunofluorescência indireta em doença de Chagas. Rev Inst Med Trop S Paulo 1969; 11: $104-10$

12. Azogue E, La Flente C, Darras Ch. Congenital Chagas' disease in Bolivia: epidemiological aspects and pathological findings. Trans Roy Soc Trop Med Hyg 1985; 79 : 176-80. 
13. Bar ME, Oscherov EB, Dambosky MP, Alvarez BM, Mizdraji G, Avalos G, Porcel E Infestación domestica por Triatoma infestans y prevalencia de seropositivos al Trypanosoma cruzi en un area rural del nordeste argentino. Rev Soc Bras Med Trop 1996; 29: 546-55

14. Barata JMS, Rocha RM, Rodrigues VLCC, Ferraz Filho A do N. Primeiro caso autóctone de tripanossomíase americana do Estado do Acre (Brasil) e sua correlação com as cepas isoladas do caso humano e de triatomíneos silvestres da área. Rev Saúde Pública 1988; 22: 401-10.

15. Barros C, Donato AC, Paiva V, Oliveira Jr W. Projeto de capacitação de recursos humanos. Rev Soc Bras Med Trop 1999; 32 Supl 2: 76

16. Barretto MP. Estudos sôbre reservatórios e vetores silvestres do Trypanosoma cruzi. XVII Contribuição para o estudo dos focos naturais da tripanossomose americana, com especial referência à região nordeste do Estado de São Paulo, Brasil. Rev Soc Bras Med Trop 1967; 1: 23-35

17. Barretto MP. Movimentos migratórios e sua importància na epidemiologia de doenças parasitárias no Brasil Rev Soc Bras Med Trop 1967; 1: 91-102

18. Barretto MP, Ribeiro RD Reservatórios silvestres do Trypanosoma (Schizotrypamum) cruzl Chagas, 1909. Rev Inst Adolfo Lutz 1979; 39: 25-36

19. Basombrio MA, Segovia A, Ramos MP, Esteban E, Stumpf R, Jurgensen MA, Winkler MA, Sayre K, Ferrer JF. Endemic Trypanosoma cruzi infection in Indian populations of South America: performance of diagnostic assays and epidemiological features. Ann Trop Med Parasitol 1999; $93: 41-8$

20. Bayma T. Molestia de Carlos Chagas (Nota sobre sua verificação parasitologica no homem, em S. Paulo). Rev Med S Paulo 1914; 17: 3.

21. Bittencourt AL. Possible risk factors for vertical transmission of Chagas' disease. Rev Inst Med Trop S Paulo 1992, 34: 403-8

22. Bonametti AM, Oliveira DS. Atendimento aos pacientes com doença de Chagas (forma indeterminada) no Ambulatório Interdisciplinar do Hospital de Clínicas (HC) da Universidade Estadual de Londrina (UEL). Rev Soc Bras Med Trop 1999; 32 Supl 2: 76.

23. Brener Z. Recent developments in the field of Chagas' disease. Bull World Health Organ 1982; 60: 463-73

24. Brenière SF, Yaksic N, Telleria J, Bosseno MF, Noireau F, Wincker P, Sanchez D Immune response to Trypanosoma cruzi shed acute phase antigen in children from an endemic area for Chagas' disease in Bolivia. Mem Inst Oswaldo Cruz 1997; 92:503-7

25. Buralli GM. Estudo do controle dos triatomíneos domiciliados no Estado de São Paulo. São Paulo; 1985. [Dissertação de Mestrado - Faculdade de Saúde Pública da USP]. 
26. Caldas Jr AL. Epidemiologia e controle da doença de Chagas. Relação com a estrutura agrária na região de Sorocaba, SP. São Paulo; 1980. [Dissertação de Mestrado - Faculdade de Medicina da USP].

27. Camargo ME. Fluorescent antibody test for the serodiagnosis of American Trypanosomiasis. Technical modification employing preserved culture forms of Trypanosoma cruzi in a slide test. Rev Inst Med Trop S Paulo 1966; 8: 227-34.

28. Camargo ME. Introdução às técnicas de imunofluorescência. São Paulo: Instituto de Medicina Tropical; 1973.

29. Camargo ME. Serological diagnosis of Chagas' disease. In: Pan American Health Organization. American trypanosomiasis research. Washington (DC): Pan American Health Organization; 1976. p. 206-11. (PAHO - Scientific Publication, 318)

30. Camargo ME, Amato Neto V. Anti-T. cruzl antibodies as serologic evidence of recent infection. Rev Inst Med Trop S Paulo 1974; 16:200-2.

31. Camargo ME, Guimarães MCS, Peres BA, Hoshino-Shimizu S. Antigenic fractionation and development of new antigens. In: Pan American Health Organization. American trypanosomiasis research. Washington (DC) Pan American Health Organization; 1976. p 227-34 (PAHO - Scientific Publication, 318).

32. Camargo ME, Segura EL, Kagan IG, Souza JMP, Carvalheiro JR, Yanovsky J.F, Guimarães MCS. Three years of collaboration on the standardization of Chagas' disease serodiagnosis in the Americas: an appraisal. Bull Pan Am Health Organ 1986; 20: $233-44$

33. Camargo ME, Silva GR da, Castilho EA, Silveira AC. Inquérito sorológico da prevalência de infecção chagásica, Brasil, 1975-1980. Rev Inst Med Trop S Paulo 1984; $26: 192-204$

34. Carini A, Maciel J. Distribution des triatomines dans l'État de São Paulo. Bull Soc Path Exot 1914, 7: 292-5

35. Carvalho ME de. Aspectos metodológicos e práticos da reação de imunofluorescência aplicada à malária. São Paulo; 1985. [Dissertação de Mestrado - Faculdade de Saúde Pública da USP]

36. Carvalho ME de, Ciaravolo RM de C, Ishihata GK, Fonseca JAB da, Litvoc J. Dados soroepidemiológicos sobre infeção chagásica em áreas com Panstrongylus megistus no Estado de São Paulo, Brasil. In: Resumos do VI Congresso Brasileiro de Parasitologia; 1981 fev 15-18, Belo Horizonte, Brasil. Belo Horizonte. Sociedade Brasileira de Parasitologia; 1981 . p. 40.

37. Carvalho ME de, Dias Jr J, Ferreira CS, Francisco SM. Infeç̧ão chagásica em localidades do municipio de Taquarituba, SP: dados soroepidemiológicos. In: Resumos do $19^{\circ}$ Congresso Brasileiro de Higiene; 1977 out 10-14, São Paulo, Brasil. São Paulo: Sociedade Brasileira de Higiene; 1977. p. 10.4. 
38. Carvalho ME de, Ferreira CS. Soroepidemiologia da infecção chagásica: contribuição para o aumento do rendimento da reação de imunofluorescência indireta. Cad Saúde Pública $1985,1,478-81$.

39. Carvalho ME de, Francisco SM, Litvoc J. Níveis de anticorpos anti-Trypanosoma cruzi em população rural de alguns municípios do Estado de São Paulo. In: Resumos do $\mathbf{1 5}^{\circ}$ Congresso da Sociedade Brasileira de Medicina Tropical, 1979 fev 4-8, Campinas, SP, Brasil. Campinas: Sociedade Brasileira de Medicina Tropical; 1979. Sala "René Rachou"

40. Carvalho ME de, Latorre M do RD de O, Ferreira CS, Mello C da S, Barata, JMS Soroprevalência de infecção chagásica em área de Triatoma infestans após medidas de controle. Rev Saúde Pública 2000; 34:15-20.

41. Carvalho ME de, Silva RA, Domingos M de F, Ciaravolo RM de C, Yasumaro S, Gomes AHA, Rodrigues VLCC, Botti MV, Prado S, Barata JMS. Serologia de la infección chagasica en el Programa de Control del Estado de São Paulo, Brasil. In:

Resumenes del XIV Congreso Latinoamericano de Parasitologia; 1999 oct 11-16; Acapulco (Gro), México. Acapulco: Federación Latinoamericana de Parasitología; 1999 p. 74

42. Carvalho ME de, Wanderley DMV, Almeida M do CRR. Sorologia da infecção chagásica em áreas restritas de focos de triatomíneos vetores no Estado de São Paulo Rev Soc Bras Med Trop 1987; 20 Supl 2: 15.

43. Carvalho ME de, Zanardi A, Delgado MR, Yazawa RY, Matos GF, Wanderley DMV. Infecção chagásica em moradores de unidades domiciliares com presença de triatomíneos vetores no Estado de São Paulo, 1984-1993. Rev Ciên. Farm 1993/1994; 15 (Supl): 16. [Apresentado na X Jornada Paulista de Parasitologia; 1994 set 16-17; Araraquara (SP)]

44. Cerisola JA, Fatala Chaben M, Lazzari JO. Test de hemaglutinación para el diagnóstico de la enfermedad de Chagas. Prensa Méd Arg 1962; 49:1761-7

45. Cerisola JA, Alvarez, De Rissio AM. Imunodiagnóstico da doença de Chagas. Evolução sorológica de pacientes com doença de Chagas. Rev Inst Med Trop S Paulo 1970; 12: 403-11

46. Chuit R, Subias E, Perez AC, Paulone I, Wisnivesky-Colli C, Segura EL. Usefulness of serology for the evaluation of Trypanosoma cruzi transmission in endemic areas of Chagas' disease. Rev Soc Bras Med Trop 1989; 22: 119-24.

47. Ciaravolo RM de C, Domingos M de F, Wanderley DMV, Gerbi LJ, Chieffi PP, Peres BA, Umezawa ES. Autochthonous acute Chagas' disease in São Paulo State, Brazil: epidemiological aspects. Rev Inst Med Trop S Paulo 1997; 39: 171-4.

48. Coda D, Falci N, Mendes FAT. Contribuição para o estudo e a profilaxia da moléstia de Chagas no Estado de São Paulo. Rev Inst Adolfo Lutz 1958; 18: 83-121. 
49. Coons $\mathrm{AH}$, Creech $\mathrm{HJ}$, Jones $\mathrm{RN}$. Immunological properties of an antibody containing a fluorescent group. Proc Soc Exp Biol Med 1941; 47: 200

50 Corrèa $R$ de $R$ Grupo de estudio sobre la enfermedad de Chagas. Técnicas de contrôle utilizadas no Estado de São Paulo. World Health Organization. Geneva; 1969. [WHO/CHAGAS/SG/69.13]

51 Corrêa R de R, Rocha e Silva EO da, Schiavi A Observações sôbre o Panstrongylus megistus, transmissor da moléstia de Chagas (Hemiptera, Reduviidae). Arq Hig Saúde Pública $1963 ; 28: 165-74$

52. Corrêa R de R, Guarita OF, França JBM. Doença de Chagas no Estado de São Paulo, Brasil. In: Resumos do $18^{\circ}$ Congresso Brasileiro de Higiene; 1970 out 26-31, São Paulo, Brasil. São Paulo: Sociedade Brasileira de Higiene; 1970

53. Costa FDA, Guarita OF. Presença do Triatoma infestans, transmissor da doença de Chagas, na baixada litorânea do Estado de São Paulo, Brasil. Rev Paul Med 1967; $70: 101-2$

54. Costa FDA, Fonseca JAB da, Carvalho ME de, Wanderley DMV, Ciaravolo RM de C, Massucato MAS, Godo C. Resultados preliminares de inquerito soroepidemiológico de doença de Chagas no Litoral Sul do Estado de São Paulo. In: Resumos do $7^{\circ}$ Congresso da Sociedade Brasileira de Parasitologia; 1982 jan-fev 31-04; Porto Alegre, Brasil. Porto Alegre: Sociedade Brasileira de Parasitologia; 1982. p. 149.

55. Coura JR. O papel dos municipios no combate à doença de Chagas e outras endemias Rev Soc Bras Med Trop 1993, 26 Supl 2: 50-1.

56. Coutinho J de O. Contribuição ao estudo da epidemiologia da doença de Chagas. Arq Hig Saúde Pública 1962; 27: 317-30

57. Cura EN, Segura EL. Quality assurance of the serologic diagnosis of Chagas' disease. Pan Am J Public Health 1998; 3 : 242-8.

58. Dawson-Saunders B, Trapp RG. Basic \& clinical biostatistics. $2^{\text {nd }}$ ed Norwalk, Connecticut: Appleton \& Lange, 1994.

59. Dean AG, Dean JA, Coulombier D, Brendel KA, Smith DC, Burton AH, Dicker RC, Sullivan K, Fagan RF, Arner TG. Epi Info, Version 6: a word processing database, and statistics program for epidemiology on microcomputers. Centers of Disease Control and Prevention, Atlanta, Georgia, U.S.A., 1994.

60. Degrave W, Levin MJ, Silveira JF, Morel C.M. Parasite genome projects and the Trypanosoma cruzi genome initiative. Mem Inst Oswaldo Cruz 1997, 92: 859-62.

61. Dellatorre MCC, Chieffi PP. Verificação de infecção chagásica em Juquiá. (Nota prévia). In: Resumos do $19^{\circ}$ Congresso Brasileiro de Higiene; 1977 out 10-14; São Paulo, Brasil. São Paulo: Sociedade Brasileira de Higiene; 1977. p. 10.6.

62. Dellatorre MCC, Buralli GM, D'Avila AC, Glasser CM, Vilanova MCT. Controle da doença de Chagas no Vale do Ribeira. In: Resumos do $2^{\circ}$ Congresso Paulista de 
Saúde Pública; 1983; São Paulo, Brasil. São Paulo: Sociedade Paulista de Saúde Pública; 1983, p. 85

63. Diamond GA Clinical epistemology of sensitivity and specificity. J Clin Epidemiol $1992 ; 45: 9-13$

64. Dias JCP. Prevalência da doença de Chagas em crianças da zona rural de Bambuí, MG, após ensaio profilático. Rev Bras Malariol 1967; 29: 135-59

65. Dias JCP. Perspectivas para o controle da doença de Chagas humana em áreas endêmicas através de profilaxia domiciliar com inseticidas de ação residual. Experiência de Bambuí, Minas Gerais, Brasil. Belo Horizonte, 1974. [Monografia de conclusão de mestrado - Faculdade de Medicina da UFMG].

66. Dias JCP. Doença de Chagas em Bambui, (MG) Brasil. Estudo clinicoepidemiológico a partir da fase aguda, entre 1940 e 1982 . Belo Horizonte; 1982. [Tese de doutorado - Faculdade de Medicina da UFMG]

67. Dias JCP. O desafio da doença de Chagas nos centros urbanos. Rev Soc Bras Med Trop 1999, 32 Supl 2: 45-7

68. Dias JCP. O papel do municipio no controle da doença de Chagas no Brasil e a proposta de extinção da Fundação Nacional de Saúde. Rev Soc Bras Med Trop 1993; 26 Supl 2: 47-50.

69. Diotaiuti L, Pereira AS, Loiola CF, Fernandes AJ, Schofield JC, Dujardin JP, Dias JCP, Chiari E. Inter-relation of sylvatic and domestic transmission of Trypanosoma cruzi in areas with and without domestic vectorial transmission in Minas Gerais, Brazil. Mem Inst Oswaldo Cruz 1995; 90: 443-8.

70. Domingos M de F. Aspectos epidemiológicos da leishmaniose tegumentar americana na região do Vale do Ribeira, Estado de São Paulo, Brasil, no período de 1981 a 1995. São Paulo, 1997. [Dissertação de Mestrado - Faculdade de Saúde Pública da USP].

71. Feitosa MF, Krieger H. An appraisal of the epidemiology of Trypanosoma cruzi serology in Brazil. Mem Inst Oswaldo Cruz 1991; 86: 159-67.

72. Ferreira CS, Carvalho ME de, Aninger V. Alguns dados sobre coleta de pequenas quantidades de sangue para reações de imunofluorescência - RIF. In: Resumos do $18^{\circ}$ Congresso Brasileiro de Higiene, 1970 out 26-31, São Paulo, Brasil, 1970. São Paulo: Sociedade Brasileira de Higiene; 1970.

73. Ferreira CS, Carvalho ME de, Helene CG. Coleta de sangue em fitas de papel-filtro (Nota prévia). Rev Paul Med 1971; 78: 36.

74. Ferreira CS, Carvalho ME de Reações de imunofluorescência indireta: algumas simplificações de sua técnica. Rev Saúde Pública 1973, 7: 303-6.

75. Ferreira CS, Carvalho ME de. Padronização de uso de papel-filtro como suporte de material para reações sorológicas. Rev Bras Malariol 1982; 34: 82-6. 
76. Ferreira MU, Camargo LMA, Ferreira CS. The median age of primary malaria infection in an Amazonian community: probit analysis of cross-sectional data. Acta Tropica $1994 ; 58: 73-8$

77. Fife Jr EH. Current state of serological tests used to detect blood parasite infections. Exp Parasit 1972, 31 : 136-52.

78. Fife Jr EH, Muschel LH. Fluorescent antibody technic for serodiagnosis of Trypanosoma cruzi infection. Proc Soc Exp Biol Med 1959, 101: 540-3

79. Figueirêdo-Silva J, Kaneda Y, Tachibana H, Furushima R, Tateno S, Corrêia-Lima FG, Bento DNC. Epidemiological survey of Trypanosoma cruzl in North-Eastern Brazil using different diagnostic methods. Rev Inst Med Trop S Paulo 1991; 33: 193-8.

80. Finney DJ. Probit analysis. 3rd ed Cambridge: Cambridge University Press; 1980.

81. Forattini OP Ecologia, epidemiologia e sociedade. São Paulo: Artes Médicas; 1992.

82. Forattini OP, Rocha e Silva EO da, Rabello EX, Andrade JCR, Rodrigues VLCC Aspectos ecológicos da tripanossomiase americana. XIII - Potencial enzoótico doméstico em área de $P$. megistus, sob vigilância epidemiológica. Rev Saúde Pública $1978,12: 417-24$

83. Forattini OP, Pattoli DBG, Serra OP, Rocha e Silva EO da, Rabello EX. Nota sobre leishmaniose tegumentar no Litoral Sul do Estado de São Paulo, Brasil. Rev Saúde Pública 1973; $7: 447-52$.

84. Forattini OP, Rocha e Silva EO da, Barata JMS, Boainain E. Nota sobre caso autóctone de tripanossomíase americana no Litoral Sul do Estado de São Paulo, Brasil. Rev Saúde Pública $1980 ; 14: 143-9$

85. Forattini OP, Rocha e Silva EO da, Barata JMS, Boainain E. Nota sobre novo caso autóctone de tripanossomíase americana no Litoral Sul do Estado de São Paulo, Brasil. Rev Saúde Pública 1981; 15: 350-2.

86. Freitas JLP de. Contribuição para o estudo do diagnóstico da moléstia de Chagas por processos de laboratório. São Paulo; 1947. [Tese de doutorado - Faculdade de Medicina da USP]

87. Freitas JLP de. Dados atuais sobre a distribuição de triatomídeos e moléstia de Chagas no Estado de São Paulo. Rev Paul Med 1950, 37: 227-36

88. Freitas JLP de, Almeida JO de. Nova técnica de fixação do complemento para moléstia de Chagas. O Hospital 1949; 35: 787-800.

89. Freitas JLP de, Romero Neto M, Nesti A, Andrade e Silva U de, Lima AB. Resultados de um inquérito sobre moléstia de Chagas realizado no município de São Carlos (Estado de São Paulo, Brasil) e arredores. Folia Clín et Biol 1950, 16: 150-7.

90. Fucks AP, Fioratti VL, Mello VA de, Boainain E. Diagnóstico sorológico na doença de Chagas. Estudo comparativo de diferentes técnicas. Rev Inst Med Trop S Paulo $1980 ; 22.242-5$ 
91. Fundação IBGE. Enciclopédia dos municípios brasileiros. Rio de Janeiro, 1958. v. XXVIII-XXX

92. Fundação SEADE. O novo retrato de São Paulo. Avaliação dos primeiros resultados do censo demográfico de 1991. $2^{\text {a }}$ ed. São Paulo; 1993

93. Goldbaum M, Litvoc J, Silva GR da, Maluf J, Valério DMB, Francisco SM Prevalência da infecção chagásica na micro-região de Campos de Itapetininga - São Paulo. In: Anais do $1^{\circ}$ Congresso da Sociedade Brasileira de Medicina Tropical; 1979 fev 04-08; Campinas (Brasil). Campinas: Sociedade brasileira de Medicina Tropical, 1979. Sala "René Rachou".

94. Goldsmith RS, Zárate RJ, Zárate LG, Kagan IG, Jacobson LB. Clinical and epidemiological studies of Chagas' disease in rural communities in Oaxaca State, Mexico, and a seven-year follow-up: I. Pan Am Health Organ Bull 1985; 19: 120-38

95. Gontijo ED. Atenção ao chagásico em centros urbanos. Rev Soc Bras Med Trop 1999; 32 Supl 2: 73

96. Guarita OF, Fomm AS, Brigido RM, Pimenta Filho TT. Inquérito sorológico para avaliação da infecção chagásica do grupo etário de 9 a 14 anos dos escolares do Estado de São Paulo, Brasil. São Paulo: Secretaria de Estado da Saúde de São Paulo - SUCEN; 1978.

97. Guarita OF, Dias Jr. Carvalho ME de, Valério DMB, Salvo A de. Infecção chagásica: inquérito escolar em alguns municipios do Estado de São Paulo, por meio de reação de imunofluorescência indireta, de 1973 a 1978 . In: Anais do $15^{\circ}$ Congresso da

Sociedade Brasileira de Medicina Tropical; $1979 \mathrm{fev}$ 04-08; Campinas (Brasil) Campinas: Sociedade Brasileira de Medicina Tropical; 1979. Sala "René Rachou".

98. Guarita OF, Ishihata GK, Carvalho ME de, Wanderley DMV, Salvo A de. Inquérito sorológico para determinação da infecção chagásica em 48 municípios do Estado de São Paulo, por meio de reação de imunofluorescência indireta, de 1973 a 1980 . In Resumos do $6^{\circ}$ Congresso Brasileiro de Parasitologia; 1981 fev 15-18; Belo Horizonte (Brasil). Belo Horizonte: Sociedade Brasileira de Parasitologia; 1981. p.42.

99. Guarita OF, Ishihata GK, Carvalho ME de, Wanderley DMV, Ciaravolo RM de C, Massucato MAS. Doença de Chagas: inquérito soroepidemiológico em população selecionada de escolares da $1^{\mathrm{a}}$ série do $1^{\circ}$ grau de alguns municípios do Estado de São Paulo. In: Resumos do $18^{\circ}$ Congresso da Sociedade Brasileira de Medicina Tropical; 1982 fev 01-06; Ribeirão Preto (Brasil). Ribeirão Preto: Sociedade Brasileira de Medicina Tropical; 1982. p. A-16.

100. Guerreiro C, Machado A. Da reação de Bordet e Gengou na moléstia de Carlos Chagas como elemento diagnóstico. Brasil Médico 1913; 23: 225-6.

101. Guimarães MCS. Chagas' disease serology: specifications and evaluation methods for immunological reagents. Washington (DC): Pan American Health Organization; 1984. (PAHO - PNSP/84 08). 
102. Guimarães MCS, Camargo ME, Ferreira AW, Castilho EA, Nakahara OS Comparison of IgG and IgM contents in serum and filter paper blood eluates. Am J Trop Med Hyg 1978; 27 : 350-3

103. Haron $\mathrm{T}$. Inquérito epidemiológico e profilaxia da moléstia de Chagas no município de Garça, Estado de São Paulo. Arq Hig Saúde Pública 1952; 17: 1-25

104. Hayes RJ, Schofield CJ. Estimación de las tasas de incidencia de infecciones y parasitosis crónicas a partir de la prevalencia: la enfermedad de Chagas en América Latina. Bol Oficina Sanit Panam 1990; 108: 308-16.

105. Hoff R, Todd CW, Maguire JH, Piesman J, Mott KE, Mota EE, Sleigh A, Sherlock IA, Weller TH. Serologic surveillance of Chagas' disease. Ann Soc Belge Méd Trop 1985; 65 Suppl. 1: 187-96

106. Kagan IG. Parasitic diseases. In: Paul JR, White C. Serological epidemiology. New York: Academic Press, 1973. p. 155-67.

107. Kagan IG, Goldsmith RS, Zárate-Catañeda R, Allain DS. Evaluación de pruebas serológicas utilizadas para estudiar la enfermedad de Chagas. Bol Of Sanit Panam $1979 ; 87: 309-18$

108. Kirchhoff LV, Gam AA, Gusmão RD'A, Goldsmith RS, Rezende JM, Rassi A. Increased specificity of serodiagnosis of Chagas' disease by detection of antibody to the 72- and 90- Kilodalton glycoproteins of Trypanosoma cruzi. J Infec Dis 1987; 155: $561-4$.

109. Lacoste Y. L'enquête et le terrain: un problème politique por les chercheurs, les étudiants et les citoyens. Hérodote 1977; 8: 3-20.

110. Lamparelli V, Lamparelli M do RM. Uma colcha de retalhos. São Paulo: Gráfica do Centro Técnico de Aeronáutica - CTA - São José dos Campos (SP); 1969. [História de familia para os netos].

111. Lima FO, Silva TL da. Distribuição dos triatomíneos no Estado de São Paulo. Arq Hig Saúde Pública 1952, 17: 27-55

112. Lima VLC DE, Yaguchi MK, Alves ZCPVT. Aspectos da atividade de "notificação de barbeiros" pela população no controle de Panstrongylus megistus em 12 municípios da região noroeste do Estado de São Paulo, Brasil, 1974 a 1983. Rev Saúde Pública 1990, $24: 497-505$

113. Litvoc J. Doença de Chagas e estrutura social: infestação domiciliar e infecção humana em áreas submetidas a ações de controle. São Paulo; 1985. [Tese de Doutorado. Faculdade de Medicina da USP].

114. Litvoc J, Goldbaum M, Silval GR da, Maluf J, Valério DMB, Francisco SM. Transmissão da doença de Chagas na micro-região Campos de Itapetininga - São Paulo. In: Anais do $15^{\circ}$ Congresso da Sociedade Brasileira de Medicina Tropical; 1979 fev 4-8; Campinas, SP, Brasil. Campinas: Sociedade Brasileira de Medicina Tropical; 1979. Sala "René Rachou". 
115. Litvoc J, Oya DRT, Goldbaum M, Maluf J, França JBM, Salvo A de. Plano de amostragem na estimativa da prevalência de infecção chagásica. In: Anais do $\mathbf{1 5}^{\circ}$ Congresso da Sociedade Brasileira de Medicina Tropical; 1979 fev 4-8; Campinas, SP, Brasil. Campinas: Sociedade Brasileira de Medicina Tropical; 1979 Sala "René Rachou".

116. Luquetti AO. Use of Trypanosoma cruzi defined proteins for diagnosis-Multicentre trial(+) Serological and technical aspects. Mem Inst Oswaldo Cruz 1990; 85: 497505 .

117. Luquetti AO. Diagnóstico laboratorial da doença de Chagas. Rev Soc Bras Med Trop $1992 ; 25: 22-3$.

118. Luquetti AO, Rassi A. Tratamiento especifico de la enfermedad de Chagas en la fase crónica: criterios de cura convencionales: xenodiagnóstico, hemocultivo y serología. Rev Pat Trop 1998; 27 Supl: 37-47

119. Luquetti AO, De Ponce E, Tavares SBN, Oliveira RA de, Ponce C. Concentración de anticuerpos en infectados chagásicos. Comparación en dos regiones endémicas de América Latina. Resultados preliminares. In: Resúmenes del XIV Congreso Latinoamericano de Parasitología; 1999 oct 11-16; Acapulco (Gro), México. Acapulco: Federación Latinoamericana de Parasitologia; 1999. p. 9.

120. Machado-Coelho GLL, Vitor RW de A, Chiari C de AC, Antunes CM de F. Validity of serology for American trypanosomiasis with eluates from filter paper. Mem Inst Oswaldo Cruz 1995; 90: 59-64

121. Maekelt GA. Die Komplementbindungsreaktion der Chagaskrankheit Zeitschrift für Tropenmedizin und Parasitologie 1960; 2: 152-86.

122. Maekelt GA, Colmenares de Alayon C. Método sencillo para el envío de sueros chagásicos desde las zonas rurales. Nota preliminar. Arch Venez Med Trop Parasit Méd 1960; 3: 133-42.

123. Maluf J, Guarita OF, Rocha e Silva EO da. O controle da doença de Chagas no município de Bariri, Estado de São Paulo. Rev Saúde Pública 1970; 4: 7-12.

124. Maluf J, França JBM, Salvo A de, Silva GR da, Litvoc J, Goldbaum M. Avaliação de efeitos de não-cobertura em levantamento epidemiológico da doença de Chagas. In: Anais do $1^{\circ}$ Congresso da Sociedade Brasileira de Medicina Tropical; $1979 \mathrm{fev}$ 4-8, Campinas, SP, Brusil. Campinas: Sociedade Brasileira de Medicina Tropical; 1979. Sala "René Rachou".

125. Marsden P, Garcia-Zapata MTA, Castillo EAS, Prata AR, Macedo VO. Los 13 primeros años del control de la enfermedad de Chagas en Mambai, Goiás, Brasil, 1980-1992. Bol Oficina Sanit Panam 1994; 116: 111-7.

126. Melo, JH de. A moléstia de Chagas no município de Santa Bárbara do Rio Pardo Estado de São Paulo - Notas sobre epidemiologia e profilaxia. Arq Hig Saúde Pública 1952; 17: 75-82 
127. Mello DA. Parasitic diseases in Brazil and the role of wild mammals: an analysis based on leishmaniasis, Chagas' disease and schistosomiasis mansoni Ciên Cul 1991; 2748 .

128. Mello C da S, Salvo A de, Rocha e Silva EO da, Dias Jr J, Noda J, Carvalho ME de, Guarita OF. Estudo epidemiológico relativo à infecção chagásica no municipio de Taquarituba, São Paulo, realizado no período de 1974 a 1976. In: Resumos do $19^{\circ}$ Congresso Brasileiro de Higiene, 1977 out 10-14, São Paulo, Brasil. São Paulo: Sociedade Brasileira de Higiene; 1977. p. 10.5

129. Mendes RP. Significado e aplicação da técnica de Western Blot. Rev Soc Bras Med Trop 1993, 26 Supl 2: 3-4

130. Moncayo A. Progress towards the elimination of transmission of Chagas disease in Latin America. World Health Stat Wtly 1997, 50: 195-98

131. Montes De Oca N de la V, Alonso CC, Martinez R, Cantelar De Francisco N, Insueta OM. Estudio serologico para el diagnostico de la enfermedad de Chagas en estudiantes nicaraguenses de la Isla de La Juventud. Rev Cubana Med Trop 1989; 41: 405-12.

132. Mott KE, Lehman Jr JS, Hoff R, Morow RH, Muniz TM, Sherlock I, Draper CC, Pugliese C, Guimarães AC. The epidemiology and household distribution of seroactivity of Trypanosoma cruzi in a rural community in northeast Brazil. Am J Trop Med Hyg 1976; 25 : 552-62.

133. Muniz J, Freitas G. Contribuição para o diagnóstico da Doença de Chagas pelas reações de imunidade. Mem Inst Oswaldo Cruz 1944, 41: 303-33.

134. Muniz J, Freitas G. Contribuição para o diagnóstico da Doença de Chagas pelas reações de imunidade. II. Isolamento de polissacarídeos de Schizotrypamum cruzi e de outros Tripanosomatídeos, seu comportamento nas reações de precipitação, de fixação do complemento e de hipersensibilidade. Os "tests" de floculação (sublimado e formol-gel). Rev Brasil Biol 1944; 4: 421-38

135. Pacheco AD, Brenière SF, Bosseno MF, Mendoza J, Rangel H, Ramos C, Espinoza B. Evaluación de la técnica de reacción en cadena de la polimerasa (PCR), como prueba de diagnóstico en pacientes com la enfermedad de Chagas. In: Resumenes del XIV Congreso Latinoamericano de Parasitología; 1999 oct 11-16; Acapulco (Gro), México. Acapulco: Federación Latinoamericana de Parasitologí; 1999. p. 10

1336. Pan American Health Organization. Study Group on Chagas' Disease. Puerto Rico: PAHO; 1966. $16 \mathrm{p}$.

1347. Pan American Health Organization. Status of Chagas' disease in the Region of the Americas. Epidemiol Bull 1984; 5(2): 5-9

138. Passalacqua C de SP. Dados gerais sobre o municipio de Araçoiaba da Serra. Arq Hig Saúde Pública 1952; 17:61-7 
139. Paul JR. Development and use of serum surveys in Epidemiology. In: Paul JR, White C. Serological epidemiology. New York: Academic Press, 1973. p. 1-13

140. Paul JR, Riordan JR. Observations on serological epidemiology: antibodies to the lansing strain of poliomyelites virus in sera from Alaskan eskimos. Am J Hyg 1950; 52: $202-12$.

141. Paul JR, White C. Objectives and scope of serum surveys. In: Paul JR, White C. Serological epidemiology. New York: Academic Press, 1973 p. 15-8.

142. Pereira JB, Coura JR. Diferenças regionais na doença de Chagas. Aspectos clínicos, epidemiológicos e laboratoriais de duas áreas endêmicas do Brasil. Rev Soc Bras Med Trop 1993; 26 Supl 2: 70-2.

143. Piesman J, Mota E, Sherlock IA, Todd CW. Trypanosoma cruzi: association between seroreactivity of children and infection rates in domestic Panstrongylus megistus (Hemiptera: Reduviidae). J Med Entomol 1985; 22: 130-3

144 Piesman J, Sherlock IA, Mota E, Todd CW, Hoff R, Weller TH. Association between household triatomine density and incidence of Trypanosoma cruzi infection during a nine-year study in Castro Alves, Bahia, Brazil. Am J Trop Med Hyg 1985; 34: 8669.

145. Pless M, Juranek D, Lozarsky P, Steurer F, Tapia G, Bermudez H. The epidemiology of Chagas' disease in na hyperendemic area of Cochabamba, Bolivia: a clinical study including electrocardiography, seroreactivity to Trypanosoma cruzi, xenodiagnosis, and domiciliary triatomine distribution. Am J Trop Med Hyg 1992; 47: 539-46.

146. Prado A de A. Meio século de existência clínica da Doença de Chagas. Rev Inst Med Trop S Paulo 1959; 11 : 219-28

147. Primavera SCK, Umezawa ES, Peres BA, Camargo ME, Hoshino-Shimizu S. Chagas' disease: $\operatorname{IgA}, \operatorname{IgM}, \operatorname{IgG}$ antibodies to Trypanosoma cruzi amastigote, trypomastigote and epimastigote antigens inacute and in different chronic forms of the disease. Rev Inst Med Trop S Paulo 1990; 32: 172-80

148. Puigbó JJ, Nava JRR, Garcia HB, Gil CY. Cuatro años de estudio longitudinal de una comunidad rural con endemicidad chagasica. Bol Oficina Sanit Panam 1969; 66 : $112-20$

149. Rabello A, Luquetti AO, Moreira EF, Gadelha M de F, Santos JA dos, Melo L, Schind P. Serodiagnosis of Trypanosoma cruzi infection using the new particle gel immunoassay-ID-PaGIA Chagas. Mem Inst Oswaldo Cruz 1999; 94 : 77-82.

150. Rabinovich JE, Wisnivesky-Colli C, Solarz ND, Gürtler RE. Probability of transmission of Chagas disease by Triatoma infestans (Hemiptera: Reduviidae) in an area of Santiago del Estero, Argentina. Bull World Health Organ 1990; 68: 737-46.

151. Ramos J, Freitas JLP de, Borges S. Moléstia de Chagas: estudo clínico e epidemiológico. Arq Bras Cardiol 1949; 2: 111 -62. 
152. Reiche EMV, Jankevicius JV. Avaliação de métodos alternativos para o diagnóstico laboratorial confirmatório da doença de Chagas. Rev Bras An Clín 1997, 29: 29-40.

153. Rocha e Silva EO da, Dias Jr J, Guarita OF. Suspensão do rociado no combate ao Triatoma infestans em áreas do Estado de São Paulo, Brasil. Rev Saúde Pública $1969,31: 173-81$

154. Rocha e Silva EO da, Maluf J, Corrêa R de R. Doença de Chagas. Atividades de vigilância entomológica numa área do Estado de São Paulo, Brasil. Rev Saúde Pública $1970 ; 4: 129-45$.

155. Rocha e Silva EO da, Ferreira CS, Maluf J, Guarita OF, Pickart H. Inquéritos sorológicos para o diagnóstico da doença de Chagas utilizando a reação de imunofluorescência (R.I.F.). In: Resumos de $6^{\circ}$ Congresso da Sociedade Brasileira de Medicina Tropical; 1970; Porto Alegre, Brasil. Porto Alegre: Sociedade Brasileira de Higiene; 1970.

156. Rocha e Silva EO da, Andrade JCR de, Lima AR de. Importância dos animais sinantrópicos no controle da endemia chagásica. Rev Saúde Pública 1975; 9: 37181

157. Rocha e Silva EO da, Andrade JCR de, Rodrigues VLCC. Investigação de foco, uma das atividades das campanhas de controle dos transmissores da tripanossomíase americana. Rev Saúde Pública 1978; 12: 425-31.

158. Rocha e Silva EO da, Guarita OF, Ishihata GK. Doença de Chagas: atividades de controle dos transmissores no Estado de São Paulo; Brasil. Rev Bras Malariol 1979; 31:99-119

159. Rocha e Silva EO da, Capinzaiki AN, Kuratomi CA, Guedes ACM. A leishmaniose tegumentar americana no Litoral Sul do Estado de São Paulo. Rev Bras Malariol 1980; 32: 9-25.

160. Rocha e Silva EO da, Wanderley DMV, Rodrigues VLCC. Triatoma infestans: importância, controle e eliminação da espécie no Estado de São Paulo, Brasil. Rev Soc Bras Med Trop 1998; 31 : 73-88

161. Romaña C, Dias E. Reação de fixação do complemento na Doença de Chagas, com antígeno alcoólico de cultura de Schizotrypanum cruzi. Mem Inst Oswaldo Cruz 1942, 37: 1-10.

162. Rosenfeld G, Cardoso FA. Distribuição dos triatomídeos e da moléstia de Chagas no Estado de São Paulo (Brasil). Rev Clín S Paulo 1941; 9: 198-209.

163. Rottenberg ME, De Titto EH, Cardoni RL, Segura EL. Respuesta inmune en la infección con Trypanosoma cruzi. Rev Arg Microbiol 1991; 23: 101-21

164. Sadun EH, Duxbury RE, Williams JS, Anderson RI. Fluorescent antibody test for the serodiagnosis of African and American trypanosomiasis in man. J Parasitol 1963; 49 . 385-8. 
165. Salvatella R, Calegari L, Casserone S, Civila E, Carbajal S, Pérez G, Somma R, Sampaio I, LLanes ME, Conti M, Paulerci C, Conti-Diáz IA, Somma-Moreira R, Pérez Moreira L. Seroprevalencia de anticuerpos contra Trypanosoma cruzi en 13 Departamentos del Uruguay. Bol Oficina Sanit Panam 1989; 107: 108-17.

166. Sánchez B, Caballero ML, Reyes PA, Monteón V, Rangel H, Ramos C, Espinoza B. Experiencia en México com la utilización de ELISA y Western Blot en el diagnóstico de la enfermedad de Chagas empleando antígenos puros. In: Resumenes del XIV Congreso Latinoamericano de Parasitología; 1999 oct 11-16; Acapulco (Gro), México. Acapulco: Federación Latinoamericana de Parasitologia, 1999 p. 8

167. São Paulo. Secretaria de Economia e Planejamento. Diagnóstico: $4^{a}$ Região Administrativa. São Paulo, 1972

168. Schattschneider ER, Lopes ER, Alencar JE de, Bienzle U, Feldmeier H. A comparative study of four serological methods of acute and chronic Chagas' disease in Brazilian patients. Trop Geogr Med 1992; 44: 210-8

169. Schenone $\mathrm{H}$, Contreras $\mathrm{M}$, Rojas A. Problema relacionado con el diagnóstico de enfermedad de Chagas. Bol Chil Parasitol 1989; 44: 24-9

170. Schenone H, Iglesias J, Schenone S, Contreras M del C. Infección chagásica congénita de segunda generación. Bol Chil Parasitol 1987, 42: 71-3.

171. Schiavi A, Lima AR de, Ramos A da S. A desinsetização da área central do Estado de São Paulo, visando os vetores da moléstia de Chagas. Arq Hig Saúde Pública 1952; 17: $117-21$

172. Secretaria de Estado da Saúde de São Paulo. Superintendência de Controle de Endemias (SUCEN). Divisão de Estudos e Programas (DEP)/Área de Epidemiologia Programa de Controle da doença de Chagas no Estado de São Paulo. Relatório Anual, 1983. São Paulo: SUCEN; 1983

173. Secretaria de Estado da Saúde de São Paulo. Superintendência de Controle de Endemias (SUCEN). Departamento de Combate a Vetores (DCV). Planejamento de Atividades do Programa de Controle da doença de Chagas do Estado de São Paulo 1987. São Paulo: SUCEN; 1988

174. Secretaria de Estado da Saúde de São Paulo. Superintendência de Controle de Endemias (SUCEN). Departamento de Combate a Vetores (DCV). Oficio Circular DCV No 005/84 de 13.01-1984. São Paulo: SUCEN; 1984.

175. Secretaria de Estado da Saúde de São Paulo. Superintendência de Controle de Endemias (SUCEN). Departamento de Combate a Vetores (DCV). Planejamentos do Serviço Regional da Grande São Paulo 1985-1988. São Paulo: SUCEN/DCV; 1985-1988.

176. Secretaria de Estado da Saúde de São Paulo. Superintendência de Controle de Endemias (SUCEN). Departamento de Combate a Vetores (DCV). Planejamentos 
do Serviço Regional de São Vicente 1985-1988. São Vicente (SP): SUCEN/DCV; 1985-1988.

177. Secretaria de Estado da Saúde de São Paulo. Superintendência de Controle de Endemias (SUCEN). Departamento de Combate a Vetores (DCV). Planejamentos do Serviço Regional de Taubaté 1985-1988. Taubaté (SP): SUCEN/DCV; 19851988

178. Secretaria de Estado da Saúde de São Paulo. Superintendência de Controle de Endemias (SUCEN). Departamento de Combate a Vetores (DCV). Planejamentos do Serviço Regional de Sorocaba 1985-1988. Sorocaba (SP): SUCEN/DCV; 19851988

179. Secretaria de Estado da Saude de São Paulo. Superintendência de Controle de Endemias (SUCEN). Departamento de Combate a Vetores (DCV). Planejamentos do Servico Regional de Campinas 1985-1988. Campinas (SP): SUCEN/DCV; 1985-1988.

180. Secretaria de Estado da Saúde de São Paulo. Superintendência de Controle de Endemias (SUCEN). Departamento de Combate a Vetores (DCV). Planejamentos do Serviço Regional de Ribeirão Preto 1985-1988. Ribeirão Preto (SP) SUCEN/DCV, 1985-1988

181. Secretaria de Estado da Saúde de São Paulo. Superintendência de Controle de Endemias (SUCEN). Departamento de Combate a Vetores (DCV). Planejamento do Serviço Regional de São José do Rio Preto 1985-1988. São José do Rio Preto (SP): SUCEN/DCV; 1985-1988.

182. Secretaria de Estado da Saúde de São Paulo. Superintendência de Controle de Endemias (SUCEN). Departamento de Combate a Vetores (DCV). Planejamentos do Serviço Regional de Araçatuba 1985-1988. Araçatuba (SP): SUCEN/DCV; 1985-1988

183. Secretaria de Estado da Saúde de São Paulo. Superintendência de Controle de Endemias (SUCEN). Departamento de Combate a Vetores (DCV). Planejamentos do Serviço Regional de Presidente Prudente 1985-1988. Presidente Prudente (SP): SUCEN/DCV; 1985-1988

184. Secretaria de Estado da Saúde de São Paulo. Superintendência de Controle de Endemias (SUCEN). Departamento de Combate a Vetores (DCV). Planejamentos do Serviço Regional de Marília 1985-1988. Marília (SP): SUCEN/DCV; 19851988.

185. Secretaria de Estado da Saúde de São Paulo. Superintendência de Controle de Endemias (SUCEN). Departamento de Combate a Vetores (DCV). Planejamento do Serviço Regional de Sorocaba 1990. Sorocaba (SP): SUCEN/DCV; 1989. 
186. Secretaria de Estado da Saúde de São Paulo. Superintendência de Controle de Endemias (SUCEN). Departamento de Combate a Vetores (DCV). Planejamentos dos Serviço Regional de Campinas 1990. Campinas (SP): SUCEN/DCV; 1989.

187. Secretaria de Estado da Saúde de São Paulo. Superintendência de Controle de Endemias (SUCEN). Descentralização de atividades de controle de endemias. São Paulo, SUCEN, 1994

188. Segura EL, Pérez AC, Yanovsky JF, Andrade J Wynne De Martini GJ. Decrease in the prevalence of infection by Trypanosoma cruzi (Chagas' disease) in young men of Argentina. Pan Am Health Organ Bull 1985; 19: 252-64

189. Silva LJ da. Evolução da doença de Chagas no Estado de São Paulo. Ribeirão Preto, SP, 1981. [Tese de Doutoramento - Faculdade de Medicina de Ribeirão Preto da USP]

190 Silva LJ da. Desbravamento, agricultura e doença: a doença de Chagas no Estado de São Paulo Cad Saúde Pública 1986, 2: 124-40

191. Silva RA, Bonifácio PR, Wanderley DMV. Doença de Chagas no Estado de São Paulo: comparação entre pesquisa ativa de triatomineos em domicílios e notificação de sua presença pela população em área sob vigilância entomológica. Rev Soc Bras Med Trop 1999; 32: 653-9

192. Silva TL da, Unti O. Epidemiologia e profilaxia da moléstia de Chagas no Estado de São Paulo. Arq Hig Saúde Pública 1952; 17: 83-90.

193. Silva TL da, Unti O. Organização so serviço para o combate à moléstia de Chagas no Estado de São Paulo. Arq Hig Saúde Pública 1952; 17: 99-107.

194. Silveira JF da. Aplicação de antígenos recombinantes de Trypanosoma cruzi no sorodiagnóstico da doença de Chagas. Rev Soc Bras Med Trop 1993; 26 Supl 2: 201 .

195. Sokal RR, Rohlf FJ. Biometry. $2^{\text {nd }}$ ed. New York: Freeman; 1981

196. Solís-Acosta HM, Ferreira CS, Carvalho ME de. Seroepidemiology of Chagas' disease in Nasca, Southern region of Peru. Rev Inst Med Trop S Paulo 1997; 39: 107-12.

197. Souza SL de, Camargo ME. The use of filter paper blood smears in a practical fluorescent test for American trypanosomiasis serodiagnosis. Rev Inst Med Trop S Paulo 1966; 8:255-8

198. Souza AG, Wanderley DMV, Buralli GM, Andrade JCR de. Consolidation of the control of Chagas' disease in the state of São Paulo. Mem Inst Oswaldo Cruz 1984; 79(Supl.): 125-31.

199. Spinella S, Liegeard P, Hontebeyrie-Joskowicz M. Trypanosoma cruzi: predominance of IgG2a in nonspecific humoral response during experimental Chagas' disease. Exp Parasitol 1992; 74: 46-56. 
200. Tanowitz HB, Kirchhoff LV, Simon D, Morris AS, Weiss LM, Wittner M. Chagas' disease. Clin Microbiol Reviews 1992; 5:400-19.

201. Teixeira M DA GLC. Doença de Chagas: estudo da forma aguda inaparente. Rio de Janeiro; 1977. [Dissertação de mestrado - Faculdade de Medicina da UFRJ].

202. Unti O, Silva TL da. Levantamento da moléstia de Chagas no Estado de São Paulo pela reação sorológica. Arq Hig Saúde Pública 1952; 17:123-32.

203. Unti O, Silva TL da, Aguiar AA de. Alguns dados sôbre a reação de Machado \& Guerreiro na infầncia. Arq Hig Saúde Pública 1952, 51 : 529-34

204. Vattuone NH, Szarfman A, Gonzales Cappa SM. Antibody response and immunoglobulin levels in humans with acute or chronic Trypanosoma cruzl infections (Chagas' disease). J Trop Med Hyg 1973; 76: 45-7.

205. Vecchio TJ. Predictive value of a single diagnostic test in unselected populations. New England J Med 1968, $274: 1171-3$.

206. Velasco-Hernandez JX. An epidemiological model for the dynamics of Chagas' disease. BioSystems 1991, 26: 127-34

207. Velasco-Castrejón O, Valdespino JL, Tapia-Conyer R, Salvatierra B, Guzmán-Bracho C, Magos C, LLausás A, Gutiérrez G, Sepúlveda J. Seroepidemiología de la enfermedad de Chagas en México. Salud Pública Méx 1992; 34 : 186-96.

208. Versiani O, Cavalcanti AC. As reações de Henry e Henry-Wolff na malária, esquistossomose, doença de Chagas e algumas outras entidades clínicas. Rev Bras Biol 1943; 3: 383-90

209. Wanderley DMV Vigilância do risco de transmissão da doença de Chagas por vetores secundários no Estado de São Paulo. Rev Soc Bras Med Trop 1993; 26 (Supl 2): $38-40$

210. Wanderley DMV Perspectivas de controle da doença de Chagas no Estado de São Paulo São Paulo, 1994. [Tese de Doutoramento - Faculdade de Saúde Pública da USP]

211. Wanderley DMV, Carvalho ME de, Glasser CM, Ciaravolo RM de C, Domingos M de F, Patucci RM de J. Vigilância epidemiológica da doença de Chagas na Região do Vale do Ribeira, Estado de São Paulo. In: Programa e resumos do $11^{\circ}$ Congresso Brasileiro de Parasitologia; 1989 jul-ago 30-03; Rio de Janeiro (BR). Rio de Janeiro: Sociedade Brasileira de Parasitologia; 1989. p. 6.

212. Wanderley DMV, Carvalho ME de, Mantegazza E, Yasumaro S, Barata LCB. Infecção chagásica transfusional detectada no programa de controle da doença de Chagas no Estado de São Paulo (Brasil). Rev Saúde Pública 1992; 26: 203-5.

213. Wanderley JS, Guariento ME, Almeida. Doença de Chagas: encaminhamento ao GEDOCH. Rev Soc Bras Med Trop 1999; 32 (Supl 2): 74-75. 
214. Wanderley JS, Anraku CD, Shiroma M, Almeida EA. Doença de Chagas: relato de 17 casos. Rev Soc Bras Med Trop 1999, 32 (Supl 2): 75.

215. Widmann FK, Itatani CA. An introduction to clinical immunology and serology $2^{\text {nd }}$ ed. Philadelphia: F A.Davis Co; 1998

216. Winker $\mathrm{P}$, Bosseno MF, Britto $\mathrm{C}$, Yaksic N, Cardoso MA, Medicis MC, Brenière F. High correlation between Chagas' disease serology and PCR-based detection of Trypanosoma cruzi kinetoplast DNA in Bolivian children living in na endemic area. FEMS Microbiol Lett 1994; 124: 419-24.

217. Wisnivesky-Colli C, Gürtler RE, Solarz ND, Lauricella MA, Segura EL.

Epidemiological role of humans, dogs and cats in the transmission of Trypanosoma cruzl in a central area of Argentina. Rev Inst Med Trop S Paulo 1985; 27: 346-52.

218. Wolff HL. The filter paper method for shipping blood samples for serological examination. Trop Geogr Med 1958; 10: 306-8.

219. World Health Organization. Control of Chagas Disease. Geneva; 1991. (WHO Technical Report Series, 811).

220. Zicker F, Smith PG, Luquetti AO, Oliveira OS. Mass screening for Trypanosoma cruzi infections using immunofluorescence, ELISA and haemagglutination tests on serum samples and on blood eluates from filter-paper. Bull World Health Organ 1990, 68: 465-71.

221. Zingales B. Biologia molecular e sua aplicação em novas técnicas de diagnóstico. Rev Soc Bras Med Trop 1993; 26 (Supl 2): 1.

222. Zingales B, Gruber A, Ramalho B, Umezawa E, Colli W. Use of two recombinant proteins of Trypanosoma cruzi in the serological diagnosis of Chagas disease. Mem Inst Oswaldo Cruz 1990; 85: 519-22.

223. Zingales B, Souto RP, Mangia RH, Lisboa CV, Campbell DA, Coura JR, Jansen A, Fernandes $\mathrm{O}$. Molecular epidemiology of American trypanosomiasis in Brazil based on dimorphisms of rRNA and mini-exon gene sequences. Int J Parasitol 1998; 28: 105-12.

224. Zuna H, Recacoechea M, Bermudez H, De Muynck A, Cardozo L. Infección chagásica en trabajadores agricolas temporales y sus familias, Proyecto AbapoIzozog, Chaco Boliviano. Bol Inf CENETROP 1979; 5: 16-21. 
Anexo I - Distribuição de frequências de localidades existentes e trabalhadas e de Unidades Domiciliaı es (UDs) trabalhadas e com reagentes sorológicos para infecção chagásica, nos municipios das Regiões de Governo no Serviço Regional da SUCEN de São Vicente (SR-2), 1984 a 1997

\begin{tabular}{|c|c|c|c|c|c|c|c|c|}
\hline \multirow[b]{2}{*}{ Municipio } & \multicolumn{3}{|c|}{ Localidades } & \multicolumn{2}{|c|}{ UDs } & \multicolumn{3}{|c|}{ Amostras } \\
\hline & exist.* & trab & $\%$ trab. & trab. & reag. & trab. & reag. & $\%$ reag. \\
\hline \multicolumn{9}{|c|}{ Região de Governo Registro } \\
\hline Barra do Turvo & 22 & 11 & 50,00 & 24 & 0 & 128 & 0 & 0,00 \\
\hline Cajati & 28 & 5 & 17,86 & 5 & 0 & 24 & 0 & 0,00 \\
\hline Cananéra & 38 & 6 & 15,79 & 23 & 0 & 119 & 0 & 0,00 \\
\hline Eldorado & 45 & 26 & 57,78 & 115 & 2 & 487 & 2 & 0,41 \\
\hline Iguape & 45 & 23 & 51,11 & 106 & 1 & 425 & 1 & 0,24 \\
\hline Illha Compnda & 8 & 0 & 0,00 & - & - & - & - & - \\
\hline Iporanga & 23 & 8 & 34,78 & 13 & 0 & 54 & 0 & 0,00 \\
\hline Itann & 29 & 15 & 51,72 & 27 & 3 & 140 & 4 & 2,86 \\
\hline Jacupiranga & 50 & 31 & 62,00 & 129 & 2 & 538 & 2 & 0,37 \\
\hline Juquia & 31 & 20 & 64,52 & 271 & 7 & 1067 & 9 & 0,84 \\
\hline Miracatu & 32 & 25 & 78,13 & 64 & 2 & 258 & 2 & 0,78 \\
\hline Panquera-Açu & 22 & 16 & 72,73 & 134 & 3 & 622 & 4 & 0,64 \\
\hline Pedro de Toledo & 26 & 10 & 38,46 & 29 & 0 & 126 & 0 & 0,00 \\
\hline Registro & 50 & 26 & 52,00 & 82 & 2 & 381 & 3 & 0,79 \\
\hline Sete Barras & 34 & 17 & 50,00 & 167 & 7 & 676 & 8 & 1,18 \\
\hline SUB-TOTAL & 480 & 239 & 49.79 & 1189 & 29 & 5045 & 35 & 0,69 \\
\hline \multicolumn{9}{|c|}{ Região de Governo Santos } \\
\hline Bertioga & & 1 & & 1 & 1 & 15 & 1 & 6,67 \\
\hline Cubatão & $\ldots$ & 2 & $\ldots$ & 3 & 0 & 7 & 0 & 0,00 \\
\hline Guaruja & & 3 & & 4 & 0 & 11 & 0 & 0,00 \\
\hline Itanhaém & 35 & 3 & 8,57 & 3 & 0 & 15 & 0 & 0,00 \\
\hline Mongaguá & 15 & 0 & 0,00 & - & - & - & - & - \\
\hline Peruibe & 28 & 9 & 32,14 & 32 & 3 & 139 & 3 & 2,16 \\
\hline Praia Grande & 27 & 0 & 0,00 & - & - & - & - & - \\
\hline $\begin{array}{l}\text { Santos } \\
\text { São Vicente }\end{array}$ & $\ldots$ & $\cdots$ & $\ldots$ & $\ldots$ & $\begin{array}{l}\ldots \\
\ldots\end{array}$ & $\ldots$ & $\ldots$ & $\ldots$ \\
\hline SUB-TOTAL & $\ldots$ & 18 & & 43 & 4 & 187 & 4 & 2,14 \\
\hline
\end{tabular}

* Fonte: SUCEN/DOT/Lista de localidades segundo municipios por Serviço Regional. 1981-1986. As lacunas nos números de localidades existentes devem-se à ausência de Reconhecimento Geográfico executado pela SUCEN. 
Anexo II - Distribuição de frequências de localidades existentes e trabalhadas e de Unidades Domiciliares (UDs) trabalhadas e com reagentes sorológicos para infecção chagásica, nos municípios das Regiões de Governo no Serviço Regional da SUCEN de Sorocaba (SR-4), 1984 a 1997.

\begin{tabular}{|c|c|c|c|c|c|c|c|c|}
\hline \multirow[t]{2}{*}{ Municipio } & \multicolumn{3}{|c|}{ Localidades } & \multicolumn{2}{|c|}{ UDs } & \multicolumn{3}{|c|}{ Amostras } \\
\hline & exist ${ }^{*}$ & trab & $\%$ trab. & trab. & reag. & trab. & reag. & $\%$ reag \\
\hline \multicolumn{9}{|c|}{ Região de Governo Avaré } \\
\hline Águas Sta. Bárbara & 11 & 1 & 9,09 & 1 & 0 & 3 & 0 & 0,00 \\
\hline Arandu & 13 & 0 & 0,00 & - & - & - & - & - \\
\hline Avaré & 35 & 2 & 5,71 & 2 & 0 & 8 & 0 & 0,00 \\
\hline Barão de Antonuna & 9 & 3 & 33,33 & 9 & 1 & 44 & 1 & 2,27 \\
\hline Cerqueira César & 21 & 0 & 0,00 & - & - & - & - & - \\
\hline Cel. Macedo & 12 & 7 & 58,33 & 10 & 6 & 44 & 7 & 15,91 \\
\hline Fartura & 22 & 7 & 31,82 & 9 & 1 & 43 & 1 & 2,33 \\
\hline Itai & 27 & 2 & 7,41 & 2 & 1 & 7 & 1 & 14,29 \\
\hline Itaporanga & 24 & 11 & 45,83 & 34 & 14 & 141 & 17 & 12,06 \\
\hline Manduri & 15 & 0 & 0,00 & - & - & - & - & - \\
\hline Paranapancma & 22 & 4 & 18,18 & 7 & 4 & 26 & 4 & 15,38 \\
\hline Piraju & 29 & 7 & 24,14 & 15 & 8 & 68 & 12 & 17,65 \\
\hline Sarutaia & 11 & 1 & 9,09 & 1 & 0 & 1 & 0 & 0,00 \\
\hline Taguai & 10 & 6 & 60,00 & 7 & 4 & 28 & 5 & 17,86 \\
\hline Taquarituba & 23 & 10 & 43,48 & 23 & 9 & 83 & 11 & 13,25 \\
\hline Tejupa & 18 & 7 & 38,89 & 12 & 5 & 53 & 5 & 9,43 \\
\hline SUB-TOTAL & 302 & 68 & 22,52 & 132 & 53 & 549 & 64 & 11,66 \\
\hline \multicolumn{9}{|c|}{ Região de Governo Botucatu } \\
\hline Anhembi & 15 & 0 & 0,00 & - & - & - & - & - \\
\hline Areiopolis & 12 & 0 & 0,00 & - & - & - & - & - \\
\hline Bofete & 18 & 0 & 0,00 & - & - & - & - & - \\
\hline Botucatu & 44 & 1 & 2,27 & 1 & 0 & 2 & 0 & 0,00 \\
\hline Conchas & 24 & 3 & 12,50 & 3 & 0 & 16 & 0 & 0,00 \\
\hline Itatinga & 18 & 0 & 0,00 & - & - & - & - & - \\
\hline Laranjal Paulista & 21 & 1 & 4,76 & 1 & 0 & 2 & 0 & 0,00 \\
\hline Pardinho & 8 & 0 & 0,00 & - & - & - & - & - \\
\hline Pereiras & 19 & 2 & 10,53 & 2 & 0 & 4 & 0 & 0,00 \\
\hline Porangaba & 23 & 7 & 30,43 & 10 & 2 & 30 & 2 & 6,67 \\
\hline São Manuel & 53 & 0 & 0,00 & - & - & - & - & - \\
\hline SUB-TOTAL & 255 & 14 & 5,49 & 17 & 2 & 54 & 2 & 3,70 \\
\hline \multicolumn{9}{|c|}{ Região de Governo Itapetininga } \\
\hline Angatuba & 37 & 22 & 59,46 & 51 & 9 & 214 & 10 & 4,67 \\
\hline Boituva & 14 & 0 & 0,00 & - & - & - & - & - \\
\hline Capela do Alto & 14 & 6 & 42,86 & 11 & 2 & 57 & 2 & 3,51 \\
\hline Cerquilho & 11 & 2 & 18,18 & 2 & 0 & 7 & 0 & 0,00 \\
\hline Cesário Lange & 13 & 6 & 46,15 & 7 & 0 & 20 & 0 & 0,00 \\
\hline Guarei & 20 & 11 & 55,00 & 30 & 7 & 133 & 10 & 7,52 \\
\hline
\end{tabular}




\begin{tabular}{|c|c|c|c|c|c|c|c|c|}
\hline \multirow[t]{2}{*}{ Municipio } & \multicolumn{3}{|c|}{ Localidades } & \multicolumn{2}{|c|}{ UDs } & \multicolumn{3}{|c|}{ Amostras } \\
\hline & exist ${ }^{*}$ & trab. & $\%$ trab. & trab. & reag. & trab. & reag. & $\%$ reag. \\
\hline Itapetuninga & 78 & 19 & 24,36 & 29 & 0 & 142 & 0 & 0,00 \\
\hline São Miguel Arcanjo & 32 & 8 & 25,00 & 14 & 0 & 70 & 0 & 0,00 \\
\hline Sarapui & 17 & 0 & 0,00 & - & - & - & - & - \\
\hline Tatui & 39 & 3 & 7,69 & 3 & 0 & 11 & 0 & 0,00 \\
\hline SUB-TOTAL & 275 & 77 & 28,00 & 147 & 18 & 654 & 22 & 3,36 \\
\hline \multicolumn{9}{|c|}{ Região de Governo Itapeva } \\
\hline Apiaí & 60 & 26 & 43,33 & 65 & 0 & 240 & 0 & 0,00 \\
\hline Buri & 27 & 4 & 14,81 & 6 & 1 & 22 & 1 & 4,55 \\
\hline Capão Bonito & 50 & 10 & 20,00 & 13 & 0 & 76 & 0 & 0,00 \\
\hline Guapiara & 35 & 7 & 20,00 & 11 & 0 & 45 & 0 & 0,00 \\
\hline Itabera & 38 & 22 & 57,89 & 67 & 16 & 268 & 19 & 7,09 \\
\hline Itapeva & 41 & 10 & 24,39 & 13 & 3 & 59 & 3 & 5,08 \\
\hline Itararé & 43 & 12 & 27,91 & 26 & 5 & 109 & 10 & 9,17 \\
\hline Ribcira & 32 & 9 & 28,13 & 21 & 1 & 73 & 1 & 0,00 \\
\hline Ribcirão Branco & 15 & 7 & 46,67 & 14 & 0 & 76 & 0 & 0,00 \\
\hline Riversul & 21 & 11 & 52,38 & 35 & 9 & 188 & 11 & 5,85 \\
\hline SUB-TOTAL & 387 & 118 & 30,49 & 271 & 35 & 1156 & 45 & 3,89 \\
\hline \multicolumn{9}{|c|}{ Região de Governo Sorocaba } \\
\hline Araçolaba da Serra & 18 & 0 & 0,00 & - & - & - & - & - \\
\hline Ibiúna & 107 & 3 & 2,80 & 7 & 0 & 31 & 0 & 0,00 \\
\hline Iperó & 16 & 0 & 0,00 & - & - & - & - & - \\
\hline Itu & 76 & 0 & 0,00 & - & - & - & - & - \\
\hline Mairinque & 40 & 0 & 0,00 & - & - & - & - & - \\
\hline Piedade & 62 & 8 & 12,90 & 8 & 0 & 36 & 0 & 0,00 \\
\hline Pilar do Sul & 31 & 5 & 16,13 & 5 & 1 & 26 & 1 & 3,85 \\
\hline Porto Feliz & 45 & 0 & 0,00 & - & - & - & - & - \\
\hline Salto & 15 & 0 & 0,00 & - & - & - & - & - \\
\hline Salto de Pirapora & 21 & 0 & 0,00 & - & - & - & - & - \\
\hline São Roque & 87 & 0 & 0,00 & - & - & - & - & - \\
\hline Sorocaba & 46 & 1 & 2,17 & 1 & 0 & 3 & 0 & 0,00 \\
\hline Tapirai & 23 & 3 & 13,04 & 8 & 0 & 21 & 0 & 0,00 \\
\hline Tietê & 38 & 1 & 2,63 & 1 & 0 & 3 & 0 & 0,00 \\
\hline Votorantim & 16 & 0 & 0,00 & - & - & - & - & - \\
\hline SUB-TOTAL & 641 & 21 & 3,28 & 30 & 1 & 120 & 1 & 0,99 \\
\hline
\end{tabular}

* Fonte: SUCEN/DOT/Lista de localidades segundo municipios por Serviço Regional. 1981-1986. 
Anexo III - Distribuição de frequências de localidades existentes e trabalhadas e de Unidades Domiciliares trabalhadas e com reagentes sorológicos para infecção chagásica, nos municípios das Regiões de Governo no Serviço Regional da SUCEN de Campinas (SR-5), 1984 a 1997.

\begin{tabular}{|c|c|c|c|c|c|c|c|c|}
\hline \multirow[b]{2}{*}{ Município } & \multicolumn{3}{|c|}{ Localidades } & \multicolumn{2}{|c|}{ UDs } & \multicolumn{3}{|c|}{ Amostras } \\
\hline & exist. ${ }^{*}$ & trab. & $\%$ trab. & trab & reag. & trab. & reag. & $\%$ reag. \\
\hline \multicolumn{9}{|c|}{ Região de Governo Bragança Paulista } \\
\hline Águas de Lindóia & 11 & 0 & 0,00 & - & - & - & - & - \\
\hline Amparo & 69 & 4 & 5,80 & 4 & 0 & 26 & 0 & 0,00 \\
\hline Atibaia & 52 & 0 & 0,00 & - & - & - & - & - \\
\hline Bom Jesus dos Perdões & 9 & 0 & 0,00 & - & - & - & - & - \\
\hline Bragança Paulista & 93 & 0 & 0,00 & - & - & - & - & - \\
\hline Joanópolis & 23 & 0 & 0,00 & - & - & - & - & - \\
\hline Lindóia & 8 & 5 & 62,50 & 7 & 0 & 35 & 0 & 0,00 \\
\hline Monte Alegre do Sul & 19 & 4 & 21,05 & 4 & 1 & 17 & 1 & 5,88 \\
\hline Nazare Paulista & 37 & 0 & 0,00 & - & - & - & - & - \\
\hline Pedra Bela & 31 & 0 & 0,00 & - & - & - & - & - \\
\hline Pinhalzinho & 27 & 1 & 3,70 & 2 & 0 & 6 & 0 & 0,00 \\
\hline Piracaia & 32 & 0 & 0,00 & - & - & - & - & - \\
\hline Serra Negra & 26 & 10 & 38,46 & 15 & 1 & 94 & 1 & 1,06 \\
\hline Socorro & 56 & 12 & 21,43 & 17 & 1 & 79 & 1 & 1,27 \\
\hline SUB-TOTAL & 443 & 36 & 8,13 & 49 & 3 & 257 & 3 & 1,17 \\
\hline \multicolumn{9}{|c|}{ Região de Governo Campinas } \\
\hline Americana & 12 & 0 & 0,00 & - & - & - & - & - \\
\hline Artur Nogueira & 26 & 0 & 0,00 & - & - & - & - & - \\
\hline Campinas & 121 & 13 & 10,74 & 17 & 2 & 67 & 2 & 2,99 \\
\hline Cosmópolis & 16 & 1 & 6,25 & 1 & 0 & 5 & 0 & 0,00 \\
\hline Indaiatuba & 35 & 4 & 11,43 & 4 & 0 & 20 & 0 & 0,00 \\
\hline Itapira & 166 & 14 & 2,43 & 22 & 1 & 89 & 2 & 2,25 \\
\hline Jaguariúna & 36 & 2 & 5,56 & 2 & 1 & 20 & 1 & 5,00 \\
\hline Mogi-Guaçu & 86 & 5 & 5,81 & 5 & 1 & 17 & 1 & 5,88 \\
\hline Mogi-Mirim & 76 & 1 & 1,32 & 1 & 0 & 7 & 0 & 0,00 \\
\hline Monte Mor & 18 & 4 & 22,22 & 5 & 0 & 26 & 0 & 0,00 \\
\hline Nova Odessa & 20 & 0 & 0,00 & - & - & - & - & - \\
\hline Paulínia & 15 & 0 & 0,00 & - & - & - & - & - \\
\hline Pedreira & 23 & 4 & 17,39 & 8 & 1 & 20 & 1 & 5,00 \\
\hline Sta Bárbara D'Oeste & 19 & 0 & 0,00 & - & - & - & - & - \\
\hline Sto Antônio da Posse & 26 & 1 & 3,85 & 1 & 0 & 1 & 0 & 0,00 \\
\hline Sumaré & 34 & 2 & 5,88 & 2 & 0 & 15 & 0 & 0,00 \\
\hline Valinhos & 19 & 2 & 10,53 & 3 & 0 & 12 & 0 & 0,00 \\
\hline Vinhedo & 25 & 2 & 8,00 & 2 & 0 & 8 & 0 & 0,00 \\
\hline SUB-TOTAL & 773 & 55 & 7,12 & 73 & 6 & 307 & 7 & 2,28 \\
\hline
\end{tabular}

(cont.) 


\begin{tabular}{|c|c|c|c|c|c|c|c|c|}
\hline \multirow[b]{2}{*}{ Municipio } & \multicolumn{3}{|c|}{ Localidades } & \multicolumn{2}{|c|}{ UDs } & \multicolumn{3}{|c|}{ Amostras } \\
\hline & exist. ${ }^{*}$ & trab. & $\%$ trab. & trab. & reag. & trab. & reag. & $\%$ reag. \\
\hline \multicolumn{9}{|c|}{ Região de Governo Jundiaí } \\
\hline Cabreuva & 24 & 0 & - & - & - & - & - & - \\
\hline Campo Limpo Paulista & 27 & 0 & - & - & - & - & - & - \\
\hline Itatiba & 52 & 1 & 1,92 & 1 & 0 & 4 & 0 & 0,00 \\
\hline Itupeva & 32 & 2 & 6,25 & 2 & 0 & 12 & 0 & 0,00 \\
\hline Jannu & 22 & 0 & - & - & - & - & - & - \\
\hline Jundiaí & 61 & 2 & 3,28 & 2 & 0 & 10 & 0 & 0,00 \\
\hline Louveira & 23 & 0 & - & - & - & - & - & - \\
\hline Morungaba & 11 & 0 & - & - & - & - & - & - \\
\hline Várzea Paulista & 14 & 0 & - & - & - & - & - & - \\
\hline SUB-TOTAL & 266 & 5 & 1,88 & 5 & 0 & 26 & 0 & 0,00 \\
\hline \multicolumn{9}{|c|}{ Região de Governo Limeira } \\
\hline Araras & 55 & 1 & 1,82 & 1 & 0 & 4 & 0 & 0,00 \\
\hline Conchal & 29 & 0 & 0,00 & - & - & - & - & - \\
\hline Cordeıropolis & 19 & 2 & 10,53 & 2 & 1 & 26 & 2 & 7,69 \\
\hline Iracemápolis & 16 & 0 & 0,00 & - & - & - & - & - \\
\hline Leme & 17 & 2 & 11,76 & 2 & 0 & 5 & 0 & 0,00 \\
\hline Limeira & 37 & 6 & 16,22 & 7 & 0 & 28 & 0 & 0,00 \\
\hline Pirassununga & 56 & 2 & 3,56 & 3 & 1 & 14 & 1 & 7,14 \\
\hline Sta Cruz da Conceição & 10 & 1 & 10,00 & 1 & 0 & 5 & 0 & 0,00 \\
\hline SUB-TOTAL & 239 & 14 & 5,86 & 16 & 2 & 82 & 3 & 3,66 \\
\hline \multicolumn{9}{|c|}{ Região de Governo Piracicaba } \\
\hline Águas de São Pedro & 1 & 0 & 0,00 & - & - & - & - & - \\
\hline Capivan & 25 & 2 & 8,00 & 2 & 0 & 8 & 0 & 0,00 \\
\hline Charqueada & 27 & 0 & 0,00 & - & - & - & - & - \\
\hline Elias Fausto & 14 & 1 & 7,14 & 1 & 0 & 4 & 0 & 0,00 \\
\hline Mombuca & 10 & 0 & 0,00 & - & - & - & - & - \\
\hline Piracicaba & 102 & 1 & 0,98 & 4 & 0 & 16 & 0 & 0,00 \\
\hline Rafard & 10 & 3 & 30,00 & 4 & 1 & 30 & 2 & 6,67 \\
\hline Rio das Pedras & 23 & 0 & 0,00 & - & - & - & - & - \\
\hline Sta Maria da Serra & 16 & 1 & 6,25 & 1 & 0 & 4 & 0 & 0,00 \\
\hline São Pedro & 25 & 0 & 0,00 & - & - & - & - & - \\
\hline SUB-TOTAL & 253 & 8 & 3,16 & 12 & 1 & 62 & 2 & 3,23 \\
\hline \multicolumn{9}{|c|}{ Região de Governo Rio Claro } \\
\hline Analândia & 32 & 0 & 0,00 & - & - & - & - & - \\
\hline Brotas & 48 & 0 & 0,00 & - & - & - & - & - \\
\hline Corumbatai & 25 & 0 & 0,00 & - & - & - & - & - \\
\hline Ipeúna & 13 & 0 & 0,00 & - & - & - & - & - \\
\hline Itirapina & 24 & 1 & 4,17 & 1 & 0 & 4 & 0 & 0,00 \\
\hline Rio Claro & 48 & 2 & 4,17 & 2 & 0 & 8 & 0 & 0,00 \\
\hline
\end{tabular}




\begin{tabular}{lrrrrrrrrr}
\hline & \multicolumn{3}{c}{ Localidades } & \multicolumn{3}{c}{ UDs } & \multicolumn{3}{c}{ Amostras } \\
Municipio & exist. & trab. & \% trab. & trab. & reag. & trab. & reag. & \%reag \\
\hline Sta Gertrudes & 10 & 0 & 0,00 & - & - & - & - & - \\
Torrinha & 25 & 0 & 0,00 & - & - & - & - & - \\
\hline SUB-TOTAL & 225 & 3 & 1,33 & 3 & 0 & 12 & 0 & 0,00 \\
\hline & Região de Governo São João da Boa Vista & & & \\
\hline Aguai & 31 & 1 & 3,23 & 1 & 0 & 9 & 0 & 0,00 \\
Aguas da Prata & 21 & 1 & 4,76 & 1 & 0 & 6 & 0 & 0,00 \\
Caconde & 61 & 24 & 39,34 & 67 & 13 & 278 & 14 & 5,04 \\
Casa Branca & 46 & 1 & 2,17 & 2 & 0 & 8 & 0 & 0,00 \\
Divinolàndia & 32 & 9 & 28,13 & 18 & 3 & 80 & 4 & 5,00 \\
Espirito Sto. do Pinhal & 67 & 17 & 25,37 & 29 & 0 & 120 & 0 & 0,00 \\
Itobi & 32 & 1 & 3,13 & 1 & 0 & 5 & 0 & 0,00 \\
Mococa & 64 & 8 & 12,50 & 10 & 2 & 50 & 2 & 4,00 \\
Sta Cruz. das Palmeiras & 30 & 0 & 0,00 & - & - & - & - & - \\
Sto Antônio do Jardim & 27 & 5 & 18,52 & 9 & 1 & 63 & 1 & 1,59 \\
S. João da Boa Vista & 137 & 38 & 27,74 & 62 & 5 & 261 & 5 & 1,92 \\
S. José do Rio Pardo & 89 & 19 & 21,35 & 31 & 1 & 126 & 1 & 0,79 \\
S. Sebastião da Grama & 45 & 17 & 37,78 & 25 & 1 & 101 & 1 & 0,99 \\
Tambau & 33 & 0 & 0,00 & - & - & - & - & - \\
Tapiratiba & 22 & 6 & 27,27 & 8 & 0 & 33 & 0 & 0,00 \\
Vargem Grande do Sul & 39 & 18 & 46,15 & 27 & 1 & 99 & 1 & 1,01 \\
\hline SUB-TOTAL & 776 & 166 & 21,39 & 291 & 27 & 1239 & 29 & 2,34 \\
\hline
\end{tabular}

* Fonte: SUCEN/DOT/Lista de localidades segundo municipios por Serviço Regional. 1981-1986. 
Anexo IV - Distribuição de frequências de localidades existentes e trabalhadas e de Unidades Domiciliares trabalhadas e com reagentes sorológicos para infecção chagásica, nos municípios das Regiões de Governo no Serviço Regional da SUCEN de Ribeirão Preto (SR-6), 1984 a 1997.

\begin{tabular}{|c|c|c|c|c|c|c|c|c|}
\hline \multirow[b]{2}{*}{ Municipio } & \multicolumn{3}{|c|}{ Localidades } & \multicolumn{2}{|c|}{ UDs } & \multicolumn{3}{|c|}{ Amostras } \\
\hline & exist ${ }^{*}$ & trab. & $\%$ trab. & trab. & reag. & trab. & reag. & \%reag. \\
\hline \multicolumn{9}{|c|}{ Região de Governo Ribeirão Preto } \\
\hline Altinópolis & 46 & 0 & 0,00 & - & - & - & - & - \\
\hline Barrinha & 7 & 0 & 0,00 & - & - & - & - & - \\
\hline Brodosqui & 19 & 1 & 5,26 & 2 & 0 & 5 & 0 & 0,00 \\
\hline Cajuru & 46 & 2 & 4,35 & 2 & 0 & 10 & 0 & 0,00 \\
\hline Cássia dos Coqueiros & 15 & 0 & 0,00 & - & - & - & - & - \\
\hline Cravinhos & 30 & 0 & 0,00 & - & - & - & - & - \\
\hline Dumont & 9 & 1 & 11,11 & 1 & 0 & 5 & 0 & 0,00 \\
\hline Guariba & 15 & 1 & 6,67 & 1 & 1 & 4 & 1 & 25,00 \\
\hline Jaboticabal & 56 & 3 & 5,36 & 4 & 0 & 17 & 0 & 0,00 \\
\hline Jardinópolis & 42 & 4 & 9,52 & 4 & 1 & 22 & 1 & 4,55 \\
\hline Luis Antônio & 14 & 0 & 0,00 & - & - & - & - & - \\
\hline Monte Alto & 42 & 3 & 7,14 & 3 & 0 & 10 & 0 & 0,00 \\
\hline Pitanguciras & 26 & 1 & 3,85 & 1 & 0 & 9 & 0 & 0,00 \\
\hline Pontal & 13 & 3 & 23,08 & 3 & 1 & 14 & 2 & 14,29 \\
\hline Pradópolis & 7 & 0 & 0,00 & - & - & - & - & - \\
\hline Ribeirão Preto & 61 & 7 & 11,48 & 9 & 1 & 36 & 1 & 2,78 \\
\hline Santa Rosa do Viterbo & 14 & 0 & 0,00 & - & - & - & - & - \\
\hline Sto Antonio da Alegria & 18 & 1 & 5,56 & 1 & 0 & 5 & 0 & 0,00 \\
\hline São Simão & 25 & 0 & 0,00 & - & - & - & - & - \\
\hline Serra Azul & 11 & 0 & 0,00 & - & - & - & - & - \\
\hline Serrana & 10 & 0 & 0,00 & - & - & - & - & - \\
\hline Sertãozinho & 34 & 4 & 11,76 & 4 & 1 & 27 & 3 & 11,11 \\
\hline SUB-TOTAL & 560 & 12 & 2,14 & 35 & 5 & 164 & 8 & 4,88 \\
\hline \multicolumn{9}{|c|}{ Região de Governo Araraquara } \\
\hline Américo Brasiliense & 10 & 0 & 0,00 & - & - & - & - & - \\
\hline Araraquara & 77 & 0 & 0,00 & - & - & - & - & - \\
\hline Boa Esperança do Sul & 34 & 0 & 0,00 & - & - & - & - & - \\
\hline Borborema & 28 & 0 & 0,00 & - & - & - & - & - \\
\hline Cândido Rodrigues & 7 & 0 & 0,00 & - & - & - & - & - \\
\hline Dobrada & 9 & 0 & 0,00 & - & - & - & - & - \\
\hline Fernando Prestes & 15 & 3 & 20,00 & 3 & 0 & 12 & 0 & 0,00 \\
\hline Ibitinga & 49 & 0 & 0,00 & - & - & - & - & - \\
\hline Itápolis & 55 & 0 & 0,00 & - & - & - & - & - \\
\hline Matão & 35 & 0 & 0,00 & - & - & - & - & - \\
\hline Nova Europa & 11 & 0 & 0,00 & - & - & - & - & - \\
\hline Rincão & 18 & 0 & 0,00 & - & - & - & - & - \\
\hline Santa Emestina & 7 & 0 & 0,00 & - & - & - & - & - \\
\hline
\end{tabular}




\begin{tabular}{|c|c|c|c|c|c|c|c|c|}
\hline \multirow[b]{2}{*}{ Municipio } & \multicolumn{3}{|c|}{ Localidades } & \multicolumn{2}{|c|}{ UDs } & \multicolumn{3}{|c|}{ Amostras } \\
\hline & exist. ${ }^{*}$ & trab. & $\%$ trab. & trab. & reag. & trab. & reag. & $\%$ reag. \\
\hline Santa Lúcia & 11 & 0 & 0,00 & - & - & - & - & - \\
\hline Tabatinga & 27 & 0 & 0,00 & - & - & - & - & - \\
\hline Taquaritinga & 44 & 1 & 2,27 & 1 & 0 & 5 & 0 & 0,00 \\
\hline SUB-TOTAL & 437 & 4 & 0,92 & 4 & 0 & 17 & 0 & 0,00 \\
\hline \multicolumn{9}{|c|}{ Região de Governo São Carlos } \\
\hline Descalvado & 49 & 0 & 0,00 & - & - & - & - & - \\
\hline Dourado & 18 & 1 & 5,56 & 1 & 0 & 5 & 0 & 0,00 \\
\hline Ibaté & 16 & 0 & 0,00 & - & - & - & - & - \\
\hline Porto Ferreira & 31 & 0 & 0,00 & - & - & - & - & - \\
\hline Ribeirão Bonito & 25 & 0 & 0,00 & - & - & - & - & - \\
\hline Sta Rita Passa Quatro & 50 & 0 & 0,00 & - & - & - & - & - \\
\hline São Carlos & 57 & 0 & 0,00 & - & - & - & - & - \\
\hline SUB-TOTAL & 246 & 1 & 0,41 & 1 & 0 & 5 & 0 & 0,00 \\
\hline \multicolumn{9}{|c|}{ Região de Governo Barretos } \\
\hline Altair & 10 & 1 & 10,00 & 1 & 0 & 3 & 0 & 0,00 \\
\hline Barretos & 57 & 3 & 5,26 & 3 & 0 & 11 & 0 & 0,00 \\
\hline Bebedouro & 43 & 1 & 2,33 & 1 & 0 & 3 & 0 & 0,00 \\
\hline Cajobı & 50 & 3 & 6,00 & 3 & 0 & 17 & 0 & 0,00 \\
\hline Colina & 21 & 1 & 4,76 & 1 & 0 & 5 & 0 & 0,00 \\
\hline Colômbia & 20 & 2 & 10,00 & 2 & 2 & 10 & 2 & 20,00 \\
\hline Guaira & 34 & 4 & 11,76 & 4 & 1 & 15 & 1 & 6,67 \\
\hline Guaraci & 39 & 5 & 12,82 & 6 & 3 & 15 & 4 & 26,67 \\
\hline Jaborandi & 13 & 1 & 7,69 & 1 & 0 & 3 & 0 & 0,00 \\
\hline Monte Azul Paulista & 23 & 1 & 4,35 & 1 & 0 & 4 & 0 & 0,00 \\
\hline Olimpia & 80 & 11 & 13,75 & 11 & 1 & 44 & 1 & 2,27 \\
\hline Pirangi & 20 & 1 & 5,00 & 1 & 0 & 4 & 0 & 0,00 \\
\hline Severinea & 21 & 0 & 0,00 & - & - & - & - & - \\
\hline Taiaçu & 13 & 0 & $C, 00$ & - & - & - & - & - \\
\hline Taiúva & 12 & 0 & 0,00 & - & - & - & - & - \\
\hline Terra Roxa & 18 & 0 & 0,00 & - & - & - & - & - \\
\hline Viradouro & 15 & 1 & 6,67 & 1 & 0 & 3 & 0 & 0,00 \\
\hline Vista Alegre do Alto & 12 & 1 & 8,33 & 1 & 1 & 3 & 1 & 33,33 \\
\hline SUB-TOTAL & 501 & 36 & 7,19 & 37 & 8 & 140 & 9 & 6,43 \\
\hline \multicolumn{9}{|c|}{ Região de Governo Franca } \\
\hline Aramina & 16 & 0 & 0,00 & - & - & - & - & - \\
\hline Batatais & 52 & 4 & 7,69 & 5 & 0 & 21 & 0 & 0,00 \\
\hline Buritizal & 18 & 2 & 11,11 & 2 & 1 & 12 & 1 & 8,33 \\
\hline Cristais Paulista & 27 & 0 & 0,00 & - & - & - & - & - \\
\hline Franca & 47 & 3 & 6,38 & 4 & 0 & 11 & 0 & 0,00 \\
\hline Guará & 37 & 1 & 2,70 & 1 & 0 & 12 & 0 & 0,00 \\
\hline Igarapava & 34 & 3 & 8,82 & 4 & 1 & 19 & 1 & 5,26 \\
\hline Itirapuã & 16 & 3 & 18,75 & 4 & 2 & 18 & 3 & 16,67 \\
\hline
\end{tabular}




\begin{tabular}{lrrrrrrrrr}
\hline & \multicolumn{3}{c}{ Localidades } & \multicolumn{3}{c}{ UDs } & \multicolumn{3}{c}{ Amostras } \\
Municipio & exist. & trab. & \%trab. & trab. & reag. & trab. & reag. & \%reag. \\
\hline Ituverava & 52 & 2 & 3,85 & 2 & 0 & 10 & 0 & 0,00 \\
Jeriquara & 8 & 0 & 0,00 & - & - & - & - & - \\
Miguelópolis & 35 & 3 & 8,57 & 4 & 1 & 6 & 2 & 33,33 \\
Patrocinio Paulista & 35 & 0 & 0,00 & - & - & - & - & - \\
Pedregulho & 41 & 4 & 9,76 & 4 & 1 & 16 & 1 & 6,25 \\
Restinga & 20 & 0 & 0,00 & - & - & - & - & - \\
Ribeirão Corrente & 15 & 1 & 6,67 & 1 & 1 & 6 & 1 & 16,67 \\
Rifaina & 8 & 0 & 0,00 & - & - & - & - & - \\
São José da Bela Vista & 23 & 1 & 4,35 & 1 & 0 & 2 & 0 & 0,00 \\
\hline SUB-TOTAL & 484 & 27 & 5,58 & 32 & 7 & 133 & 9 & 6,77 \\
\hline & Região de Governo São Joaquim da Barra & & & \\
\hline Ipuã & 24 & 1 & 4,17 & 1 & 1 & 4 & 1 & 25,00 \\
Morro Agudo & 39 & 1 & 2,56 & 1 & 0 & 4 & 0 & 0,00 \\
Nuporanga & 23 & 1 & 4,35 & 1 & 0 & 3 & 0 & 0,00 \\
Orlândia & 19 & 0 & 0,00 & - & - & - & - & - \\
Sales de Oliveira & 25 & 0 & 0,00 & - & - & - & - & - \\
São Joaquim da Barra & 31 & 3 & 9,68 & 3 & 0 & 14 & 0 & 0,00 \\
\hline SUB-TOTAL & 161 & 6 & 3,73 & 6 & 1 & 25 & 1 & 0,00 \\
\hline
\end{tabular}

* Fonte: SUCEN/DOT/Lista de localidades segundo municipios por Serviço Regional. 1981-1986. 
Anexo V - Distribuição de frequêencias de localidades existentes e trabalhadas e de Unidades Domiciliares trabalhadas e com reagentes sorológicos para infecção chagásica, nos municípios das Regiões de Governo no Serviço Regional da SUCEN de São José do Rio Preto (SR-8), 1984 a 1997.

\begin{tabular}{|c|c|c|c|c|c|c|c|c|}
\hline \multirow[t]{2}{*}{ Municipio } & \multicolumn{3}{|c|}{ Localidades } & \multicolumn{2}{|c|}{ UDs } & \multicolumn{3}{|c|}{ Amostras } \\
\hline & exist ${ }^{*}$ & trab. & $\%$ trab. & trab. & reag. & trab. & reag. & $\%$ reag. \\
\hline \multicolumn{9}{|c|}{ Região de Governo Catanduva } \\
\hline Ariranha & 17 & 1 & 5,88 & 1 & 0 & 5 & 0 & 0,00 \\
\hline Catanduva & 76 & 13 & 17,11 & 27 & 2 & 106 & 2 & 1,89 \\
\hline Catiguá & 27 & 1 & 3,70 & 1 & 0 & 10 & 0 & 0,00 \\
\hline Irapuã & 34 & 17 & 50,00 & 33 & 3 & 127 & 3 & 2,36 \\
\hline Itajobi & 35 & 13 & 37,14 & 18 & 0 & 70 & 0 & 0,00 \\
\hline Novo Horizonte & 81 & 13 & 16,05 & 17 & 0 & 59 & 0 & 0,00 \\
\hline Palmares Paulista & 11 & 3 & 27,27 & 6 & 3 & 33 & 3 & 9,09 \\
\hline Paraíso & 19 & 4 & 21,05 & 9 & 0 & 37 & 0 & 0,00 \\
\hline Pindorama & 36 & 1 & 2,78 & 1 & 0 & 2 & 0 & 0,00 \\
\hline Sales & 29 & 7 & 24,14 & 11 & 1 & 60 & 1 & 1,67 \\
\hline Santa Adćlia & 43 & 6 & 13,95 & 12 & 1 & 41 & 1 & 2,44 \\
\hline Tabapuã & 57 & 8 & 14,04 & 8 & 1 & 33 & 1 & 3,03 \\
\hline Unupês & 44 & 20 & 45,45 & 41 & 1 & 167 & 1 & 0,60 \\
\hline SUB-TOTAL & 509 & 107 & 21,02 & 185 & 12 & 750 & 12 & 1,60 \\
\hline \multicolumn{9}{|c|}{ Região de Governo Fernandópolis } \\
\hline Estrela d'Oeste & 42 & 3 & 7,14 & 3 & 0 & 17 & 0 & 0,00 \\
\hline Fernandópolis & 64 & 11 & 17,19 & 11 & 2 & 52 & 3 & 5,77 \\
\hline Guarani d'Oeste & 45 & 9 & 20,00 & 13 & 4 & 52 & 4 & 7,69 \\
\hline Indiaporã & 31 & 6 & 19,35 & 8 & 3 & 27 & 3 & 11,11 \\
\hline Macedônia & 31 & 7 & 22,58 & 9 & 3 & 31 & 3 & 9,68 \\
\hline Meridiano & 44 & 5 & 11,36 & 6 & 1 & 15 & 1 & 6,67 \\
\hline Mira Estrela & 28 & 7 & 25,00 & 9 & 1 & 28 & 1 & 3,57 \\
\hline Pedranopolis & 26 & 6 & 23,08 & 7 & 0 & 16 & 0 & 0,00 \\
\hline Populina & 64 & 6 & 9,38 & 7 & 2 & 18 & 2 & 11,11 \\
\hline S João das Duas Pontes & 10 & 2 & 20,00 & 2 & 0 & 11 & 0 & 0,00 \\
\hline Turmalina & 20 & 6 & 30,00 & 9 & 0 & 31 & 0 & 0,00 \\
\hline SUB-TOTAL & 405 & 68 & 16,79 & 84 & 16 & 298 & 17 & 5,70 \\
\hline \multicolumn{9}{|c|}{ Região de Governo Jales } \\
\hline Aparecida d'Oeste & 13 & 3 & 23,08 & 6 & 1 & 30 & 1 & 3,33 \\
\hline Dolcinópolis & 17 & 2 & 11,76 & 2 & 0 & 8 & 0 & 0,00 \\
\hline Jales & 87 & 29 & 33,33 & 70 & 6 & 332 & 8 & 2,41 \\
\hline Marinápolis & 7 & 4 & 57,14 & 7 & 1 & 26 & 1 & 3,85 \\
\hline Palmeira d'Oeste & 54 & 27 & 50,00 & 63 & 4 & 299 & 8 & 2,68 \\
\hline Paranapuã & 55 & 14 & 25,45 & 18 & 5 & 82 & 5 & 6,10 \\
\hline Rubinéia & 29 & 7 & 24,14 & 10 & 0 & 46 & 0 & 0,00 \\
\hline Santa Albertina & 52 & 15 & 28,85 & 22 & 6 & 97 & 7 & 7,22 \\
\hline
\end{tabular}




\begin{tabular}{|c|c|c|c|c|c|c|c|c|}
\hline \multirow[t]{2}{*}{ Municipıo } & \multicolumn{3}{|c|}{ Localidades } & \multicolumn{2}{|c|}{ UDs } & \multicolumn{3}{|c|}{ Amostras } \\
\hline & exist * & trab. & $\%$ trab. & trab. & reag. & trab. & reag. & $\%$ reag. \\
\hline Santa Clara d'Oeste & 55 & 10 & 18,18 & 22 & 3 & 94 & 5 & 5,32 \\
\hline Santa Fé do Sul & 48 & 15 & 31,25 & 29 & 6 & 122 & 6 & 4,92 \\
\hline Santa Rita d'Oeste & 65 & 11 & 16,92 & 17 & 4 & 55 & 6 & 10,91 \\
\hline Santana da Ponte Pensa & 25 & 6 & 24,00 & 9 & 2 & 39 & 4 & 10,26 \\
\hline São Francisco & 37 & 9 & 24,32 & 21 & 3 & 94 & 3 & 3,19 \\
\hline Três Fronteiras & 66 & 11 & 16,67 & 18 & 1 & 86 & 2 & 2,33 \\
\hline Urânia & 61 & 13 & 21,31 & 18 & 4 & 87 & 5 & 5,75 \\
\hline SUB-TOTAL & 671 & 176 & 26,23 & 332 & 46 & 1497 & 61 & 4,07 \\
\hline \multicolumn{9}{|c|}{ Região de Governo São José do Rio Preto } \\
\hline Adolfo & 15 & 7 & 46,67 & 9 & 4 & 37 & 4 & 10,81 \\
\hline Bady Bassit & 13 & 10 & 76,92 & 26 & 0 & 100 & 0 & 0,00 \\
\hline Bálsamo & 16 & 4 & 20,00 & 5 & 0 & 33 & 0 & 0,00 \\
\hline Cedral & 24 & 6 & 25,00 & 8 & 2 & 34 & 2 & 5,88 \\
\hline Guapıaçu & 48 & 4 & 8,33 & 8 & 0 & 30 & 0 & 0,00 \\
\hline Ibirà & 31 & 8 & 25,81 & 10 & 0 & 46 & 0 & 0,00 \\
\hline Icém & 16 & 6 & 37,50 & 8 & 0 & 25 & 0 & 0,00 \\
\hline Jaci & 31 & 9 & 29,03 & 11 & 0 & 39 & 0 & 0,00 \\
\hline José Bonifácio & 105 & 31 & 29,52 & 51 & 8 & 196 & 10 & 5,10 \\
\hline Mendonça & 16 & 4 & 25,00 & 4 & 2 & 16 & 3 & 18,75 \\
\hline Mirassol & 62 & 11 & 17,74 & 13 & 0 & 50 & 0 & 0,00 \\
\hline Mirassolândia & 30 & 4 & 13,33 & 4 & 1 & 11 & 2 & 18,18 \\
\hline Monte Aprazivel & 66 & 20 & 30,30 & 25 & 1 & 102 & 1 & 0,98 \\
\hline Neves Paulista & 47 & 9 & 19,15 & 14 & 1 & 58 & 1 & 1,72 \\
\hline Nipoã & 20 & 6 & 30,00 & 11 & 2 & 50 & 2 & 4,00 \\
\hline Nova Aliança & 39 & 14 & 35,90 & 23 & 1 & 87 & 1 & 1,15 \\
\hline Nova Granada & 75 & 3 & 4,00 & 5 & 2 & 31 & 5 & 16,13 \\
\hline Onda Verde & 21 & 2 & 9,52 & 2 & 1 & 12 & 1 & 8,33 \\
\hline Orindiúva & 20 & 7 & 35,00 & 10 & 1 & 25 & 2 & 8,00 \\
\hline Palestina & 76 & 18 & 23,68 & 20 & 2 & 76 & 2 & 2,63 \\
\hline Paulo de Faria & 56 & 16 & 28,57 & 22 & 5 & 67 & 7 & 10,45 \\
\hline Planalto & 44 & 13 & 29,55 & 19 & 2 & 77 & 3 & 3,90 \\
\hline Poloni & 14 & 8 & 57,14 & 11 & 0 & 41 & 0 & 0,00 \\
\hline Potirendaba & 44 & 20 & 45,45 & 46 & 2 & 182 & 4 & 2,20 \\
\hline São José do Rio Preto & 91 & 9 & 9,89 & 19 & 3 & 76 & 3 & 3,95 \\
\hline Tanabi & 53 & 15 & 28,30 & 22 & 3 & 89 & 3 & 3,37 \\
\hline Uchoa & 41 & . 4 & 9,76 & 4 & 0 & 14 & 0 & 0,00 \\
\hline União Paulista & 9 & 4 & 4,49 & 7 & 1 & 29 & 1 & 3,45 \\
\hline SUB-TOTAL & 1123 & 254 & 22,62 & 417 & 44 & 1633 & 57 & 3,49 \\
\hline
\end{tabular}

(cont.) 


\begin{tabular}{|c|c|c|c|c|c|c|c|c|}
\hline \multirow[t]{2}{*}{ Município } & \multicolumn{3}{|c|}{ Localidades } & \multicolumn{2}{|c|}{ UDs } & \multicolumn{3}{|c|}{ Amostras } \\
\hline & exist.* & trab. & $\%$ trab. & trab. & reag. & trab. & reag. & $\%$ reag. \\
\hline \multicolumn{9}{|c|}{ Região de Governo Votuporanga } \\
\hline Alvares Florence & 39 & 11 & 28,21 & 14 & 2 & 53 & 2 & 3,77 \\
\hline Américo de Campos & 27 & 4 & 14,81 & 4 & 2 & 14 & 2 & 14,29 \\
\hline Cardoso & 57 & 9 & 15,79 & 12 & 2 & 38 & 2 & 5,26 \\
\hline Cosmorama & 53 & 14 & 26,42 & 22 & 2 & 84 & 3 & 3,57 \\
\hline Floreal & 16 & 9 & 56,25 & 11 & 2 & 45 & 2 & 4,44 \\
\hline Macaubal & 29 & 9 & 31,03 & 16 & 5 & 57 & 5 & 8,77 \\
\hline Magda & 9 & 4 & 44,44 & 6 & 0 & 25 & 0 & 0,00 \\
\hline Monções & 10 & 0 & - & - & - & - & - & - \\
\hline Nhandeara & 49 & 12 & 24,49 & 17 & 3 & 71 & 3 & 4,23 \\
\hline Pontes Gestal & 10 & 1 & 10,00 & 1 & 0 & 5 & 0 & 0,00 \\
\hline Riolândia & 35 & 9 & 25,71 & 14 & 6 & 54 & 7 & 12,96 \\
\hline Sebastianópolis do Sul & 17 & 8 & 47,06 & 9 & 1 & 34 & 1 & 2,94 \\
\hline Valentim Gentil & 28 & 2 & 7,14 & 3 & 0 & 9 & 0 & 0,00 \\
\hline Votuporanga & 78 & 16 & 20,51 & 22 & 5 & 87 & 5 & 5,75 \\
\hline SUB-TOTAL & 457 & 108 & 23,63 & 151 & 30 & 576 & 32 & 5,56 \\
\hline
\end{tabular}

* Fonte: SUCEN/DOT/Lista de localidades segundo municipios por Serviço Regional. 1981-1986. 
Anexo VI - Distribuição de frequèncias de localidades existentes e trabalhadas e de Unidades Domiciliares (UDs) trabalhadas e com reagentes sorológicos para infecção chagásica, nos municípios das Regiões de Governo no Serviço Regional da SUCEN de Araçatuba (SR-9), 1984 a 1997

\begin{tabular}{|c|c|c|c|c|c|c|c|c|}
\hline \multirow[t]{2}{*}{ Município } & \multicolumn{3}{|c|}{ Localidades } & \multicolumn{2}{|c|}{ UDs } & \multicolumn{3}{|c|}{ Amostras } \\
\hline & exist. ${ }^{*}$ & trab. & $\%$ trab. & trab. & reag. & trab. & reag. & $\%$ reag. \\
\hline \multicolumn{9}{|c|}{ Região de Governo Andradina } \\
\hline Andradina & 45 & 2 & 4,44 & 3 & 0 & 13 & 0 & 0,00 \\
\hline Castilho & 36 & 10 & 27,78 & 16 & 0 & 52 & 0 & 0,00 \\
\hline Guaraçai & 29 & 5 & 17,24 & 5 & 1 & 17 & 1 & 5,88 \\
\hline Ilha Soltcira & & 1 & & 1 & 0 & 5 & 0 & 0,00 \\
\hline Itapura & 8 & 2 & 25,00 & 5 & 0 & 22 & 0 & 0,00 \\
\hline Lavinia & 22 & 1 & 4,55 & 1 & 0 & 6 & 0 & 0,00 \\
\hline Mirandópolis & 46 & 3 & 6,52 & 3 & 0 & 18 & 0 & 0,00 \\
\hline Murutınga do Sul & 17 & 0 & 0,00 & - & - & - & - & - \\
\hline Nora Independência & 8 & 1 & 12,50 & 1 & 1 & 4 & 1 & 25,00 \\
\hline Pereira Barreto & 57 & 11 & 19,30 & 16 & 1 & 68 & 1 & 1,47 \\
\hline Sud-Menucci & 21 & 4 & 19,05 & 4 & 0 & 13 & 0 & 0,00 \\
\hline SUB-TOTAL & 289 & 40 & $13,84+$ & 55 & 3 & 218 & 3 & 1,38 \\
\hline \multicolumn{9}{|c|}{ Região de Governo Araçatuba } \\
\hline Alto Alegre & 32 & 10 & 31,25 & 12 & 0 & 51 & 0 & 0,00 \\
\hline Araçatuba & 91 & 34 & 37,36 & 60 & 7 & 215 & 7 & 3,26 \\
\hline Auriflama & 37 & 7 & 19,44 & 9 & 0 & 30 & 0 & 0,00 \\
\hline Avanhandava & 14 & 4 & 28,57 & 4 & 0 & 27 & 0 & 0,00 \\
\hline Barbosa & 12 & 4 & 33,33 & 4 & 2 & 11 & 2 & 18,18 \\
\hline Bento de Abreu & 12 & 0 & 0,00 & - & - & - & - & - \\
\hline Bilac & 14 & 3 & 21,43 & 9 & 0 & 36 & 0 & 0,00 \\
\hline Birigui & 39 & 23 & 58,97 & 52 & 1 & 191 & 1 & 0,52 \\
\hline Braúna & 18 & 7 & 38,89 & 11 & 0 & 36 & 0 & 0,00 \\
\hline Buritama & 18 & 7 & 38,89 & 10 & 5 & 39 & 5 & 12,82 \\
\hline Clementina & 13 & 4 & 30,77 & 5 & 0 & 23 & 0 & 0,00 \\
\hline Coroados & 18 & 7 & 38,89 & 24 & 0 & 90 & 0 & 0,00 \\
\hline Gabriel Monteiro & 8 & 6 & 75,00 & 8 & 0 & 26 & 0 & 0,00 \\
\hline Gastão Vidigal & 15 & 5 & 33,33 & 6 & 1 & 24 & 1 & 4,17 \\
\hline General Salgado & 38 & 14 & 36,84 & 17 & 1 & 64 & 1 & 1,56 \\
\hline Glicério & 22 & 8 & 36,36 & 15 & 2 & 44 & 2 & 4,55 \\
\hline Guararapes & 46 & 6 & 13,04 & 7 & 0 & 27 & 0 & 0,00 \\
\hline Guzolândıa & 15 & 3 & 20,00 & 5 & 0 & 19 & 0 & 0,00 \\
\hline Luiziânia & 14 & 7 & 50,00 & 9 & 1 & 37 & 1 & 2,70 \\
\hline Nova Lusıtânia & 7 & 3 & 42,86 & 3 & 1 & 18 & 1 & 5,56 \\
\hline Penápolis & 52 & 19 & 36,54 & 29 & 4 & 117 & 4 & 3,42 \\
\hline Piacatu & 8 & 5 & 62,50 & 9 & 0 & 34 & 0 & 0,00 \\
\hline Rubiácea & 15 & 0 & 0,00 & - & - & - & - & - \\
\hline Santópolis do Aguapei & 7 & 0 & 0,00 & - & - & - & - & - \\
\hline
\end{tabular}




\begin{tabular}{lrrrrrrrrr}
\hline Municipio & \multicolumn{3}{c}{ Localidades } & \multicolumn{2}{c}{ UDs } & \multicolumn{3}{c}{ Amostras } \\
& exist ${ }^{*}$ & trab. & $\%$ trab. & trab. & reag. & trab. & reag. & $\%$ reag. \\
\hline Turiuba & 18 & 6 & 33,33 & 11 & 0 & 39 & 0 & 0,00 \\
Valparaiso & 24 & 0 & 0,00 & - & - & - & - & - \\
\hline SUB-TOTAL & 607 & 192 & 31,63 & 319 & 25 & 1200 & 25 & 2,00 \\
\hline
\end{tabular}

* Fonte: SUCEN/DOT/Lista de localidades segundo municipios por Serviço Regional. 1981-1986. Dado não existente nos arquivos da SUCEN/DOT.

+ Calculado sobre total existente excluindo-se Ilha Solteira 
Anexo VII - Distribuição de frequências de localidades existentes e trabalhadas e de Unidades Domiciliares (UDs) trabalhadas e com reagentes sorológicos para infecção chagásica, nos municípios das Regiões de Governo no Serviço Regional da SUCEN de Presidente Prudente (SR-10), 1984 a 1997.

\begin{tabular}{|c|c|c|c|c|c|c|c|c|}
\hline \multirow[t]{2}{*}{ Município } & \multicolumn{3}{|c|}{ Localidades } & \multicolumn{2}{|c|}{ UDs } & \multicolumn{3}{|c|}{ Amostras } \\
\hline & exist. ${ }^{*}$ & trab. & $\%$ trab. & trab. & reag. & trab. & reag. & $\%$ reag. \\
\hline \multicolumn{9}{|c|}{ Região de Governo Adamantina } \\
\hline Adamantina & 35 & 1 & 2,86 & 1 & 0 & 3 & 0 & 0,00 \\
\hline Flora Rica & 8 & 0 & 0,00 & - & - & - & - & - \\
\hline Flórida Paulista & 31 & 0 & 0,00 & - & - & - & - & - \\
\hline Inúbia Paulista & 10 & 1 & 10,00 & 1 & 0 & 3 & 0 & 0,00 \\
\hline Irapuru & 27 & 0 & 0,00 & - & - & - & - & 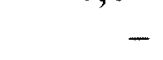 \\
\hline Lucélia & 17 & 0 & 0,00 & - & - & - & - & - \\
\hline Mariápolis & 12 & 0 & 0,00 & - & - & - & - & - \\
\hline Osvaldo Cruz & 36 & 0 & 0,00 & - & - & - & - & - \\
\hline Pacaembu & 32 & 0 & 0,00 & - & - & - & - & - \\
\hline Sagres & 13 & 0 & 0,00 & - & - & - & - & - \\
\hline Salmorão & 12 & 0 & 0,00 & - & - & - & - & - \\
\hline SUB-TOTAL & 233 & 2 & 0,86 & 2 & 0 & 6 & 0 & 0,00 \\
\hline \multicolumn{9}{|c|}{ Região de Governo Dracena } \\
\hline Dracena & 49 & 5 & 10,20 & 5 & 0 & 13 & 0 & 0,00 \\
\hline Junqueirópolis & 45 & 2 & 4,44 & 3 & 1 & 14 & 1 & 7,14 \\
\hline Monte Castelo & 26 & 6 & 23,08 & 6 & 0 & 31 & 0 & 0,00 \\
\hline Nova Guataporanga & 12 & 4 & 33,33 & 5 & 0 & 19 & 0 & 0,00 \\
\hline Ouro Verde & 16 & 0 & 0,00 & - & - & - & - & - \\
\hline Panorama & 19 & 1 & 5,26 & 1 & 0 & 2 & 0 & 0,00 \\
\hline Paulicéia & 14 & 5 & 35,71 & 8 & 0 & 17 & 0 & 0,00 \\
\hline Santa Mercedes & 17 & 1 & 5,88 & 1 & 0 & 1 & 0 & 0,00 \\
\hline S. João do Pau D'Alho & 13 & 4 & 30,77 & 5 & 0 & 16 & 0 & 0,00 \\
\hline Tupi Paulista & 43 & 11 & 25,58 & 14 & 0 & 43 & 0 & 0,00 \\
\hline SUB-TOTAL & 254 & 39 & 15,35 & 48 & 1 & 156 & 1 & 0,64 \\
\hline \multicolumn{9}{|c|}{ Região de Governo Presidente Prudente } \\
\hline Alfredo Marcondes & 27 & 0 & 0,00 & - & - & - & - & - \\
\hline Álvares Machado & 70 & 1 & 1,43 & 1 & 0 & 4 & 0 & 0,00 \\
\hline Anhumas & 15 & 0 & 0,00 & - & - & - & - & - \\
\hline Caiabu & 23 & 0 & 0,00 & - & - & - & - & - \\
\hline Caiuá & 26 & 0 & 0,00 & - & - & - & - & - \\
\hline Emilianopolis & 15 & 0 & 0,00 & - & - & - & - & - \\
\hline Estrela do Norte & 9 & 0 & 0,00 & - & - & - & - & - \\
\hline Euclides da Cunha & 21 & 0 & 0,00 & - & - & - & - & - \\
\hline Iepê & 47 & 2 & 4,25 & 2 & 2 & 9 & 2 & 22,22 \\
\hline Indiana & 22 & 0 & 0,00 & - & - & - & - & - \\
\hline Marabả Paulista & 27 & 0 & 0,00 & - & - & - & - & - \\
\hline Martinópolis & 76 & 0 & 0,00 & - & - & - & - & - \\
\hline
\end{tabular}




\begin{tabular}{lrrrrrrrrr}
\hline Municipio & \multicolumn{3}{c}{ Localidades } & \multicolumn{3}{c}{ UDs } & \multicolumn{3}{c}{ Amostras } \\
& exist. & trab. & $\%$ trab. & trab. & reag. & trab. & reag. & $\%$ reag. \\
\hline Mirte. Paranapanema & 67 & 0 & 0,00 & - & - & - & - & - \\
Narandiba & 17 & 0 & 0,00 & - & - & - & - & - \\
Piquerobi & 18 & 0 & 0,00 & - & - & - & - & - \\
Pirapozinho & 22 & 0 & 0,00 & - & - & - & - & - \\
Presidente Bernardes & 57 & 0 & 0,00 & - & - & - & - & - \\
Presidente Epitácio & 50 & 1 & 2,00 & 2 & 0 & 8 & 0 & 0,00 \\
Presidente Prudente & 93 & 3 & 3,22 & 3 & 1 & 9 & 1 & 11,11 \\
Presidente Venceslau & 56 & 1 & 1,79 & 1 & 0 & 3 & 0 & 0,00 \\
Rancharia & 65 & 1 & 1,54 & 1 & 0 & 3 & 0 & 0,00 \\
Regente Feijó & 36 & 0 & 0,00 & - & - & - & - & - \\
Rosana & 18 & 2 & 11,11 & 2 & 0 & 13 & 0 & 0,00 \\
Sandovalina & 14 & 0 & 0,00 & - & - & - & - & - \\
Santo Anastácio & 57 & 1 & 1,75 & 1 & 0 & 6 & 0 & 0,00 \\
Santo Expedito & 12 & 0 & 0,00 & - & - & - & - & - \\
Taciba & 22 & 1 & 4,54 & 1 & 0 & 2 & 0 & 0,00 \\
Tarabai & 14 & 0 & 0,00 & - & - & - & - & - \\
Teodoro Sampaio & 25 & 0 & 0,00 & - & - & - & - & - \\
\hline SUB-TOTAL & 1021 & 13 & 1,27 & 14 & 3 & 57 & 3 & 5,26 \\
\hline
\end{tabular}

* Fonte: SUCEN/DOT/Lista de localidades segundo municípios por Serviço Regional. 1981-1986 
Anexo VIII - Distribuição de frequências de localidades existentes e trabalhadas e de Unidades Domiciliares (UDs) trabalhadas e com reagentes sorológicos para infecção chagásica, nos municipios das Regiões de Governo no Serviço Regional da SUCEN de Marilia (SR-11), 1984 a 1997

\begin{tabular}{|c|c|c|c|c|c|c|c|c|}
\hline \multirow[t]{2}{*}{ Municipio } & \multicolumn{3}{|c|}{ Localidades } & \multicolumn{2}{|c|}{ UDs } & \multicolumn{3}{|c|}{ Amostras } \\
\hline & exist.* & trab. & $\%$ trab. & trab. & reag. & trab. & reag & $\%$ reag. \\
\hline \multicolumn{9}{|c|}{ Região de Governo Assis } \\
\hline Assis & 28 & 3 & 10,71 & 3 & 1 & 12 & 1 & 8,33 \\
\hline CamposNovosPaulista & 14 & 1 & 7,14 & 1 & 1 & 3 & 2 & 66,67 \\
\hline CândidoMota & 47 & 10 & 21,28 & 15 & 3 & 61 & 3 & 4,92 \\
\hline Cruzália & 13 & 0 & 0,00 & - & - & - & - & - \\
\hline Florinea & 8 & 0 & 0,00 & - & - & - & - & - \\
\hline Ibirarema & 14 & 2 & 14,29 & 2 & 1 & 6 & 1 & 16,67 \\
\hline Lutécia & 8 & 0 & 0,00 & - & - & - & - & - \\
\hline Maracai & 18 & 0 & 0,00 & - & - & - & - & - \\
\hline Palmital & 39 & 1 & 2,56 & 1 & 0 & 3 & 0 & 0,00 \\
\hline ParaguaçuPaulista & 29 & 1 & 3,45 & $i$ & 1 & 4 & 1 & 25,00 \\
\hline Platina & 6 & 0 & 0,00 & - & - & - & - & - \\
\hline SUB-TOTAL & 224 & 18 & 8,04 & 23 & 7 & 89 & 8 & 8,99 \\
\hline \multicolumn{9}{|c|}{ Região de Governo Marilia } \\
\hline Alvaro de Carvalho & 13 & 0 & 0,00 & - & - & - & - & - \\
\hline Alvinlàndia & 10 & 0 & 0,00 & - & - & - & - & - \\
\hline Echaporã & 19 & 0 & 0,00 & - & - & - & - & - \\
\hline Gália & 41 & 3 & 7,32 & 3 & 0 & 13 & 0 & 0,00 \\
\hline Garça & 82 & 1 & 1,22 & 1 & 0 & 5 & 0 & 0,00 \\
\hline Júlio Mesquita & 12 & 0 & 0,00 & - & - & - & - & - \\
\hline Lupércio & 15 & 0 & 0,00 & - & - & - & - & - \\
\hline Marilia & 100 & 8 & 8,00 & 8 & 1 & 41 & 1 & 2,44 \\
\hline Ocauçu & 25 & 0 & 0,00 & - & - & - & - & - \\
\hline Oriente & 21 & 0 & 0,00 & - & - & - & - & - \\
\hline Oscar Bressane & 13 & 0 & 0,00 & - & - & - & - & - \\
\hline Pompeia & 38 & 1 & 2,63 & 1 & 0 & 3 & 0 & 0,00 \\
\hline Vera Cruz. & 32 & 0 & 0,00 & - & - & - & - & - \\
\hline SUB-TOTAL & 421 & 13 & 3,09 & 13 & 1 & 62 & 1 & 1,61 \\
\hline \multicolumn{9}{|c|}{ Região de Governo Ourinhos } \\
\hline Bernardino de Campos & 19 & 4 & 21,05 & 7 & 0 & 24 & 0 & 0,00 \\
\hline Chavantes & 28 & 2 & 7,14 & 2 & 0 & 5 & 0 & 0,00 \\
\hline Ipauçu & 16 & 2 & 12,50 & 2 & 1 & 4 & 1 & 25,00 \\
\hline Óleo & 18 & 1 & 5,56 & 1 & 0 & 3 & 0 & 0,00 \\
\hline Ourinhos & 26 & 2 & 7,69 & 4 & 0 & 9 & 0 & 0,00 \\
\hline Ribeirão do Sul & 8 & 2 & 25,00 & 2 & 1 & 6 & 1 & 16,67 \\
\hline Salto Grande & 14 & 5 & 35,71 & 7 & 1 & 31 & 1 & 3,23 \\
\hline Sta. Cruz do Rio Pardo & 58 & 8 & 13,79 & 10 & 5 & 49 & 5 & 10,20 \\
\hline São Pedro do Turvo & 33 & 2 & 6,06 & 2 & 1 & 20 & 1 & 5,00 \\
\hline Timburi & 15 & 6 & 40,00 & 10 & 0 & 39 & 0 & 0,00 \\
\hline SUB-TOTAL & 235 & 34 & 14,47 & 47 & 9 & 190 & 9 & 4.74 \\
\hline
\end{tabular}




\begin{tabular}{|c|c|c|c|c|c|c|c|c|}
\hline \multirow[t]{2}{*}{ Municipio } & \multicolumn{3}{|c|}{ Localidades } & \multicolumn{2}{|c|}{ UDs } & \multicolumn{3}{|c|}{ Amostras } \\
\hline & exist * & trab. & $\%$ trab & trab. & reag. & trab. & reag. & $\%$ reag. \\
\hline \multicolumn{9}{|c|}{ Região de Governo Tupã } \\
\hline Bastos & 18 & 0 & - & - & - & - & - & - \\
\hline Borá & 6 & 0 & - & - & - & - & - & - \\
\hline Herculândia & 30 & 0 & - & - & - & - & - & - \\
\hline Iacn & 39 & 1 & 2,56 & 1 & 0 & 4 & 0 & 0,00 \\
\hline João Ramalho & 20 & 0 & - & - & - & - & - & - \\
\hline Parapuã & 28 & 0 & - & - & - & - & - & - \\
\hline Quatá & 14 & 0 & - & - & - & - & - & - \\
\hline Queirós & 8 & 0 & - & - & - & - & - & - \\
\hline Quintana & 23 & 0 & - & - & - & - & - & - \\
\hline Rinópolis & 43 & 1 & 2,33 & 1 & 0 & 1 & 0 & 0,00 \\
\hline Tupã & 96 & 1 & 1,04 & 1 & 0 & 7 & 0 & 0,00 \\
\hline SUB-TOTAL & 325 & 3 & 0,92 & 3 & 0 & 12 & 0 & 0,00 \\
\hline \multicolumn{9}{|c|}{ Região de Governo Bauru } \\
\hline Agudos & 44 & 0 & - & - & - & - & - & - \\
\hline Arealia & 35 & 3 & 8,57 & 3 & 0 & 11 & 0 & 0,00 \\
\hline Avai & 23 & 0 & - & - & - & - & - & - \\
\hline Balbinos & 14 & 1 & 7,14 & 1 & 0 & 4 & 0 & 0,00 \\
\hline Bauru & 45 & 2 & 4,44 & 2 & 1 & 8 & 1 & 12,50 \\
\hline Cabrália Paulista & 14 & 1 & 7,14 & 2 & 0 & 16 & 0 & 0,00 \\
\hline Duartina & 35 & 0 & - & - & - & - & - & - \\
\hline lacanga & 36 & 3 & 8,33 & 4 & 0 & 10 & 0 & 0,00 \\
\hline Lençóis Paulista & 27 & 0 & - & - & - & - & - & - \\
\hline Lucianópolis & 13 & 1 & 7,69 & 1 & 1 & 6 & 1 & 16,67 \\
\hline Macatuba & 26 & 0 & - & - & - & - & - & - \\
\hline Pederneiras & 63 & 0 & - & - & - & - & - & - \\
\hline Pirajui & 50 & 0 & - & - & - & - & - & - \\
\hline Piratininga & 33 & 0 & - & - & - & - & - & - \\
\hline Presidente Alves & 23 & 0 & - & - & - & - & - & - \\
\hline Reginópolis & 19 & 2 & 10,53 & 2 & 0 & 5 & 0 & 0,00 \\
\hline Ubirajara & 12 & 1 & 8,33 & 1 & 0 & 10 & 0 & 0,00 \\
\hline SUB-TOTAL & 512 & 14 & 2,73 & 16 & 2 & 70 & 2 & 2,90 \\
\hline \multicolumn{9}{|c|}{ Região de Governo Jaú } \\
\hline Barin & 44 & 1 & 2,27 & 1 & 0 & 3 & 0 & 0,00 \\
\hline Barra Bonita & 25 & 0 & - & - & - & - & - & - \\
\hline Bocaina & 28 & 0 & - & - & - & - & - & - \\
\hline Boracéia & 16 & 0 & - & - & - & - & - & - \\
\hline Dois Córregos & 33 & 1 & 3,03 & 1 & 0 & 2 & 0 & 0,00 \\
\hline Igaraçu do Tietê & 12 & 0 & - & - & - & - & - & - \\
\hline Itaju & 19 & 0 & - & - & - & - & - & - \\
\hline Itapui & 24 & 0 & - & - & - & - & - & - \\
\hline Jaú & 74 & 0 & - & - & - & - & - & - \\
\hline
\end{tabular}




\begin{tabular}{|c|c|c|c|c|c|c|c|c|}
\hline \multirow[t]{2}{*}{ Municipio } & \multicolumn{3}{|c|}{ Localidades } & \multicolumn{2}{|c|}{ UDs } & \multicolumn{3}{|c|}{ Amostras } \\
\hline & exist.* & trab. & $\%$ trab. & trab. & reag. & trab. & reag. & $\%$ reag. \\
\hline Mineiros do Tietề & 16 & 0 & - & - & - & - & - & - \\
\hline \multirow[t]{2}{*}{ SUB-TOTAL } & 291 & 2 & 0,69 & 2 & 0 & 5 & 0 & 0,00 \\
\hline & \multicolumn{7}{|c|}{ Região de Governo Lins } & \\
\hline Cafelândia & 53 & 1 & 1,89 & 1 & 0 & 1 & 0 & 0,00 \\
\hline Getulina & 30 & 1 & 3,33 & 1 & 0 & 7 & 0 & 0,00 \\
\hline Guaiçara & 14 & 4 & 28,57 & 5 & 0 & 19 & 0 & 0,00 \\
\hline Guaimbê & 16 & 0 & - & - & - & - & - & 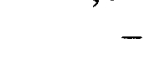 \\
\hline Guarantã & 25 & 0 & - & - & - & - & - & - \\
\hline Lins & 44 & 2 & 4,55 & 2 & 0 & 10 & 0 & 0,00 \\
\hline Pongaí & 14 & 0 & - & - & - & - & - & - \\
\hline Promissão & 31 & 9 & 29,03 & 30 & 4 & 145 & 5 & 3,45 \\
\hline Sabino & 10 & 1 & 10,00 & 1 & 0 & 14 & 0 & 0,00 \\
\hline Uru & 10 & 0 & - & - & - & - & - & - \\
\hline SUB-TOTAL & 247 & 18 & 7,29 & 40 & 4 & 196 & 5 & 2,55 \\
\hline
\end{tabular}

* Fonte: SUCEN/DOT/Lista de localidades segundo municipios por Serviço Regional. 1981-1986 